\title{
Sistemática de Croton sect. Cleodora (Euphorbiaceae s.s.)
}

Maria Beatriz Rossi Caruzo

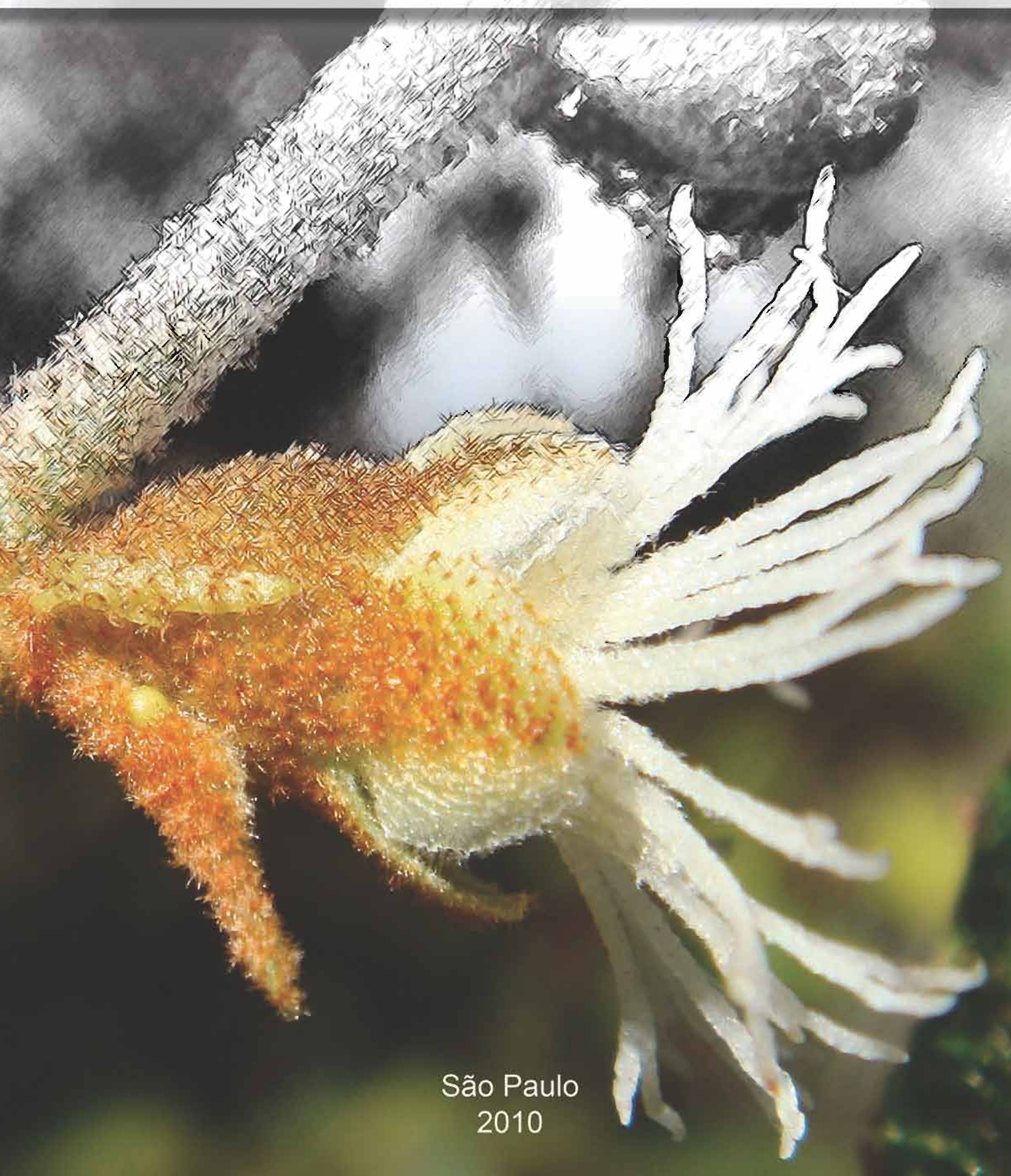


Maria Beatriz Rossi Caruzo

Sistemática de Croton sect. Cleodora (Euphorbiaceae s.s.)

São Paulo

2010 
Universidade de São Paulo

Maria Beatriz Rossi Caruzo

\section{Sistemática de Croton sect. Cleodora (Euphorbiaceae s.s.)}

Tese apresentada ao Instituto de Biociências da Universidade de São Paulo, para a obtenção de Título de Doutor em Ciências Biológicas, na Área de Botânica.

Orientadora: Profa. Dra. Inês Cordeiro.

São Paulo 


\section{Caruzo, Maria Beatriz Rossi}

Sistemática de Croton sect. Cleodora

(Euphorbiaceae s.s.)

273 páginas.

Tese (Doutorado) - Instituto de

Biociências da Universidade de São Paulo.

Departamento de Botânica.

1. Euphorbiaceae 2. Croton 3. Sistemática Universidade de São Paulo. Instituto de Biociências. Departamento de Botânica.

Comissão Julgadora:

Prof(a). Dr(a).

Prof(a). Dr(a).
Prof(a). Dr(a).

Prof(a). Dr(a).

Profa. Dra. Inês Cordeiro

Orientadora 
À MINHA FAMÍLIA, MEUS AMIGOS E MEUS MESTRES DEDICO 
It is interesting to contemplate an entangled bank, clothed with many plants of many kinds, with birds singing on the bushes, with various insects flitting about, and with worms crawling through the damp earth, and to reflect that these elaborately constructed forms, so different from each other, and dependent on each other in so complex a manner, have all been produced by laws acting around us.

Charles Darwin (1809-1882) 


\section{Agradecimentos}

Este trabalho somente seria possível com o apoio, auxílio e estímulo de todos que estiveram presentes em minha vida nos últimos anos. Assim, agradeço:

Primeiramente a Deus, pela permissão de desenvolver este trabalho e concretizar mais um sonho.

À minha querida orientadora, Inês, por me ensinar a amar a botânica, pelos valiosos ensinamentos, pela paciência, amizade e carinho com que me conduziu durante todos esses anos.

Ao meu orientador no exterior, Paul Berry, por gentilmente me receber em seu laboratório e por fornecer toda estrutura necessária ao desenvolvimento do meu trabalho na Universidade de Michigan.

Ao Pirani, pelo apoio, incentivo e idéias referentes ao trabalho.

Aos que auxiliaram, de maneira muito especial, no desenvolvimento de partes do trabalho: Ricarda Riina e Benjamin Van Ee, pelo auxílio com a Filogenia; Silvana Amaral, Luciana Arasato e Cristina Bestetti Costa pelo auxílio com a Modelagem.

Às instituições que disponibilizaram toda estrutura para o desenvolvimento do trabalho: Instituto de Botânica de São Paulo, Instituto de Biociências (USP) e Department of Ecology and Evolutionary Biology (UMICH).

Ao CNPq pelas bolsas concedidas, ao International Association of Plant Taxonomists (IAPT) e ao Smithsonian Institute pelos auxílios financeiros.

Aos curadores e demais funcionários dos herbários ALCB, BHCB, CEN, CEPEC, CESJ, ESA, GUA, HB, HEPH, HRB, HRCB, HUEFS, IAC, IBGE, MAC, MBM, MG, MICH, MYF, PMSP, PORT, R, RB, SP, SPF, SPSF, TFAV, UB, UEC, US, VEN, pela receptividade e apoio durante minhas visitas.

Aos pesquisadores e funcionários da Seção de Curadoria do Herbário do Instituto de Botânica: Gerleni Lopes Esteves, Maria Margarida R.F. de Melo, Lúcia Rossi, Maria das Graças L. Wanderley, Marie Sugiyama, Maria Cândida Henrique Mamede, Rosangela Simão-Bianchini, Sergio Romaniuc-Neto, Sonia Aragaki, Cintia Kameyama, Jefferson Prado, Fábio de Barros, Suzana E. Martins, Ana Célia de Almeida Calado e Claudinéia, pelo apoio, incentivo, amizade e por estarem sempre prontos a auxiliar.

Aos funcionários do Instituto de Biociências da Universidade de São Paulo: Norberto do departamento de Botânica, Abel da Curadoria do Herbário, Helder e Erika da secretaria de pós-graduação.

À Hope Draheim e ao Jeffery Morawetz, pelo auxílio no laboratório, e a todos os outros colegas do laboratório do Paul Berry (e de outros laboratórios), na Universidade de Michigan, por me receberem muito bem e tornarem meu trabalho por lá mais prazeroso.

Ao Paulo R. Moreno, coordenador de projetos em que me envolvi durante a realização do trabalho, pelo apoio, incentivo e financiamentos. 
Às minhas companheiras crotonólogas Ricarda Riina, Leticia Ribes de Lima e Daniela Carneiro-Torres, pela companhia em viagens de coleta, longas conversas e trocas de experiências sobre o fascinante e complexo (e, conhecendo melhor as Cleodoras, pode-se dizer também colorido!) mundo dos Crotons!!!

À todos que, gentilmente, me acompanharam em expedições de coleta: Anderson Santos (IBt), Carlos Reyes (Caracas, Venezuela), Efigênia (HUEFS), Flávio França (HUEFS), Gisele Silva (IBt), Joice Savietto (USP), Juan Carlos Fermin (MYF, Venezuela), Lucimar Barbosa Motta (USP), Luiz Alvarez (MYF, Venezuela), Marilia Cristina Duarte (IBt), Nataly Camps, Paulo Moreno (USP), Renata Sebastiani (IBt), Suzana E. Martins (IBt). Em especial ao meu marido Daniel, que me acompanhou em coleta até mesmo durante nossa lua-de-mel!

À todos os amigos do Instituto de Botânica com quem tive o prazer imensurável de conviver durante esse período: Alexandre Indriunas, Anderson Santos, André Gaglioti, Berta Villagra, Cátia Takeuchi, Fábio Pinheiro, Gisele de O. Silva, Juliana Santos, Klei Souza, Leonardo Versieux, Luciana Fiorato, Rafael Louzada, Regina Hirai, Renata Sebastiani, Victor Martins Gonçalez, entre outros... Em especial aos meus “irmãos” de orientação: Marcos E. Leite e Allan Carlos Pscheidt, e às minhas grandes amigas (que, assim como eu, também são “patrimoniadas” pelo IBt!), Marília C. Duarte e Fátima O. de Souza Buturi, pelo companheirismo, incentivo, discussões, favores...

Aos colegas do laboratório de Sistemática do IB-USP, em especial as amigas Juliana Lovo e Maria Fernanda Calió.

Ao desenhista Klei Rodrigo Souza pelas belas ilustrações.

Ao meu amigo Carlos Eduardo Nickel (Cadu), pela confecção da capa e por dar um toque especial aos mapas.

Aos meus amigos não-biólogos, que muito colaboraram para o meu bem estar e que, mesmo que indiretamente, auxiliaram no desenvolvimento do meu trabalho.

Finalmente, agradeço, com a minha mais profunda gratidão, toda minha família, em especial aos meus pais Hélio e Sonia, minhas irmãs Letícia e Clara, e ao meu marido Daniel, pois sem o apoio, incentivo e amor de vocês, não seria possível concluir este trabalho. 


\section{ÍNDICE}

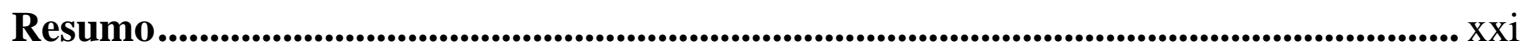

Abstract............................................................................................................................................ Xxiii

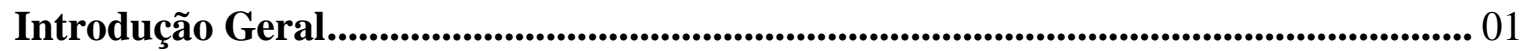

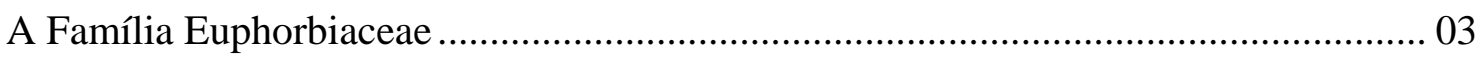

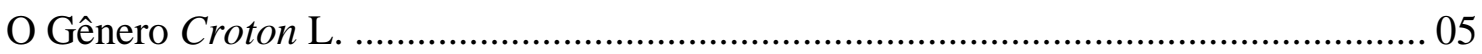

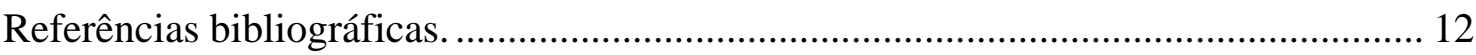

Capítulo 1. Molecular phylogenetics, character evolution, and pharmacological potential of the "sacaca" clade: novel relationships of Croton section Cleodora

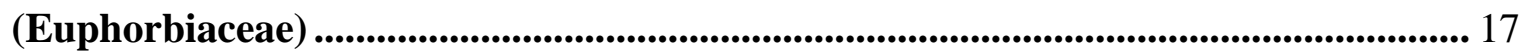

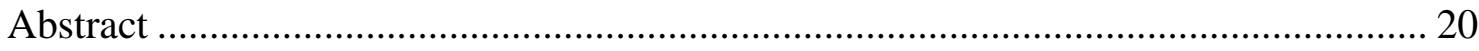

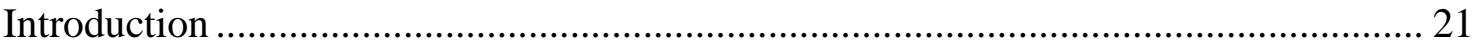

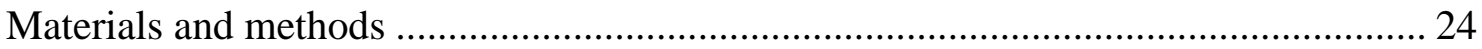

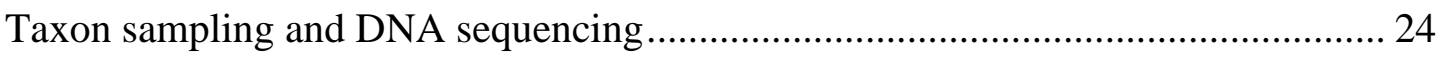

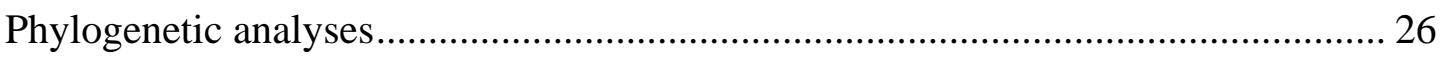

Character state mapping …............................................................................... 27

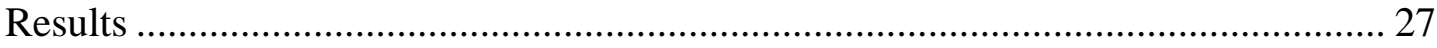

Molecular data sets and congruence ...................................................................... 27

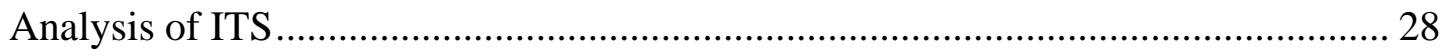

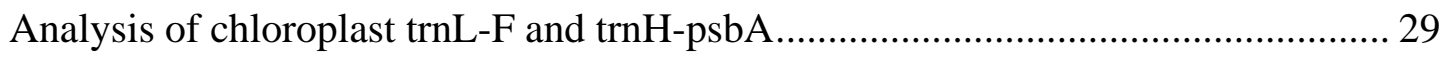

Combined nuclear and chloroplast analysis ......................................................... 29

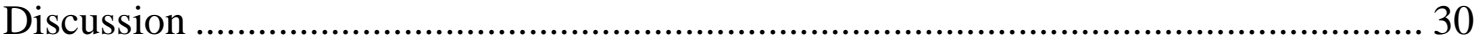

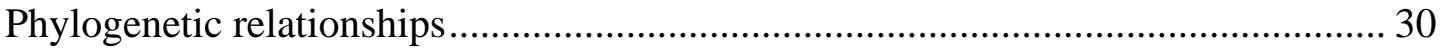

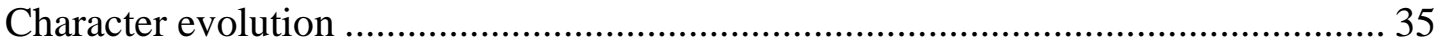

A new circumscription for the section................................................................ 38

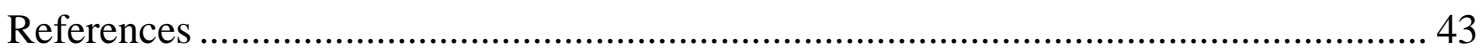

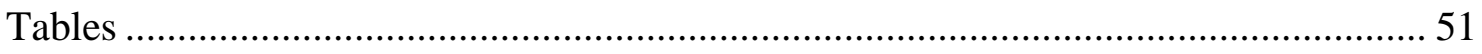

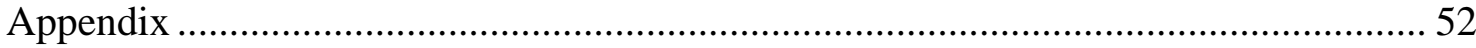

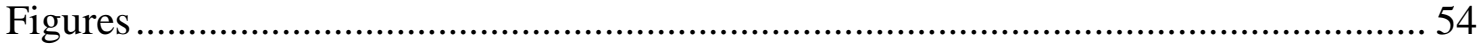

Capítulo 2. Revisão taxonômica de Croton sect. Cleodora (Klotzsch) Baill. ............... 61

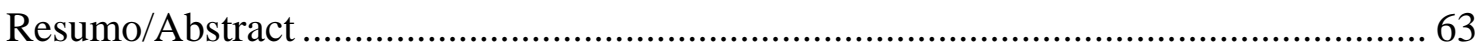

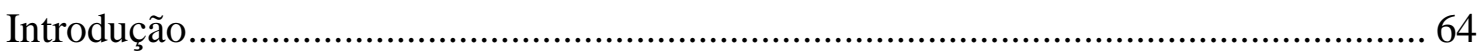

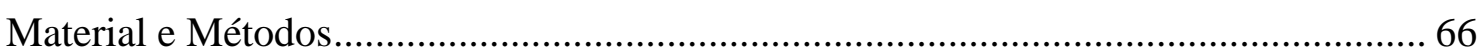

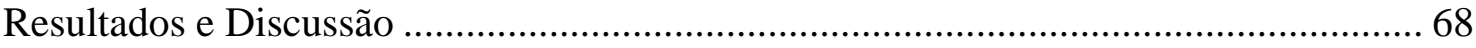




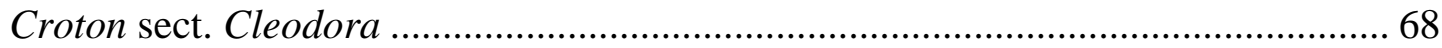

Morfologia das espécies de Croton sect. Cleodora ................................................. 70

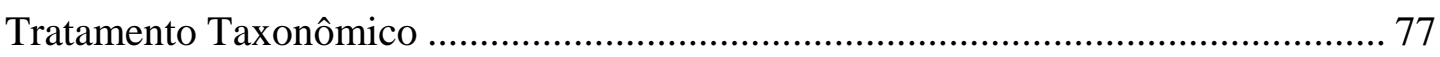

Chave de identificação para as espécies Croton sect. Cleodora ................................ 80

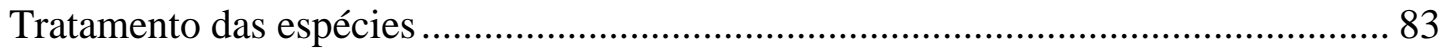

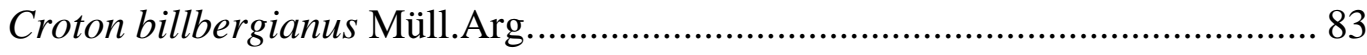

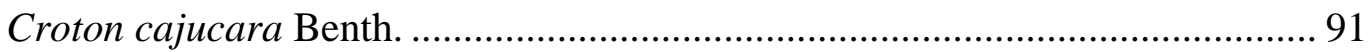

Croton campanulatus Caruzo \& Cordeiro.......................................................... 98

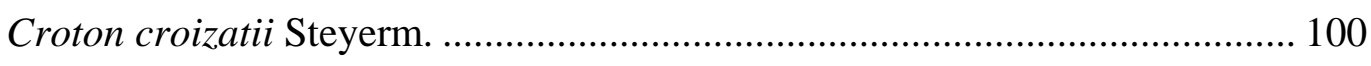

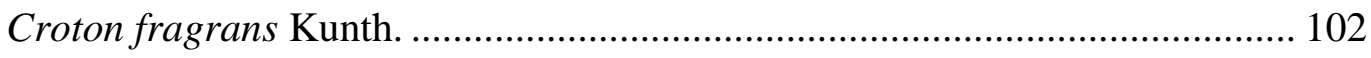

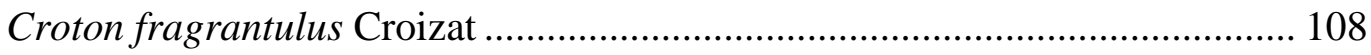

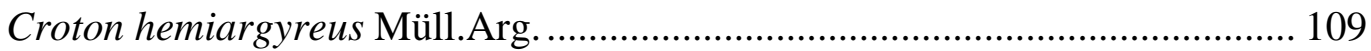

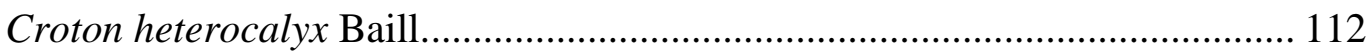

Croton hoffmannii Müll.Arg...................................................................... 114

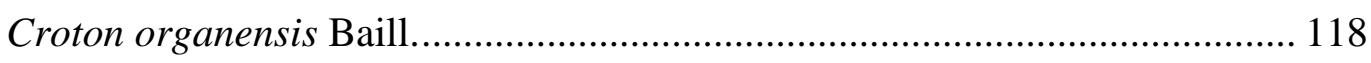

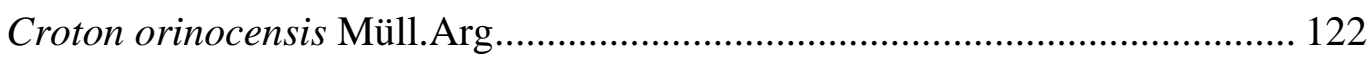

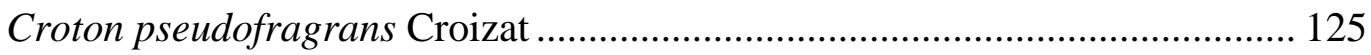

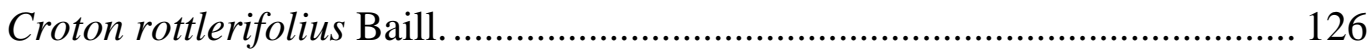

Croton rufolepidotus Caruzo \& Riina ............................................................... 130

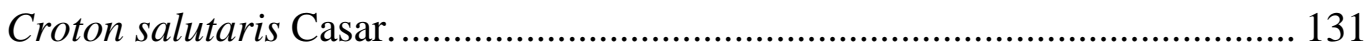

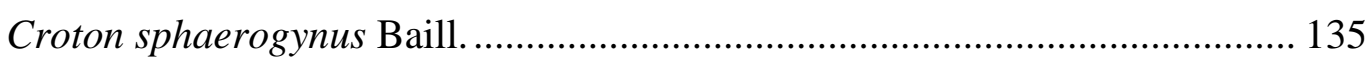

Croton spruceanus Benth. …...................................................................... 140

Croton stellatoferruginus Caruzo \& Cordeiro.................................................. 143

Táxons excluídos de Croton sect. Cleodora............................................................ 145

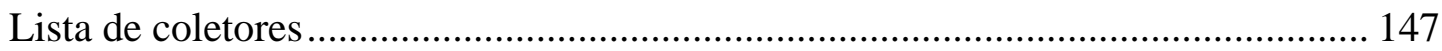

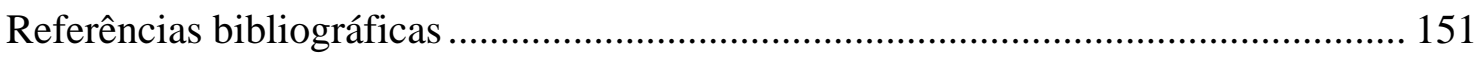

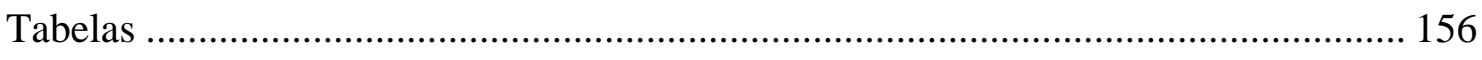

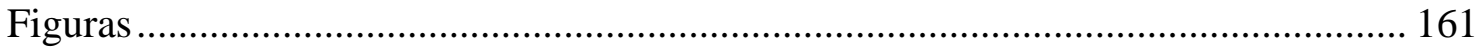

Capítulo 3. Tricomas foliares em Croton sect. Cleodora (Euphorbiaceae) ................ 181

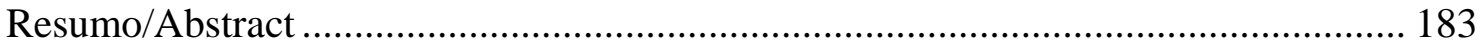

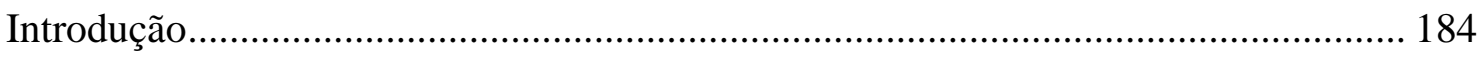

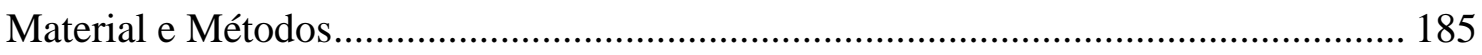

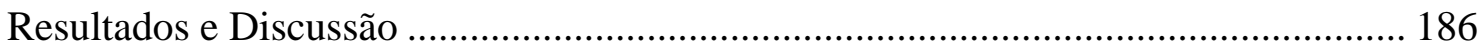




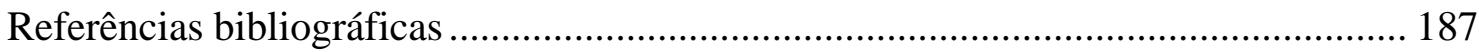

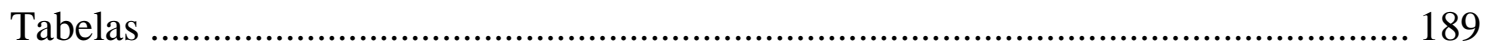

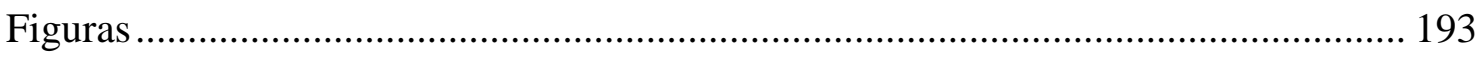

Capítulo 4. Padrões de distribuição em Croton sect. Cleodora (Euphorbiaceae)..... 199

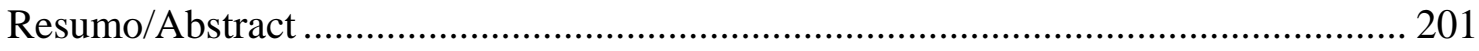

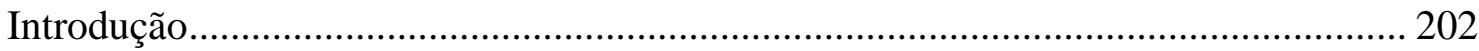

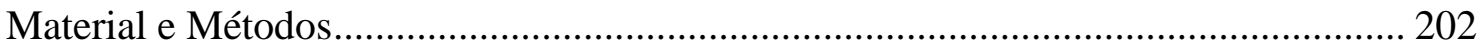

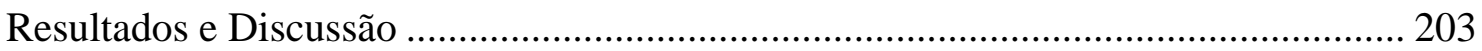

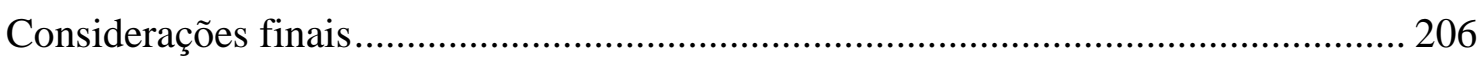

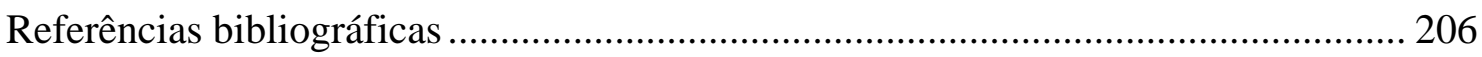

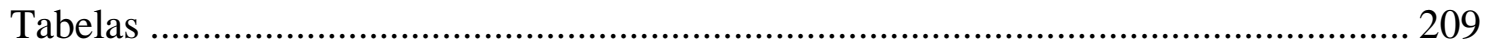

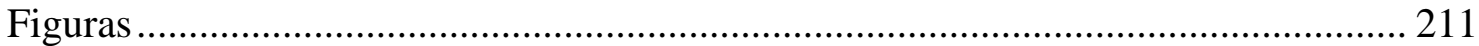

Capítulo 5. Modelagem de nicho ecológico de espécies de Croton sect. Cleodora (Euphorbiaceae) ocorrentes no Brasil) ............................................................................. 221

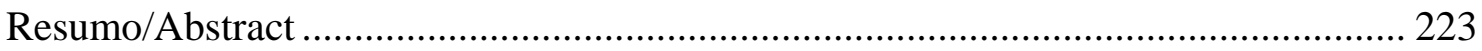

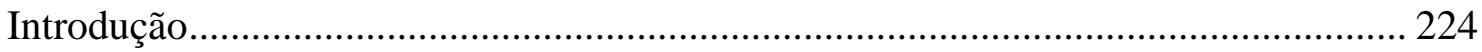

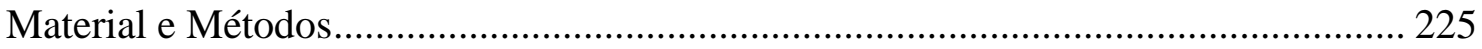

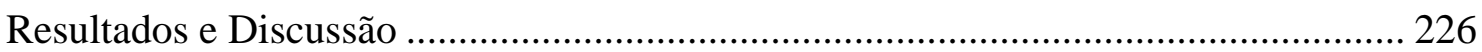

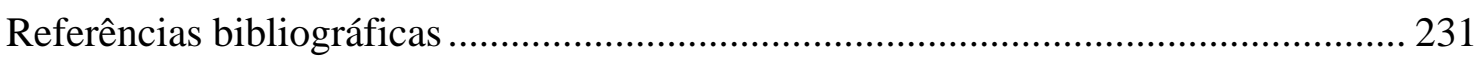

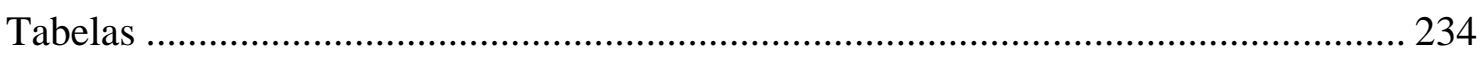

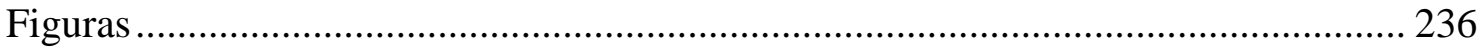

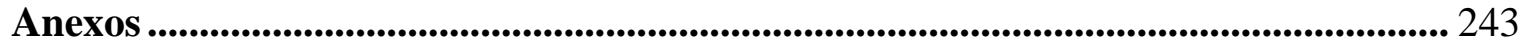




\section{Resumo}

No presente trabalho foram testados o monofiletismo e relações filogenéticas de Croton sect. Cleodora (Klotzsch) Baill. (Euphorbiaceae s.s.) utilizando-se sequências da região nuclear ITS e das regiões plastidiais trnL-F e trnH-psbA (capítulo 1). Os resultados obtidos demonstraram que a seção, em sua delimitação tradicional, não é monofilética e portanto uma nova circunscrição foi proposta para a mesma. Com base nessa nova circunscrição, foi realizada a revisão taxonômica da seção (capítulo 2), que inclui chave para identificação das espécies, descrições, ilustrações, fotos, sinonímias e comentários sobre ecologia e taxonomia das 18 espécies reconhecidas para a seção. Estudos detalhados sobre a morfologia dos tricomas foliares (capítulo 3) e dos padrões de distribuição geográfica (capítulo 4) das espécies também são aqui apresentados. Modelos preditivos de habitats foram construídos de maneira a esclarecer aspectos da ecologia do grupo estudado (capítulo 5). Em sua nova circunscrição, a seção Cleodora possui 18 espécies, é exclusivamente Neotropical, e apresenta distribuição disjunta entre o sul do México/América Central, norte e noroeste da América do Sul e leste do Brasil. Algumas caracteristicas compartilhadas pelas espécies da seção são: porte arbóreo ou arbustivo; presença de látex; tricomas lepidotos (vários subtipos), raramente estrelados ou multiradiados; folhas com um par de glândulas acropeciolares ou basilaminares; inflorescências geralmente com címulas basais bissexuadas; flores masculinas com sépalas geralmente unidas até a metade; estames 15-25; flores femininas com sépalas unidas na base ou mais acima, geralmente imbricativas; estiletes 4-fidos ou multifidos, unidos na base ou um pouco mais acima, geralmente formando uma coroa. 


\begin{abstract}
In the present study the monophyly and phylogenetic relationships of Croton sect. Cleodora (Euphorbiaceae s.s.) were examined using sequences of nuclear ITS and the plastid regions trnL-F e trnH-psbA (chapter 1). The results shown that the section, in its traditional circumscription, is not monophyletic and, therefore, a new circumscription was proposed. Based on this new circumscription a taxonomic revision was done (chapter 2), where were presented, for the 18 recognized species, identification keys, descriptions, illustrations, pictures, synonymous, and comments on ecology and taxonomy of the species. A detailed study about morphology of foliar trichomes and patterns of distribution are presented. Predictive habitat distribution models were built to understand the ecology of the studied group (chapter 5). In its new circumscription, section Cleodora has 18 species and it is exclusively Neotropical, disjunctly distributed between south Mexico/Central America, north and northwestern South America and eastern Brazil. Some features shared by the member of this section are: arborescent or shrubby habit; presence of latex; lepidote trichomes (all subtypes), rarely stellate or multiradiate; leaves with a pair of basilaminar or acropetiolar glands; inflorescences usually with basal bisexual cymules; sepals of the staminate flowers usually united half of their length; 15-25 stamens; sepals of the pistillate flowers united at the base or higher, usually imbricative, and 4-fid or multifid styles, united at the base or higher, usually forming a crown.
\end{abstract}


INTRODUÇÃO GERAL 


\section{A família Euphorbiacae}

A família Euphorbiaceae s.s. é uma das maiores, mais diversas e complexas das Angiospermas. A família, que é a mais numerosa da ordem Malpighiales, conta com 246 gêneros e aproximadamente 6300 espécies (Wurdack \& Davis, 2009), distribuídas em todo o mundo, principalmente nas regiões tropicais (Govaerts et al., 2000). O centro de diversidade primário da família é a região Indomalaia, sendo os Neotrópicos considerados seu centro de diversidade secundário. O maior gênero da família é Euphorbia L., com mais de 2000 espécies de distribuição cosmopolita, seguido de Croton L. (1223 espécies) e Acalypha L. (450 espécies), ambos pantropicais (Govaerts et al. 2000).

Segundo Souza \& Lorenzi (2005), no Brasil a família está representada por cerca de 1000 espécies distribuídas em 70 gêneros, em todos os tipos de vegetação, sendo uma das principais famílias da flora brasileira. Dentre os gêneros brasileiros mais importantes estão o amazônico Hevea Aubl., e os mais amplamente distribuídos Croton L., Acalypha L., Cnidoscolus Pohl., Dalechampia L., Jatropha L. e Manihot Mill.

Como espécies de grande importância econômica na família podem ser destacadas: Manihot esculenta Crantz, a mandioca, uma das principais fontes de amido para a alimentação humana, Hevea brasiliensis Müll.Arg., a seringueira, principal fonte de borracha natural e a mamona, Ricinus communis L., cujas sementes fornecem um óleo muito utilizado na indústria aeronáutica, em virtude de sua alta viscosidade, mesmo em baixas temperaturas, e mais recentemente como fonte de um polímero empregado na confecção de próteses humanas (Ereno, 2003) e na produção do Biodiesel, além de seu tegumento servir como adubo rico em nitrogênio.

Algumas espécies da família são utilizadas como ornamentais, dentre elas destacam-se: Euphorbia milii Desmoul., a coroa-de-cristo, espécie de Madagascar muito utilizada como cerca viva; Euphorbia pulcherrima Willd. ex. Klotzsch, bico-de-papagaio, espécie mexicana muito utilizada em decorações natalícias; Codiaeum variegatum (L.) A.Juss., o cróton dos floricultores; Acalypha hispida Burm.f., espécie da Índia, conhecida como rabo-de-gato, entre outras.

A família foi descrita originalmente em 1789 por Jussieu na obra Genera Plantarum e, em sua delimitação tradicional, as Euphorbiaceae sensu lato apresentavam tal variabilidade 
morfológica, que apenas as flores unissexuais e os óvulos providos de obturador placentário eram características compartilhadas por todos os seus representantes.

Apesar de muitas espécies de Euphorbiaceae serem objeto de estudos multidisciplinares, envolvendo taxonomia, morfologia, anatomia, fitoquímica, filogenia e botânica econômica, em virtude de seu grande número de espécies, o conhecimento sobre o grupo ainda apresenta lacunas consideráveis, que constituem problemas até mesmo no que se refere à própria circunscrição da família. A grande amplitude de variação morfológica sempre dificultou a delimitação da família e, alguns autores, mesmo antes das análises filogenéticas baseadas em dados moleculares, já haviam sugerido uma origem polifilética para as Euphorbiaceae.

Antes dos estudos filogenéticos que redefiniram os limites da família, Webster (1975, 1994a, 1994b), seguindo o sistema de Müller (1866, 1873), delimitou as Euphorbiaceae em 5 subfamílias (Acalyphoideae, Crotonoideae, Euphorbiodeae, Oldifieldioideae e Phyllantoideae) e 49 tribos, reconhecendo 317 gêneros. Os principais caracteres utilizados por Webster (1975, 1994a, 1994b) na delimitação das subfamílias referem-se a: número de óvulos por lóculo do ovário, morfologia polínica e tipo e presença de laticíferos. Esse sistema foi seguido por Radcliffe-Smith (2001), que incorporou 3 novas tribos, 2 novas subtribos e alguns gêneros, reconhecendo então 5 subfamílias, 52 tribos e 334 gêneros para a família.

Huber (1991) e Meeuse (1990) já haviam proposto a exclusão das subfamílias com lóculos 2-ovulados das Euphorbiaceae. Chase et al. (1993, 2002), em seus estudos filogenéticos baseados em dados macromoleculares, demonstraram claramente o polifiletismo das Euphorbiaceae sensu lato. Chase et al. (2002), por não encontrarem evidências moleculares que sustentassem as Euphorbiaceae s.l., propuseram formalmente uma nova delimitação da família, excluindo dela os grupos com lóculos 2-ovulados, ou seja, as subfamílias Phyllanthoideae e Oldfieldioideae, ficando nas Euphorbiaceae s.s. apenas as subfamílias 1-ovuladas: Euphorbioideae, Crotonoideae e Acalyphoideae, enquanto as Phyllanthoideae foram desmembradas nas famílias Phyllanthaceae e Putranjivaceae, e as Oldfieldioideae compuseram a família Picrodendraceae.

Wurdack et al. (2005), em seu estudo filogenético sobre as Euphorbiaceae s.s. demostraram que apenas a subfamília Euphorbioideae é monofilética, enquanto Crotonoideae necessitaria ser desmembrada, com a criação de duas novas subfamílias: Peroideae (Pera, Chaetocarpus, Pogonophora, Clutia, Trigonopleura) e Cheilosoideae (Cheilosa, 
Neoscortechinia). Mais recentemente, Davis et al. (2007) demonstraram que as Euphorbiaceae s.s. não eram monofiléticas, pois, em sua filogenia, a família Rafflesiaceae emergia entre as Euphorbiaceae s.s. Posteriormente a este trabalho, Wurdack \& Davis (2009), revisando as relações filogenéticas entre as famílias da ordem Malpighiales, corroboraram os resultados encontrados por Davis et al. (2007) e, para tornar as Euphorbiaceae monofiléticas, elevaram as Peroideae ao status de família (Peraceae), tornando assim Euphorbiaceae s.s. monofilética.

Nessa circunscrição, as Euphorbiaceae s.s. caracterizam-se por apresentar hábito bastante variado, ocorrendo desde ervas, subarbustos, arbustos a árvores, muitas vezes suculentas, monóicas ou dióicas, freqüentemente com látex colorido ou leitoso. Suas folhas são alternas ou opostas, mais raramente verticiladas, simples ou compostas, e neste caso digitadas, de nervação pinada ou palmada, as estípulas são livres ou unidas, reduzidas a glândulas ou ausentes. Possuem indumento variado, de tricomas estrelados a escamiformes, mas alguns representantes são glabros. As inflorescências são terminais ou axilares, basicamente cimosas, podendo ser fascículos, racemos, espigas, panículas, dicásios, e outras do tipo pseudanto como em Dalechampia e Euphorbia, neste último mais conhecido como ciátio. As flores são unissexuais, actinomorfas, raramente zigomorfas, monoclamídeas, diclamídeas ou aclamídeas. O número de estames é muito variável, com filetes livres ou unidos e anteras rimosas; os grãos de pólen são tectados ou não-tectados, inaperturados ou poliaperturados, na maioria 3-colporados (Webster, 1967). Uma importante característica da família é o ovário tricarpelar e trilocular, com cada lóculo contendo 1 óvulo de placentação axilar; os estiletes podem ser inteiros ou ramificados, livres ou unidos. O fruto é tipicamente uma cápsula de deiscência septicida-loculicida, com 1 semente por lóculo, de tegumento externo fino, ósseo ou carnoso, provida ou não de carúncula, com endosperma abundante.

\section{$O$ gênero Croton $L$.}

Croton L. é o segundo maior gênero das Euphorbiaceae s.s compreendendo aproximadamente 1200 espécies distribuídas principalmente nas regiões tropicais do mundo (Govaerts et. al., 2000), com alguns representantes em áreas tropicais e subtropicais. O gênero apresenta maior concentração de espécies na região Neotropical, onde os principais centros de diversidade são o Brasil, as Antilhas e o México (Burger \& Huft, 1995). No Brasil, ocorrem 
cerca de 350 espécies, incluindo ervas, arbustos e árvores, em todos os tipos vegetacionais, mas com um maior número de espécies na parte leste do país, principalmente em áreas de vegetação aberta.

O gênero é muito comum em áreas perturbadas e de vegetação secundária, estando entre os dez mais abundantes (aproximadamente 750 espécies) na América do Sul (GomezPompa,1971).

Espécies de Croton são úteis para reflorestamentos de áreas degradadas (C. floribundus Spreng., C. piptocalyx Müll.Arg., C. salutaris Casar. e C. urucurana Baill.); outras, como Croton glandulosus L. e Croton lundianus (Didr.) Müll.Arg., são invasoras de culturas e pastagens. Algumas espécies, conhecidas vulgarmente como marmeleiros na região nordeste do Brasil, têm importância em virtude dos óleos voláteis medicinais presentes em altas concentrações em suas folhas (Bezerra \& Fernandes, 1982), o que tem despertado o interesse para o desenvolvimento de estudos com outras espécies do gênero.

Em sua circunscrição atual (Berry et al. 2005b), Croton é um gênero monofilético e muito bem caracterizado pelas inflorescências terminais em pseudoracemo, estames encurvados no botão e pétalas das flores femininas geralmente reduzidas. Além disso, o tipo de indumento (estrelado ou escamiforme) e o látex não-leitoso em Croton permitem distinguí-lo facilmente dos outros gêneros da subfamília Crotonoideae (Webster, 1967). No campo, o gênero pode ser facilmente reconhecido por um conjunto de caracteres que incluem o indumento de tricomas estrelados ou lepidotos, o látex colorido, geralmente avermelhado, ou incolor, folhas frequentemente com glândulas no ápice do pecíolo junto à lâmina foliar, que tornam-se alaranjadas ou avermelhadas quando senescentes, além das inflorescências geralmente terminais, com flores femininas geralmente presentes em nós proximais e as estaminadas nos distais.

Na monografia da família Euphorbiaceae para o De Candolle Prodromus, Müller (1866) apresentou pela primeira vez sua classificação infragenérica para Croton, incluindo todas as espécies conhecidas do gênero na época, faltando entretanto, chaves de identificação para as espécies. Já na Flora brasiliensis (Müller, 1873), chaves de identificação para as seções, subseções, séries e espécies são apresentadas, o que foi, sem dúvida, fundamental para a aceitação de seu sistema, que incluía 10 seções, 4 subseções e 8 séries, baseadas principalmente na morfologia das flores pistiladas e no tipo de indumento. 
Várias das seções propostas por Baillon $(1858,1864)$ para Croton foram, à princípio, ignoradas, uma vez que as monografias mais completas sobre o gênero na época, foram realizadas por Müller (1866, 1873). Para Webster et al. (1993), entretanto, a classificação infragenérica de Baillon $(1858,1864)$ é mais indicadora de relações de parentesco entre as espécies, o que o levou a aceitar várias das seções de Baillon em sua classificação para o gênero.

Em sua sinopse provisória do gênero Croton, Webster (1993) incorporou seções propostas por Baillon (1858, 1864) e Grisebach (1864), e estabeleceu outras novas, totalizando 40 seções e 5 subseções, baseadas pricipalmente em indumento, filotaxia, presença e tipo de nectários extraflorais, presença de címulas basais bissexuadas nas inflorescências, presença e tipo de pétalas em ambas as flores, prefloração, número de estames e de ramificações dos estiletes.

Mesmo sendo uma importante contribuição para a sistemática do gênero, na sinopse de Webster (1993) muitas das espécies de Croton não foram incluídas nas seções e, mais recentemente, Berry et al. (2005b) demostraram que várias delas não são monofiléticas, como Croton sect. Argyrocroton (Müll.Arg.) G.L. Webster, C. sect. Cascarilla Griseb. e C. sect. Tiglium (Klotzsch) Baill.

Segundo a classificação de Webster (1994b), o gênero pertence à Tribo Crotoneae e, apesar do grande número de espécies e da grande diversidade morfológica, seria aparentemente um táxon monofilético pertencente à subfamília Crotonoideae (Webster, 1993). Entretanto, estudos filogenéticos com dados moleculares (regiões ITS e trnL-F), realizados por Berry et al. (2005b), demonstraram que Croton não era monofilético. Neste trabalho, Croton emergiu como grupo irmão de Brasiliocroton P.E. Berry \& Cordeiro, com 11 grupos infragenéricos reconhecidos, entre eles Moacroton Croizat, um pequeno gênero endêmico de Cuba, e Julocroton Mart., tradicionalmente tratados como gêneros, mas no caso de Julocroton já formalmente sinonimizado a Croton por Webster $(1967,1992)$. Além disso, Croton sect. Astraea (Klotzsch) Baill. necessitou ser excluída do gênero, sendo restabelecida como gênero Astraea (fig. 1). A tribo Crotoneae em sua mais recente delimitação (Berry et al., 2005; Wurdack et al., 2005) inclui, além de Croton, que é o maior e mais diverso gênero da tribo, Acidocroton, Astraea, Brasiliocroton, Ophellantha, Sagotia e Sandwithia. 


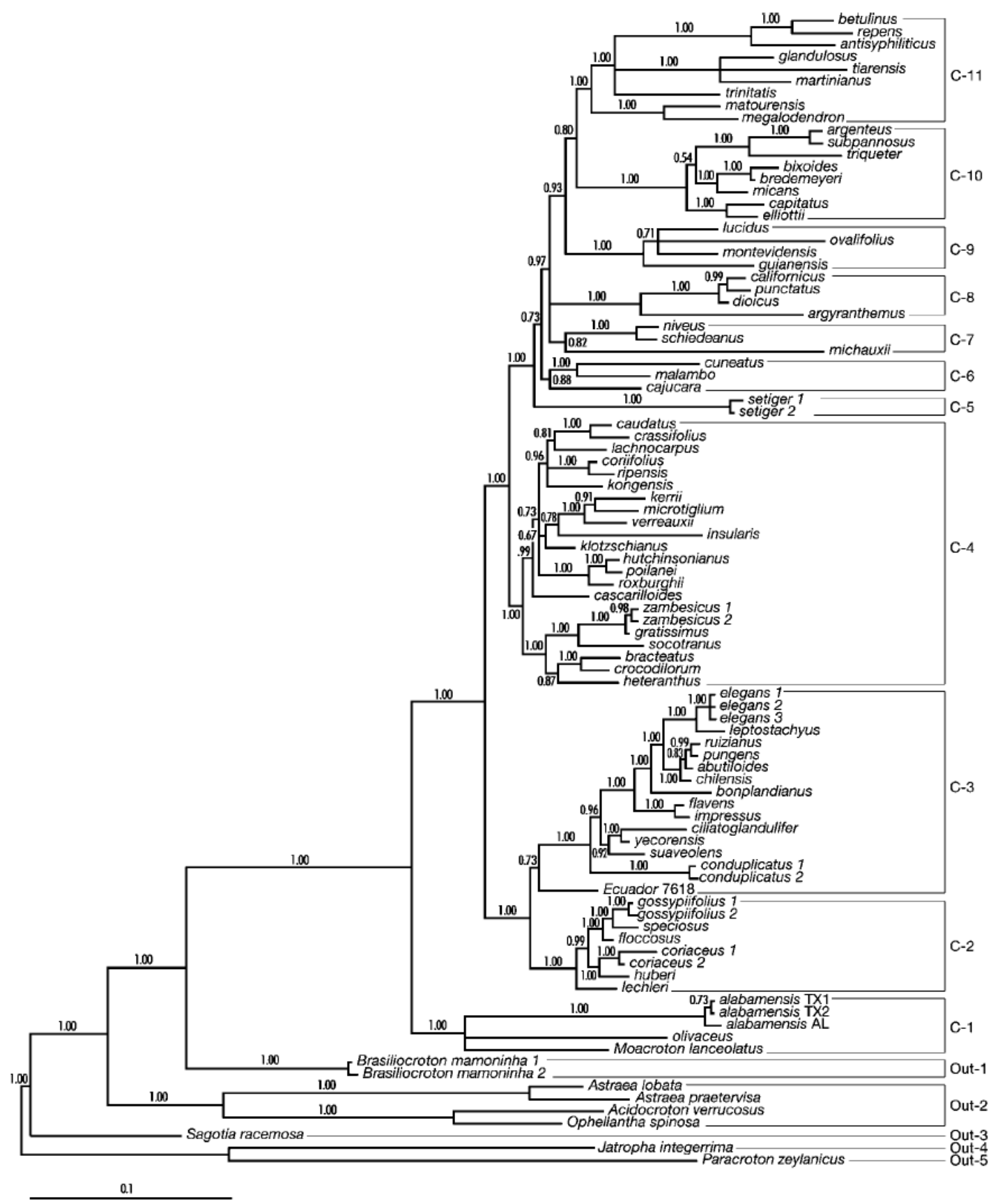

Figura 1: Filograma de análise bayesiana combinada de dados de trnL-F e ITS. Números acima dos ramos são as probabilidades posteriores (extraído de Berry et al., 2005b). 
Mesmo com os recentes estudos, a circunscrição infragenérica de Croton ainda não se encontra resolvida, e apenas algumas seções encontram-se devidamente circunscritas e já foram revistas, como Argyroglossum Baill. (Gomes, 2006), Cyclostigma Griseb. (Riina, 2006), Lamprocroton (Lima \& Pirani, 2008) e Crotonopsis (van Ee \& Berry, 2009).

Segundo Berry (2002), há cerca de 1200 nomes aceitos e 1100 sinônimos em Croton. Portanto, entre as dificuldades para estabelecer formalmente uma classificação do gênero, além do elevado número de espécies, há também a grande confusão nomenclatural envolvendo centenas de nomes de espécies e variedades, com tipos muitas vezes não localizados ou mesmo destruídos, como aqueles do Herbário de Berlim, onde encontravam-se vários dos tipos de espécies de Croton descritas por Müller.

Muitos trabalhos realizados sobre o gênero são de cunho regional, sendo basicamente partes de floras ou descrições de novas espécies. Dentre os principais tratamentos realizados sobre Croton no continente Americano, podem ser destacados os de Lanjouw (1932) para o Suriname; os de Croizat (1940, 1941, 1944) para Argentina, Brasil e Uruguai; Macbride (1951) para o Peru; Jablonski (1965) para Guiana; Webster \& Burch (1968) para o Panamá; Gordillo (1996) e Webster (2001) para o México; Ramella \& Perret (1998) para o Paraguai e Murillo-A. (1999) para a Colombia. No Brasil, os principais trabalhos que tratam sobre o gênero são: Flora Ilustrada Catarinense (Smith et al., 1988); Flora Fanerogâmica da Reserva do Parque Estadual das Fontes do Ipiranga, em São Paulo (Cordeiro, 1989); Flora Fanerogâmica da Ilha do Cardoso, em São Paulo (Cordeiro, 1992a); Flora da Serra do Cipó, em Minas Gerais (Cordeiro, 1992b); Notas sobre as lianas do gênero Croton L. (Secco, 1992); Croton ascendens (Euphorbiaceae), a new Liana from Eastern Amazonia (Secco \& Rosa, 1992); Flora do Pico das Almas na Bahia (Cordeiro, 1995); Flora de Inselbergs da região de Milagres, Bahia (Carneiro et al., 2002); O gênero Croton na Cadeia do Espinhaço, em Minas Gerais (Lima \& Pirani, 2003); Flora da Reserva Ducke, Amazonas (Secco, 2005); Sinopse da tribo Crotoneae Dumort. (Euphorbiaceae s.s.) no Estado de São Paulo, Brasil (Caruzo \& Cordeiro, 2007); Sinopse das espécies de Croton L. (Euphorbiaceae) na Amazônia brasileira (Secco, 2008); Diversidade de Croton L. (Euphorbiaceae) no bioma Caatinga (D.S. CarneiroTorres, 2009). Os trabalhos de cunho filogenético que podem ser destacados são: Molecular Phylogenetics and Biogeography of the caribbean-centered subgenus Moacroton (Euphorbiaceae s.s.) (van Ee et al., 2008); Molecular Phylogenetics of the Dragon's Blood 
Croton sect. Cyclostigma (Euphorbiaceae): A Polyphyletic Assemblage Unraveled (Riina et al., 2009). Os trabalhos em andamento com o gênero que merecem destaque são os de O. C. De Paula, que trata da ontogenia e estrutura dos nectários extraflorais e florais em Croton, e o estudo revisional da seção Geiseleria por M.F. Sales.

Os objetivos principais do presente trabalho foram: realizar a revisão taxonômica e reavaliar a circunscrição de Croton sect. Cleodora (Klotzsch) Baill.; determinar novos caracteres morfológicos para a circunscrição das espécies do gênero; produzir uma filogenia para as espécies de Croton sect. Cleodora, utilizando método cladístico, com base em dados moleculares; entender padrões de evolução morfológica no grupo; propor hipóteses biogeográficas para Croton sect. Cleodora, de maneira a entender o estabelecimento das espécies da seção em relação aos diferentes tipos de ambiente em que ocorrem; interpretar os padrões de distribuição geográfica com base na filogenia resultante da análise cladística; contribuir para a construção de uma classificação infragenérica de Croton; contribuir para o conhecimento do gênero Croton na região neotropical. A fim de facilitar o processo de publicação, este trabalho está apresentado em capítulos:

Capítulo 1: Molecular PHYLOGENETICS, CHARACTER EVOLUTION, AND PHARMACOLOGICAL POTENTIAL OF THE "SACACA" CLADE: NOVEL RELATIONSHIPS OF CROTON SECTION CLEODORA (EUPHORBIACEAE). (Filogenia molecula, evolução de caracteres a potencial farmacológico do clado das "sacacas": novas relações em Croton sect. Cleodora (Euphorbiaceae)). Neste capítulo, o monofiletismo e as relações evolutivas de Croton sect. Cleodora são testadas utilizando-se dados moleculares. Em sua circunscrição tradicional a seção Cleodora não é monofilética. A seção torna-se monofilética com a inclusão de algumas espécies anteriormente posicionadas em diferentes seções de Croton e, portanto, uma nova delimitação para Croton sect. Cleodora é proposta.

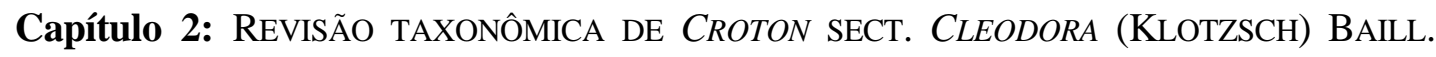
Aqui é apresentado um estudo taxonômico da seção Cleodora. Foram reconhecidas 18 espécies para a seção. De maneira geral, a seção Cleodora pode ser caracterizada por seus representantes arbóreos e latescentes, flores masculinas com 15-25 estames, flores femininas com prefloração geralmente quincuncial, lobos do cálice unidos na base ou até um pouco mais acima, estiletes quatro a muitas vezes divididos e unidos na base. 
Capítulo 3: Tricomas foliares em CROTON SECt. CleOdORA (EuPHORBIACEAE). Foram analisados os indumentos foliares das espécies de Croton sect. Cleodora em uma tentativa de utilizar o tipo de tricoma na delimitação da seção e de suas espécies. Os tricomas em Croton sect. Cleodora são, pricipalmente, do tipo lepidoto e suas variações. O estudo demonstrou que os padrões de tricomas na seção não devem ser utilizados isoladamente na delimitação da seção, mas sim como auxiliar na caracterização da mesma.

Capítulo 4: PAdRÕES DE Distribuição GEOGRÁficA EM CROTON SECT. CLEODORA (EuPHORBIACEAE). Croton sect. Cleodora é exclusivamente Neotropical e possui 18 espécies, dentre as quais 12 ocorrem no Brasil, região que pode ser considerada o centro de diversidade da seção. Este trabalho visa reconhecer e estabelecer padrões de distribuição das espécies da seção Cleodora, bem como reconhecer a que tipos vegetacionais essas espécies estão associadas.

Capítulo 5: MODELAGEM DE NICHO ECOLÓGICO DE ESPÉCIES DE CROTON SECT. CLEODORA (EUPHORBIACEAE) OCORRENTES NO BRASIL. As espécies brasileiras de Croton sect. Cleodora tiveram seus nichos ecológicos modelados, com a finalidade de esclarecer quais fatores ambientais estão relacionados à sua distribuição. Apesar de diferentes fatores climáticos e bioclimáticos parecerem determinar a distribuição das espécies, o tipo de solo parece ser o fator decisivo para as espécies dessa seção.

\section{Anexos}

Anexo 1: Caruzo, M.B.R.; Riina, R.; Cordeiro, I. \& Berry, P.E. Croton campanulatus (Euphorbiaceae s.s.), a new species from the Brazilian Atlantic rain forest. Brittonia 60(3): 261-264.

Anexo 2: Caruzo, M.B.R.; Riina, R.; Cordeiro, I. \& Berry, P.E. Croton rufolepidotus (Euphorbiaceae s.s.), a new species from Colombia. Novon. (submetido)

Anexo 3: Caruzo, M.B.R.; Cordeiro, I.; Berry, P.E. \& Riina, R. A new species of Croton section Cleodora (Euphorbiaceae s.s.) from Minas Gerais, Brazil. Phytotaxa. (submetido) 


\section{Referências bibliográficas}

Baillon, H. 1858. Etude générale du groupe des Euphorbiacées. Victor Masson, Paris.

Baillon, H. 1864. Euphorbiaceés Americaines. Adansonia 4: 257-377.

Baillon, H. 1873. Nouvelles observations sur les Euphorbiacées australiennes. Adansonia 7: 352-360.

Berry, P.E. 2002. Croton Research Network. Madison: University of Wisconsin-Madison. Disponível em: <http://botany.wisc.edu/croton/>.

Berry, P.E.; Cordeiro, I.; Wiedenhoeft, A.C.; Vitorino-Cruz, M.A. \& Lima, L.R. 2005 a. Brasiliocroton, a new crotonoid genus of Euphorbiaceae s.s. from eastern Brazil. Systematic Botany 30(20): 357-365.

Berry, P.E.; Hipp, A.L.; Wurdack, K.J.; Van Ee, B. \& Riina, R. 2005b. Molecular phylogenetics of the giant genus Croton and tribe Crotoneae (Euphorbiaceae sensu stricto) using ITS and trnL-trnF DNA sequence data. Amer. J. Bot. 92(9): 1520-1534.

Bezerra, P. \& Fernandes, A. 1982. Anais XXXIII Congresso Nacional de Botânica. 145156.

Burger, W. \& Huft, M. 1995. Flora costaricensis: Euphorbiaceae. Fieldiana 36: 1-169.

Carneiro, D. S.; Cordeiro, I.; França, F. 2002. A família Euphorbiaceae na Flora de Inselbergs da região de Milagres, Bahia, Brasil. Bol. Bot. Univ. São Paulo. 20: 31-47.

Carneiro-Torres, D. S. 2009. Diversidade de Croton L. (Euphorbiaceae) no bioma Caatinga. Tese de doutorado. Universidade Estadual de Feira de Santana, Brasil.

Caruzo, M.B.R. \& Cordeiro, I. 2007. Sinopse da tribo Crotoneae Dumort. (Euphorbiaceae s.s.) no Estado de São Paulo, Brasil. Hoehnea 34(4): 571-585.

Chase, M.W.; Soltis, D.E.; Olmstead, R.G.; Morgan, D.; Les, D.H.; Mishler, B.D.; Duvall, M.R.; Price, R.A.; Hills, H.G.; Qiu, Y.L.; Kron, K.A.; Rettig., J.H.; Conti, E.; Palmer, J.D.; Manhart, J.R.; Sytsma, K.J.; Michaels, H.J.; Kress, W.J.; Karol., K.H.; Clarck, W.D.; Hedrén, M.; Gaut, B.S.; Jansen, R.K.; Kim, K.J.; Wimpee, C.F.; Smith, J.F.; Furnier, G.R.; Strauss, S.H.; Xiang, Q.Y.; Plunkett, G.M.; Soltis, P.S.; Swensen, S.M.; Willians, S.E.; Gadek, P.A.; Quinn, C.J.; Eguiarte, L.E.; Golenberg, E.; Learn, J.R.; Graham, S.W.; Barrett, S.C.H.; Dayanandan, S. \& Albert, V.A. 1993. Phylogenetics of seed plants: an analysis of nucleotide sequences from plastide gene rbcL. Ann. Missouri Bot. Gard. 80(3): 528-580. 
Chase, W.M.; Zmarzty, S., Lledó; M.D., Wurdack; K.J., Swensen; S.M. \& Fay, M.F. 2002. When in doudt, put in Flacourtiaceae: a molecular phylogenetic analysis based on plastid $r b c L$ DNA sequences. Kew Bulletin 57: 141-181.

Cordeiro, I. 1989. Euphorbiaceae. Flora Fanerogâmica do Parque Estadual das Fontes do Ipiranga (São Paulo, Brasil). Hoehnea 16: 11-29.

Cordeiro, I. 1992a. Euphorbiaceae. Flora Fanerogâmica da Ilha do Cardoso (São Paulo, Brasil). 3:141-160.

Cordeiro, I. 1992b. Flora da Serra do Cipó, Minas Gerais: Euphorbiaceae. Bol. Bot. Univ. São Paulo 13:169-217.

Croizat, L. 1940. 35 New species of American Croton. J. Arnold Arb. 21: 76-107.

Croizat, L. 1941. Preliminaries for the study of Argentine and Uruguayan species of Croton. Darwiniana 5: 417-462.

Croizat, L. 1944. Additions to the genus Croton L. in South America. Darwiniana 6: 442-468.

Davis , C. C.; Latvis, M.; Nickrent, D. L.; Wurdack, K. J. \& Baum, D. A. 2007. Floral gigantism in Rafflesiaceae. Science 315: 1812.

Ereno, D. 2003. Polímero derivado de óleo vegetal sintetizado por Químico de São Carlos ganha mercado internacional. Revista FAPESP (setembro) 91: 66-71.

Gomes, A.P.S. 2006. Revisão das espécies sul-americanas de Croton L. subgen. Croton sect. Argyroglossum Baill. (Crotonoideae-Euphorbiaceae). Tese de doutorado. Universidade Federal Rural de Pernambuco, Brasil.

Gomes-Pompa, A. 1971. Possible papel de la vegetación secundaria en la evolución de la flora tropical. Biotropica 3(2): 125-135.

Gordillo M.M. 1996. Contribución al conocimiento del género Croton (Euphorbiaceae), en el estado de Guerrero, México. Contribuciones del Herbario de la Facultad de Ciencias, UNAM. 2. Mexico: Coordenación de Servicios Editoriales, Facultad de Ciencias, UNAM.

Govaerts, R.; Frodin, D.G. \& Radcliffe-Smith, A. 2000. World Checklist and Bibliography of Euphorbiaceae (and Pandaceae), v. 2. Kew, Royal Botanic Gardens.

Grisebach, A.H.R. 1864. Croton. In Flora of the British West Indian Island (Grisebach, A.H.R. ed.), London. 37-42. 
Huber, H. 1991. Angiospermen. Leitfaden durch die ordnungen und familien der Bedektsamer. Gustav Fischer, Stuttgart.

Jablonski, E. 1965. Botany of the Guayana highlands-part VI: Euphorbiaceae. Mem. New York Bot. Gard. 12: 150-169.

Jussieu, A.L. 1789. Euphorbiae. In Genera Plantarum. p. 384-385.

Lanjouw, J. 1932. Euphorbiaceae. In Flora of Suriname (Pulle, A. ed.). J.H. de Bussy Ltda., Amsterdam. 2 (1): 1-101.

Lima, L.R. \& Pirani, J.R. 2003. O gênero Croton L. (Euphorbiaceae) na Cadeia do Espinhaço, Minas Gerais, Brasil. Bol. Bot. Univ. São Paulo 21(2): 299-344.

Lima, L.R. \& Pirani, J.R. 2008. Revisão taxonômica de Croton sect. Lamprocroton (Müll.Arg.) Pax (Euphorbiaceae s.s.). Biota Neotropica 8(2): 21-75.

Macbride, J.F. 1951. Flora of Peru: Euphorbiaceae. Field Museum of Natural History 13(3A1): 3-200.

Meeuse, A.D.J. 1990. The Euphorbiaceae auct. Plur. an unnatural taxon. Privetely printed.

Müller, J. 1865/66. Euphorbiaceae. Linnaea 34: 1-224.

Müller, J. 1866. Euphorbiaceae exceto suborfo Euphorbieae. In Prodomus Systematics Universalis Regni Vegetabilis (De Candolle, A.P. ed.) 15(2): 189-1286.

Müller, J. 1873. Euphorbiaceae. In Flora Brasiliensis (Martius, C. F. P. \& Eichler, A. G. eds.) 11(2): 293-750, pl. 43-104.

Murillo-A., J. 1999. Composición y distribucíon del género Croton (Euphorbiaceae) en Colombia, con cuatro especies nuevas. Caldasia 21(2): 141-166.

Radcliffe-Smith, A. 2001. Genera Euphorbiacearum. Kew, Royal Botanic Gardens. 455p.

Ramella, L. \& Perret, P. 1998. Notulae ad Floram Paraguaiensem. Candollea 53: 117-131.

Riina, R. 2006. Molecular Systematics of the Neotropical Dragon's Blood trees Croton sect. Cyclostigma (Euphorbiaceae). PhD thesis. University of Wisconsin-Madison, USA.

Riina, R.; Berry, P.E. \& van Ee, B.W. 2009. Molecular Phylogenetics of the Dragon's Blood Croton sect. Cyclostigma (Euphorbiaceae): A Polyphyletic Assemblage Unraveled. Systematic Botany 34(2): 360-374.

Secco, R.S. 2005. Flora da Reserva Ducke, Amazônia, Brasil: Euphorbiaceae - Parte I. Rodriguésia 56(86): 143-168. 
Secco, R.S. 2008. Sinopse das espécies de Croton L. (Euphorbiaceae) na Amazônia brasileira: um ensaio taxonômico. 1ํㅡㄹ ed. Belém: Museu Paraensi Emilio Goeldi. 169p.

Smith, L. B.; Downs, R.J. \& Klein, R.M. 1988. Euforbiáceas. In Flora Ilustrada Catarinense (R. Reitz, ed.). p. 62-137.

Souza, C. V. \& Lorenzi, H. 2005. Botânica Sistemática: guia ilustrado para identificação das famílias de Angiospermas da flora brasileira, baseado em APG II. Nova Odessa, SP, Instituto Plantarum. 640p.

Van Ee, B.W.; Berry, P.E.; Riina, R. \& Amaro, J.E.G. 2008. Molecular Phylogenetics and Biogeography of the caribbean-centered subgenus Moacroton (Euphorbiaceae s.s.). Bot. Rev. 74: 132-165.

Van Ee, B.W. \& Berry, P.E. 2009. The circumscription of Croton sect. Crotonopsis (Euphorbiaceae), a north american endemic. Harvard Papers in Botany 14(1): 61-70.

Webster, G. L. 1967. The genera of Euphorbiaceae in the Southeastern United States. J. Arnold Arb. 48: 303-357.

Webster, G.L. 1975. Conspectus of a new classification of the Euphorbicaceae. Taxon 24: 593-601.

Webster, G.L. 1987. The saga of the spurges: a review of classification and relationships in the Euphorbiales. Bot. J. Linn. Soc. 94: 3-46.

Webster, G.L. 1992. Realignments in americam Croton (Euphorbiaceae). Novon 2: 269-273.

Webster, G. L. 1993. A provisional synopsis of the sections of the genus Croton (Euphorbiaceae). Taxon 42: 793-823.

Webster, G. L. 1994a. Classification of the Euphorbiaceae. Ann. Missouri Bot. Gard. 81(1): $1-144$.

Webster, G. L. 1994b. Synopsis of the genera and suprageneric taxa of Euphorbiaceae. Ann. Missouri Bot. Gard. 81(1): 33-144.

Webster, G. L. 2001. Synopsis of Croton and Phyllanthus (Euphorbiaceae) in Western Tropical Mexico. Contr. Univ. Michigan Herb. 23: 353-388.

Webster, G. L. \& Burch, D. 1968. Flora do Panama. Euphorbiaceae. Ann. Missouri Bot. Gard. 54 (3): 211-350.

Webster, G.L. \& Huft, M.J. 1988. Revised synopsis of panamanian Euphorbiaceae. Ann. Missouri Bot. Gard. 75: 1087-1144. 
Webster, G. L.; Del-Arco-Aguilar, M.J. \& Smith, B.A. 1996. Systematic distribution of foliar trichome types in Croton (Euphorbiaceae). Bot. J. Linn. Soc. 121: 41-57.

Wurdack, K.J.; Hoffmann, P. \& Chase, M.W. 2005. Molecular phylogenetic analysis of uniovulate Euphorbiaceae (Euphorbiaceae sensu stricto) using plastid rbcL and trhL-F sequences. Amer. J. Bot. 92(8): 1397-1420.

Wurdack, K.J. \& Davis, C.C. 2009. Malpighiales phylogenetics: gaining ground on one of the most recalcitrant clades in the angiosperm tree of life. Amer. J. Bot. 96(8): 15511570. 
CAPÍtulo 1 
Molecular phylogenetics, character evolution, and pharmacological potential of the "sacaca" clade: novel relationships of Croton section Cleodora (Euphorbiaceae) ${ }^{1}$

Maria Beatriz R. Caruzo ${ }^{\mathrm{a}, \mathrm{b}}$, Benjamin W. van Ee $\mathrm{e}^{\mathrm{c}}$, Inês Cordeiro ${ }^{\mathrm{b}}$, Paul E. Berry ${ }^{\mathrm{d}}$ \& Ricarda Riina ${ }^{\text {d,e }}$

aaDepartamento de Botânica, Instituto de Biociências, Universidade de São Paulo, Cx. Postal 11461, 05422-970, São Paulo, SP, Brazil; email: mbrcaruzo@hotmail.com; (55 11) 5073-6300 ext. 281 (author for correspondence)

bInstituto de Botânica, Secretaria do Meio Ambiente, Cx. Postal 3005, 01061-970, São Paulo, SP, Brazil

${ }^{\mathrm{C}}$ University of Michigan Herbarium, 3600 Varsity Drive, Ann Arbor, MI 48109-2228, USA

${ }^{c}$ Harvard University Herbaria, 22 Divinity Ave, Cambridge, MA 02138 U.S.A.

d Real Jardín Botánico, CSIC, Plaza Murillo 2, Madrid 28014, Spain

\footnotetext{
${ }^{1}$ *Manuscrito a ser submetido à revista Molecular Phylogenetics and Evolution.
} 


\section{Abstract}

Phylogenetic relationships of Croton section Cleodora (Klotzsch) Baill. were evaluated using the nuclear ribosomal ITS and the chloroplast regions trnL-F and trnH-psbA, individually and in combination. The combined and separate nuclear and chloroplast phylogenies recovered a non-monophyletic section Cleodora sensu Webster. Our results show a strongly supported clade containing almost all previously recognized Cleodora species, plus some other species morphologically similar to them. Two morphological synapomorphies support section Cleodora as a clade: sepals of the pistillate flowers with some degree of overlap, and styles united at their base or higher. The evolution of floral characters, such as calyx aestivation, within this group was evaluated in light of the phylogenetic hypotheses. Within section Cleodora there are two well supported clades, which are proposed here as subsections (subsection Stolidanthus and subsection Spruceanus) with their taxonomic circumscriptions provided. The resulting phylogenetic hypothesis identifies the close relatives of the medicinally important and essential oil-rich Croton cajucara Benth. as candidates for future screening in phytochemical and pharmacological studies.

Keywords: Neotropical flora, Croton cajucara, essential oils, ITS, trnL-F, trnH-psbA. 


\section{Introduction}

Croton L., the second largest genus of Euphorbiaceae, is an important pantropical genus of which several species are employed in traditional medicine practices in Africa, Asia and South America (Moreno et al., 2009; Salatino et al., 2007). The genus has an estimated 1223 species (Govaerts et al., 2000), ranking it as the $11^{\text {st }}$ largest angiosperm genus (Frodin, 2004), and is found in tropical regions worldwide, although there are some representatives in subtropical and northern temperate areas. Within the Neotropics, the richest region for the genus, its main centers of diversity are Brazil, the West Indies, and Mexico (Burger and Huft, 1995). Croton has great morphological diversity, ranging from herbs to shrubs to trees, and it occupies a wide range of habitats. The genus is found in all types of vegetation, but the greatest number of species grow in open vegetation and disturbed sites.

The monophylly and relationships of the 40 sections and five subsections of Croton proposed by Webster (1993), many of them restored from proposals by other authors (e.g., Baillon, 1858, 1864), were first tested with molecular phylogenetic methods by Berry et al. (2005). In this first molecular phylogeny of tribe Crotoneae, the genus Croton, as circumscribed by Webster (1993), was found to be non-monophyletic, and to make the genus monophyletic they excluded section Astraea (L.) Klotzsch, and included several segregate satellite genera. Since then, several other phylogeneic studies (van Ee et al., 2008; Riina et al., 2009; van Ee and Berry, 2009; van Ee and Berry, 2010; Riina et al., in press), have contributed to building an infrageneric classification of Croton reflecting phylogenetic relationships. Despite this, many species remain to be classified to section, and the basic relationships of most sections are yet to be explored. 
One of these groups in need of study is Croton section Cleodora (Klotzsch) Baill., which is concentrated in Brazil but with a few members extending as far north as central Mexico. A species belonging to this section, Croton cajucara Benth., popularly known as "sacaca” (from the Tupi language, sake’ka, which means witchcraft or spellcasting; Le Cointe, 1934), has historically been used in the Amazon region to treat diarrhea, diabetes, liver and kidney problems, to lower cholesterol, and for weight loss (Salatino et al., 2007). Guided by the traditional ethnobotanical uses of C. cajucara numerous researchers have explored the phytochemical and pharmacological properties of this species (Carvalho et al., 1996; Farias et al., 1997; Maciel et al., 1998a; Maciel et al., 1998b; Souza-Brito et al., 1998; Grynberg et al., 1999; Lemos et al., 1999; Hiruma-Lima et al., 1999a; Maciel et al., 2000; Campos et al., 2002; Hiruma-Lima et al., 2002; Maciel et al., 2002; Grassi-Kassisse et al., 2003; Rosa et al., 2003; Alviano et al., 2005; Brito et al., 2006; Santos et al., 2006; Souza et al., 2006; Perazzo et al., 2007). The effectiveness of $C$. cajucara at reducing lipid and glucose levels has been demonstrated in laboratory by several authors (Farias et al., 1996, 1997; Costa et al., 1999; Grynberg et al., 1999; Hiruma-Lima et al., 1999b; Maciel et al., 2000; Silva et al., 2001a, 2001b). Croton cajucara has also been shown to contain high levels of Linalool, an alcohol used in the perfume industry (Araújo et al., 1971) which has raised much interest in this species among researchers in recent years (Moreno et al., 2009). Although Müller (1873) implied a close relationship by placing C. cajucara, C. heterocalyx, and C. sphaerogynus together in his key, we are aware of no publication until Webster (1993) that suggests what the closest relatives of $C$. cajucara might be. Therefore, from among the species we place in section Cleodora, all phytochemical and pharmacological investigations had been confined to $C$. cajucara until Moreno et al. (2009), who guided by the hypothesis of close relationship implied by the taxonomic treatment of Webster (1993), tested C. heterocalyx and 
discovered that it also contains Linalool and antimicrobial properties. Moreno et al. (2009) found 17 chemical compounds in common between the essential oils of $C$. heterocalyx and those found in C. cajucara by Lopes et al. (2000). Now, with a more comprehensive hypothesis of the phylogenetic relationships of the species related to these, we provide information useful for bioprospecting in this group. We expect that most, if not all, of the species of section Cleodora will be subjected to phytochemical assays in the coming years, information that will then be able to be traced onto the phylogeny to reconstruct patterns of chemical evolution.

Croton section Cleodora was defined morphologically by Webster (1993) by the presence of appressed-stellate trichomes, petiolar glands, terminal inflorescences usually with bisexual cymules, 15--20 stamens, and pistillate flowers with multifid styles and united and/or imbricate sepals. Webster (1993) placed the following species in the section: Croton cajucara Benth., C. calycularis Huber (= C. spruceanus Benth.), C. hemiargyreus Müll.Arg., C. heterocalyx Baill., C. hoffmannii Müll.Arg., C. maracauyensis Chodat \& Hassl. (= C. floribundus Spreng.), C. sepotubensis Hoehne (= C. cajucara), and C. sphaerogynus Baill.

In their analysis of relationships within section Cyclostigma, Riina et al. (2009) recovered two species previously placed in section Cyclostigma, namely Croton organensis Baill. and C. warmingii Müll.Arg. (= C. rottlerifolius Baill.), in a clade consisting primarily of species traditionally placed in section Cleodora. However, this group was not recovered as a clade in their analysis of the chloroplast trnL-F marker. Given the extensive pharmacological interest in C. cajucara, we set out to use molecular phylogenetic methods to test the monophyly of section Cleodora and provide a new circumscription for it, reconstruct the phylogenetic relationships of its members, identify 
morphological synapomorphies and diagnostic characters, investigate evolution of floral characters within the group, and identify the close relatives of the medicinally important C. cajucara to point out new candidate species for bioprospecting studies.

\section{Materials and methods}

\subsection{Taxon sampling and DNA sequencing}

Species from section Cleodora sensu Webster (1993), and species with a similar morphology but of uncertain sectional placement, were included in our molecular sampling. A selection of taxa belonging to other sections and lineages of Croton were used to establish the limits of section Cleodora. We used two outgroup taxa, Astraea lobata (L.) Klotzsch and Brasiliocroton mamoninha P.E.Berry \& Cordeiro, following the findings of Berry et al. (2005).

DNA was extracted from live, silica-dried, and herbarium tissue of single individuals using DNeasy Plant Mini kits (Qiagen, Valencia, California) following the manufacturer's instructions. The nuclear ribosomal ITS (ITS1, 5.8s, and ITS2) and the cpDNA trnL intron and trnL-F intergenic spacer regions were amplified and sequenced employing the same methods as described in Berry et al. (2005). These two loci have been used in all species level phylogenies of Croton to date (Berry et al., 2005; van Ee et al., 2008; Cordeiro et al., 2008; van Ee and Berry, 2009, 2010; Riina et al., 2009, in press). We added the plastid region $\operatorname{trn} H$-psbA, which given its variability has been shown to be a good candidate for a DNA barcoding region (Kress et al., 2005; Lahaye et al., 2008). The trnH-psbA region was amplified and sequenced using primers trnH ${ }^{\mathrm{GUG}}$ (Tate and Simpson, 2003) and psbA (Sang et al., 1997). 
Polymerase chain reaction (PCR) amplification of the trnH-psbA marker was performed with $25 \mu \mathrm{L}$ reactions containing 0.1 of HotStarTaq DNA Polymerase (5

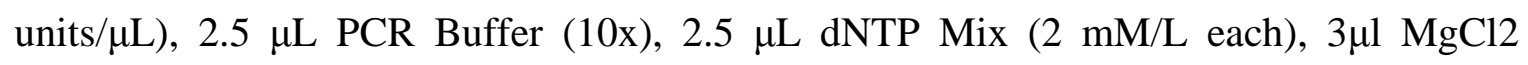
(25mM), $1 \mu \mathrm{l}$ of each primer $(10 \mathrm{pmol} / \mu \mathrm{l}), 14 \mu \mathrm{l}$ of ddH2O, and $1 \mu \mathrm{l}$ of template DNA. The PCR profile consisted of an initial denaturing step at $95^{\circ} \mathrm{C}$ for $15 \mathrm{~min}$, amplification of the trnH-psbA region proceeded at one cycle of $95^{\circ} \mathrm{C}$ for $1 \mathrm{~min}, 65^{\circ} \mathrm{C}$ for $1 \mathrm{~min}, 72^{\circ} \mathrm{C}$ for 1 min; one cycle of $95^{\circ} \mathrm{C}$ for $1 \mathrm{~min}, 64^{\circ} \mathrm{C}$ for $1 \mathrm{~min}, 72^{\circ} \mathrm{C}$ for $1 \mathrm{~min}$; one cycle of $95^{\circ} \mathrm{C}$ for $1 \mathrm{~min}, 63^{\circ} \mathrm{C}$ for $1 \mathrm{~min}, 72^{\circ} \mathrm{C}$ for $1 \mathrm{~min}$; one cycle of $95^{\circ} \mathrm{C}$ for $1 \mathrm{~min}, 62^{\circ} \mathrm{C}$ for $1 \mathrm{~min}$, $72^{\circ} \mathrm{C}$ for $1 \mathrm{~min}$; one cycle of $95^{\circ} \mathrm{C}$ for $1 \mathrm{~min}, 60^{\circ} \mathrm{C}$ for $1 \mathrm{~min}, 72^{\circ} \mathrm{C}$ for $1 \mathrm{~min}$; one cycle of $95^{\circ} \mathrm{C}$ for $1 \mathrm{~min}, 57^{\circ} \mathrm{C}$ for $1 \mathrm{~min}, 72^{\circ} \mathrm{C}$ for $1 \mathrm{~min}$; then followed by 19 cycles of $95^{\circ} \mathrm{C}$ for $1 \mathrm{~min}, 55^{\circ} \mathrm{C}$ for $1 \mathrm{~min}, 72^{\circ} \mathrm{C}$ for $1 \mathrm{~min}$, with a final 15 min extension at $72^{\circ} \mathrm{C}$. PCR products were cleaned using ExoSAP-IT (USB Corp., Cleveland, Ohio) following the manufacturer's protocol, and sequenced on ABI model 3730 automated sequencers at the University of Michigan DNA Sequencing Core. Sequences were edited and assembled using the Staden Package v. 2003.0b1 (Staden, 1996), and then aligned in Clustal X (Thompson et al., 1997). The programs BioEdit v. 7.0.0 (Hall, 1999) and MEGA4 (Tamura et al., 2007) were used to make manual adjustments to the alignment generated by Clustal $\mathrm{X}$.

The combined data matrix consists of 42 accessions, and although it was not possible to obtain satisfactory sequences of trnH-psbA from five species (C. hircinus, C. hirtus, $C$. megalodendrum, C. pallidulus and C. velutinus) and two of trnL-F (C. cuneatus and C. schiedeanus), given that their DNA was from older herbarium collections and presumably degraded, they were included in the combined analysis with the portions coded as missing. A list of species sampled with their localities, herbarium vouchers, and GenBank numbers for all sequences is provided in Appendix 1. All trnH-pbsA sequences are new, 
20 of the trnL-F sequences, those beginning with $\mathrm{XX}$-, are new, and 18 of the ITS sequences, those beginning with $\mathrm{XX}$-, are also new.

\subsection{Phylogenetic analyses}

Congruence between the nuclear and chloroplast loci, as well as between the two different chloroplast loci, was evaluated using the incongruence length difference (ILD) test (Farris et al., 1994) as implemented in PAUP* v. 4.0b10 (Swofford, 2002). The ILD test was conducted using 1,000 partition homogeneity replicates of 10 RASR each, heuristic searches with tree-bisection-reconnection (TBR) branch-swapping, holding one tree at each step, nchuck $=100$, and excluding uninformative characters and taxa with missing data.

Maximum parsimony (MP) analyses were conducted in PAUP*. MP heuristic searches were performed with 1,000 random taxon addition replicates using TBR branch swapping. All characters were equally weighted, and gaps were treated as missing data. MP bootstrap (BS) values of the combined and separated nuclear and chloroplast loci were estimated using 1,000 bootstrap replicates of 100 RASR each, TBR, and nchuck = 100.

Bayesian analyses were conducted in MrBayes v. 3.1.2 (Huelsenbeck and Ronquist, 2001). Bayesian posterior probabilities (PP) were calculated from two Markov chain Monte Carlo (MCMC) analyses, each consisting of four linked chains (heat $=0.02$ ), 1,000,000 generations, and sampling every 50 generations. The data was divided into three partitions (ITS, $\operatorname{trn} L-F$, and trnH-pbsA) with MrBayes estimating the best model parameters for each independently. The burn-in period was estimated by visual examination of the likelihood-by-generation plot and, after removing the trees from the 
burn-in period, PP values were obtained by computing a majority rule consensus of the trees from both MCMC chains.

\subsection{Character state mapping}

Nine morphological characters were scored, based on fresh material and herbarium samples, for the entire dataset (see Table 2 for characters and character states coding information). Most of the selected characters have been used in the past by several systematics studies in Croton (Webster, 1993; Caruzo and Cordeiro, 2007; Lima and Pirani, 2008; van Ee et al., 2008). To assess the patterns of evolution of these characters, we mapped them onto one of the most parsimonious trees obtained from the combined parsimony analysis. We reconstructed ancestral characters states using parsimony as implemented in Mesquite v. 2.72 (Maddison and Maddison, 2009). All characters were treated as unordered.

\section{Results}

\subsection{Molecular data sets and congruence}

The aligned lengths of the three regions used, as well as information regarding the variables and parsimony-informative characters are found in Table 1. The nuclear ITS (Fig. 1) and trnL-F + trnH-psbA chloroplast (Fig. 2) phylogenies do not differ from each other, or from the results of the combined analysis (Fig. 3), in any strongly-supported way, with the exception that the chloroplast analyses recovered section Cyclostigma apart from section Cascarilla, a result discussed in greater detail by Riina et al. (2009). This difference in topology is probably the cause of the ILD test rejecting the hypothesis of no meaningful conflict within the combined data $(p=0.004)$. In contrast, the ILD test 
conducted between the two chloroplast regions (trnLF and $t r n H-p s b A$ ) failed to reject the hypothesis of no meaningful conflict between them $(p=0.630)$. The phylogenetic relationships within section Cleodora inferred from different sources of data, and different methods, are very similar to each other. We therefore discuss the phylogenetic relationships among species of section Cleodora using the combined data phylogeny, and referring to the contrasting results obtained from independent analyses of the nuclear and chloroplast data.

\subsection{Analysis of ITS}

The parsimony search of the ITS data set retained 220 trees with length $(\mathrm{L})=838$, $\mathrm{CI}=0.5561$, and $\mathrm{RI}=0.6346$. The "sumt" command in MrBayes was used to compute the consensus of the post-burn-in trees from the Bayesian analysis of ITS (Fig.1), the posterior probability values represent the percentage of all the retained (post-burn-in) trees that have that given clade, and each branch length represents the average of that branch on all retained trees.

Our results from all analytical approaches performed on this data set recovered a non-monophyletic section Cleodora sensu Webster (1993). Showing that three species placed in other sections by Webster (1993) actually belong to Cleodora (C. fragrans Kunth, previously placed in section Lasiogyne, and $C$. organensis Baill. and $C$. rottlerifolius Baill. previously placed in section Cyclostigma). These three species emerge within a strongly supported clade (100\% PP, $75 \%$ BS) along with all of the sampled Cleodora species (Fig. 1). These are similar results to those obtained by Riina et al. (2009) 
In the ITS phylogeny section Cleodora emerges in a trichotomy with other New World clades of Croton including sections Lamprocroton, Lasiogyne, Luntia, Eluteria, Barhamia, Medea, and Geiseleria. The recently recognized section Cuneati (G.L. Webster) Riina \& P.E. Berry (Riina et al., in press) is recovered sister to this trichotomy (Fig. 1). Nevertheless, within Cleodora two highly supported clades (100\% PP each, 99\% BS each) are recovered (Fig. 1), which represent the two subsection of Cleodora that we describe here (subsections Stolidanthus and Spruceanus).

\subsection{Analysis of chloroplast trnL-F and trnH-psbA}

The parsimony search of the chloroplast data set retained 209 trees with length $(\mathrm{L})=$ 826, $\mathrm{CI}=0.8257$, and $\mathrm{RI}=0.7725$. The consensus of the post-burn-in trees from the Bayesian analysis of the combined chloroplast MCMC chains are depicted in Figure 2.

Similarly to the ITS phylogeny, the results from all analytical approaches performed to the chloroplast data recovered a non-monophyletic section Cleodora sensu Webster (1993), with the same species (C. fragrans Kunth, C. organensis Baill. and $C$. rottlerifolius Baill.) emerging within a well supported Cleodora clade (100\% PP, 61\% BS) (Fig. 2). However, the chloroplast phylogeny recovered, with strong Bayesian posterior probability support (94\% PP), section Cuneati sister to section Cleodora. The chloroplast results provide high support (100\% PP, 88\% BS) for subsection Spruceanus, but only weak support (68\% PP, <50\% BS) for subsection Stolidanthus (Fig. 2).

\subsection{Combined nuclear and chloroplast analysis}

The parsimony search of the combined data set retained four trees with length $(\mathrm{L})=$ 1686, $\mathrm{CI}=0.6809$ e $\mathrm{RI}=0.6741$. The consensus of the post-burn-in trees from the Bayesian analysis of the combined data MCMC chains are depicted in Figure 3. 
All approaches performed for this data set recovered a non-monophyletic section Cleodora with the same three previously non-Cleodora species (Croton fragrans, C. organensis, and C. rottlerifolius) emerging within a highly supported clade (100\% PP, 94\% BS) with the other members of section Cleodora sensu Webster (1993) (Fig. 3).

Our results, those of Riina et al. (in press), even given the reduced overall sampling of Croton, show the same overall topology as in previous Croton phylogenies (e.g. Berry et al., 2005; van Ee et al., 2008; Riina et al., 2009) in which two monophyletic subgenera (subgenus Moacroton and subgenus Croton) are recovered. In addition to these results, New World clade 2 (NW2) emerges sister to the Old World clade, and together they go sister to New World clade 1 (NW1) (sensu Berry et al., 2005). Section Cleodora belongs to New World clade 2, which corresponds to clades C-4 through C-11 of Berry et al. (2005).

The sister group of section Cleodora, although with weak support (50\% PP, $<50 \%$ BS), is a portion of the remainder of the NW2 clade, which includes groups such as section Lamprocroton, section Geiseleria, and section Cuneati.

Section Cleodora is composed of two major sister clades, which are each strongly supported (100\% PP each; 100\% and 99\% BS), and henceforth will be referred as subsections. Subsection Stolidanthus, depicted on the bottom in figure 3, includes the type of the section (C. sphaerogynus), and subsection Spruceanus is depicted on the top in figure 3.

\section{Discussion}

\subsection{Phylogenetic relationships}


The results of this study indicate that section Cleodora sensu Wesbter (1993) is not monophyletic. These results corroborate those found by Riina et al. (2009), where Croton organensis and C. rottlerifolius (treated as C. warmingii in their study), both formerly placed in the section Cyclostigma by Webster (1993), emerge among a well supported clade with most members of Webster's section Cleodora. Besides these two species, Croton fragrans, a species placed by Webster (1993) in section Lasiogyne, also emerges among the species of Croton section Cleodora.

Section Cleodora is embedded in the subgenus Croton clade (sensu van Ee et al., 2008) and is recovered as part of the New World clade 2 (NW2) of Croton (Fig. 3) which is equivalent to clades C-4 through C-11 of Berry et al. (2005). Our results show that the chloroplast (trnL-F + trnH-psbA) and ITS trees are discordant regarding the sister group of section Cleodora. The chloroplast phylogeny strongly supports (94\% PP) section Cuneati as the sister group of section Cleodora (Fig. 2), whereas the ITS phylogeny places it in an unresolved position within the NW2 clade (Fig. 1). The results from the chloroplast phylogeny are similar to those reported by Riina et al. (in press) in a study about arborescent clades of netropical Croton. Croton section Cuneati is morphologically similar to section Cleodora in its arborescent habit, presence of petiolar glands, bisexual cymules sometimes present, and low stamen number (10--20), but it differs from section Cleodora mainly by its discoid glands in the leaf margins (absent in section Cleodora), valvate sepals in the pistillate flowers (which are quincuncial, imbricate or reduplicatevalvate in Cleodora), free styles (which are united at the base or upper in Cleodora), seeds ecarunculate or with a vestigial caruncle (compared to the small and usually reniform caruncle in Cleodora), or sometimes with a distinctive aril (absent in Cleodora).

Our results from the combined data (ITS + chloroplast) show a Cleodora clade with high support (100\% PP, 94\% BS) (Fig. 3). This clade has two morphological 
synapomorphies: sepals of the pistillate flowers with some kind of overlap (Fig. 7, D, E) and styles united at the base or higher, usually forming a "crown" (Fig. 7, C). All species of the Cleodora clade are shrubs or small trees, with the exception of Croton organensis, which is a large tree up to $15 \mathrm{~m}$ tall, from wet forest borders, and usually have reddish or clear latex. Some other important features shared by the majority of the species belonging to this clade are the presence of lepidote trichomes of all subtypes (sensu Webster et al., 1996; Fig. 7, G, H), leaves with a pair of glands at the apex of the petiole (acropetiolar glands; Fig. 7, B) or near the base of the lamina (basilaminar glands; Fig. 7, A), inflorescences with basal bisexual cymules (a plesiomorphic characteristic for the genus), sepals of the staminate flowers usually united half of their length, 15-25 stamens, sepals of the pistillate flowers united at the base or higher, and 4-fid (12 terminal tips; Fig. 7, C) or multifid (> 12 terminal tips; Fig. 7, E) styles.

Within section Cleodora it is possible to identify two major clades with $100 \%$ PP, 99\% and 100\% BS support (Fig. 3). The first clade (top), subsection Stolidanthus, is predominantly Brazilian, with most species occurring in eastern Brazil, and the second clade (bottom), subsection Spruceanus, has species that occur in northwestern South America and southern Central America, with the exception of Croton rottlerifolius which occurs in deciduous forests of Brazil, and C. fragrantulus which occurs in the same kind of vegetation in eastern Bolivia and western Peru.

Subsection Stolidanthus, where the type species of the section Cleodora (Croton sphaerogynus Baill.) is recovered, is supported by a morphological synapomorphy, namely, the sepals of the pistillate flowers with quincuncial aestivation. Other features shared between species within subsection Stolidanthus are globose fruits, sepals of pistillate flowers that are usually fleshy at the base, and pistillate flowers with a disk that is usually segmented (an unusual feature among pistillate flowers of most Croton 
species). The species of subsection Stolidanthus occur mostly in the Atlantic Rain forest of eastern Brazil, with the exception of C. cajucara, an Amazonian species from lowland wet forests. Only C. heterocalyx occurs in seasonally dry forests and "restinga” forests in eastern Brazil.

Within subsection Stolidanthus, two highly supported groups (each with 100\% BS, PP) can be recognized (Fig. 3): the first (bottom) is an entirely lepidote clade with the typical subentire scales (Croton salutaris, C. campanulatus, and C. hemiargyreus) and the other one (top) consists of species that have appressed-stellate or multiradiate trichomes and lack lepidote subentire trichomes (C. heterocalyx, C. sphaerogynus, C. cajucara, and C. organensis).

Our results show that the nuclear ITS and chloroplast trees are discordant about the exact placement of Croton hemiargyreus within subsection Stolidanthus (Figs. 1, 2). ITS (Fig. 1) supports C. hemiargyreus as sister to C. salutaris $+C$. campanulatus while the chloroplast data (Fig. 2) places it sister to the other members of the subsection. However, morphology is consistent with the placement of this species as sister to $C$. salutaris $+C$. campanulatus, as recovered in the ITS phylogeny (Fig. 1), which is the same position recovered in the combined phylogeny (Fig. 3). The group consisting of $C$. hemiargyreus sister to C. salutaris + C. campanulatus is strictly arborescent, and is the only one within section Cleodora where subentire lepidote trichomes, long stipitate acropetiolar glands, and pistillate flowers that are only apparently monochlamydeous (with petals reduced to ovoid glands) are found.

The second group of subsection Stolidanthus as recovered in the combined phylogeny (Croton organensis sister to C. cajucara sister to C. heterocalyx, $+C$. sphaerogynus) share, in addition to the appressed-stellate, multiradiate, and stellate trichomes, the presence of sessile basilaminar glands. Moreover, with the exception of $C$. 
organensis, are usually found in places with sandy soils. Croton organensis is supported as the the sister species to the rest of this clade, followed by C. cajucara which was recovered sister to $C$. heterocalyx $+C$. sphaerogynus. Within this group are two species, C. cajucara and C. heterocalyx, that have been reported to contain Linalool, an alcohol largely used in the perfume industry and having antimicrobial properties, making this clade interesting for bioprospecting studies. Therefore, our results point out $C$. sphaerogynus as one of the closest relatives of C. cajucara. Based on our phylogenetic hypothesis we suggest that $C$. sphaerogynus is a good potential candidate for future bioprospecting studies.

Subsection Spruceanus is formed mostly by species of northwestern South America and southern Central America. This subsection can be generally characterized by the presence of imbricate aestivation in the pistillate flowers, sepals of the pistillate flowers that are usually united at least half of their length, and subglobose to ellipsoid fruits. Croton fragrans, followed by C. billbergianus, are supported as sister to the rest of the species (Fig. 3). These share 4-fids styles, and are clustered into two highly supported subclades (each with 100\% BS and PP): the first (top) containing species of seasonally dry forests of South America and Central America (C. fragrantulus, C. rottlerifolius, and C. hoffmannii), and their distribution are in the area consistent with the "Pleistocenic arc" reported by Pennington et al. (2000) and Prado (2000). The species of this group share the presence of stellate trichomes, acropetiolar leaf glands, and campanulate pistillate flowers. The second clade (bottom) is composed by species from the lowland Amazon rainforests (C. spruceanus, C. orinocensis, and C. pseudofragrans).

Relationships among species of the first group (Croton fragrantulus, C. rottlerifolius, and C. hoffmannii) are not congruent between the phylogenies from the different markers (ITS and chloroplast). ITS (Fig. 1) supports C. rottlerifolius as sister to C. hoffmannii, 
while the chloroplast data (Fig. 2) places C. fragrantulus as sister to C. rottlerifolius. Morphology is consistent with the placement of $C$. rottlerifolius as the sister species of $C$. hoffmannii as recovered in the ITS and combined phylogenies. These two species (C. rottlerifolius + C. hoffmannii) are morphologically more similar to each other than either one is to $C$. fragrantulus. Some of the morphological characteristics shared between $C$. rottlerifolius and C. hoffmannii are the presence of cylindrical branches (vs flat in $C$. fragrantulus), the presence of blackened trichomes in the pistillate flowers, and the sepals of the pistillate flowers with a different texture at the margin.

\subsection{Character evolution}

Our results support previous claims that the characters traditionally used in systematic of Croton are highly homoplasious (Berry et al., 2005; van Ee et al., 2008; Riina et al., 2009). Most of the clades, or sections, within Croton are supported by a suite of homoplasious characters, with a few exceptions.

Trichome types have been largely used for the systematics of Croton (Webster et al., 1996). Trichomes within the genus vary between two basic types, stellate and lepidote, although there are intermediate forms between them. The reconstruction of the evolution of lepidote trichomes within Cleodora (Fig. 4, A) revealed that the presence of this type of trichome is plesiomorphic, and is shared not only by Cleodora but by other clades of subgenus Croton (van Ee et al., 2008). Trichome type transitioned between stellate and lepidote multiple times during the evolution of Croton, and can be regarded as a synapomorphy to the entire tribe Crotoneae (Fig. 4, B). And within Cleodora, stellate trichomes evolved independently three different times (Fig. 4, B).

The presence or absence of extrafloral nectaries on leaves is a frequently used diagnostic character within Croton. Although we have a relatively small sampling for 
tribe Crotoneae in our analysis, the inferred evolution of this character indicates that the presence of petiolar glands (Fig. 4, C) in Croton, as well as in the Cleodora clade, is plesiomorphic.

Flowers in Croton are usually disposed in thyrsoid inflorescences where pistillate flowers are solitary at the lower nodes, and staminate flowers are in groups at the upper nodes. But, some species possess inflorescences with bisexual basal cymules, in which pistillate and staminate flowers occur concomitantly, as Webster (1993) described for sections Cleodora and Cyclostigma. The presence of bisexual cymules (Fig. 4, D), as already pointed out by van Ee et al. (2008), is homoplasious across the whole genus. The possession of inflorescences with bisexual basal cymules, used by Webster (1993) to define Cleodora, is a plesiomorphic character for the section.

The optimization of the fusion of sepals in pistillate flowers onto the phylogeny (Fig. 5, A) implies that the union of sepals only at the base is a plesiomorphic character state, found in almost the entire genus. The fusion of sepals in pistillate flowers up to half of their length has evolved three different times, once within Cleodora subsection Spruceanus (Croton fragrantulus, C. hoffmannii and C. rottlerifolius), again in $C$. megalodendron and other members of section Luntia, and a third time in C. astroites and other species of section Lasiogyne (Fig. 5, A). The fusion of sepals almost at the apex has evolved only once in Croton, and this is within section Cleodora (Fig. 5, A; 7, F), and it is an exclusive character (autapomorphy) for $C$. spruceanus. The total fusion of the sepals in C. spruceanus might have some implications for its reproductive biology, however specialized pollinators for this species have not yet been reported. Most Croton species are visited by different kinds of insects, and their flowers are either insect or wind pollinated (Domínguez and Bullock, 1989; Bullock, 1994; Decker and Pilson, 2000; 
Freitas et al., 2001), so it will be to study the reproductive biology of C. spruceanus and investigate whether this calyx morphology is associated with a more specific pollinator.

Styles in Croton vary from 2-fid (with six terminal tips) to multifid (with more than 12 terminal tips; Fig. 7, E). The inferred evolution of styles division indicates that 4-fid and multifid styles are highly homoplasious within Croton. The presence of multifid styles is a synapomorphy for the subgenus Croton clade (with some reversals), with all members of the subgenus Moacroton clade having either bifid or simple styles (van Ee et al., 2008; Fig. 5, B). Therefore, the possession of multifid styles (Fig. 5, B), one of the characters defining section Cleodora (Webster, 1993), is plesiomorphic for the entire Cleodora clade, and 4-fids styles (with twelve terminal tips) evolved at least two times in this Croton lineage.

Pistillate flowers in Croton are generally apetalous, but when petals are present they are usually reduced to filaments or glands, being rarely conspicuous. Our results show that the presence of reduced petals is the ancestral condition for the entire New World clade of subgenus Croton (Fig. 5, C), which can be regarded as a synapomorphy for the group, with a loss of this character in members of section Luntia (C. megalodendron and C. palanostigma), and in almost all members of Cleodora except for the small clade consisting of $C$. hemiargyreus, C. salutaris, and C. campanulatus, which has petals reduced to ovoid glands.

Our results imply a single origin for both sepals of pistillate flowers with some kind of overlap (Figs. 5, D; 7, D, E) and for having styles united at base or higher, usually forming a "crown" (Figs. 6, A; 7, C), and these characters can be regarded as key synapomorphies for the Cleodora clade. 
The aestivation of pistillate flowers of Croton is usually valvate, rarely reduplicatevalvate. Tracing this character onto the molecular phylogeny indicates that valvate aestivation in pistillate flowers is ancestral within Croton (Fig. 5, D). Overlapping aestivation (imbricate or quincuncial) is present in pistillate flowers of all members of the Cleodora clade, except for a reversion to a reduplicate-valvate aestivation in Croton fragrans, which thus can be regarded as a synapomorphy for the Cleodora clade. Two different types of aestivation in pistillate flowers have evolved within Cleodora, quincuncial aestivation in subsection Stolidanthus, and imbricate aestivation in subsection Spruceanus, with one reversal to a reduplicate-valvate aestivation in C. fragrans (Fig. 7, D). Therefore, our results support an evolutionary trend within Croton from pistillate flowers with valvate or reduplicate-valvate aestivation to pistillate flowers with imbricate or quincuncial aestivation in species of section Cleodora.

\subsection{A new circumscription for the section}

Croton section Cleodora (Klotzsch) Baill., Étude Euphorb.: 369. 1858. Type: Cleodora sellowiana Klotzsch [= Croton sphaerogynus Baill.].

Trees or shrubs, monoecious, generally laticiferous; covered with appressed-stellate, stellate-lepidote or lepidote subentire trichomes, rarely stellate or multiradiate trichomes. Leaves alternate, with a pair of acropetiolar or basilaminar glands, usually sessile, rarely stipitate. Inflorescences terminal, rarely axillary, basal cymules bisexual, sometimes falsely unisexual or rarely unisexual; staminate flowers dichlamydeous, campanulate, rarely subcampanulate, valvate or slightly imbricate aestivation, sepals usually united up to half of their length, stamens 15--25; pistillate flowers monochlamydeous, rarely apparently monochlamydeous (with petals reduced to glands), zygomorphic or 
actinomorphic, sessile or pedicellate, campanulate, flask-shaped or urceolate, imbricate or quincuncial aestivation, styles 4-fid or multifid, united at base or upper, usually forming a “crown.”

In the description of Cleodora Klotzsch (1841) cited only Cleodora sellowiana Klotzsch, making it the obligate type of the genus. Müller (1866) recognized Cleodora sellowiana as a synonym of Croton sphaerogynus Baill., but did not transfer it to Croton, perhaps in recognition that he had earlier (Müller, 1865) described C. sellowianus Müll.Arg., based on a different type and therefore occupying the epithet in Croton. Webster (2001) mistakenly indicated that he had earlier (Webster, 1993) designated Cleodora sellowiana the type of Cleodora, which was not the case. Given that the epithet honoring Friedrich Sellow is occupied in Croton, and our confidence that Cleodora sellowiana and Croton sphaerogynus are the same species, there is no need to make a new name in Croton. Müller (1873) excluded both Croton sphaerogynus and Cleodora sellowiana from what he treated as subsection Cleodora. We therefore consider that Müller (1873) described a new subsection of Croton, rather than transferring Klotzsch’s (1841) taxon to the subsectional level. Johannes Müller is therefore the author of subsection Cleodora (Fl. Bras., 11(2): 133. 1873.), with no parenthetical author. Subsection Cleodora Müller (1873) lacks a designated type and is in need to lectotypification. Its members include two species of section Cleodora (Klotzsch) Baill., C. salutaris and C. orinocensis, which are in subsections Stolidanthus and Spruceanus respectively.

Species included: Croton billbergianus Müll.Arg., C. cajucara Benth., C. campanulatus Caruzo \& Cordeiro, C. croizatii Steyerm., C. fragrans Kunth, C. fragrantulus Croizat, C. hemiargyreus Müll.Arg., C. heterocalyx Baill., C. hoffmannii Müll.Arg., C. organensis Baill., C. orinocensis Müll.Arg., C. pseudofragrans Croizat, C. 
rottlerifolius Baill., C. rufolepidotus Caruzo \& Riina, C. salutaris Casar., C. sphaerogynus Baill. Arg., C. spruceanus Benth., C. stellatoferrugineus Caruzo \& Cordeiro.

There are two species excluded from section Cleodora in its new circumscription, namely Croton maracayuensis Chodat \& Hassl. (= C. floribundus Spreng.), and Croton velutinus Baill.

Croton maracayuensis was synonymized by Govaerts et al. (2000) under $C$. floribundus. Webster (1993) placed Croton floribundus in section Argyroglossum mainly due to its leaves without glands, inflorescences without bisexual cymules, 10--15 stamens, and reduplicate-valvate sepals in the pistillate flowers, which are all characteristics that exclude this species from section Cleodora.

Although Webster (1993) had synonymized section Stolidanthus under section Cleodora, he did not include Croton velutinus in the later section or in any other section recognized in his synopses. This is probably due to its subshrubby habit, stellate indumentum, leaves without glands at the junction of the blade with the petiole, inflorescences without bisexual cymules, between 10--12 stamens, and sepals of the pistillate flowers reduplicate-valvate, all characteristics which exclude this species from section Cleodora. In our opinion, the best placement for $C$. velutinus, considering all the features above, would be in section Medea (Klotzsch) Baill.

Species of Croton section Cleodora fall into two distinct groups, recognized here as subsections:

Croton subsection Stolidanthus (Baill.) Caruzo, stat. nov. Type: Croton heterocalyx Baill. (lectotype, designated by Webster, 1993: 800). इ Croton section Stolidanthus Baill., Adanasonia 4: 323. 1864. 
Pistillate flowers with quincuncial aestivation, sepals usually fleshy at the base; disk usually segmented. Fruits globose to ellipsoid.

As circumscribed here, subsection Stolidanthus is broader than section Stolidanthus in the treatment of Baillon (1864), including all species placed by Baillon in his section Stolidanthus (except for Croton velutinus Baill, which seems to be better positioned in section Medea mainly due to its absence of leaf glands, staminate flowers with less than 15 stamens, and valvate aestivation in the pistillate flowers) plus other species described after Baillon's treatment (such as the recently described Croton campanulatus Caruzo \& Cordeiro, a new species from Brazilian Atlantic Rain forest; Caruzo et al., 2008).

Species included here occur in eastern Brazil, with the exception of Croton cajucara, an Amazonian species occurring in Bolivia, Brazil, Peru, and Venezuela. All species from subsection Stolidanthus occupy wet forests, except for C. heterocalyx which occurs in dry forests and in "restinga” forests.

Species included: Croton cajucara Benth., C. campanulatus Caruzo \& Cordeiro, C. hemiargyreus Müll.Arg., C. heterocalyx Baill., C. organensis Baill., C. salutaris Casar., C. sphaerogynus Baill.

Croton rufolepidotus Caruzo \& Riina, a recently described species from Colombia (Antioquia), is also a member of this subsection based on its similarity with C. salutaris (Caruzo et al., in press). Another recently described species, C. stellatoferrugineus Caruzo \& Cordeiro (Caruzo et al. in press), fits the morphological definition of this subsection and therefore is well positioned on it.

Croton subsection Spruceanus Caruzo, subsect. nov. - Floribus femineis imbricatis, fructibus subglobosis. - Type: Croton spruceanus Benth.

Pistillate flowers with imbricate aestivation, sepals usually united at least half of their length, disk entire. Fruits subglobose, usually trigone. 
Species of subsection Spruceanus occur in northwestern South America up to central Mexico, and in Central America, except for Croton rottlerifolius which occurs only in deciduous forests of Brazil and C. fragrantulus which occurs in a same type of vegetation in eastern Bolivia and western Peru

Species included: Croton billbergianus Müll.Arg., $C$. fragrans Kunth, $C$. fragrantulus Croizat, C. hoffmannii Müll.Arg., C. orinocensis Müll.Arg., C. pseudofragrans Croizat, C. rottlerifolius Baill., C. spruceanus Benth.

Croton croizatii Steyerm. is also part of this subsection based on its similarity with C. orinocensis. 


\section{References}

Alviano, W.S., Mendonça, R.R., Alviano, D.S., Bizzo, H.R., Souto-Padron, T., Rodrigues, M.L., Bolognese, A.M., Alviano, C.S., Souza, M.M.G., 2005. Antimicrobial activity of Croton cajucara Benth linalool-rich essential oil on artificial biofilms and planktonic microorganisms. Oral Microbiol. Immunol. 20(2), 101-105.

Araújo, V.C., Corrêa, G.C., Maia, J.G.S., Silva, M.L., Gottlieb, O.R., Marx, M.C., Magalhães, M.T., 1971. Óleos essenciais da Amazônia contendo linalol. Acta Amaz. 1, 45-47.

Baillon, H., 1858. Etude générale du groupe des Euphorbiacées. Victor Masson, Paris.

Baillon, H., 1864. Euphorbiaceés Americaines. Adansonia 4, 257-377.

Berry, P.E., Hipp, A.L., Wurdack, K.J., Van Ee, B.W., Riina, R., 2005. Molecular phylogenetics of the giant genus Croton and tribe Crotoneae (Euphorbiaceae sensu stricto) using ITS and trnL--trnF DNA sequence data. Amer. J. Bot. 92, 1520-1534.

Brito, N.M.B., Silva-Neto, G.P.N., Torres, I.O., Pacheco, F.T., Batista, L.L., 2006. Efeito do extrato de sacaca (Croton cajucara Benth.) nas glândulas mamárias de ratas submetidas à ooforectomia. Rev. Para. Med. 20(1), 15-18.

Bullock, S. H., 1994. Wind pollination of neotropical dioecious trees. Biotropica 26: 172179.

Burger, W., Huft, M., 1995. Flora costaricensis: Euphorbiaceae. Fieldiana 36, 1-169.

Campos, A.R.;,Albuquerque, F.A.A., Rao, V.S.N., Maciel, M.A.M., Pinto, A.C., 2002. Investigations on the antinociceptive activity of crude extracts from Croton cajucara leaves in mice. Fitoterapia 73(2), 116-120. 
Caruzo, M.B.R., Cordeiro, I., 2007. Sinopse da tribo Crotoneae Dumort. (Euphorbiaceae s.s.) no Estado de São Paulo, Brasil. Hoehnea 34, 571-585.

Caruzo, M.B.R., Riina, R., Cordeiro, I., Berry, P.E., 2008. Croton campanulatus (Euphorbiaceae s.s.), a new species from the Brazilian Atlantic rain forest. Brittonia 60(3), 261-264.

Caruzo, M.B.R., Riina, R., Cordeiro, I., Berry, P.E., In press. Croton rufolepidotus (Euphorbiaceae s.s.), a new species from Colombia. Novon XX, XX-XX.

Caruzo, M.B.R., Cordeiro, I., Berry, P.E., Riina, R., In press. A new species of Croton section Cleodora (Euphorbiaceae s.s.) from Minas Gerais, Brazil. Phytotaxa XX, XX$\mathrm{XX}$.

Carvalho, J.C.T., Silva, M.F.C., Maciel, M.A.M., Pinto, A.C., Nunes, D.S., Lima, R.M., Bastos J.K., Sarti, S.J., 1996. Investigation of anti-inflammatory and antinociceptive activities prototype of trans-dehydrocrotonin, a 19-nor-clerodane diterpene from Croton cajucara. Part 1. Planta Med. 62, 402-404.

Cordeiro, I., Berry, P.E., Caruzo, M.B., Van Ee, B.W., 2008. Croton laceratoglandulosus (Euphorbiaceae s.s.), a new glandular-stipulate species from Brazil and Bolivia, and its systematic position based on molecular analysis. Bot. J. Linn. Soc. 158, 493-498.

Costa, A.M.L., Silva, J.C.R., Campos, A.R., Rao, V.S.N., Maciel, M.A.M., Pinto, A.C., 1999. Antioestrogenic effect of trans-dehydrocrotonin, a nor-clerodane diterpene from Croton cajucara Benth. in rats. Phytother. Res. 13, 689-691.

Decker, K.L., Pilson, D., 2000. Biased sex ratios in the dioecious annual Croton texensis (Euphorbiaceae) are not due to environmental sex determination. Amer. J. Bot. 87, 221229. 
Domínguez, C.A., Bullock, S.H., 1989. La reproducción de Croton suberosus en luz y sombra. Rev. Biol. Trop. 37, 1-10.

Farias, R.A.F., Neto, M.F.O., Viana, G.S.B., Rao, V.S.N., 1996. Effects of Croton cajucara extract on serum lipids of rats fed a high fat diet. Phytother. Res. 10, 697-699.

Farias, R.A., Rao, V.S., Viana, G.S., Silveira, E.R., Maciel, M.A., Pinto, A.C., 1997. Hypoglycemic effect of trans-dehydrocrotonin, a nor-clerodane diterpene from Croton cajucara. Planta Med. 63, 558-560.

Farris, J.S., Kallersjo, M., Kluge, A.G., Bult, C., 1994. Testing significance on incongruence. Cladistics 10, 315-319.

Freitas, L., Bernardello, G., Galetto, L., Paoli, A.A.S., 2001. Nectaries and reproductive biology of Croton sarcopetalus (Euphorbiaceae). Bot. J. Linn. Soc. 136, 267-277.

Frodin, D.G., 2004. History and concepts of big plant genera. Taxon 53(3), 753-776.

Govaerts, R., Frodin, D.G., Radcliffe-Smith, A., 2000. World Checklist and Bibliography of Euphorbiaceae (and Pandaceae). 4 vols. Royal Botanic Gardens, Kew, England.

Grassi-Kassisse, D. M., Wolf-Nunes, V., Miotto, A. M., Farias-Silva, E., Souza-Brito, A. R. M., Nunes, D. S., Spadari-Bratfisch, R. C., 2003. Sensitivity to B-adrenoceptor agonists of adipocytes from rats treated with an aqueous extract of Croton cajucara Benth. J. Pharm. Pharmacol. 55, 253-257.

Grynberg, N.F., Echevarria, A., Lima, J.E., Pamplona, S.S.R., Pinto, A.C., Maciel, M.A.M., 1999. Anti-tumour activity of two 19-nor-clerodane diterpenes, transdehydrocrotonin and trans-crotonin, from Croton cajucara. Planta Med. 65, 687-689.

Hall, T.A., 1999. BioEdit: a user-friendly biological sequence alignment editor and analysis program for Windows 95/98/NT. Nucl. Acids. Symp. Ser. 41, 95-98. 
Hiruma-Lima, C.A., Gracioso, J.S., Nunes, D.S., Souza Brito, A.R.M., 1999a. Effects of an essential oil from the bark of Croton cajucara Benth. on experimental gastric ulcer models in rats and mice. J. Pharm. Pharmacol. 51, 341-346.

Hiruma-Lima, C.A., Spadari-Bratfisch, R.C., Grassi-Kassisse, D.M., Souza-Brito, A.R.M., 1999b. Antiulcerogenic mechanisms of deydrocrotonin, a diterpene lactone obtained from Croton cajucara. Planta Med. 65(4), 325-30.

Hiruma-Lima, C.A., Gracioso, J.S., Bighetti, E.J., Grassi-Kassisse, D.M., Nunes, D.S., Brito, A.R., 2002. Effect of essential oil obtained from Croton cajucara Benth. on gastric ulcer healing and protective factors of the gastric mucosa. Phytomedicine 9(6), 523-529.

Kress, W.J., Wurdack, K.J., Zimmer, E.A., Weigt, L.A., Janzen, D.H., 2005. Use of DNA barcodes to identify flowering plants. Proc. Natl. Acad. Sci. USA 102(23), 8369-8374.

Lahaye, R., van der Bank, M., Bogarin, D., Wagner, J., Pupulin, F., Gigot, G., Maurin, O., Duthoit, S., Barraclough, T.G., Savolainen, V., 2008. DNA barcoding the floras of biodiversity hotspots. Proc. Natl. Acad. Sci. USA 105(8), 2923-2928.

Le Cointe, P., 1934. Árvores e plantas úteis (indígenas e aclimatadas). Série: A Amazônia Brasileira, nº 3. Livraria Clássica, Belém.

Lemos, T.L.G., Machado, M.I.L., Menezes, J.E.S.A., Sousa, C.R., 1999. Essential oil of Croton cajucara Benth. J. Essent. Oil Res. 11, 411-412.

Lima, L.R., Pirani, J.R., 2008. Revisão taxonômica de Croton sect. Lamprocroton (Müll. Arg.) Pax (Euphorbiaceae s.s.). Biota Neotrop. 8(2), 21-75.

Lopes, D., Bizzo, H.R., Sa-Sobrinho, A.F., Pereira, M.V.G., 2000. Linalool-rich Essential Oil from Leaves of Croton cajucara Benth. J. Essent. Oil Res. 12, 705-708. 
Maciel, M.A.M., Pinto, A.C., Brabo, S.N., Arruda, A.C., 1998a. Estudo da variação dos teores de terpenóides bioativos isolados das cascas de Croton cajucara, nativos e cultivados no estado do Pará. Rev. Univers. Rural 20, 17-34.

Maciel, M.A.M., Pinto, A.C., Brabo, S.N., Da Silva, M.N., 1998b. Terpenoids from Croton cajucara. Phytochemistry 49, 823-828.

Maciel, M.A.M, Pinto, A.C., Arruda, A.C., Pamplona, S.G.S.R., Vanderlinde, F.A., Lapa A.J., Echevarria, A., Grynberg, N. F., Côlus, I.M.S., Farias, R.A.F., Costa, A.M.L., Rao, V.S.N., 2000. Ethnopharmacology, phytochemistry and pharmacology: a successful combination in the study of Croton cajucara. J. Ethnopharmacol. 70(1), 41-55.

Maciel, M.A.M., Pinto, A.C., Veiga Jr, V.F., Martins, J.R., Grynberg, N.F., Echevarria, A, Lapa, A.J., Vanderlinde, F.A., 2002. Croton cajucara as an alternative to traditional medicine in a modern health system. Recent Prog. in Med. Plant 8, 502-517.

Maddison, W.P., Maddison, D.R., 2009. Mesquite: a modular system for evolutionary analysis. Version 2.72 http://mesquiteproject.org

Moreno, P.R., Lima, M.E.L., Caruzo, M.B.R., Torres, D.S.C., Cordeiro, I., Young, M.C.M., 2009. Chemical Composition and Antimicrobial Activity of the Essential Oil from Croton heterocalyx Baill. (Euphorbiaceae s.s.) Leaves. J. Essent. Oil Res. 21, 190192.

Mueller, J., 1873. Euphorbiaceae. In Flora Brasiliensis (Martius, C. F. P. \& Eichler, A. G. eds.) 11(2), 293-750, pl. 43-104.

Perazzo, F.F., Carvalho, J.C.T., Rodrigues, M., Morais, E.K.L., Maciel, M.A.M., 2007. Comparative anti-inflammatory and antinociceptive effects of terpenoids and an aqueous extract obtained from Croton cajucara Benth. Rev. Bras. Farmacogn. 17(4), 521-528. 
Prado, D.E., 2000. Seasonally dry forestsof tropical South America: from forgotten ecosystems to a new phytogeographic unit. Edinburgh Journal of Botany 57, 437-461.

Riina, R., Berry, P.E., Van Ee, B.W., 2009. Molecular phylogenetics of the dragon's blood Croton section Cyclostigma (Euphorbiaceae): a polyphyletic assemblage unraveled. Syst. Bot. 34, 360-374.

Riina, R., Van Ee, B.W., Wiedenhoeft, A.C., Cardozo, A., Berry, P.E. In press. Sectional rearrangement of arborescent clades of Croton (Euphorbiaceae) in South America: evolution of arillate seeds and a new species, Croton domatifer. Taxon XX, XX-XX.

Rosa, M.D.S., Mendonca R.R., Bizzo, H.R., Rodrigues, I.D., Soares, R.M.A., SoutoPadron, T., Alviano, C.S., Lopes, A.H.C.S., 2003. Antileishmanial activity of a linaloolrich essential oil from Croton cajucara. Antimicrob. Agents Chemother. 47, 1895-1901.

Salatino, A., Salatino, M.L.F., Negri, G., 2007. Traditional uses, chemistry and pharmacology of Croton species (Euphorbiaceae). J. Braz. Chem. Soc. 18(1), 11-33.

Sang, T., Crawford, D.J., Stuessy, T.F., 1997. Chloroplast DNA phylogeny, reticulate evolution, and biogeography of Paeonia (Paeoniaceae). Amer. J. Bot. 84(9), 1120-1136.

Santos, F.V., Mesquita, S.F.P., Faria, M.J.S.S., Poersh, A., Maciel, M.A.M., Pinto, A.C., Morimoto, H.K., Cólus, I.M.S., 2006. Absence of mutagenicity in stomatic and germ cells of mice submitted to subchronic treatment with an extract of Croton cajucara Benth. (Euphobiaceae). Genet. Molec. Biol. 29(1), 159-165.

Silva, R.M., Santos, F.A., Maciel, M.A.M., Pinto, A.C., Rao, V.S., 2001a. Effect of transdehydrocrotonin, a 19-nor-clerodane diterpene from Croton cajucara on experimental hypertriglyceridaemia and hypercholesterolaemis induced by Triton WR 1339 (tyloxapol) in mice. Planta Med. 67, 763-765. 
Silva, R.M., Santos, F.A., Rao, V.S.N., Maciel, M.A.M., Pinto, A.C., 2001b. The lipidlowering effect of trans-dehydrocrotonin from Croton cajucara Benth. In mice fed on high-fat diet. J. Pharm. Pharmacol. 53, 535-539.

Souza, M.A.A., Souza, S.R., Veiga Jr, V.F., Cortez, JK.P.C., Leal, R.S., Dantas, T.N.C., Maciel, M.A.M., 2006. Composição química do óleo fixo de Croton cajucara e determinação das suas propriedades fungicidas. Rev. Bras. Farmacogn. 16, 599-610.

Souza-Brito, A.R.M., Rodríguez, J.A., Hiruma-Lima, C.A., Haun, M., Nunes, D.C., 1998. Antiulcerogenic activity of trans-dehydrocrotonin from Croton cajucara. Planta Med. 64, 126-129.

Staden, R., 1996. The Staden Sequence Analysis Package. Mol. Biotechnol. 5, 233-241.

Swofford, D.L., 2002. PAUP* Phylogenetic Analysis Using Parsimony (*and other methods), version 4.0b10. Sunderland: Sinauer Associates.

Tamura, K., Dudley, J., Nei, M., Kumar, S., 2007. MEGA 4: Molecular Evolutionary Genetics Analysis (MEGA) Software version 4.0. Mol. Biol. Evol. 24(8), 1596-1599.

Tate, J.A., Simpson, B.B., 2003.Paraphyly of Tarasa (Malvaceae) and diverse origins of the polyploidy species. Sys. Bot. 28(4), 723-737.

Thompson, J.D., Higgins, D.G., Gibson, T.J., 1994. CLUSTAL W: improving the sensitivity of progressive multiple sequence alignment through sequence weighting, position-specific gap penalties and weight matrix choice. Nucleic Acids Res. 22, 4673-4680.

Van Ee, B.W., Berry, P.E., Riina, R., Gutiérrez Amaro, J.E., 2008. Molecular Phylogenetics and Biogeography of the Caribbean-centered Croton subgenus Moacroton (Euphorbiaceae s.s.). Bot. Rev. 74, 132-165.

Van Ee, B.W., Berry, P.E., 2009. A Phylogenetic and taxonomic review of Croton (Euphorbiaceae s.s.) on Jamaica including the description of Croton jamaicensis, a new species of section Eluteria. Syst. Bot. 34, 129-140. 
Van Ee, B.W., P. E. Berry, 2010. In press. Taxonomy and Phylogeny of Croton section Heptallon (Euphorbiaceae). Syst. Bot. 35, XX-XX.

Webster G.L., 1993. A provisional synopsis of the sections of the genus Croton L. (Euphorbiaceae). Taxon 42, 793-823.

Webster, G. L., Del-Arco-Aguilar, M.J., Smith, B.A., 1996. Systematic distribution of foliar trichome types in Croton (Euphorbiaceae). Bot. J. Linn. Soc. 121, 41-57. 
Table 1. Numbers of total, constant, variables and parsimony-informative characters for all datasets.

\begin{tabular}{|l|c|c|c|c|c|}
\hline \multicolumn{1}{|c|}{ Region } & total characters & constant & variable & informative & \% informative \\
\hline ITS & 743 & 428 & 315 & 229 & 31 \\
\hline trnL-F & 1155 & 901 & 146 & 108 & 9 \\
\hline psbA-trnH & 767 & 434 & 333 & 138 & 18 \\
\hline chloroplast & 1922 & 1335 & 587 & 246 & 13 \\
\hline
\end{tabular}

Table 2. Morphological characters and coding information.

\begin{tabular}{|l|l|}
\hline Character & Code \\
\hline Lepidote trichomes & $0=$ absent, $1=$ present \\
\hline Stellate trichomes & $0=$ absent, $1=$ present \\
\hline Petiolar glands & $0=$ absent, $1=$ present \\
\hline Bisexual cymules & $0=$ absent, $1=$ present \\
\hline Union of pistillate sepals & $\begin{array}{l}0=\text { united at the base, } 1=\text { united half of } \\
\text { their length, } 2=\text { united almost to the apex }\end{array}$ \\
\hline Pistillate flowers aestivation & $\begin{array}{l}0=\text { valvate, } 1=\text { reduplicate-valvate, } 2= \\
\text { imbricate, } 3=\text { quincuncial }\end{array}$ \\
\hline Styles division & $0=2$-fids, $1=4$-fids, $2=$ multifids \\
\hline Union of styles & $0=$ absent, $1=$ present \\
\hline
\end{tabular}


Appendix 1. Taxa, localities, vouchers, and GenBank accession numbers for all sequences analyzed. Taxon, Origin, Voucher, GenBank accession numbers: (trnL-F; ITS; trnH-psbA). Missing data: --; Sequences without GenBank accession number:

Astraea lobata (L.) Klotzsch, BRAZIL, Bahia, van Ee 486 (WIS), (--; EU586945; --); A. lobata, BRAZIL, Bahia, van Ee 487 (WIS), (__; --; --); A. lobata, PUERTO RICO, Vega Baja, van Ee 549 (WIS), (EU497699; EU497727; _); Brasiliocroton mamoninha P.E.Berry \& I.Cordeiro, BRAZIL, Espirito Santo, Pirani 4947 (SPF), (EU586998; EU586944; _); Croton alchorneicarpus Croizat, BRAZIl, São Paulo, Caruzo 71 (SP), (___ _; --); C. alchorneicarpus, BRASIl, Rio de Janeiro, Riina 1529 (WIS), (--; --; _); C. astroites Dryand., PUERTO RICO, van Ee 537 (WIS), (EU586955; EU586902; _); C. billbergianus Müll.Arg., COSTA RICA, Alajuela, Van Ee 342 (WIS), (EU478148; EU477998; __); C. cajucara Benth., BRAZIL, Caruzo 95 (SP), (EU586968; EU586913, -); C. cajucara, BRAZIL, Caruzo 96 (SP), (_; _, _); C. campanulatus Caruzo \& Cordeiro, BRAZIL, Rio de Janeiro, Caruzo 93 (SP), (_; _ _ _); C. cuneatus Klotzsch, VENEZUELA, Riina 1491 (WIS), (--; --; EU497735); C. cupreatus Croizat, Ecuador, Pichincha, Riina 1408 (WIS), (EU586974; EU586919, __); C. echioides Baill., BRAZIL, Santos 795 (HUEFS), (EU586967; EU586907; _); C. echinocarpus Müll.Arg., BRAZIL, Minas Gerais, Riina 1371 (WIS), (EU586979; EU586922, --); C. echinocarpus, BRASIL, Rio de Janeiro, Riina 1519 (WIS), (--; --; __); C. fragrans Kunth, VENEZUELA, Bolívar, Aymard 9387 (MO, PORT, VEN), (--; EU478000; --); C. fragrans, VENEZUELA, Cojedes, Riina 1824 (MICH, VEN), (_; _ _ - ) C. fragrantulus Croizat, BOLIVIA, Santa Cruz, Foster 424 (MO, USZ), (_; _ _ _); C. glandulosus L., U.S.A., Wisconsin, van Ee 512 (WIS), (EU497713; EU478066; _); C. gracilipes Baill., BOLIVIA, Nee 47412 (NY), (EU586962; EU586909; __); C. hemiargyreus Müll.Arg., BRAZIL, Minas Gerais, Caruzo 114 (SP), (_; _ _ _); C. heterocalyx Baill., BRAZIL, Bahia, Caruzo 108 (SP), (_; _ _ _); C. hircinus Vent., VENEZUELA, Caracas, Riina 1291 (WIS), (EU478127; EU477889; --); C. hirtus L’Her., BRAZIL, Lima 345 (SPF), (EU478160; EU478070; --); C. hoffmannii Müll.Arg., Costa Rica, van Ee 598 (WIS), (EF408111; EF421773; __); C. jacobinensis Baill., BRAZIL, Bahia, Carneiro-Torres 789 (HUEFS), (__ _; _); C. malambo Karst., COLOMBIA, Zarucchi 3856 (MO), (--; --; _); C. manampetsae Leandri, MADAGASCAR, Toliar, van Ee 950 (MICH), (_; _; _); C. niveus Jacq., COSTA RICA, Guanacaste, Van Ee 284 (WIS), (EU478155; EU478046;_); C. niveus, MEXICO, León 52 (DAV), (--; --; _-); C. nobilis Baill., MADAGASCAR, Toliar, van Ee 938 (MICH), (_; _ ; _); C. organensis Baill., BRAZIL, Rio de Janeiro, Caruzo 90 (WIS), (EU586969; EU586914; __); C. orinocensis Müll. Arg., VENEZUELA, Amazonas, Gröger 672 (MO, TFVA, VEN), (--; __ _ ); C. orinocensis, VENEZUELA, Amazonas, Riina 1818 (MICH, VEN), (_; _ _ _); C. palanostigma Klotzsch, PERU, Loreto, Riina 1492 (WIS), (EU586997; EU586943; __); C. pallidulus Baill., BRAZIl, São Paulo, Caruzo 31 (SP), (EU586993; EU586939; --); C. piptocalyx Müll.Arg., BRAZIL, São Paulo, Caruzo 54 (SP), (--; EF421791; _); C. piptocalyx, BRAZIL, São Paulo, Riina 1533 (EF408148; --; --); C. pseudofragrans Croizat, Peru, Loreto, Woodward s.n. (MICH, WIS), (______); C. rottlerifolius Baill., Brazil, São Paulo, Caruzo 56 (SP, WIS), (EU586970; EU586915; __); C. rottlerifolius, Brazil, São Paulo, Riina 1534 (WIS), (_; _; --); C. sacaquinha Croizat, BRAZIL, Pará, Caruzo 97 (SP), (_; _ _ _) ; C. salutaris Casar., BRASIl, São Paulo, Caruzo 81 (SP), (--; __; --); C. salutaris Casar., BRAZIl, Rio de Janeiro, Caruzo 89 (SP), (_; _; _); C. sapiifolius Müll. Arg., BRAZIL, Bahia, Lima 667 (CEPEC), (EF408150; EF421754; _ ); C. schiedeanus Schltdl., MEXICO, Yucatan, van 
Ee 458 (WIS), (EU478156; EU478051; _); C. schiedeanus, COSTA RICA, Aguilar 886 (MO), (AY971331; AY971246; --); C. sphaerogynus Baill., BRAZIL, Rio de Janeiro, Van Ee 505 (WIS), (__ _; _ ); C. spruceanus Benth., BRAZIL, Pará, Caruzo 101 (SP), (_; --; _); C. spruceanus, COLOMBIA, Valle del Cauca, Baker 6493 (MO), (--; __; --); C. velutinus Baill., BRAZIL, Bahia, Carneiro-Torres 902 (HUEFS), (_; _; --); C. trichotomus Geiseler, MADAGASCAR, Toamasina, van Ee 991 (MICH), (_; _ _ _); C. troncosoi Ahumada, ARGENTINA, Belgrano 423 (SI), (EU586994; EU586940; _); C. yavitensis Croizat, BOLIVIA, Beck 5710 (LPB), (EU586973; EU586918; _). 


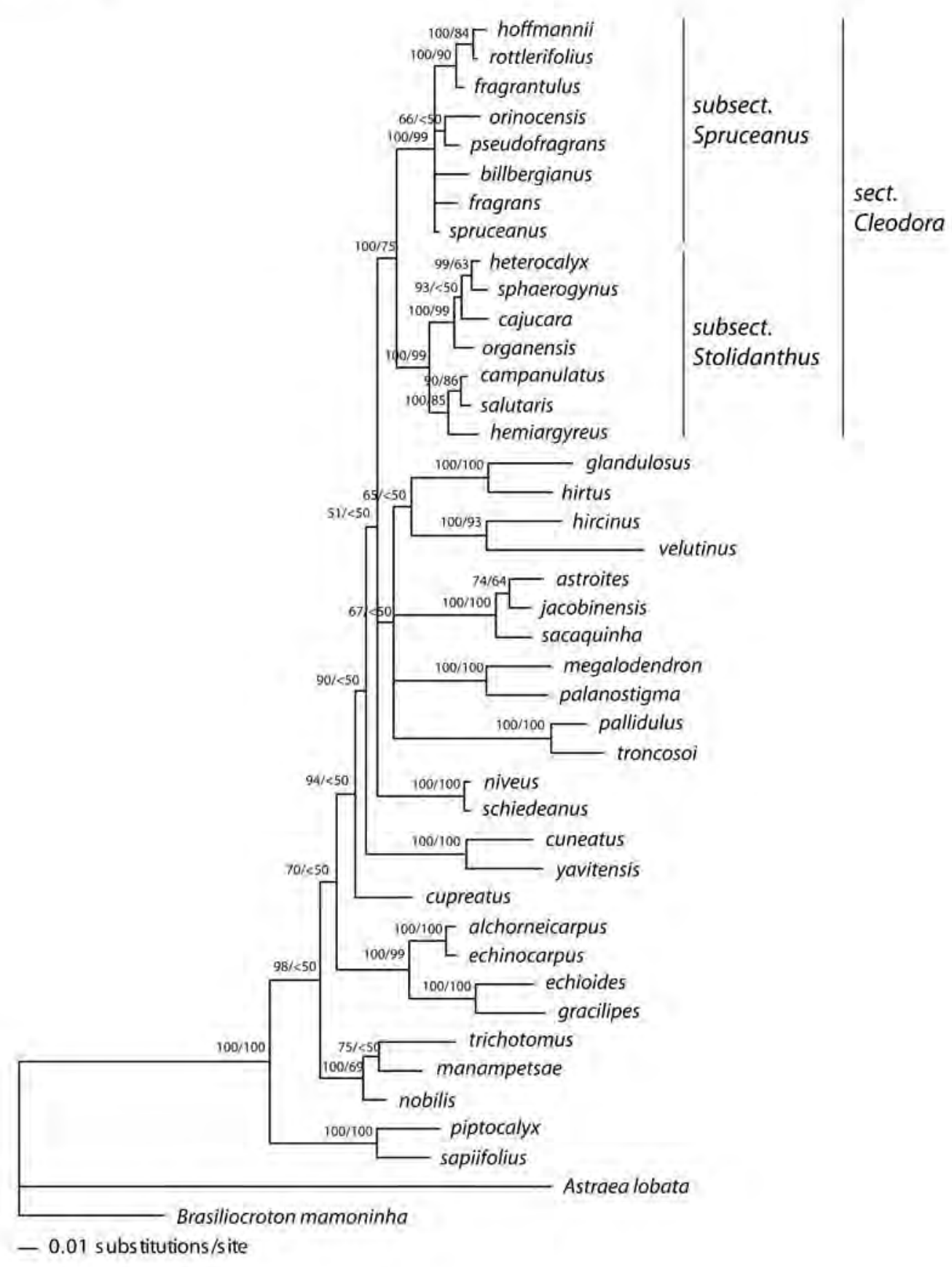

Figure 1. Phylogram of Bayesian analysis of ITS data. The numbers represent support values in the following order: Bayesian posterior probability (PP)/Maximum parsimony bootstrap support (BP). 


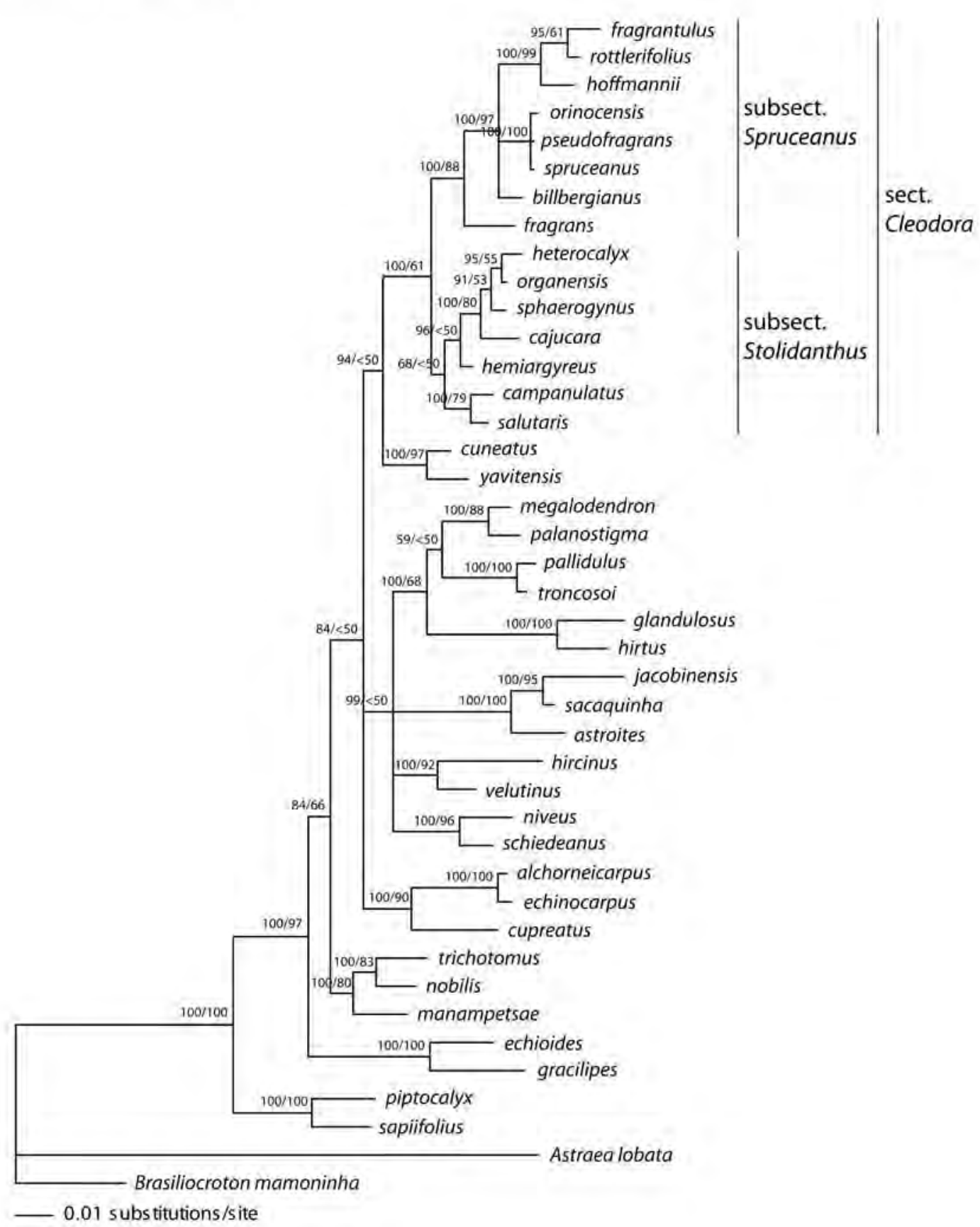

Figure 2. Phylogram of Bayesian analysis of combined chloroplast trnL-F and trnH-psbA data. The numbers represent support values in the following order: Bayesian posterior probability (PP)/Maximum parsimony bootstrap support (BP). 


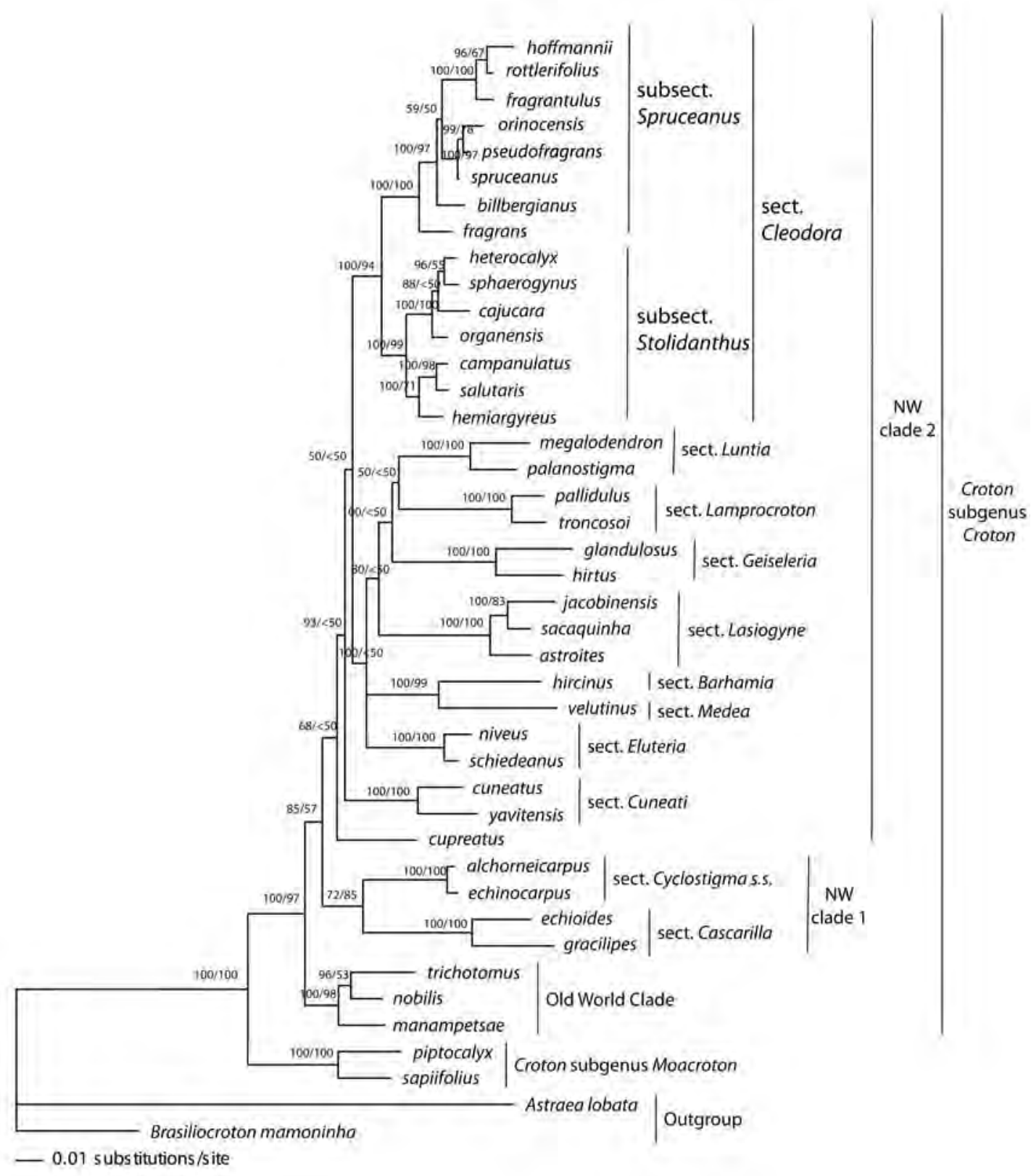

Figure 3. Phylogram of Bayesian analysis of combined trnL-F, trnH-psbA and ITS data. The numbers represent support values in the following order: Bayesian posterior probability (PP)/Maximum parsimony bootstrap support (BP). Names on the right of vertical bars represent the sectional or informal clade assignment of the species. 


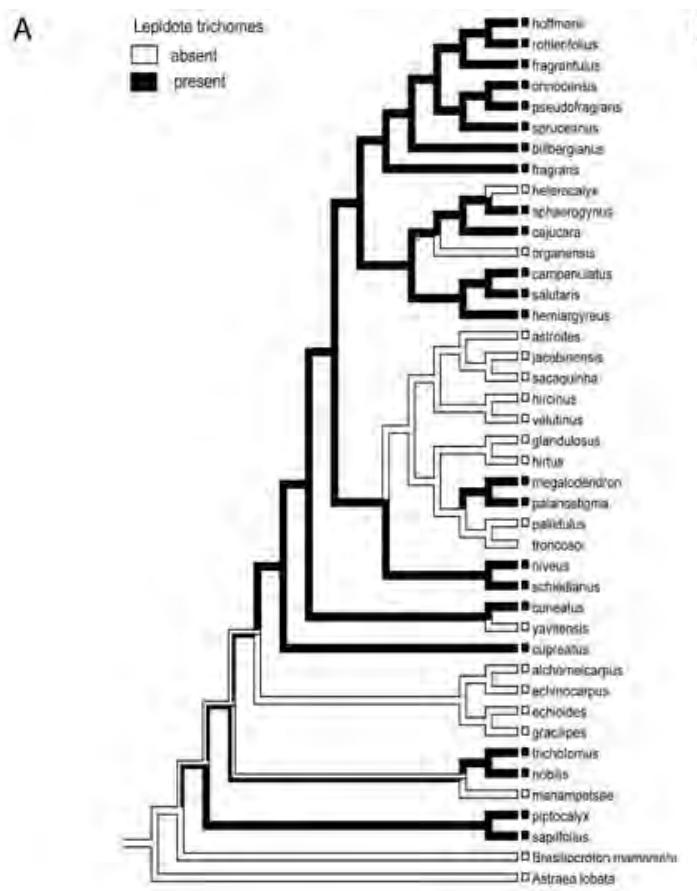

B

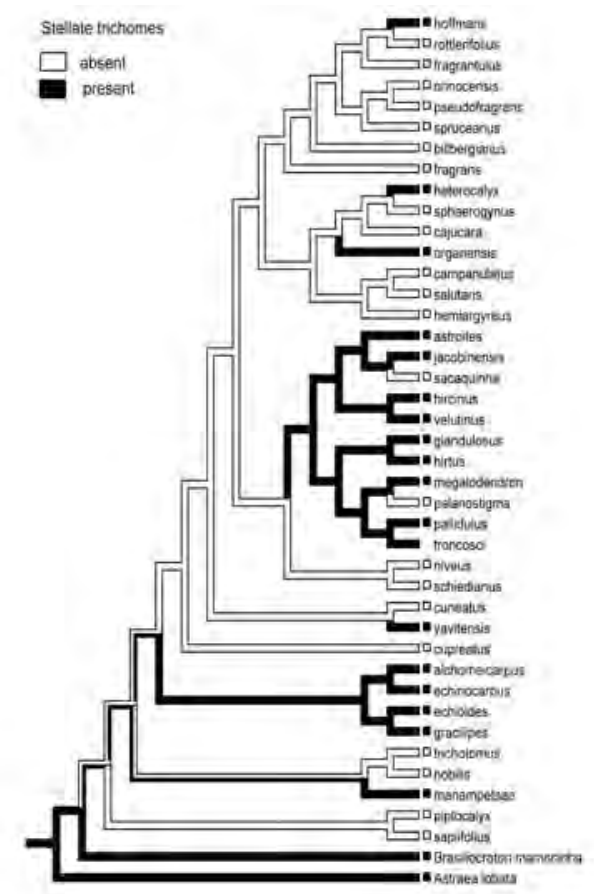

C

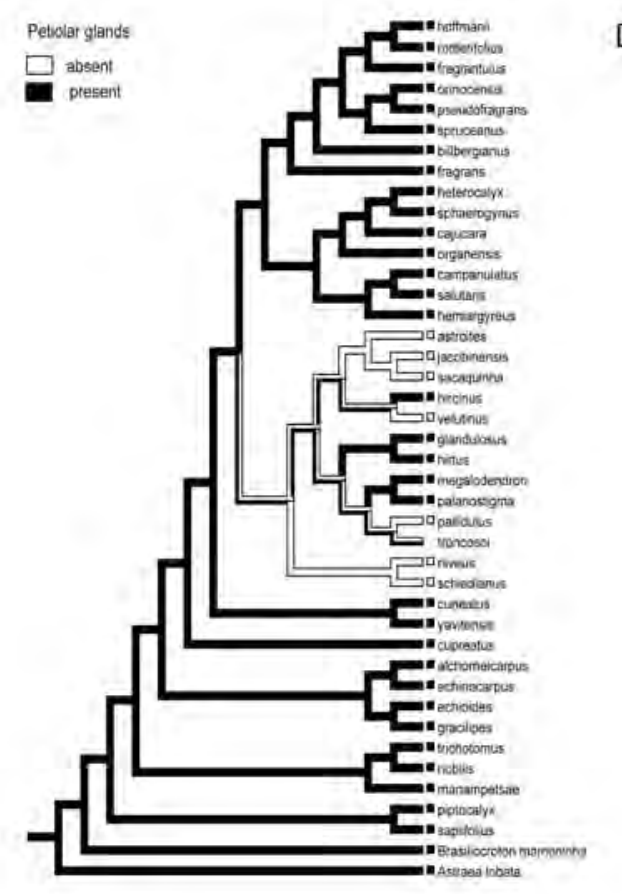

D

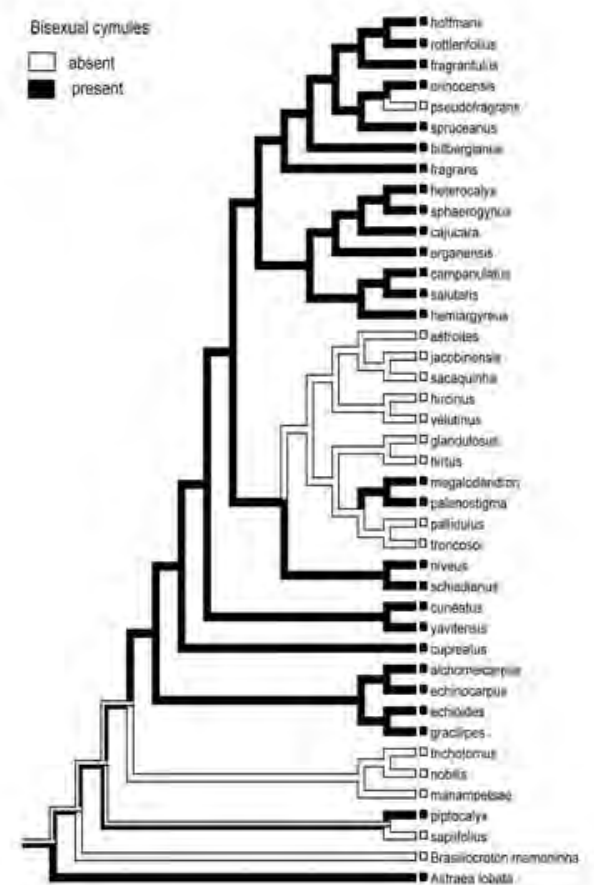

Figure 4. Patterns of evolution of morphological characters mapped using parsimony onto one of the most parsimonious trees obtained from the combined parsimony analysis. A. Lepidote trichomes. B. Stellate trichomes. C. Petiolar glands. D. Bisexual cymules. 
A

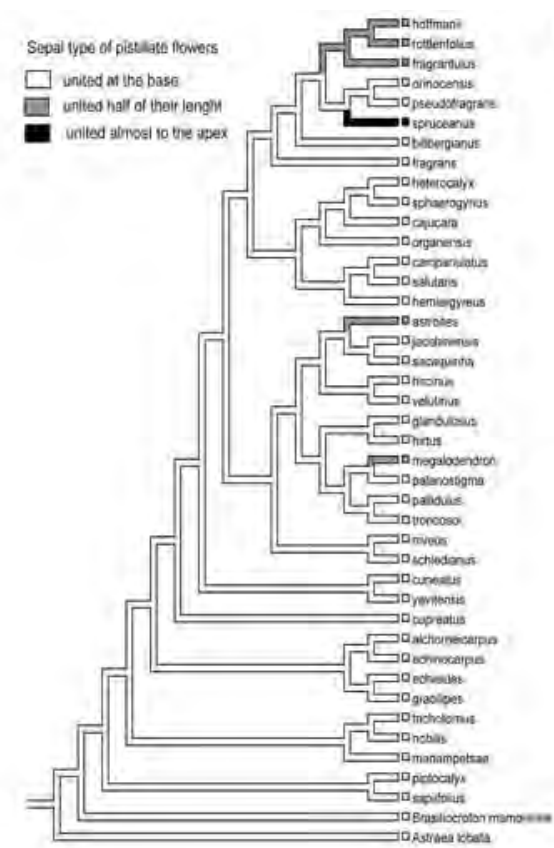

C

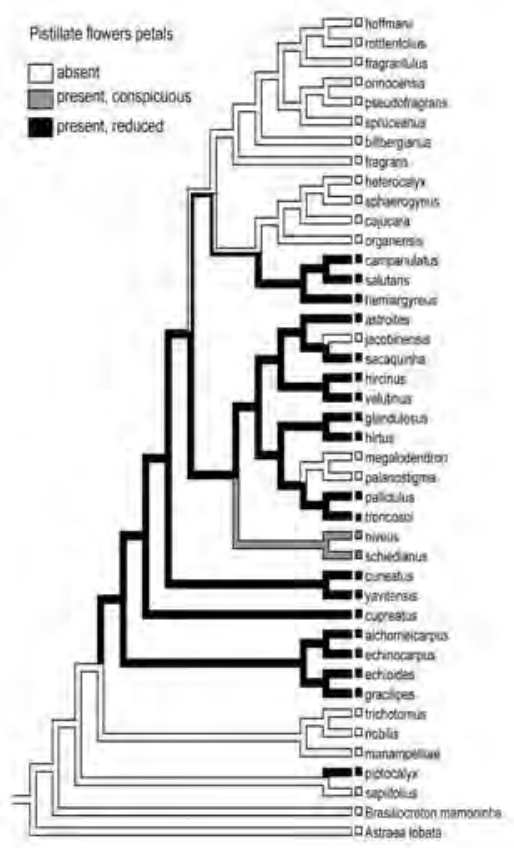

B

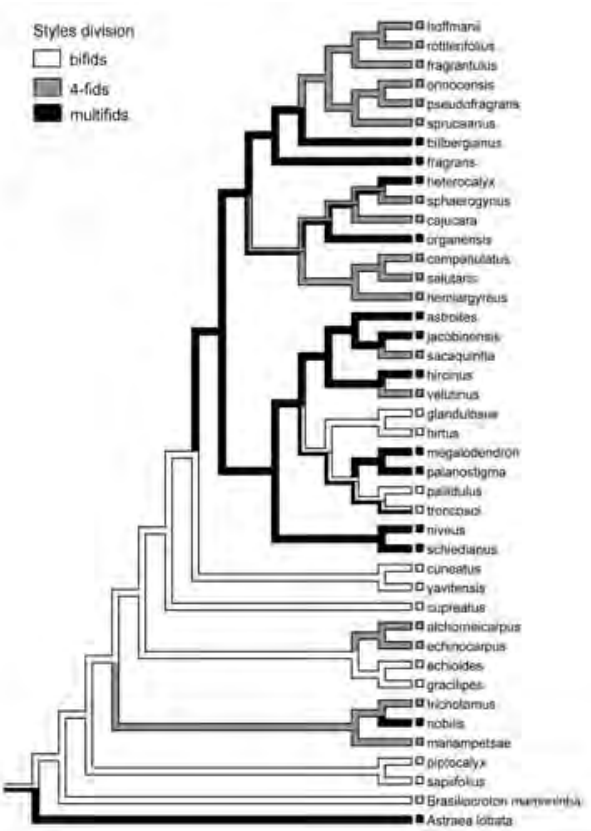

D

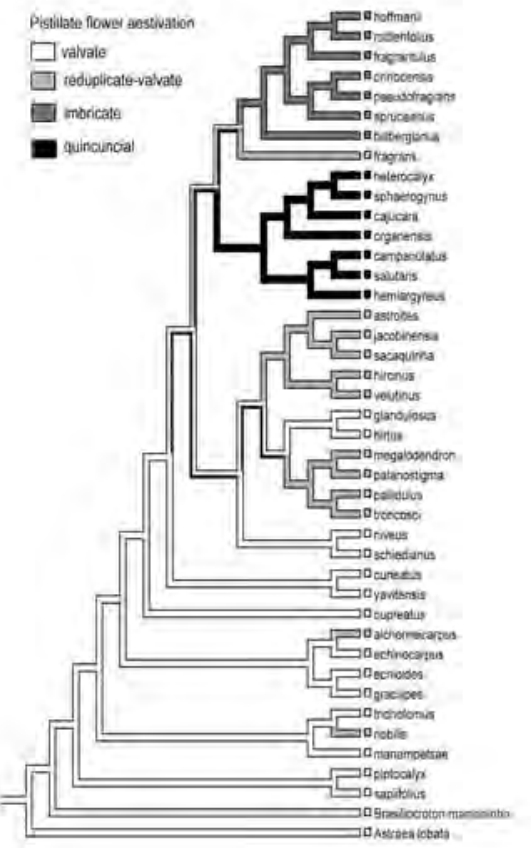

Figure 5. Patterns of evolution of morphological characters mapped using parsimony onto one of the most parsimonious trees obtained from the combined parsimony analysis.

A. Sepal type of pistillate flowers. B. Styles division. C. Pistillate flowers petals. D. Pistillate flowers aestivation. 


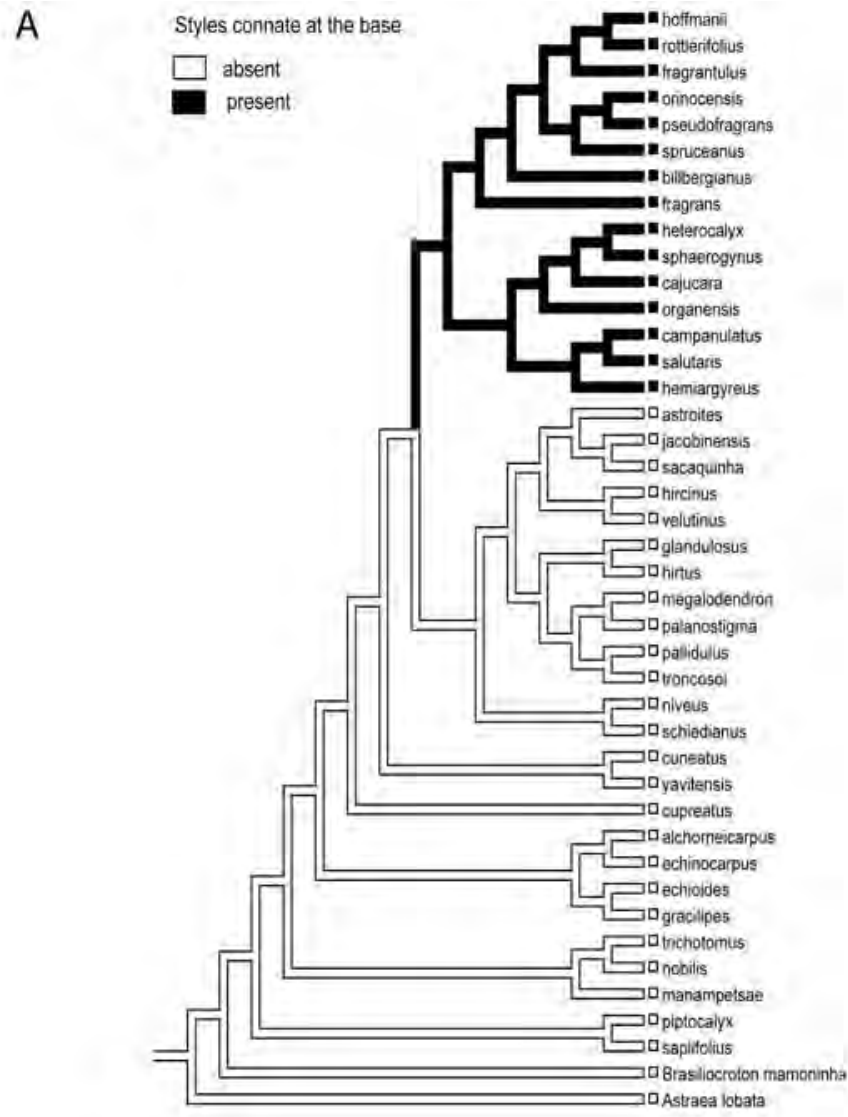

Figure 6. Patterns of evolution of morphological characters mapped using parsimony onto one of the most parsimonious trees obtained from the combined parsimony analysis. A. Styles connate at the base. 

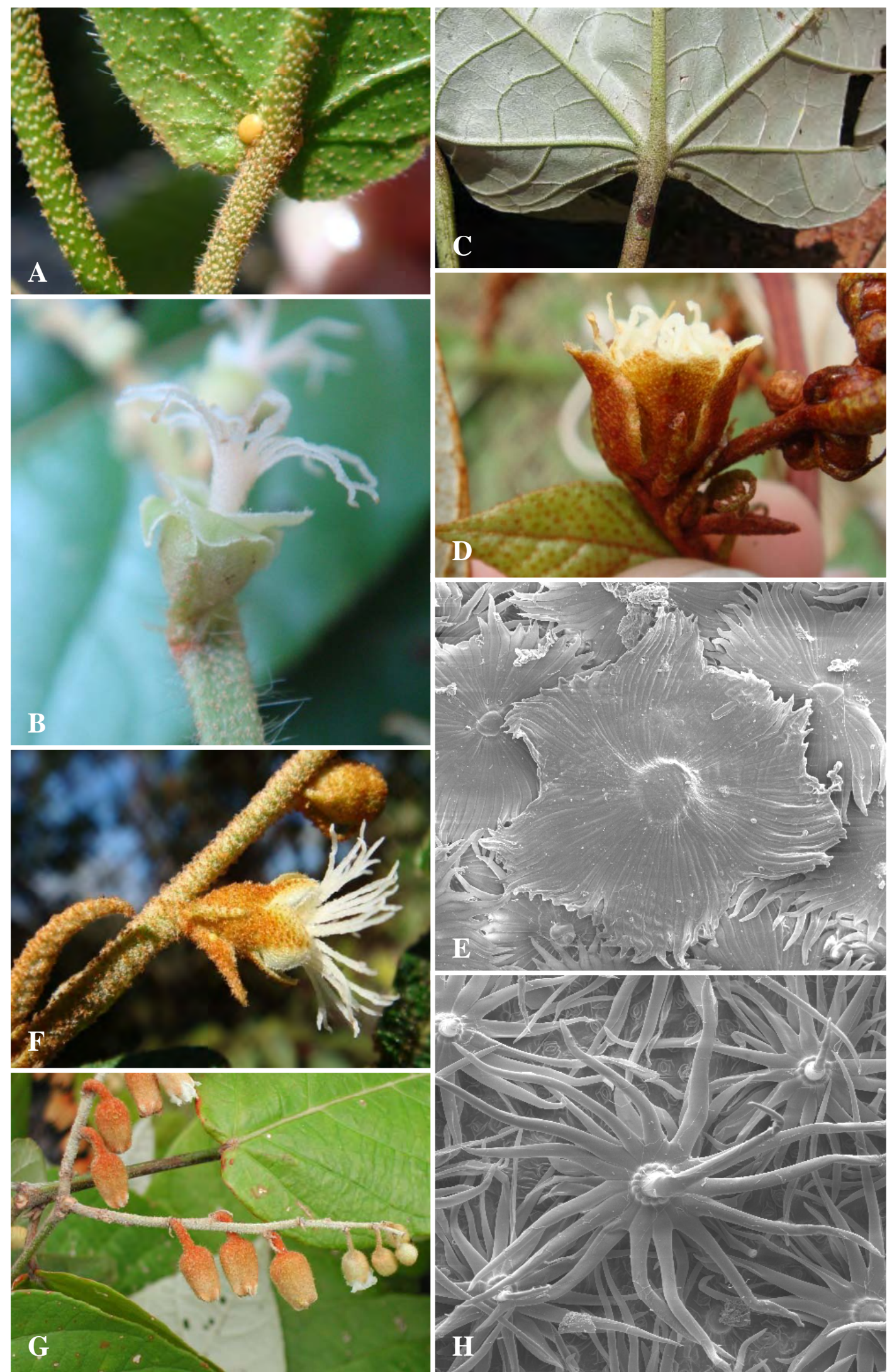

Figure 7. Morphological features of some members of Croton sect. Cleodora. A-B. C. sphaerogynus. a. Basilaminar glands; b. Pistillate flower, showing stylar column, and 12 terminal tips. C. C. hemiargyreus. c. Acropetiolar glands. D-E. C. campanulatus. d. Pistillate flower showing quincuncial aestivation; e. lepidote subinteire trichome. F. C. stellatoferrugineous. f. Pistillate flower showing multifid styles (more than 12 terminal tips). G-H. C. spruceanus. g. Pistillate flowers showing sepals united almost at the apex. h. Adpressed-stellate trichomes. 
CAPÍTULO 2 


\title{
Revisão taxonômica de Croton sect. Cleodora (Klotzsch) Baill. ${ }^{1}$
}

\section{Resumo}

Croton sect. Cleodora (Klotzsch) Baill. é uma seção exclusivamente neotropical, com distribuição disjunta entre o México, América Central, norte e noroeste da América do Sul e leste do Brasil. Foram reconhecidas 18 espécies para a seção, que se caracterizam pelo porte arbóreo ou arbustivo, geralmente com látex avermelhado, alaranjado, acastanhado ou transparente, indumento de tricomas adpresso-estrelados, estrelado-lepidotos, lepidotos ou mais raramente estrelados e multiradiados, folhas com um par de glândulas acropeciolares ou basilaminares; inflorescências terminais, raramente axilares, címulas basais geralmente bissexuadas; flores masculinas campanuladas, raramente subcampanuladas, valvares ou levemente imbricadas, estames 15-25; flores femininas campanuladas a urceoladas, em geral conspicuamente imbricativas, estiletes 4-fidos ou multifidos, unidos na base ou um pouco mais acima, formando uma coroa. No presente trabalho são apresentadas: chave de identificação, descrições, ilustrações, fotos e comentários sobre taxonomia, fenofases, habitat e distribuição geográfica das espécies.

Palavras chave: Croton, Flora Neotropical, Euphorbiaceae

\begin{abstract}
Croton sect. Cleodora (Klotzsch) Baill. is an exclusively neotropical section that has a disjunct distribution in Central America, northern and northwestern South America and eastern Brazil. Eighteen species were recognized to the section, characterized by arborescent or shrubby habit, usually with reddish, orange, brown or translucid latex, indument of adpressed-stellate, stellate-lepidote, lepidote or rarely stellate and multiradiate trichomes, leaves with a pair of acropetiolar or basilaminar glands; inflorescences terminal, rarely axillar, basal cymules usually bisexual; male flowers campanulate, rarely subcampanulate, valvate or slightly imbricate, stamens 15-25; female flowers campanulate to urceolate, conspicually imbricate, styles 4-fides or multifides, united at the base or upper, usually forming a crown. An identification key, descriptions, illustrations, pictures and comments about taxonomy, geographic distribution and phenological informations are provided here.
\end{abstract}

Key words: Croton, Neotropical Flora, Euphorbiaceae

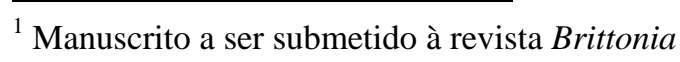




\section{Introdução}

O gênero Croton L., segundo maior da família Euphorbiaceae s.s., compreende aproximadamente 1223 espécies distribuídas, em sua maioria, nas regiões tropicais do mundo (Govaerts et. al., 2000). Apesar de ser predominantemente tropical, também encontram-se algumas espécies em áreas subtropicais e temperadas. Os principais centros de diversidade do gênero estão localizados na região Neotropical, nas Antilhas, México e Brasil (Burger \& Huft 1995), onde, neste último, é notavelmente bem representado, com cerca de 350 espécies concentradas principalmente na porção leste do país, principalmente em vegetações abertas.

A história taxômica do gênero teve início em 1700, com Tournefort atribuindo-lhe seu primeiro nome, Ricinoides. Linnaeus, em 1735, desejando substituir os nomes com terminação -oides, renomeou-o como Oxydectes, alterando para Croton dois anos depois (Ferguson, 1901). O nome Kroton, de origem grega, que significa carrapato, faz alusão à semelhança de suas sementes com este aracnídeo (Webster, 1967). Linnaeus, na primeira edição de sua obra Species Plantarum (1753), descreveu 13 espécies para o gênero.

Em 1913, Small designou Croton tiglium L. como lectótipo do gênero (apud Webster, 1967). Entretanto, Webster (1967) observando problemas na delimitação de C. tiglium, substituiu-o por Croton aromaticus L., por ser uma das únicas espécies de Linnaeus (1753) que não apresentava controvérsias em sua circunscrição.

O estudo sobre a filogenia de Croton, baseado em dados moleculares, realizado por Berry et al. (2005b), demonstrou que o gênero, em sua circunscrição tradicional não era monofilético e que, para tornar-se, deveria incluir Moacroton Croizat, um pequeno gênero endêmico de Cuba, e alguns outros pequenos gêneros formalmente posicionados na tribo Crotoneae, Crotonopsis Michx., Eremocarpus Benth., Cubacroton Alain, além de Julocroton Mart, com várias espécies descritas para o Brasil e já sinonimizado em Croton por Webster (1967). sendo também necessária a exclusão de Croton seção Astraea, que foi restabelecido como gênero Astraea Klotzsch.

Müller $(1866,1873)$ em seus dois grandes tratamentos sobre a família Euphorbiaceae, propôs para Croton um sistema de classificação infragenérico hierarquizado, com seções, subseções e séries e na Flora brasiliensis com chaves de identificação e ilustrações (Müller 1873), que apesar de artificial, como o próprio autor deixou implícito em vários de seus comentários sobre as espécies, foi o mais aceito, sendo apenas substituído, na atualidade, pelo de Webster (1993). Os tratamentos de Bentham (1880) e Pax \& 
Hoffmann (1931) são, de maneira geral, muito semelhantes ao de Müller, com algumas pequenas alterações.

Baillon (1858, 1864) outro especialista na família Euphorbiaceae, contemporâneo de Müller, que trabalhou no Herbário de Paris, também propôs várias seções para Croton, as quais, em sua maioria, foram ignoradas por Müller $(1866,1873)$ que apenas aceitou, em sua circunscrição quase original, uma única seção de Baillon, a seção Astraea (Klotzsch) Baill., entre as 10 seções que reconheceu em Croton, e também reduziu a subseções algumas das seções de Baillon, como Lasiogyne e Eutropia, subordinando-as a sua grande seção Eucroton.

Apesar dos evidentes problemas com a classificação infra-genérica de Müller (1866, 1873), uma nova proposta apenas surgiria no século seguinte, com a sinopse das seções do gênero produzida por Webster (1993), onde foram incorporadas seções de Baillon (1858, 1864), Grisebach (1864), algumas poucas de Müller (1866, 1873) e outras novas, sendo reconhecidas para o gênero 40 seções e 5 subseções.

A sinopse de Webster (1993), onde o autor propôs uma nova classificação infragenérica para Croton, mesmo sem ainda incorporar os paradigmas da sistemática filogenética, foi uma importante contribuição para o desenvolvimento de vários estudos sobre o gênero, inclusive a primeira abordagem filogenética realizada por Berry et al. (2005b), cuja principal contribuição foi a redelimitação do gênero. Berry et al. (2005b) demonstraram claramente que diversas das seções tradicionalmente aceitas para Croton, como C. sect. Cyclostigma Griseb., Croton sect. Argyrocroton (Müll.Arg.) G.L. Webster, C. sect. Cascarilla Griseb. e C. sect. Tiglium (Klotzsch) Baill, não eram monofiléticas. Neste trabalho os autores reconheceram 11 grupos informais para o gênero, propondo as bases para uma nova classificação infragenérica para Croton.

O evidente polimorfismo, o grande número de espécies e a amplitude de distribuição geográfica, dificultam a caracterização e circunscrição das espécies do gênero, problema já evidenciado por diversos autores (Berry et al., 2005b; Lima \& Pirani, 2008; Riina et al., 2009). As várias espécies e variedades descritas, principalmente por Müller (1865, 1866, 1873, mas também por Baillon (1864), demonstram como os autores reconheciam e trabalhavam com a variabilidade das espécies do gênero. Ferguson (1901), em seu tratamento sobre Croton nos Estados Unidos, comenta que poucas das espécies do gênero admitem uma circunscrição rígida, isso porque em uma única população, grande variabilidade morfológica pode ser observada. Burger \& Huft (1995) admitem que o grande polimorfismo das espécies de Croton, dificulta a determinação de espécimes 
individuais. Para Croizat (1941), a grande variabilidade morfológica intra-específica de Croton deve-se às variações altitudinais e fatores edáficos.

O grande número de espécies de Croton, sua alta ocorrência em praticamente todas as formações vegetais do continente americano, e principalmente o polimorfismo de suas espécies, fazem deste gênero o principal desafio taxonômico das Euphorbiaceae s.s. na região neotropical. Uma determinação mais clara dos limites específicos em Croton deve ser um dos principais objetivos para estudos do gênero na região.

\section{Material e Métodos}

Durante o desenvolvimento do presente trabalho foram realizadas viagens de campo (Tab. 1) para enriquecimento das coleções de Croton seção Cleodora, observação da variabilidade morfológica das populações, obtenção de material fresco para estudos morfológicos e macromoleculares, além de registros fotográficos das plantas em seu habitat natural.

O material coletado foi herborizado segundo técnicas tradicionais (Mori et al., 1989), e incluído no Herbário do Instituto de Botânica de São Paulo (SP), com duplicatas enviadas a vários herbários.

O estudo foi baseado em bibliografia especializada e na análise de aproximadamente 700 coleções depositadas nos acervos dos seguintes herbários: ALCB*, BHCB*, BOTU, CEN*, CEPEC*, CESJ*, CPAP, COL, CR, EAC, ESA*, ESAL, FUEL, GFJP, GUA*, HAMAB, HB*, HEPH*, HF, HRB*, HRCB*, HUEFS*, HUFU, IAC*, IBGE*, INPA, IPA, JPB, LPB, MAC, MBM*, MBML, MEXU, MG*, MICH*, MO, MYF*, NY, P, PEUFR, PMA, PMSP*, PORT*, QCA, R*, RB*, SJRP, SP*, SPF*, SPSF*, TEPB, TFAV*, UB*, UEC*, US*, USM, VEN*, VIC, W, WU.

O tratamento taxonômico da seção está apresentado em ordem alfabética das espécies, e inclui descrições morfológicas, citação do material-tipo, sinonímia, observações sobre habitat e fenofases, comentários sobre variabilidade morfológica e taxonomia, distribuição geográfica e ilustrações de caracteres diagnósticos.

Foram examinadas as coleções tipo de quase todas as espécies de Croton sect. Cleodora. Também foram analisadas imagens dos tipos através de fotos da coleção do Field Museum of Natural History (Foto F), microfichas do Candolle Prodromi Herbarium (G-DC), imagens digitais fornecidas pelo projeto “Tackling a Taxonomic Giant - The 
Genus Croton (Euphorbiaceae)”, e outras localizadas através de sites de herbários. As coleções tipo aparecem referidas no cabeçalho das espécies, onde as informações fornecidas foram transcritas do protólogo, e as informações adicionais relevantes estão apresentadas entre aspas. Os materiais-tipo depositados no herbário de Berlim que aparecem seguidos de $\mathrm{B} \dagger$, foram destruídos durante a Segunda Guerra Mundial.

A abreviação de nomes de autores e obras clássicas foi feita de acordo com Stafleu \& Cowan (1976-1988) e os periódicos segundo Bridson \& Smith (1991). As siglas dos herbários seguem o "Index Herbariorum - Part I: the Herbaria of the World"² (Thiers, continuously updated).

Para a tomada de decisões sobre problemas nomenclaturais, seguiu-se o Código Internacional de Nomenclatura Botânica atualizado durante o Congresso Internacional de Botânica (Mcneill et al., 2007), realizado em Viena. Este trabalho não deve ser considerado publicação efetiva e válida para as propostas nomenclaturais nele contidas.

Os principais caracteres diagnósticos utilizados para a circunscrição e descrição das espécies foram: tipo de indumento dos órgãos vegetativos e reprodutivos; padrão de nervação das folhas; morfologia dos ramos; distribuição e morfologia de nectários extraflorais; distribuição das flores masculinas e femininas nas inflorescências, forma e tipo de prefloração do cálice, morfologia do disco nectarífero; ocorrência e morfologia das pétalas das flores femininas; número de estames; número de ramos do estilete; forma dos frutos e sementes; ornamentação da testa das sementes. O exame dos tipos, associado à observação da variabilidade morfológica e aspectos ecológicos das populações no campo, foi essencial para determinar a circunscrição de várias espécies.

Os termos morfológicos utilizados nas descrições são aqueles contidos em Hickey (1973), Radford (1986), Stearn (1992), Weberling (1989), Webster (1993) e Webster et al. (1996).

As coleções examinadas encontram-se relacionados por ordem de país, estado e município, e as coleções de cada município foram organizadas em ordem crescente de data. Siglas utilizadas: fl. (flor), fr. (fruto), s.c. (sem coletor designado), s.d. (sem data de coleta) e s.n. (sem número de coletor).

As ilustrações de detalhes morfológicos foram feitas em câmara-clara acoplada a estereomicroscópio e cobertas a nanquim, sendo que, para cada uma das espécies estudas

\footnotetext{
${ }^{2}$ http://sweetgum.nybg.org/ih/
} 
foram selecionados detalhes morfológicos de importância taxonômica para serem ilustradas. Como modelo para a ilustração dos ramos foram utilizadas exsicatas e fotografias das plantas vivas. Também foram montadas pranchas com fotografias obtidas durante as expedições de coleta.

\section{Resultados e Discussão}

\section{Croton sect. Cleodora (Klotzsch) Baill.}

Na circunscrição aqui proposta para Croton sect. Cleodora, são aceitas 18 espécies que distribuem-se na região Neotropical, com disjunção entre o sul do México, América Central e, norte e noroeste da América do Sul e leste do Brasil (Tab. 3).

De maneira geral, a seção Cleodora caracteriza-se pelo hábito lenhoso, arbóreo ou arbustivo, de suas espécies, que possuem látex avermelhado, alaranjado, castanho ou incolor, indumento de tricomas adpresso-estrelados, estrelado-lepidotos, lepidotos ou mais raramente estrelados e multiradiados, folhas com um par de glândulas acropeciolares ou basilaminares; inflorescências terminais, raramente axilares, címulas basais geralmente bissexuadas; flores masculinas campanuladas, raramente subcampanuladas, valvares ou levemente imbricadas, estames 15-25; flores femininas campanuladas a urceoladas, em geral conspicuamente imbricadas, estiletes 4-fidos ou multifidos, unidos na base ou um pouco mais acima, formando uma coroa.

Assim como a maioria das espécies florestais de Croton, as de Cleodora são caracteristicamente heliófilas e pioneiras, ocorrendo nas bordas de florestas ou clareiras, em florestas pluviais ou estacionais.

Algumas espécies da seção são reconhecidas por sua importância econômica, como Croton salutaris Casar., que é indicado para o reflorestamento de áreas degradadas no Estado de São Paulo (legislação SMA 47 de 27/11/2003); Croton cajucara Benth., nativo da amazônia, popularmente conhecido como sacaca, empregado na medicina popular, com princípios ativos comprovados de ação antiulcerogênica (Hiruma-Lima et al. 2002, SouzaBrito et al. 1998), antiinflamatória (Carvalho et al., 1996) e antitumoral (Grynberg et al. 1999).

A seção Cleodora foi criada com base no gênero Cleodora, estabelecido por Klotzsch (1841), a partir da espécie Cleodora sellowiana, descrita nesta obra, porém sem nenhuma referência a coleções tipo. Baillon (1858), em sua sinopse dos gêneros de Euphorbiaceae, 
reduziu Cleodora a uma das 19 seções que reconheceu para o gênero nesta obra, mas sem mencionar nenhuma espécie para a seção, apenas referindo o trabalho de Klotzsch (1841).

Baillon (1864), em seu trabalho sobre as Euphorbiaceae das Américas, onde descreveu várias novas espécies brasileiras de Croton, estabeleceu mais cinco seções para o gênero, dentre elas Stolidanthus, cuja descrição é muito semelhante à de sua seção Cleodora, principalmente no que se refere às flores pistiladas com sépalas imbricadas e persistentes no fruto, nela incluindo C. heterocalyx Baill., C. organensis Baill., $C$. velutinus Baill., C. sphaerogynus Baill. e C. rottlerifolius Baill.

Müller (1866), em sua monografia sobre Croton no De Candolle Prodromus, considerou Cleodora sellowiana Klotzsch um sinônimo de Croton sphaerogynus Baill. Apesar da primeira ter sido publicada por Klotzsch anteriormente a Croton sphaerogynus, a escolha de Müller corrigiu um problema de homonímia, pois Ocalia sellowiana, publicada simultaneamente a Cleodora sellowiana (Klotzsch 1841), já havia sido combinada em Croton por Baillon (1858).

Certamente a semelhança entre as descrições das seções Cleodora e Stolidanthus de Baillon (1858, 1864), levou Webster (1993) a propor Stolidanthus como um sinônimo de Cleodora e, na ausência da coleção tipo de Cleodora sellowiana, provavelmente destruída no herbário de Berlim, a aceitar a sinonímia proposta por Müller (1866), de Cleodora sellowiana em Croton sphaerogynus, firmando-a como a espécie tipo da seção Cleodora.

Algumas das espécies atribuídas a Cleodora por Webster (1993) encontram-se dispersas nas subseções Cyclostigma e Eutropia da grande seção Eucroton de Müller. Apenas duas espécies inseridas na seção Stolidanthus foram referidas por Webster (1993) para Cleodora, e o posicionamento de C. cajucara sensu Baillon já havia sido suposto, mas não confirmado pelo próprio Baillon (1864) (Tab. 2).

A Flora brasilensis é o único trabalho em que Müller (1873) considerou Cleodora como um táxon infragenérico de Croton, subdividido em duas series. Entretanto, sua circunscrição é mais ampla e muito diferente daquela de Baillon (1858) para sua seção Cleodora e principalmente daquela de Webster (1993), pois incluia espécies de Croton com címulas basais unissexuadas, indumento de tricomas estrelados ou lepidotos e estiletes divididos de duas a quatro vezes, enquanto Baillon (1858) e Webster (1993) caracterizaram Cleodora principalmente pelas címulas basais bissexuadas, flores com sépalas imbricadas e pequeno número de estames de suas espécies.

A grande maioria das espécies posicionadas por Müller (1873) na subseção Cleodora serie Argyrocroton foram posteriormente transferidas para a seção Lamprocroton por 
Webster (1993), sendo grande parte confirmada por Lima \& Pirani (2008), e as da serie Medea foram transferidas por Webster (1993) para diferentes seções de Croton, como Velamea e Ocalia, restando apenas C. orinocensis, C. salutaris e C. spruceanus da subseção Cleodora de Müller, aqui consideradas na seção Cleodora sensu Caruzo.

A circunscrição da seção Cleodora aqui apresentada é baseada na filogenia do grupo (Cap. 1) e inclui espécies referidas anteriormente para a seção Stolidanthus Baill. (1864), subseções Cyclostigma, Lasiogyne, Eutropia e Cleodora da seção Eucroton de Müller (1866, 1873), e seção Cleodora sensu Webster (1993), além de espécies recentemente descritas ou ainda inéditas (Tab. 3).

\section{Morfologia das Espécies de Croton sect. Cleodora}

\section{Hábito e Sexualidade}

As espécies da seção possuem hábito lenhoso, variando de arbustos a árvores de pequeno a médio porte. Dentre as coleções de herbário e populações de Croton hoffmannii e $C$. hemiargyreus, espécies arbóreas da seção, foram encontrados exemplares já férteis, mas de porte ainda arbustivo, como já foi observado por Caruzo (2005) em outras espécies do gênero, e.g. C. alchorneicarpus Croizat. Todas as espécies da seção são eretas, com exceção de Croton pseudofragrans, que possue hábito arbustivo escandente.

Apesar da variabilidade na expressão das inflorescências em espécies de Croton descrita por Webster (1993), inclusive em Cleodora, todos os exemplares examinados apresentavam inflorescências bissexuadas, caracterizando todas as espécies da seção como monóicas.

\section{Tronco e Ramos jovens}

Apenas Croton salutaris (Fig. $7 \mathrm{H}$ ) apresenta a casca do tronco ornamentada por costas agudas, enquanto nas demais espécies ela é lisa. Os ramos jovens das espécies da seção podem ser cilíndricos, achatados ou quadrangulares, com predominância do tipo cilíndrico. Dentre as espécies com ramos jovens achatados estão Croton fragrantulus, $C$. organensis (Fig. 15B), C. sphaerogynus e C. stellatoferrugineus, sendo C. fragrans a única espécie com ramos jovens quadrangulares.

A ornamentação dos ramos jovens é estriada ou conspicuamente estriada, como em Croton organensis e $C$. salutaris, sendo raramente encontrados ramos jovens lisos (apenas em C. heterocalyx). 


\section{Látex}

A maioria das espécies da seção Cleodora produz látex, mas geralmente em pequena quantidade quando comparado, por exemplo, com espécies da seção Cyclostigma Griseb. (e.g. Croton macrobothrys Baill.). Látex incolor ou colorido, foi observado em treze das espécies estudadas. O látex é incolor em Croton fragrans, $C$. hemiargyreus, $C$. heterocalyx, C. organensis, C. rottlerifolius, C. sphaerogynus, C. spruceanus e C. stellatoferrugineus. Em C. billbergianus, C. cajucara, C. campanulatus, C. orinocensis e C. salutaris, o látex é avermelhado (Fig. 3B) ou alaranjado, e castanho em C. croizatii.

\section{Indumento}

O indumento no gênero Croton é composto principalmente de tricomas tectores que, à grosso modo, podem ser classificados como estrelados, dendríticos e escamiformes (Payne, 1978), mas também ocorrem com menor frequência tricomas glandulares.

As espécies de Croton sect. Cleodora possuem sempre algum tipo de indumento recobrindo órgãos reprodutivos e vegetativos, sendo nestes últimos geralmente mais denso nas partes jovens. Os tricomas variam de estrelados a lepidotos, além de seus diversos subtipos, aqui classificados conforme Webster (1993). De maneira geral, as espécies apresentam mais de um tipo de tricoma em cada um de seus órgãos, mas sempre com o predomínio de um, geralmente presente em praticamente toda a planta.

Uma revisão detalhada dos tricomas em Croton foi realizada por Froembling (apud Webster et al. 1996). O autor estudou a anatomia foliar de 132 espécies do gênero, reconhecendo cinco tipos básicos de tricomas: 'Schilghaare’ (lepidoto), 'Sternhaare' (estrelado), ‘Buschelhaare’ (fasciculado ou rosulado), 'Morgensternförmige Haare’ (fasciculado-estipitado) e ‘Candelaberhaare’ (dendrítico). Mais recentemente, Webster et al. (1996), baseados no trabalho de Froembling, reconheceram oito tipos básicos de tricomas para Croton: estrelado, fasciculado, multiradiado, rosulado, dendrítico, lepidoto, papiloso e glandular.

A morfologia dos tricomas foliares em Croton foi utilizada por diversos autores na circunscrição de espécies e taxa infragenéricos (e.g. Müller 1866, 1873; Baillon 1858; Webster 1996), sendo portanto de grande importância na taxonomia do grupo.

No presente trabalho foi utilizada, de maneira geral, a nomenclatura de Webster et al. (1996) para a classificação dos tricomas, tendo sido encontrados os seguintes tipos: 
1. Estrelados: Apresentam um único ciclo de raios dispostos no mesmo plano ou levemente deslocados para cima.

1.1. Estrelado-porrecto: Possuem a mesma estrutura do estrelado, com um raio central ereto alongado.

2. Multiradiados: Apresentam os raios dispostos ascendentemente. Número de raios: dez ou mais.

3. Simples: Apresentam estrutura filiforme

4. Dendríticos: Possuem um eixo central alongado com vários ciclos de raios que são inseridos em diversos níveis.

4.1. Dendrítico-porrecto: Têm a mesma estrutura do dendrítico, com um raio central ereto, alongado.

5. Lepidotos: São tricomas peltados, escamiformes, com um único ciclo de raios unidos total ou parcialmente.

5.1. Adpresso-estrelados: Apresentam uma pequena união dos raios (aproximadamente 0-30\%).

5.2. Estrelado-lepidotos: Apresentam união mediana dos raios (aproximadamente 50\%).

5.3. Lepidoto-subinteiros: São unidos quase que inteiramente (aproximadamente 80-100\%), e a região central é geralmente proeminente ou de coloração distinta dos raios.

O tricoma mais frequente nas espécies da seção Cleodora é o lepidoto e suas variações. Indumento de tricomas exclusivamente lepidotos (e seus subtipos) ocorrem em: Croton croizatii, C. rufolepidotus, C. pseudofragrans, C. campanulatus, C. hemiargyreus e C. salutaris. Tricomas dendríticos ocorrem em Croton billbergianus, $C$. cajucara, C. organensis, C. orinocensis e C. spruceanus, geralmente associados a outros tipos como o estrelado e/ou lepidoto, frequentemente nos ramos jovens destas espécies. Tricomas simples são pouco frequentes em órgãos vegetativos de Cleodora, ocorrendo apenas na face adaxial das folhas de $C$. organensis, $C$. orinocensis, $C$. spruceanus e $C$. rottlerifoius, sendo entretanto bem comuns nas flores masculinas (receptáculo, filetes, margens dos lobos do cálice e margem das pétalas) de todas as espécies da seção. Tricomas estrelados são encontrados em C. fragrans, C. fragrantulus, C. heterocalyx, $C$. hoffmannii, C. organensis e C. stellatoferrugineus, geralmente associados aos tipos simples, dendríticos ou multiradiados. 
Uma revisão mais detalhada dos tipos de tricomas foliares das espécies de Croton sect. Cleodora encontra-se no capítulo 3.

\section{Nectários Extraflorais}

Nectários extraflorais em Croton são muito comuns na junção da lâmina foliar com o pecíolo (geralmente um par, raramente mais numerosos) e nas margens das folhas, e mais raramente nas lâminas foliares e nas brácteas (e.g. C. stellatoferrugineus; Fig. 9E). A ocorrência e a morfologia desses nectários são importantes para a circunscrição de espécies e taxa infragenéricos em Croton, como observa-se em Baillon (1864, 1858), Müller (1865, 1866, 1873) e Webster (1993).

Todas as espécies da seção Cleodora apresentam nectários extraflorais em suas folhas, podendo ser classificados, segundo Hickey (1973), como acropeciolares (localizados no ápice do pecíolo, junto à lâmina foliar; Fig. 4E) ou basilaminares (localizados na base da lâmina foliar, junto à nervura principal; Fig. 8A), podem ser sésseis ou estipitados, estes últimos ocorrendo apenas nos acropeciolares, pateliformes ou globosos, geralmente voltados para a face abaxial das folhas, em geral dispostos aos pares, bem evidentes ou mais raramente inconspícuos, como em Croton organensis (Fig. $6 \mathrm{C})$.

Nectários basilaminares estão presentes em Croton billbergianus, C. cajucara, C. heterocalyx, C. organensis, C. orinocensis, C. pseudofragrans, C. rufolepidotus, C. sphaerogynus, C. spruceanus e C. stellatoferrugineus, e acropeciolares em $C$. campanulatus, C. fragrans, C. fragrantulus, C. hemiargyreus, C. hoffmannii, C. rottlerifolius e C. salutaris; sendo sésseis em C. fragrantulus, C. hoffmannii e C. rottlerifolius. Os nectários basilaminares de C. organensis são aqui denominadas de maculares, por serem extremamente adpressos e inconspícuos, de difícil observação no material herborizado.

\section{Folhas}

As folhas em Croton são simples, alternas, inteiras e extremamente variáveis quanto à forma e tamanho das lâminas. Em Cleodora a lâmina foliar varia de elíptica a oval, com margens serrilhadas (Fig. 13F, detalhe), ou mais raramente inteiras, como em Croton salutaris.

Todas as espécies de Cleodora possuem nervação pinada, nervação secundária camptódroma na maioria das espécies e craspedódroma apenas em Croton fragrans, e 
nervuras terciárias percurrentes (Fig. 6B). Entre as espécies com nervação camptódroma, foram reconhecidos dois padrões: broquidódroma, na maioria das espécies, e eucamptódrom, apenas em C. cajucara e C. organensis.

Em Cleodora as estípulas estão sempre presentes, sendo geralmente persistentes, inteiras na maioria das espécies, profundamente laceradas apenas em $C$. fragrans (figs. 4B, 12G), e com dimensões e formas variáveis.

\section{Inflorescências}

Venkata Rao (1971) denominou as inflorescências em Croton de pseudoracemos, os quais caracterizam-se por um eixo principal, no qual cada bráctea subtende um agrupamento de flores que partem, aparentemente, do mesmo ponto. No entanto, de acordo com o sistema de Weberling (1989), as inflorescências em Croton devem ser classificadas como tirsos terminais, indeterminados, formados por inflorescências parciais determinadas, que neste trabalho são denominadas címulas.

Em Cleodora, assim como na maioria das espécies de Croton, as brácteas são bastante distintas das folhas caulinares, sendo encontradas em todos os nós da raque, caracterizando a inflorescência como bracteosa, com exceção de Croton stellatoferrugineus que possui as brácteas muito semelhantes às folhas, sendo aqui denominadas foliáceas.

Em Cleodora as brácteas das flores masculinas e femininas são semelhantes, com morfologia e dimensões diferentes entre as espécies, sendo geralmente inteiras, com exceção de Croton fragrans (Fig. 12I), C. pseudofragrans e C. orinocensis, onde são laceradas ou lobadas. Os profilos são geralmente semelhantes às brácteas, porém bem menores, sendo inconspícuos em apenas algumas das espécies estudadas, como por exemplo em C. spruceanus.

As inflorescências em Cleodora são geralmente terminais, mas axilares também podem ocorrer em Croton billbergianus (Fig. 10A) e C. hoffmannii, enquanto que em C. pseudofragrans (Fig. 16A) são exclusivamente axilares. São geralmente laxas, raramente congestas, como em C. orinocensis, bissexuadas, raramente falsamente unissexuadas, quando as flores masculinas caem e nas címulas basais restam apenas as flores femininas, com címulas basais em geral bissexuadas.

Em Croton billbergianus, C. croizatii, C. fragrantulus e C. hoffmannii as plantas ramificam-se através de gemas dos nós das folhas localizadas logo abaixo das inflorescências, semelhante ao padrão encontrado em algumas espécies de Croton sect. 
Julocroton (Cordeiro, 1993). Os ramos, produzidos pelo desenvolvimento dessas gemas, rapidamente produzem inflorescências que juntamente com a inflorescência mais antiga, formam um verticilo de 3 ou 4 inflorescências, aqui denominadas inflorescências falsamente ramificadas.

Entre as espécies de Cleodora há 2 padrões de distribuição das flores (Fig. 1), dentre os três já descritos por Caruzo (2005) para o gênero: 1) tirsos com címulas proximais femininas: Croton croizatii, C. pseudofragrans, C. rufolepidotus e C. stellatoferrugineus; 2) tirsos com címulas proximais bissexuadas: Croton billbergianus, C. cajucara, C. campanulatus, C. fragrans, C. fragrantulus, C. hemiargyreus, C. heterocalyx, C. hoffmannii, C. organensis, C. orinocensis, C. salutaris, C. sphaerogynus, C. spruceanus e C. rottlerifolius.

De maneira geral, as címulas masculinas são mais numerosas que as femininas ou as bissexuadas, e possuem de 1-4 flores, enquanto as femininas são geralmente unifloras e as bissexuadas, possuem 2-3 flores masculinas e uma feminina.

\section{Flores}

As flores masculinas em Cleodora são pentâmeras, campanuladas (Fig. 3A), mais raramente subcampanuladas, possuem cálice 5-lobado, geralmente com prefloração valvar, sépalas pilosas externamente e glabras internamente. As pétalas são iguais e inteiras, mais raramente recortadas no ápice (e.g. C. rufolepidotus; Fig. 17F), livres entre si, geralmente glabras em ambas as faces, vilosas no ápice e margens. Os estames variam de 15-25, sendo o número relativamente constante em cada espécie, os filetes são lineares a subulados (Fig. 14J), vilosos nas margens ou apenas na porção basal, mais raramente glabros, as anteras são rimosas, basifixas, bitecas e introrsas, sem conectivo bem diferenciado.

As flores femininas de Cleodora são monoclamídeas ou aparentemente monoclamídeas, com estruturas glandulares no lugar das pétalas em algumas espécies, como em C. hemiargyreus (Fig. 13H), actinomorfas, campanuladas, cupuliformes, ampuliformes ou urceoladas, sésseis a pediceladas, geralmente recobertas por alguns tipo de indumento externamente e glabras internamente. O cálice é pêntamero, de prefloração quincuncial (Fig. 11J) ou imbricada, mais raramente valvar ou reduplicado valvar (Fig. $12 \mathrm{~K})$. 
O ovário nas espécies de Cleodora pode ser globoso ou subgloboso, sendo geralmente recoberto por tricomas semelhantes aos encontrados nas partes vegetativas da planta.

Em Cleodora os estiletes são duas vezes ramificados, com um total de 12 ramos terminais, aqui denominados tetráfidos, a muitas vezes ramificados, com mais de 12 ramos terminais, aqui denominados multifídos. Essas ramificações podem ocorrer em diversos níveis, podendo ser desde a base ou mais acima, algumas vezes formando uma “coroa” na base dos estiletes (característica sinapomórfica para a seção Cleodora; Fig. 9C). Podem ser inclusos, como em Croton campanulatus ou exsertos do cálice, como em C. heterocalyx, e recobertos por tricomas em quase toda sua extenção ou apenas em sua porção basal. Nos estiletes tetráfidos de C. spruceanus, a segunda divisão dos ramos dos estiletes ocorre apenas junto ao ápice, da mesma forma que em algumas espécies da seção Lamprocroton, onde os estiletes são denominados bibífidos (Lima \& Pirani, 2008).

No receptáculo das flores de Cleodora são encontrados nectários segmentados nas flores masculinas, formados por 5 glândulas opostas aos lobos do cálice, e inteiros, geralmente lobados, nas flores femininas, com exceção de Croton cajucara, $C$. heterocalx, C. orinocensis, C. organensis, C. salutaris, C. sphaerogynus e $C$. stellatoferrugineus, cujas flores femininas possuem disco 5-segmentado.

\section{Fruto e Semente}

Os frutos de Cleodora são cápsulas de deiscência septicida-loculicida, que abrem-se quase simultaneamente pelos septos e lóculos, liberando as sementes. O cálice é persistente no fruto, assim como na maioria das espécies do gênero, sendo além disso conspicuamente acrescente em algumas espécies, tornando-se inflados em Croton campanulatus, C.fragrans e C. spruceanus, ou revolutos, como em C. hemiargyreus. Os frutos são globosos ou trígonos, mais raramente elipsóides, como em Croton salutaris. O indumento é semelhante ao do ovário, geralmente menos denso, e o epicarpo é freqüentemente liso, exceto em $C$. billbergianus, C. orinocensis e C. spruceanus, onde é ornamentado.

As sementes de Cleodora são globosas, subglobosas, romboidais ou elipsóides, raramente oblongas, como em Croton rottlerifolius. A exotesta é geralmente ornamentada, sendo lisa apenas em C. salutaris e C. rottlerifolius. 


\section{Tratamento Taxônomico}

Croton L., Sp. Pl. 2: 1004. 1753. Tipo: Croton aromaticus L. (lectótipo designado por Webster, J. Arnold. Arbor. 48: 354. 1967).

Ervas, subarbustos, arbustos ou árvores, raramente escandentes, geralmente monóicos; ramos cilíndricos, raramente quadrangulares, eretos ou raro prostrados; látex geralmente presente, colorido ou incolor; indumento de tricomas simples, escamiformes, mais freqüentemente estrelados e em várias espécies também glandulares em alguns orgãos. Folhas alternas, mais raramente opostas ou verticiladas, simples, inteiras, margem inteira a denteada, nervação pinada ou palmada, pecioladas, estípulas persistentes ou cedo caducas, inteiras ou laciniadas, glândulas frequentemente presentes no pecíolo ou base do limbo, geralmente 1 par, raramente mais numerosas. Inflorescências indeterminadas, terminais, mais raramente axilares, compostas, do tipo tirso; inflorescências parciais de címulas paucifloras, as distais masculinas e as proximais em geral femininas, frequentemente unifloras, ou acompanhadas de 2 ou mais flores masculinas; flores masculinas diclamídeas, pediceladas, (4-)5(-10)-meras, actinomorfas, valvares ou imbricadas; nectário floral composto de 5 glândulas opostas aos lobos do cálice, raramente inteiro; estames livres, em número variado; filetes encurvados no botão; anteras 2-tecas, basifixas, rimosas; grãos de pólen esféricos, inaperturados, com ornamentação do tipo crotonóide; flores femininas geralmente monoclamídeas, raro diclamídeas, sésseis ou pediceladas, (4-)5(-10)-meras, actinomorfas ou mais raramente zigomorfas, valvares ou imbricativas; pétalas ausentes ou reduzidas; nectário floral inteiro, raramente dividido; gineceu (2-)3-carpelar; ovário (2-)3-locular; lóculos 1ovulados; óvulo anátropo; estiletes (2-)3, geralmente ramificados, unidos ou livres entre si. Fruto cápsula septicida-loculicida, de deiscência explosiva, com estiletes persistentes; epicarpo liso ou ornamentado; carpóforo geralmente persistente; semente uma por lóculo, carunculada, plana na face ventral, convexa na dorsal, com testa lisa ou ornamentada, albuminosa; embrião reto.

Croton L., é o segundo maior gênero da família Euphorbiaceae s.s. e um dos dez maiores entre as Angiospermas, possui aproximadamente 1223 espécies (Govaerts et al., 2000) distribuídas principalmente nas regiões tropicais do globo, mas também em áreas subtropicais e temperadas. Na região neotropical os centros de diversidade são Brasil, Antilhas e México (Burger \& Huft, 1995). No Brasil ocorrem cerca de 350 espécies, 
incluindo ervas, arbustos e árvores, em quase todos os tipos de vegetação, mas com uma especial concentração em vegetações abertas no leste do país.

Croton sect. Cleodora (Klotzsch) Baill., Étude Euphorb. 369. 1858. Tipo: Cleodora sellowiana Klotzsch [= Croton sphaerogynus Baill.]

Árvores ou arbustos, raramente escandentes, monóicos, geralmente latescentes, látex transparente, amarelado, avermelhado ou acastanhado; indumento de tricomas adpressoestrelados, estrelado-lepidotos, lepidotos subinteiros ou mais raramente estrelados e multirradiados. Folhas alternas, com um par de glândulas geralmente sésseis, raramente estipitadas, acropeciolares ou basilaminares. Inflorescências terminais, raramente axilares, címulas basais bissexuadas, às vezes falsamente unissexuadas ou mais raramente unissexuadas; flores masculinas diclamídeas, campanuladas, raramente subcampanuladas, valvares ou levemente imbricadas, lobos do cálice geralmente unidos até a metade, estames 15-25; flores femininas monoclamídeas, raro aparentemente monoclamídeas (pétalas reduzidas a glândulas), sésseis ou pediceladas, campanuladas, ampuliformes ou urceoladas, geralmente conspicuamente imbricativas, estiletes 4-fidos ou multifidos, unidos na base ou mais acima, geralmente formando uma coroa.

A seção Cleodora é exclusivamente Neotropical e possui 18 espécies que distribuemse disjuntamente entre o México, América Central, norte e noroeste da América do Sul e leste do Brasil. O centro de diversidade primário da seção está localizado na porção leste do Brasil, onde podem ser encontradas 8 das 18 espécies.

De acordo com Webster (1993), há uma incerteza quanto à aplicação do nome Cleodora sellowiana Kloztsch, pois nenhum material tipo foi localizado. Durante a realização do presente trabalho, também não foi encontrado material tipo de Cleodora sellowiana e portanto, assim como em Webster (1993), na ausência de evidência contrária, foi seguida a posição de Müller (1866: 591; 1873: 101) que considerou Cleodora sellowiana como um sinônimo de Croton sphaerogynus.

Segundo Caruzo et al. (em prep.), são reconhecidas duas subseções para Cleodora, descritas abaixo:

Croton subseção Stolidanthus (Baill.) Caruzo. comb. inéd. Tipo: Croton heterocalyx Baill. (lectótipo, designado por Webster, 1993). ミ Croton section Stolidanthus Baill., Adansonia 4: 323. 1864. 
Flores femininas de prefloração quincuncial; lobos do cálice geralmente unidos apenas na base, em geral carnosos; disco geralmente segmentado. Frutos globosos a elipsóides.

A subseção Stolidanthus ocorre disjuntamente entre o noroeste da América do Sul (Colômbia, Venezuela, Suriname, Peru, Bolívia e região amazônica brasileira) e leste do Brasil, em florestas pluviais, com exceção de C. heterocalyx que ocorre em floresta estacional e floresta de restinga.

Croton subseção Spruceanus Caruzo. inéd. Tipo: Croton spruceanus Benth.

Flores femininas de prefloração imbricada ou raramente reduplicado-valvar; lobos do cálice geralmente unidos até a metade, não carnosos; disco inteiro. Frutos subglobosos, geralmente trígonos.

A subseção Spruceanus ocorre disjuntamente entre o México, América Central, Norte e Noroeste da América do Sul e leste do Brasil em florestas pluviais e estacionais. 


\section{Chave para as espécies de Croton sect. Cleodora}

1. Flores femininas com prefloração quincuncial. Frutos globosos ou elipsóides, não trígonos (com exceção de C. rufolepidotus). Croton sect. Cleodora subsect.

\section{Stolidanthus.}

2. Glândulas foliares acropeciolares.

3. Ramos angulosos. Flores femininas ampuliformes; disco 5-segmentado; lobos do cálice não acrescentes no fruto 15. C. salutaris 3’. Ramos cilíndricos. Flores femininas campanuladas; disco inteiro, profundamente 5-lobado; lobos do cálice conspicuamente acrescentes no fruto.

4. Plantas com indumento rufo-argênteo. Margem foliar inteira. Flores masculinas com ca. 25 estames. Flores femininas com estiletes inclusos. 3. C. campanulatus 4'. Plantas com indumento argênteo. Margem foliar miudamente serrilhada. Flores masculinas com ca. 15 estames. Flores femininas com estiletes exsertos. 7. C. hemiargyreus

2’. Glândulas foliares basilaminares (em C. organensis as glândulas são maculares, inconspícuas).

5. Estiletes 4-fidos.

6. Ramos achatados. Glândulas foliares globosas. Flores masculinas campanuladas; flores femininas ampuliformes. Floresta Atlântica 16. C. sphaerogynus 6’. Ramos cilíndricos. Glândulas foliares pateliformes. Flores masculinas subcampanuladas; flores femininas ovóides. Floresta Amazônica 2. C. cajucara

5’. Estiletes multifidos.

7. Planta endêmica da Colômbia. Indumento de tricomas lepidotos 14. C. rufolepidotus

7’. Plantas do leste do Brasil. Indumento de tricomas estrelados ou multiradiados.

8. Ramos cilíndricos. Flores masculinas cupuliformes; flores femininas sésseis

8. C. heterocalyx 
8’. Ramos achatados. Flores masculinas subcampanuladas; flores femininas pediceladas.

9. Nervação eucamptódroma; glândulas do pecíolo maculares. Brácteas não foliáceas, sem glândulas na base. Flores masculinas subcampanuladas; flores femininas com lobos do cálice unidos na base 10. C. organensis

9’. Nervação broquidódroma; glândulas do pecíolo conspícuas. Brácteas foliáceas, com um par de glândulas na base. Flores masculinas campanuladas; flores femininas com lobos do cálice unidos até a metade 18. C. stellatoferrugineus

1'. Flores femininas com prefloração imbricada ou reduplicado-valvar. Frutos subglobosos, geralmente trígonos. Croton sect. Cleodora subsect. Spruceanus.

10. Glândulas foliares acropeciolares.

11. Ramos cilíndricos; glândulas foliares sésseis. Flores femininas de prefloração imbricada; estiletes 4-fidos 6. C. fragrantulus

11'. Ramos quadrangulares; glândulas foliares curtamente estipitadas. Flores femininas de prefloração reduplicado-valvar; estiletes multifidos 5. C. fragrans 10’. Glândulas foliares basilaminares.

12. Estiletes multífidos.

13. Plantas com indumento ferrugíneo. Flores masculinas campanuladas; lobos do cálice não deflexos no fruto. Epicarpo liso 4. C. croizatii 13'. Plantas com indumento albescente. Flores masculinas subcampanuladas; lobos do cálice deflexos no fruto. Epicarpo verrucoso 1. C. billbergianus

12’. Estiletes 4-fidos (ou bibífidos).

14. Flores femininas urceoladas 17. C. spruceanus 14’. Flores femininas campanuladas. 
15. Arbustos escandentes; ramos levemente achatados. Estames ca. 25. 12. C. pseudofragrans 15’. Árvores a arbustos eretos; ramos cilíndricos. Estames ca. 15.

16. Folhas elípticas, fortemente discolores. Inflorescências congestas. Flores femininas com disco 5-segmentado. Epicarpo verruculoso 11. C. orinocensis 16’. Folhas ovais a cordiformes, raramente ovallanceoladas, levemente discolores. Inflorescências laxas. Flores femininas com disco inteiro, 5-lobado. Epicarpo liso.

17. Inflorescências terminais, mais raramente axilares. Pétalas das flores masculinas com ápice recortado, ondulado; filetes subulados. Fruto trígono 9. C. hoffmannii 17’. Inflorescências terminais, nunca axilares. Pétalas das flores masculinas com ápice inteiro, obtuso; filetes filiformes. Fruto não trígono 13. C. rottlerifolius 


\section{Tratamento das espécies}

1. Croton billbergianus Müll.Arg., Linnaea 34: 98. 1865. Tipo: Panama, Colón, Portobelo, Billberg 316 (holótipo: B†; lectótipo: S!, aqui designado). (Figs. 2 A-D, 10 A-D).

= Croton grosseri Pax., Bot. Jahrb. Syst. 33: 290. 1904. Tipo: Costa Rica, “Carrilo, 300 m”, Pittier 1206 (holótipo: CR; isótipo: US!). (sinônimo proposto por Burger \& Huft, 1995).

$=$ Croton billbergianus subsp. pyramidalis (Donn.Sm.) G.L.Webster, Ann. Missouri Bot. Gard. 75: 1123. 1988. Croton pyramidalis Donn.Sm. Bot. Gaz. 35: 7. 1903. Tipo: Guatemala, “Alta Veracruz: Río Dolores near Cubilgüitz”, Türckheim 7974 (holótipo: US!; isótipo: K!). (sinônimo proposto por Burger \& Huft, 1995).

Arbustos a árvores 2--10m alt., às vezes escandentes, látex alaranjado, tricomas multiradiados, adpresso-estrelados e dendríticos, geralmente porrectos; ramos cilíndricos; ramos jovens estriados, geralmente achatados, flocosos, com tricomas dendríticos. Folhas inteiras, discolores, elípticas, ovais a cordiformes, ápice longamente acuminado a cuspidado, base levemente arredondada a cordada; lâmina 3--25x2--18 cm, margem miudamente serrilhada, com glândulas; face adaxial glabrescente, tricomas adpressoestrelados, porretos, principalmente sobre as nervuras, face abaxial pubescente a esparsamente pubescente, tricomas multiradiados e adpresso-estrelados, geralmente porrectos; nervação pinada, camptódroma, broquidódroma, nervuras terciárias percurrentes, oblíquas, levemente sinuosas; pecíolo 1--5 cm, 1 par de glândulas basilaminares, pateliformes, sésseis; estípulas $0,1--1 \mathrm{~cm}$, inteiras, linear-lanceoladas, caducas. Inflorescências 7--22 cm, laxas, terminais, mais raramente axilares, falsamente ramificadas; raque achatada, estriada, flocosa, com tricomas dendríticos; címulas contíguas, as proximais bissexuadas, 2 flor masculina e 1 flor feminina, as distais masculinas, bifloras; brácteas 2--4mm compr., inteiras, lineares, profilos ca. $1 \mathrm{~mm}$ compr., lineares. Flores masculinas 0,7--1cm, subcampanuladas, longamente pediceladas; pedicelo 3--6 mm; cálice 3--5 mm, pubescente externamente, tricomas adpresso-estrelados, glabro internamente; lobos do cálice 5, unidos até a metade, 1--2 $\mathrm{mm}$, inteiros, iguais, valvares, ovais, ápice agudo, vilosos na margem; pétalas 3--5 mm, espatuladas, ápice arredondado, vilosas nas margens; disco 5-segmentado; estames ca. 16, filetes filiformes, vilosos na base, anteras elipsóides; receptáculo viloso, tricomas simples. Flores femininas 6--8 mm, campanuladas, pediceladas; pedicelo 2--3 mm; 
cálice 4--6 mm, pubescente externamente, tricomas adpresso-estrelados, castanhos, glabrescente internamente; lobos do cálice 5, unidos na porção basal, 3--5 mm compr., inteiros, iguais, imbricados, oval-lanceolados a triangulares, ápice agudo a acuminado; pétalas ausentes; disco inteiro, profundamente 5-lobado; ovário subgloboso, hirtotomentoso, tricomas adpresso-estrelado porrectos; estiletes unidos na base, inteiros no terço inferior, multifidos, inclusos, recobertos por tricomas adpresso-estrelados. Fruto ca. $1,5 \mathrm{~cm}$, subgloboso, verrucoso, com esparsos tricomas adpresso-estrelados, lobos do cálice inconspicuamente acrescentes, deflexos nos frutos jovens e maduros; sementes 4-6 mm, elipsóides; testa costada.

A espécie é amplamente distribuída na América Central, sendo encontrada desde o México até a Colômbia, em florestas pluviais, desde o nível do mar até cerca de $800 \mathrm{~m}$ de altitude. Foi coletada com flores nos meses de fevereiro a setembro e novembro e frutos de abril a outubro e dezembro.

Croton billbergianus diferencia-se das demais espécies da seção Cleodora pelos ramos jovens geralmente achatados, folhas com face adaxial glabrescente, inflorescências ramificadas e algumas vezes axilares, além do cálice nos frutos apresentar lobos conspicuamente deflexos.

Na sinopse das seções de Croton, Wesbter (1993) já havia inserido C. billbergianus na seção Cleodora, bem como em seu trabalho posterior (Webster, 2001). Aqui, C. billbergianus é considerada uma espécie com distribuição contínua em sua ampla área de ocorrência, com grande variabilidade morfológica, principalmente no que diz respeito a caracteres vegetativos, o que levou à concordância com os sinônimos já propostos para a espécie.

Como o holótipo de Croton billbergianus foi destruído, uma duplicata depositada no Herbário de Estocolmo foi selecionada como lectótipo.

Material examinado: MÉXICO. Yucatan and Tabasco, s.d., E.P. Johnson 118 (NY). CHIAPAs: $43 \mathrm{~km}$ al sur de Pichucalco, sobre la carretera Villahermosa-Tuxtla Gutiérrez, 13.VIII. 1983, E. Cabrera \& H. de Cabrera 5216 (MBM 200085, MEXU); 3 km de la carretera Palenque-Ococingo el camino al Parque Natural Cascadas de Agua Azul, 15. VIII. 1983, E. Cabrera \& H. de Cabrera 5252 (MBM 200083, MEXU); Interior

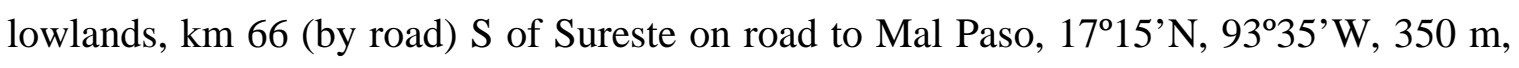
fr., 24. VIII. 1965, K. Roe et al. 1433 (MICH 1159232); Pichucalco, hacia el Carbon, 200 m, 25. VIII. 1950, F. Miranda 6636 (US 2448352); Scrub and woods on limestone, $21 \mathrm{mi}$ 
N of Ocozocoautla, 1700’N, 93³2’W, 1600 ft., fr., 16. VIII. 1972, G.L. Webster 17890 (DAV 10928); Tecpatan, Km. 11.1 de Malpaso, Km. 83.8 de Huimanguillo hacia Malpaso, 210 m, fl., 20. VI. 1980, M.A. Magaña \& C. Cowan 3060 (DAV 88655). OAXACA: Sta. Maria Chimalapa, Arroyo Palmares, ca. $1.5 \mathrm{~km}$ al N de Sta. Maria por la vereda a la Canastilla del Río Corte, fl., 8. VI. 1984, 1655’’, $94^{\circ} 41^{\prime}$ W, 250 m, H. Hernández G. 100 (CHAPA, MO 3398679); Tuxtepec, Chiltepec and vicinity, 20 m, fl., 16. VII. 1940, G. Martínez-Calderon 27 (US 1808105). VeracrUZ: 5 mi. S of Sontecomapan, ca. $18^{\circ} 29^{\prime} \mathrm{N}, 9^{\circ} 03^{\prime}$ W, alt. ca. 1700 ft., fl., 23. VI. 1969, G.L. Webster et al. 15423 (DAV 137065, WIS); Arroyo Agrio, Laguna de Catemaco, $22.5^{\circ} \mathrm{N}, 56.5^{\circ} \mathrm{W}$, 300 m, fr., 11. IX. 1966, M. Sousa 2751 (MEXU, US 2634475); Catemaco, a 10000 m. al sur de la Estacion Biologica Tropical los Tuxtlas Catemaco, 18³5’ N, 95¹’W, fl., fr., 27. VI., 1972, A. Villegas H. 20 (MEXU, MO 2628386); Catemaco, Vicinity of Playa Escondida, $10 \mathrm{~km}$. $\mathrm{N}$ of Sontecomapan, mun. Catemaco, selva alta perennifolia, evergreen tropical forest, some cleared for pastures, on slopes around and above Hotel Playa Escondida and the beach on the Gulf of Mexico, 18³6' N, 95³’ W, 0-150 m, 30. VI. 1982, M. Nee 24746 (DAV 97173, F); Fortuño, Coatzacoalcos river, 30-50 m, III. 1937, L. Williams 8934 (US 1741251); Hidalgotitlán, 3.9 km al S Ejido Hidalgo Amajac, sobre el camino al campamento La Laguna. 15.2 km. al N del Poblado10; lomitas calizas con acahual en región de selva mediana, $17^{\circ} 25^{\prime} \mathrm{N}, 94^{\circ} 27^{\prime} \mathrm{W}, 170 \mathrm{~m}, 11$. VII. 1980, T. Wendt et al. 2508 (DAV 91163); Moist shaded side of trail, on slope below saddle on s.e. of ridge of Volcan San Martin Tuxtla, s.e. of road between Catemaco and Sontecomapan, 1800 ft., fl., s.d., D.B. Ward 7923 (MICH 1160604); San Andres Tuxtla, Estacion Biolog., 22º N, 54 W, 140 m, fl., 20. VII. 1968, G.M. Calderon 1730 (MEXU, MICH 1159231); Vicinity of playa escondida, $10 \mathrm{~km} \mathrm{~N}$ of Sotecomapan, 18³5'30'’ N, 9503'W, fl., 21. IV. 1983, M. Nee 26703 (DAV 129805, F, MICH 1160638, NY, US 3329056, XAL); Colectado en el caminode la Estación Biológica del Instituto de Biologia de la UNAN de los Tuxtlas a Montepio, Veracruz, 18³6'15.5'’ N, 9504’W, fl., Léon B. \& H. Vester 104 (CIQR, DAV 164016, MICH, WIS).

BELIZE. 9 miles West of Punta Gorda on road from Punta Gorda to San Jose, fr., 1. VIII. 1970, J.R. Wiley 7 (US 2845972); Grace Rock, fl., 29. V. 1974, J.D. Dwyer 12505 (MO, US 2787792); Mullins River Road, fl., 8. VI. 1929, W.A. Schipp 205 (US 1588515); Rooning Creek, VIII. 1929, C.L. Lundell 453 (US 1472727); S. proc., 200 ft., 16. IX. 1929, W.A. Schipp 336 (MICH 1159233, US 1586302). Cayo: Along Sibun River near 
crossing of Hummingbird Highway, 200-300 ft., fl., 21. VI. 1973, A. Gentry 8439 (US 2788465); Between Millionaio and Cuevas, fl., 30. V. 1973, J.D. Dwyer 10801 (MO, US 2845636); High ridge, base of hill, 47 miles section Humming Bird highway, 3. IX. 1955, P.H. Gentle 8851 (MICH 1159235); La Flor hunting camp on Rio la Flor, miles south of Grano de Oro, 1700-2000 ft., fl., 3. VI. 1973, A. Gentry 7840 (MO, US 2780593); Vaca, fl., 13. V. 1938, P.H. Gentle 2613 (MICH 1159237). STANn CREEK: Along southern highway ca 3 miles south of junction with Himmingbird highway, 6 miles west Stann Creek, fl., 11. VI. 1973, J.D. Dwyer 11073 (MO, US 2733908); Middlesex, fl., 6. VI. 1939, P.H. Gentle 2835 (MICH 1159240); Stann Creek Railway, 15 miles, fr., 9. VIII. 1937, P.H. Gentle 2113 (MICH 1159238, US 1688113); Stann Creek Valley, Big Eddy Ridge, fl., 10. V. 1940, P.H. Gentle 3324 (MICH 1159234); Silk Grass Reserve, fr., 1. IX. 1939, P.H. Gentle 2979 (MICH 1159239). Toledo: Bladen Nature Reserve, 16³3’N, 8843’W, 45 m, fl., 19. VI. 1997, S.W. Brewer 275 (DAV 145640); In broken cohune ridge, between Punta Gorda - San Antonio Road and Moho River, fl., 24. V. 1949, P.H. Gentle 6749 (MICH 1159236); In the lowlands near the northeastern Bladen Nature Reserve, tree c. $8 \mathrm{~m}$. tall next to an old logging road at BFREE. Field collected in isopropyl alcohol (70\%), 16 $33^{\circ} \mathrm{N}, 8^{\circ} 42^{\prime} \mathrm{W}, 45 \mathrm{~m}$, fr., 31. VIII. 1995, S.W. Brewer 93 (DAV 145649); In the lowlands near the northeastern Bladen Nature Reserve, at BFREE in 15-20 yr. old forest on alluvium over limestone, next to the Bladen River, $16^{\circ} 32^{\prime} \mathrm{N}$, 8842’W, 45 m, fl., 28. VI. 1997, S.W. Brewer 292 (DAV 145643); Punta Corda, 1. VIII. 1980, J.D. Dwyer 15176 (DAV 97234, MO); Rio Grande, fr., 18. VIII. 1944, P.H. Gentle

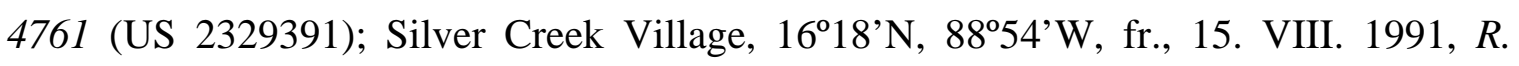
Arvigo et al. 626 (DAV 126254); Trail to Esperanza, beginning 1 milee north of Columbia Forest Station, fl., 12. VI. 1973, J.D. Dwyer 11113 (MO, US 2786965); Vicinity of San Jose Myan Indian Village, 6.7 mi north of Columbia Forest Station, 13. VI. 1973, T.B. Croat 24445 (MO, SI). COSTA RICA. Hacienda de Guacimo, fr., s.d., United Fruit Company 109 (US 861487); Los Diamantes station, Guapiles, fl., 3. VII. 1980, G.S. Hartshorn 2260 (NY); Rio Hondo, Plains of Santa Clara, fl., 7. V. 1993, O.F. Cook \& C.B. Doyle 580 (US 474445); U.S.D.A. Station, Guapiles, Los Diamantes, 250 m, fl., 16. VI. 1951, J.B. Carpenter 394 (US 2704907). AlAJUELA: Arenal, al lade de un camino $4 \mathrm{~km}$ de la carretera de La Tigra a San Ramon, cerca al poste numero 19, 10²'60’'N, 84³4'47’'W, 470 m, fl., 26. VII. 2002, B.W. Va Ee \& K. Rodden 342 (WIS); Cantón de Upala, Cordillera Volcanica de Guanacaste Bijagua, Finca de Werner, 1044’20’’N, 8503’20’’W, 500-600 m, fr., 12. VIII. 1994, J. González et al. 358 (CR 
184234, MO); Cantón de San Ramon, Valley of río Esperanza, 4 km SE of La Tigra, Finca Araya Ledezma, Bosque Eterno de los Niños, $10^{\circ} 18^{\prime}$ N, 84³7’ W, fr., 1. VII. 1992, W. Haber et al. 11240 (CR 165123, MO); P. Nac. Rincón de la Vieja, Colonia Libertad, Río Jala Piedras, 1050’N, 85¹5’W, 800 m, fr., G. Rivera 1470 (CR 170325, DAV

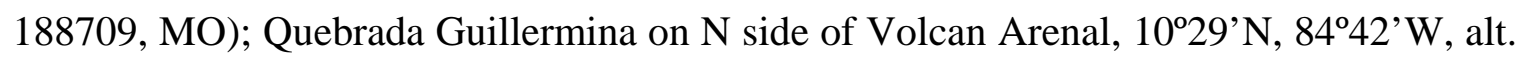
500 m, fl., 21. IV. 1973, R.W. Lent et al. 3380 (CR 126823); San Carlos, Florencia, elev. 250 m, fl., 27. VI. 1985, W.A. Haber et al. 1851 (CR 129330, MG 139226, MO); San Carlos, San Miguel de San Isidro, quebrada seca a 600 m, fr., 29. VI. 1985, W.A. Haber \& E. Bello C. 1688 (MO 04673948). CARTAgo: Turialba, terrenos del Instituto, $600 \mathrm{~m}$, fl., 16. VI. 1949, J. Leon 1639 (US 2218145); Turialba, terrenos del Instituto, fl., 13. VII. 1949, J. Leon 1673 (US 2218163); Turialba, rainforest on steep W slope of the Río Reventazón, near Centro Agronomico Tropical, Turrialba, 954’N, 83³9’W, 1500-1800 ft., fl., 10. VII. 1977, G.L. Webster 21888 (DAV 107063); Turialba, 600 m, fl., 17. VI. 1952, J.J. Córdoba 151 (CR 78534); Turrialba, Río Reventazón, IICA, 15. X. 1964, L.L. Little Jr. 20002 (CR 78571); Turrialba, terrenos del Instituto Interamericano de Ciencias Agrícolas, 600 m, fr., 23. IX. 1968, J.J. Córdoba 1009 (CR 78533); Turrialba, Florencia Sur - I.I.C.A., 20. IV. 1972, L.J. Poveda 43 (CR 50122); Turrialba, Catie, bosque Los Espabeles, a orilla del río Reventazón, alt. 500 m, fr., 12. X. 1984, N. Zamora V. \& L.J. Poveda 766 (CR, MO 3648132); Turialba, 650 m.s.n.m., fl., 7. VI. 1992, D. Hazlett \& M. Artavía 7089 (CR 104030); Valley of Rio Reventazon, near Inter-American Institute of Agricultural Sciences, 3 km SE of Turrialba, 500-600 m, fl., 21. VI. 1949, R.W. Holm \& H.H. Iltis 62 (US 2037781). HeREDiA: Cantón de Sarapiquí Rara Avis, ca. 15 km al

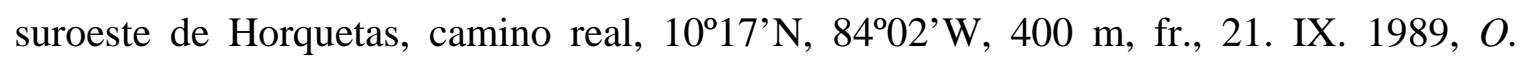
Vargas 161 (CR 177943, MO); Finca La Selva, the OTS Field Station on the Río Puerto Viejo just E of its junction with the Río Sarapiquí. Elevation about $100 \mathrm{~m}$, rock and sandy area along the Sarapiqui at the crossing on the new property, $100 \mathrm{~m}$, fl., 26. IV. 1982, B. Hammel 11862 (DAV 103521); Finca La Selva, the OTS Field Station on the río Puerto Viejo just E of its junction with the río Sarapíqui, elevation about $100 \mathrm{~m}$, southwestern cornerof the new property, along de El Peje, fl., 18 V. 1985, B. Jacobs 3096 (CR 209103); Sarapiquí, Z.P. La Selva, Cuenca de Sarapiquí, La Selva, 10²6’00’’N, 8400’30’’W, 100 m, fr., 02. VII. 2003, D. Solano et al. 118 (CR 243598, MO). LiMóN: Along Río Costa Rica, SW of Guálipes, 10²’N, 8352’W, 300 m, fl., 16. VI. 1984, M.H. Grayum et al. 3282 (MO 3238048); Along Río Costa Rica, SW of Guálipes, 10²', 8352’W, 300 m, fl., 16. VI. 1984, M.H. Grayum et al. 3282 (DAV 106468, 
MO); Cantón de Limón, R.B. Hitoy Cerere, Valle de la Estrella, estación río Cerere, 940’30’’N, 8300’20’’W, 100 m, fl., fr., 14. IX. 1993, G. Carballo 493 (CR 191655, MO 5581046); Cantón de Limón, R.B. Hitoy Cerere, Valle de la Estrella, río Cerere, Quebrada Barrera, 940’30’’N, 8301'25'’W, 100 m, fl., fr., 14. IV. 1994, G. Gallardo 131 (CR 200706, MO); Cantón de Pococí, Along the margin of Rio Corinto, approx. 1.5km S of where Hwy. 32 crosses the river, 10¹2'14.1'’ N, 8353'16.1'’ W, $1080 \mathrm{~m}$, fl., 12. IV. 2006, B. Van Ee \& M. Van Ee 595 (MICH, WIS); Finca La Lola, Madre de Dios, 50-75 m, fl., 17. II. 1942, L.R. Holdridge 2505 (US 2218265); Matina, no protegida, cuenca del Matina, 1 km este de Finca Bana, 959'54,7656’'N, 83¹3'48,2073' 'W, 40 m, 07. VI. 2003, L. González et al. 2272 (INB, MBM 307444, MO); Ridge n of Quebrada El Molinete, between Río Chirripó and Río Corinto, E of new highway, elev. ca. 400 m., $10^{\circ} 12^{\prime}$ N, 8354’W, fr., 19. VII. 1984, M.H. Grayum \& B. Jacobs 3528 (MO 3238047); Talamanca, Reserva Indígena Bribri, Asentamento Volio, cuanca del río Uatsí, 9³7’30’’N, 8254’W, 100-300 m, fl., 25. XI. 1998, O. Valverde et al. 1154 (CR 224455). Puntarenas: Cantón de Gabarito, R. B. Carara, Valle del Tárcoles, Estación quebrada bonita, 946’50’’N, 85³6’00’’W, 100 m, fl., 26. VI. 1990, E. Rojas 68 (CR 185957, MO); Golfito, P.N. Corcovado, Península de Osa, Estación Sirena, Senderos Naranjos, 8'28'40’’N, 83³5'40' 'W, fl., 14. VI. 2000, R. Aguilar 6256 (CR 243818, MO); Parque Nacional Corcovado Sirena, Ollas Trail, Skyway Trail, 8²8’ N, 83³5’W, 1-50 m, fl., 1. VII. 1989, C. Kernan \& P. Phillips 1200 (CR 108861, MO); Parque Nacional Corcovado Sirena, río claro trail, 8²8’ N, 83³5’W, 0-200 m, fr., 3. VII. 1991, P. Delprete 5156 (CR 154689, MO, NY); Reserva Biológica Carara, Estación Quebrada Bonita, 946’N, 84³6’W, 30 m, fr., 26. VI. 1990, E. Bello \& E. Rojas 2274 (CR 158601, MO). SAN JosE: Near entrance to Bijajual guard post, Carara reseve, ca. $2 \mathrm{~km} N$ of Bijagual de Turrubares, 945’N, 84³4’W, ca. 430 m, fr., 26. VI. 1985, M.H. Grayum et al. 5511 (CR 134868, MO); Reserva Biológica Carara, Estación Bijagual, 945’N, 84³3’W, fr., 2. VII. 1990, E. Bello 2305 (CR 159090, MO); Western part of Montañas Jamaica, ca. 3 km NE of Bijagual Turrubares, Carara reserve, 9 $45.5^{\prime} \mathrm{N}, 84^{\circ} 33^{\prime} \mathrm{W}$, elev. 500-600 m, fr., 7. VIII. 1985, M.H. Grayum et al. 5883 (CR 133294, MO); Z.P. La Cangreja, Santa Rosa de Puriscal, bosque primário en las mágenes del río Negro, 942’06' 'N, 84²3’35' 'W, 350 m, fr., 26. VIII. 1992, J.F. Morales 515 (CR 167636, MO). GUATEMALA. Alta VerAPAZ: Cubilquitz, 350 m, fr., VII. 1903, H. Von Tuerckheim 467 (US 936108); Cubilquitz, fr., VII. 1903, H. Von Tuerckheim s.n. (US 936109); Cubilquitz, 350 m, fr., VII. 1907, H. Von Tuerckheim II 390 (US 860703); Finca Mercedes, Teleman, Panzós, 
fr., 3. IX. 1988, E. M. Martínex S. et al. 23466 (MO 3659733); Panzós Finca Mercedes,

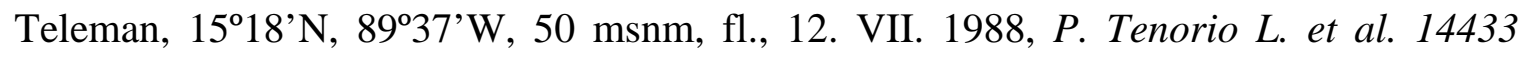
(MEXU, MG 139628); Río Dolores, 350 m, fl., VII. 1901, H. Von Tuerckheim s.n. (US 398429). IzABaL: Cadenas, Puerto Mendez, bordering Rio Dulce, in high forest, fl., 24. V. 1970, E. Contreras 9880 (MICH MICH 1159241); Cadenas, Puerto Mendez, bordering Rio Dulce, in high forest, fr., 24. V. 1970, E. Contreras 9881 (MICH 1159243); Cadenas, 4 km. WS on La Guitarra Road, in low forest, fr., 6. VII. 1970, E. Contreras 10121 (MICH 1159244); Quebradas, fl., 19-22.V. 1919, H. Pittier 8568 (US 1013586); Vicinity of Quiriguá, 75-225 m, 15-31. III. 1922, P.C. Standley 23949 (US 1139609). Peten: 47 km south of Poptun, fl., 29. VI. 1979, W.E. Harmon 2838 (US 2787807); La Cumbre, km. 136 of Cadenas Road, in clearing, fr., 1. X. 1966, E. Contreras 6306 (MICH 1159242); La Cumbre, in zapotal, 4km. east on Rio Purula Road, on hill in high forest, fr., 19. IX. 1975, C.L. Lundell \& E. Contreras 19885 (MICH 1159245); La Cumbre, bordering the road, km. 138/139, clearing, fr., 22. VII. 1976, C.L. Lundell \& E. Contreras 20092 (DAV 133506); Off Poptun-Cadenas Road, in rain forest, fl., V. 1967, E. Contreras s.n. (DAV 40476). HONDURAS. Edge of lake Yojoa, 29. VII. 1951, R. Howard et al. 626 (US 3005569). ATLANTIDA: Lancetilla Valley, near Tela, 20600 m, fr., 6. XII. 1927, P.C. Standley 53661 (US 1407872); Lancetilla Valley, near Tela, 20-600 m, fr., 6. XII. 1928, P.C. Standley 52629 (US 1407214); Rain forest on slopes, Lancetilla Valley, c. 3 mi. south of Tela, 200-500 m, 30. VII. 1962, G.L. Webster 12691 (DAV 138063); Rocky bank of Tela River, near Lancetilla, 90 ft., fl., 10. VII. 1934, T.G. Yuncker 4516 (MICH 1159251). ComayAguA: Bosque Iluvioso de Pito Solo, Lago de Yojoa, 600 m, fl., 25. V. 1956, A. Molina R. 7222 (US 2412060). CopÁN: Cut over forest between Sta. Rita and Sta. Isabel, 655-750 m, fl., 22. VI. 1975, A. Molina R. 30610 (EAP, MO 2576482). CoRTES: E shore of Lago de Yojoa, 7 mi S of Agua Azul, alt. 2000 ft., fl., 01. VIII. 1962, G.L. Webster et al. 12754 (DAV 48918, MBM 153991, MICH 1159250); Matorrales humedos entre Agua Azul y Pito solo, area de Lago Yojoa, 600 m, fr., 26. VIII. 1955, A. Molina R. 5556 (US 2572511). NICARAGUA. ZELAYA: Along Río Plata, just past Colonia Río Plata, forest remnants along the river, $11^{\circ} 43^{\prime} \mathrm{N}, 84^{\circ} 27^{\prime} \mathrm{W}, 150 \mathrm{~m}$, fr., 20. VIII. 1983, J.S. Miller \& J.C. Sandino 1191 (MO 5684800); Ciduad Rama, San

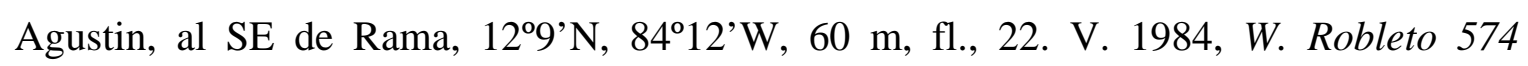

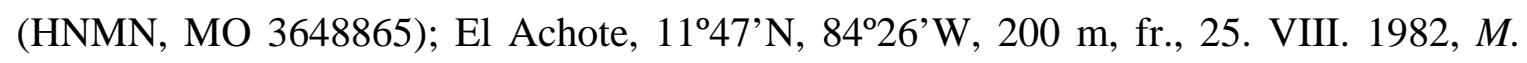

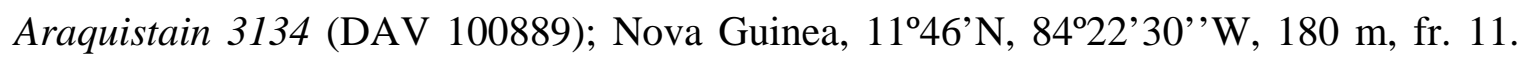
VIII. 1982, M. Araquistain 3084 (DAV 100891, HNMN); Nova Guinea, Colonia Yolaina, 


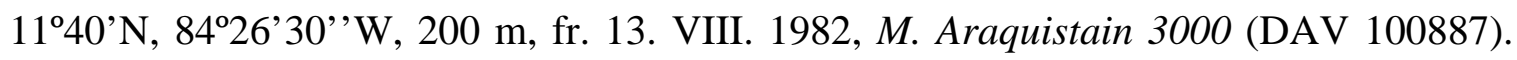
PANAMÁ. 5-10 km NE of Altos de Pacora, 700-800 m, fl., 10. V. 1975, S. Mori \& J. Kallunki 6030 (MO, US 2787136); Around Gamboa, Canal Zone, along roads and in waste places, 25. VI. 1911, H. Pittier 3698 (US 678766); Barro Colorado Island, Gatún Lake, Canal Zone, 17. I. 1924, P.C. Standley 31436 (US 1219817); Barro Colorado Island in Gatún Lake, Canal Zone, 18-24. XI. 1925, P.C. Standley 40967 (US 1251744); Barro Colorado Island, Canal Zone, fr., 26. VII. 1927, L.A. Kenoyer 411 (US 1319149); Barro Colorado Island, Canal Zone. B.C. Id. Barbour end, fr., 11. VII. 1934, Shattuck 929 (US 2366710); Barro Colorado Island, Canal Zone, fr., 17. VII. 1934, Shattuck 952 (US 2366711); Barro Colorado Island, along shore east of dock, fr., 26. VI. 1960, J.E. Ebinger 213 (MICH 1160594, US 2561666); Darién Station, Canal Zone, 19. I. 1924, P.C. Standley 31611 (US 1219904); Canal Area, Barro Colorado Island, Gatún Lake, Canal Zone, fl., 6. VI. 1923, W.R. Maxon et al. 6798 (US 1180529); Barro Corolado Island, west shore of Fairchild Peninsula, in cove, fr., 26. VII. 1982, R. J. Schalzel 718 (MO 3639497); Canal Zone, Barro Colorado I., rain forest near laboratory, fl., 4. VI. 1971, G.L. Webster 16400 (DAV 109020); Canal Zone, Barro Colorado I., rain forest along shore betw, Slothia \& Barbour Pt., fr., 6. VI. 1971, G.L. Webster \& G. Brekon 16446 (DAV 91472); Canal Zone, seazonal rain forest along pipeline road $3 \mathrm{mi}$ NW of Gamboa, 100-200 ft., fr., 27. VI. 1971, G.L. Webster 16769 (DAV 160037); Canal Zone, rain forest along 8-10, c. 5.5 mi SW of Gatun Looks, fl., 6. VII. 1971, G.L. Webster \& H. Kennedy 16880 (DAV 109021); Cruces Trail, fl., 30. VI. 1940, H.H. Bartlett \& T. Lasser 16350 (MICH 1159247); End of Pipeline road, 19 km NW of Gamboa.alt. 25-50m. At bay of Gatun Lake, 1 km S of Pueblo Limone, 25-50 m, fl., 6. IV. 1974, M. Nee \& D. Smith 11081 (US 2787428); George Greene Memorial, C. 29, fr., 1965, J.D. Dwyer 6579 (US 2787129); Near Fort Randolph, Canal Zone, fl., 26. V. 1923, W.R. Maxon \& A.D. Harvey 6521 (US 1180272); Near Fort Randolph, Canal Zone, 28. XII. 1923, P.C. Standley 28718 (US 1218265); Obispo, Canal Zone, 19. I. 1924, P.C. Standley 31683 (US 1219950); Río Pedro Miguel, near East Paraíso, Canal Zone, 7. I. 1924, P.C. Standley 29942 (US 1218994); S. proc., fl., E.D. Christopherson 194 (US 716480); Vicinity of Fort Sherman, Canal Zone, 15. I. 1924, P.C. Standley 30968 (US 1219619); Vicinity of Juan Mina, flat rock, chagres river, fr., 24. VIII. 1940, H.H. Bartlett \& T. Lasser 16840 (MICH 1159246); Isthmus of Panama, fl., 24. III. 1850, A. Flender 292 (US 71438); Vicinity of Juan Mina, wooded hillside at Canal Zone boundary, fr., 26. VII. 1940, H.H. Bartlett \& T. Lasser 16554 (MICH 1159248). BoCAS DEL TORO: Vicinity of Chiriqui 
Lagoon, fr., 13. VII. 1941, H. Von Wedel 2524 (US 1823880). CoLóN: Between France Field, Canal Zone, and Catival, 9. 1. 1924, P.C. Standley 30204 (US 1219133); Road to Rio Indios, 3 km S of Pina, elev. 50 m, 7. VII. 1976, G.A. Sullivan 134 (MO, VEN 400077); Salud, 30 m, fr., 27. VII. 1971, E.A. Lao \& L.R. Holdridge 170 (MO 2064381); Villa Alondra. Carretera a Portobelo, 30 m, 13. IV. 1971, E.A. Lao \& L.R. Holdridge 20 (MO 2322237). Panama: Forests on dry limestone, around Alhajuela, Chagres Valley, province of Panama, 30-100 m, fl., 12-15. V. 1911, H. Pittier 3513 (US 678566); SE slopes of Cerro Trinidad, fl., 5. V. 1968, J.H. Kirbride \& J.A. Duke 1666 (NY). SAN Blas: El Llano-Cartí road, between Río Pingandí and Río Cartí Grande, 9²19’N, 7855’W, 150 m, fl., 24. V. 1985, G. de Nevers 5806 (MO 5696803); Trail from Puerto Obaldía to La Bonga, tributary of the Río Armila, ca 2 hours walk from Puerto Obaldía. Tropical wet forest, $8^{\circ} 40^{\prime} \mathrm{N}, 7^{\circ} 25^{\prime} \mathrm{W}, 0-50 \mathrm{~m}$, fl., 17. IV. 1982, S. Knapp \& J. Mallet 4667 (MO 3006259).

COLÔMBIA. ANTioquia: Disturbed forest area approx. $15 \mathrm{~km}$ southeast of Turbo near the highway to Chigorodó , elevation less than 100 m, fl., 31. III. 1962, C. Feddema 2104 (MICH, NY, US 2813181).

2. Croton cajucara Benth., Hooker’s J. bot. Kew gard. misc. 6: 376. 1854. Tipo: Brasil, Pará, “On the Lago de Quiriquiry, near Obidos”, XII. 1849, Spruce s.n. (holótipo: K!; isótipos: A, M, foto F!, P!). (Figs. 2 E-G, 10 E-H).

= Croton seputubensis Hoehne, Exped. Rosevelt-Rondon, Bot.: 55. 1914. Tipo: Brasil, Mato Grosso, “Colhido na matta do Salto da Felicidade, no rio Sepotuba, florescendo em Janeiro. Existe em grande abundancia nas margens da estrada que vae pela matta ao Kilometro 50, onde a colhemos em fins de Janeiro de 1914. Nos. 56155619. Est. no. 23”, I. 1914, Hoehne 5615 (lectótipo: R!, aqui designado). syn. nov.

= Croton motilonorum Croizat, Mem. Soc. Cienc. Nat. La Salle 10 (26): 126. 1950. Tipo: Venezuela, Zulia, Colón: “Orillas de bosques vírgenes a lo largo del ferrocarril de Los Encontrados a Casigua-El Cubo, Dto. Colón, Estado Zulia, unos 10-15 kilómetros al norte de Casigua-El Cubo”, V. 1949, Croizat s.n. (holótipo: CAR; isótipo: F 1426209!). syn. nov.

Nomes populares: “sacaca”, “sacaca-vermelha”, “sacaca-branca”, “musacaca”, “maria-vuvuia”, ‘murasacaca-vermelha”. 
Árvores 3--12m alt., látex ferrugíneo; tricomas estrelados, adpresso-estrelados, multiradiados e dendríticos; ramos cilíndricos, ramos jovens flocosos, com tricomas dendríticos, levemente estriados. Folhas inteiras, levemente discolores, oval-lanceoladas, ápice acuminado, base cuneada a obtusa; lâmina 2--14x1--4,5cm; margem inteira a serrilhada, com glândulas, face adaxial glabra, tricomas multiradiados apenas sobre a nervura central, face abaxial glabrescente, ferrugínea, tricomas adpresso-estrelados; nervação pinada, camptódroma, eucamptódroma; nervuras terciárias percurrentes, oblíquas, levemente sinuosas; pecíolo 0,2--1cm compr., 1 par de glândulas basilaminares, pateliformes, esverdeadas, sésseis, inconspícuas, maculares; estípulas ca. 1mm compr., inteiras, linear-lanceoladas, caducas. Inflorescências 8--28cm compr., laxas, pendentes; raque cilíndrica, estriada, pubescente, tricomas estrelados; címulas contíguas, as proximais bissexuadas, ca. 2 flores masculinas e 1 flor feminina, as distais masculinas, ca. 2 flores; brácteas 1,5--2 mm compr., inteiras, lanceoladas, profilos ca. 0,5mm, linearlanceolados. Flores masculinas 3--6 mm, subcampanuladas, pediceladas; pedicelo 1-4mm compr.; cálice ca. $2 \mathrm{~mm}$, pubescente externamente, alvo-esverdeado, tricomas estrelados, glabro internamente; lobos do cálice 5, unidos apenas na porção basal, ca. 1,5 mm compr., iguais, inteiros, levemente imbricados, ovais, ápice agudo, margem vilosa; pétalas ca. 2,5 mm compr., lanceoladas a espatuladas, ápice agudo a obtuso, vilosas externamente, tricomas estrelados, glabras internamente, margem vilosa; disco 5segmentado; estames ca. 16; filetes subulados, vilosos nas margens, anteras sagitadas; receptáculo viloso, tricomas simples. Flores femininas ca. $5 \mathrm{~mm}$, ovóides, curtamente pediceladas, pedicelo ca. 1,5 mm compr.; cálice ca. $4 \mathrm{~mm}$, pubescente externamente, alvo-esverdeado, tricomas estrelados, glabrescente internamente, tricomas estrelados; lobos do cálice 5, ca. $4 \mathrm{~mm}$ compr., inconspicuamente unidos na base, inteiros, iguais, quincuncinais, carnosos, largamente ovais a romboidais, ápice agudo, margem vilosa; pétalas ausentes; disco 5-segmentado; ovário globoso, viloso, tricomas estrelados; estiletes 4-fidos, unidos até a metade formando um tubo, segmentos exsertos, tubo recoberto por tricomas estrelados. Fruto 0,6--1 cm compr., globoso, liso, tricomas estrelados; lobos do cálice persistentes, acrescentes; sementes ca. 4mm compr., globosoelipsóides, testa levemente costada.

Espécie amazônica de florestas pluviais de terra firme e inundáveis da Bolívia, Brasil, Peru, Venezuela e Suriname, nível do mar até 850 m de altitude. Coletada com flores em 
janeiro, fevereiro, abril a junho e de outubro a dezembro, e frutos em janeiro a julho e de outubro a dezembro.

Croton cajucara é tratado aqui como um táxon de ampla variabilidade morfológica, no que diz respeito a caracteres vegetativos (principalmente quantitativos), e que, mesmo assim é bastante característico por seus ramos jovens com indumento flocoso e folhas oval-lanceoladas de nervação eucamptódroma, dispostas disticamente nos ramos.

Croton seputubensis foi descrito por Hoehne (1914) com base em cinco amostras coletadas pelo autor no Estado do Mato Grosso, Brasil. Com base na descrição original, na ilustração do trabalho, e no material tipo depositado no herbário do Museu Nacional do Rio de Janeiro, foi possível verificar que essa espécie deve ser considerada um sinônimo de C. cajucara.

Croizat (1950) nos comentários de Croton motilonorum, menciona que as únicas espécies que poderiam estar a ela relacionadas seriam C. seputubensis e C. cajucara. O autor também refere que $C$. motilonorum poderia ser facilmente reconhecido pelas flores femininas fechadas, com estiletes expostos. No entanto, flores desse tipo são típicas de $C$. cajucara. Através da análise do protólogo das espécies e do estudo detalhado das coleções tipo das mesmas, foi possível verificar que, assim como C. seputubensis, $C$. motilonorum deve ser considerado um sinônimo de C. cajucara.

A única espécie de Cleodora que poderia ser confundida com Croton cajucara é Croton sphaerogynus, que além de ocorrer no leste do Brasil, na Floresta Atlântica, diferencia-se da primeira pelo ápice foliar (acuminado em C. cajucara vs agudo em $C$. sphaerogynus), padrão de nervação secundária das folhas (eucamptódroma em $C$. cajucara vs broquidódroma em C. sphaerogynus), flores masculinas (subcampanuladas em C. cajucara vs campanuladas em C. sphaerogynus) e flores femininas (ovóides em C. cajucara vs ampuliformes em C. sphaerogynus).

Conhecido popularmente como “sacaca”, Croton cajucara vem sendo estudado fitoquimicamente já há vários anos. O óleo essencial da espécie possui um importante componente aromático, o Linalool (Lemos et al. 1999; Lopes et al., 2000), amplamente utilizado na indústria cosmética. Além disso o óleo da sacaca possui ação antiulcerogênica (Hiruma-Lima et al. 2002; Souza-Brito et al., 1998), antiinflamatória (Carvalho et al., 1996) e antitumoral (Grynberg et al. 1999). 
Material examinado: SURINAME. Lely Mts., SW plateaus covered by ferrobauxite, in base line 2600, E of airstrip, high forest, 550-710 m, 22. IX. 1975, J.C. Lindeman et al. 172 (US 00646713, VEN 174903). VENEZUELA. AMAZONAS: Atures, $23 \mathrm{~km}$ NE of Puerto Ayacucho and $10 \mathrm{~km}$ E of the highway, hills and base of hills, near Cachama, elev. 90 m, 551’N, 67²4’W, fl., 17-19. IV. 1978, G. Davidse \& O. Huber 15303 (US 3058503, VEN 363343); Atures, 23 km NE of Puerto Ayacucho and 10 km E of the highway, hills and base of hills, near Cachama, elev. 90 m, 551' $\mathrm{N}, 67^{\circ} 24^{\prime} \mathrm{W}$, fl., 17. IV. 1978, G. Davidse \& O. Huber 15334 (DAV 83895, MO 345659, US 3058501, VEN 133970); Atures, forested areas and igneous outcrops along Río Coromoto, at Tobogán de la Selva, 35 km southeast of Puerto Ayacucho, 5²2’N 67³3’W, 150 m, fl., 14. V. 1980, J.A. Steyermark et al. 122472 (MO 2999908, VEN 65948); Atures, Puerto Ayacucho, 6²5’N, 67²5’W, 37 m.s.n.m., 22. VII. 1981, A. Castillo 1386 (DAV 103502, VEN 291387); Caño del Paso, cercano a Pto Sipapo, 6³4’N, 675’’W, 26. III. 1993, A. Castillo 3469 (TFVA 14802, MYF 17137, VEN 324665, WIS); Isla Ratón, Sabana de Ratón, ecotono, bosque-conuco, suelo arenoso, 100 m, 7. IV. 1978, G. Morillo et al. 7370 (TFVA 10220, VEN 224796). Bolívar: Cedeño, vicinity of Panare village of Corozal, 6 km from Maniapure toward Caicara, 655’ N, 66³0’W, 90-400 m, fr., 12. X. 1985, B. Boom \& M. Grillo 6339 (NY, US 32833669, VEN 291592). BARINAS: 13 km NE of Santa Barbara on road to Barinas, 200 m, fr., 22. VI. 1975, A. Gentry \& L. Puiz-Ross 14276 (MO 2376604, US 2788468); Santa Bárbara de Barinas, Carretera Rural San Antonio abajo, arbusto de 3m altura y 7cm de diâmetro, fl., 1. VI. 1989, L. Valverde \& I. Peña 1169 (IBGE 25255, MER, MO 3758349, VEN 324022). ZuLIA: Colón, margin of virgin forest by the railroad Encontrados-Casigua-El-Cuba, some 10-15 kilometers north of Casigua-El-Cuba, V. 1949, Croizat s.n. (F 1426209); Colón, entre Casígua el Cubo y Km 8 de la vía rumbo a Palmira, y en el sector Puerto Tigre (hasta la finca de Luiz Cardozo), desviando en Km 8 a la izquierda y continuando hasta el río Tarra, distancia de $5 \mathrm{Km}$, en zona de bosque macrotérmico e higrófilo, fl., 28. IV. 1979, G.S. Bunting et al. 7310 (VEN 159698). BRASIL. Estrada cuiabá-Santarém, Km 67, fr., 4. II. 1979, M.R. Cordeiro et al. 1378 (IAN 155268); s.proc., fr., 22. I. 1932, M. Costa 285 (IAN 48814).

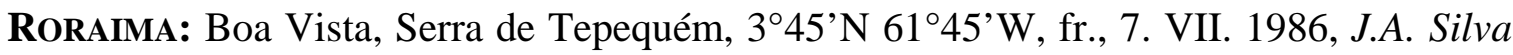
et al. 435 (INPA 160545, NY, MICH); Cantá, fl., 18. V. 1997, C. Farias s.n. (INPA 199547); Estação Ecológica de Maracá, Município de Boa Vista, fr., 15. V. 1987, J. Lima \& B. Nelson 704 (INPA 150200); Ilha de Maracá, Mun. Alto Alegre, SEMA Estação, 3²2’N 6120’W, fl., fr., 11. VI. 1986, M.J.G. Hopkins et al. 653 (INPA 152269, MG, 
MICH, MO); Ilha de Maracá, Mun. Alto Alegre, SEMA Estação, 3²2’N 61²0’W, fl., 13. VI. 1986, M.J.G. Hopkins et al. 722 (INPA 152333, MG); Ilha de Maracá, Mun. Alto Alegre, SEMA Estação, 3²2’N 61²0’W, fl., 18. VI. 1986, M.J.G. Hopkins et al. 847 (INPA 152451, MG, US 3336278); SEMA Ecological Reserve, Ilha de Maracá, 3²3’N 61²7’W, fl., 22. IV. 1987, W. Milliken 79 (INPA 167309); Mucajaí, Vila do Apiaú, arbusto ca. 2m alt., inflorescências com coloração amarelada, beira da estrada Muccajaí/Apiaú, fl., 7. V. 1998, A.C. Sevilha \& J.M. Felfili 1776 (IBGE 44720). Amazonas: s.proc., XI. 1933, s.col. (MG, RB 15872); LBA, 03. V. 1991, A. Cortês \& L. Coelho 78 (INPA 161670); Manaus, fr., s.d., A. Ducke 2246 (IAN 43371, R 35221); Manaus, cultivada, “sacaca”, 1934, A. Bevilaqua s.n. (MG 49545, RB 24882, US 24882); Manaus, margem do Igarapé de Santa Maria, fl., 10. X. 1955, W.A. Rodrigues s.n. (INPA 2107, MG 21876, UB 46855); Manaus, no horto da CPPN, fl., 14. I. 2003, M. Santos s.n. (INPA 213337); Manaus, Sítio São José, Estrada Torquato Tapajós, km 8, próximo a Nokia e a Brastemp, fr., 17. I. 2003, J.E. da C. Souza s.n. (INPA 213339); Parque Nacional do Jaú, 2³5’00'’S e 63²1’38’’W, 25. IX. 1995, E. Rodrigues s.n. (MG, SP 319378); Tefé, 8. II. 1973, PLK \& Marilene 12524 (CESJ, RB 205370); Tefé, 10. II. 1974, PLK \& Eliana 12688 (CESJ, INPA 55739). PARÁ: Almeirim, Mt. Dourado, beira de estrada entre S. Miguel e Igarapé Ideal, 17. IV. 1986, M.J. Pires et al. 877 (INPA 149048, JARI, MG 125379); Almeirim, Mt. Dourado, bloco Caracurí, próximo ao rio Caracurú, 055’S e 5244’W, 25. XI. 1986, fl., M.J. Pires \& N. Silva 1478 (INPA 149271, MG 125486); Alter do Chão, Jardim de Dona Concha, Santarém, 09. VII. 1982, L.C. Blanch 126 (INPA 106293); Alter do Chão, 22. VII. 1982, L.C. Branch 193 (INPA 106355); Augusto Corrêa, Vila de Aturiaí, rio Aturiaí, 14. IX. 1999, L. Corrêa et al. (MG 165738); Belém, mata da serraria Santa luzia, grounds of IAN, 4. IX. 1965, G.T. Prance \& T.D. Pennington 1262 (IAN 116947); Belém, fl., 13. II. 1970, E. Oliveira 5104 (IAN 133199); Belém, 18. VI. 1997, J.M. Albuquerque s.n. (IAN 165013); Belém, Embrapa Brasileira de Pesquisa Agropecuária, Centro de Pesquisa Agroflorestal da Amazônia Oriental, cultivada atrás do prédio da Botânica, 1. III. 2006, M.B.R. Caruzo \& R. Riina 95 (SP 84414, WIS); Belém, Embrapa Brasileira de Pesquisa Agropecuária, Centro de Pesquisa Agroflorestal da Amazônia Oriental, cultivada no horto de plantas medicinais, 1. III. 2006, M.B.R. Caruzo \& R. Riina 96 (SP 84415, WIS); Belterra, fl., 18. X. 1947, G.A. Black 47-1705 (IAN 29922, IAC 12061); Belterra, fl., 23. XII. 1956, J.M. Pires et al. 6517 (IAN 91934); Benfica, 1. XII. 1997, Domingos s.n. (IAN 170278); Bragança, campos temporariamente alagado de Quatipuru, arredores de Santa Maria, 18. IV. 1978, 
fr., N.A. Rosa 2410 (IAN 155769, INPA 83564, MG 58703); Bragança, 1¹2’S e 46²3W, 21. II. 2000, M. Rios \& L.Q. Cardoso 711 (IAN 177141); Campo de Peixe-Boi, E.F. Bragança, 18. I. 1949, fl., N.T. Silva 177 (IAN 42582, UB 46868); Capanema, Rio Quatipuru, in vicinity of Mirasselvas, ca. $30 \mathrm{~km}$ by road west of Bragança, elev. 50msm, ca. 104'S e 4659’W, 9. IV. 1980, fr., G. Davidse et al. 18139 (INPA 131710, MG 95756, NY, SPF 125791); Capanema, Vila de Mirasselvas, entrada pela estrada Capanema-Bragança, a aproximadamente 30km de Capanema, próximo ao rio Quatipuru, margem direita subindo o rio, beira de mata na propriedade da Sra. Raquel, 50msm, $1^{\circ} 4^{\prime} \mathrm{S}$ e 4659”W, 3. III. 2006, M.B.R. Caruzo \& R. Riina 98 (SP 84397, WIS); Carajás, estrada do N5, 25. X. 1985, R. Secco \& O. Cardoso 618 (MBM 193946, MG 131839); E.F.B. Igarapé-Assú, fl, 1. II. 1903, R.S. Rodriguez s.n. (INPA 11507, MG 3380); EMBRAPA, Amazônia Ocidental, Belém, 18. III. 1999, A.F.S. Sobrinho s.n. (IAN, INPA 218867); Faro, fr., 28. I. 1927, A. Ducke s.n. (RB 7432, US 1617625); Lageira, airstrip, on Rio Maicuru, alt. ca. 800ft, 0555’S e 54²6’W, 2. VIII. 1981, J. J. Strudwick et al. 3989 (INPA 125579, MG, NY); Marabá, Serra dos Carajás, N-1, fr., 19. I. 1985, O.C. Nascimento \& R.P. Bahia 913 (MG 115549); Obidos, fl., 2. XII. 1926, A. Ducke s.n. (RB 10279, US 161726); Porto Trombetas, Casa da Memória, 01²7’53’’S e 56²2’38’’W, 14. XI. 2000, S.M. Faria et al. 2115 (RB 376863); R. Tapajós, Villa Braga, 9. I. 1918, A. Ducke s.n. (MG 16904); Região dos Tiriós, rio Paru do Oeste, fr., 22. III. 1962, Dr. Fittkau \& D. Coelho s.n. (INPA 12782); Rio Branco de Obidos, 16. VII. 1918, A. Ducke s.n. (RB 10275); Rio Paru de Oeste, Missão Tiriyo, arredores da aldeia Paimeru, $2^{\circ} 20^{\prime} \mathrm{S}$ 5545’W, fl., 10. II. 1970, P. Cavalcante 2333 (IAN 122268, MG 37482); Santarém, Serra Diamantina, fr., 14. XII. 1966, P. Cavalcante \& M. Silva 1772 (MG 32439, SP 111017); Santarém, Belterra, Porto Novo, 02. XII. 1978, M.G.A. Lobo et al. 21 (MG 65169); Santarém, Alter do Chão, Jardim de Dona Concha, 9. VII. 1982, L.C. Blanch 126 (INPA 106293); Santarém, Alter do Chão, Jardim de Dona Concha, 27. VII. 1982, L.C. Blanch 1193 (INPA 106355); Serra dos Carajás, 20-25 Km NW of fr., Serra Norte mining camp. Approx. 5²6’'S e 50²6’W, 6. XII. 1981, fl., fr., D.C. Daly et al. 1756 (INPA 117236, MG 89742, NY, US 3038379); Serra de Santarém, fl., 17. I. 1933, A. Ducke s.n. (RB 24883); Tucuruí dam area, Rio Tocantins, Jatobal, área to be flooded by Tucuruí dam, município de Jacundá, margin of rio Tocantins, fl., 21. X. 1977, A.S. Silva et al. 101 (MG 58865, RB 252800); Usina Hidroelétrica de Tucuruí, PA 263, fr., 26. I. 1989, E.A.M. Lins 311 (GUA 41263); Viseu, próximo ao lugarejo Fazenda Imperial, 15. II. 1968, P. Cavalcante 1933 (MG 35174). MARANHÃo: Bom Passar, aproximandamente a 
24 Km de Peritoró na estrada BR316, entre Peritoró e a bifurcação para Codó, um pouco

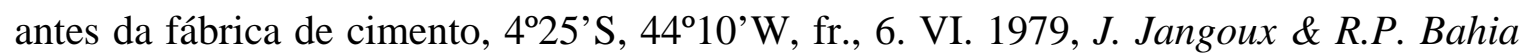
1051 (INPA 145536, MG 83872); Fazenda Bacaba, Doctor Aroldo, 5 Km S of MA 119 from entrance $3 \mathrm{Km}$ NW of Lago do Junco, 4²6’'S, 4458’W, fl., 3. X. 1980, D.C. Daly et al. 435 (HRB 13969, INPA 116483, MG 88519, MICH, NY, US 3111557); Funai, a 40 Km da cidade do Arame, fr., 14. III. 1983, R. Vilhena et al. 1011 (MG 103789); Island of São Luiz, fl., II. 1939, R. Fróes \& B.A. Krukoff 11537 (MICH, NY, US 1905811); Maracassumé River Region, "Santa Maria”, fr., 28. IV. 1932, R. Fróes \& B.A. Krukoff 1701 (MICH, US 1660094); Morro do Finca, arredores de campos de pinheiro, fr., 06. VII. 1978, N.A. Rosa \& O. Cardoso 2532 (MG 61243); Reserva Florestal do Sacavem, S. Luis, fl., 11. II. 1993, F.H. Muniz 220 (HRCB, INPA 184739, UB); Reserva da Vale do Rio Doce, 04. IV. 1988, R.S. Secco \& N.A. Rosa 773 (MG 131958); Santa Luzia, Fazenda Agripec da Varig, margem esquerda do rio Pindaré, fr., 02. IV. 1983, M.G. Lobo et al. 329 (MG 103723, SPF 127910, US 3301489); Santa Rosa, Município de São Vicente, 30, IV. 1998, R. Secco \& N.A. Rosa 902 (MG 153901); São Luiz, arredores da estiva, 06. VIII. 1980, M.G. Silva 5660 (MG 84487). MAto Grosso: s.proc., fl., 1891, S. Moore 613 (R 6532); Barra do Bugres, Fazenda Oschsenfeld, 23. X. 1995, fl., G. Hatschbach et al. 63776 (MBM 184920). RondôNiA: Guarajá-Mirim, fr., 3. IV. 1976, M.R. Cordeiro 969 (IAN152508); Estrada Porto Velho- Cuiabá, margem esquerda da linha 608, 4 km dentro da mata de terra firme, solo argiloso, fr., 15. II. 1983, C.A.A. Freitas et al. 119 (INPA 111126, MBM 108714, MO); Mineração Taboca, at Massangana (ca. 35 Km

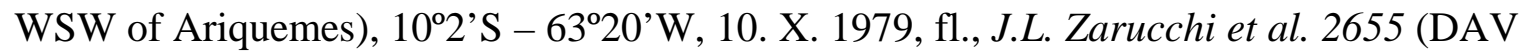
105782, INPA 90125, MG 70607, NY, RB 237409); Mineração Campo Novo BR 421 a $2 \mathrm{~km}$ a oeste da mineração de Campo Novo a $120 \mathrm{~km}$ de Ariquemes WSW, $10^{\circ} 35^{\prime}$ S e 63³7’W, fl., 13. X. 1979, G. Vieira et al. 398 (INPA 88723, MG 74476, MO, NY); T.F. de Rondônia a $13 \mathrm{Km}$ de Vilhena, Km 20, base da chapada dos Parecis, $12^{\circ} 45^{\text {'S }}$ 60¹0’W, fl., fr., 2. XI. 1979, M.G. Vieira et al. 864 (INPA 89187, MG 74854, RB 235844). PERU. MAdRE De Dios: Tambopata Province Las Piedras, Cusco Amazónico, 200m, 12²9’S 6903’W, 17. X. 1991, M. Timaná \& n. Jaramillo 2664 (MO, WIS); Tambopata Province Las Piedras, Cusco Amazónico, 200m, 12²9’S 6903’W, 28. X. 1991, M. Timaná \& n. Jaramillo 2843 (MO, WIS). BOLÍVIA. SANTA CrUZ: Guarayos, $40 \mathrm{~km}$ al SW de rio San Matín, $14^{\circ} 30^{\circ} \mathrm{S}, 62^{\circ} 06^{’} \mathrm{~W}, 200 \mathrm{msnm}$, fl., 26 Oct - 05 nov 1992, I.G. Vargas et al. 1778 (MO 4795466, USZ); Velasco, Parque Nacional Noel Kempff Mercado, Los Fierros, pie de monte, 14³4’33’’S 6049’50’’W, 200 m, fl., 23. X. 1993, 
T. Killeen et al. 5917 (DAV 130842); Velasco, Parque Nacional Noel Kempff Mercado, 14³3’28’’S 6055’51’’W, 230m, fl., 12. X. 1996, T. Killeen 8119 (DAV 152815, MO 5572855, USZ); Velasco, Camino a las mechitas, a 8Km de regreso del aserradero Cerro Pelado, a la orilla de un arroyo, siguiendo el curso hacia abajo, $14^{\circ} 32^{\prime} 35^{\prime}$ 'W 61²9’52'’S, 450m, fr., 23. I. 1997, J. Guillen et al. 265 (DAV 152813, USZ); Velasco, camino a las Mechitas, a 8km de regreso del aserradero Cerro Pelado, a la orilla de un arroyo, siguiendo el curso hacia abajo, 14³2'35'’'W 61²9'52'’'s, 450m, 23. I. 1997, fr., J. Guillen et al. 268 (USZ); Velasco, Parque Nacional Noel Kempff Mercado, Campamento Las Gamas, ecotonos de bosque alto, pampa, cerrado y bosques de galería, 14²8'17'’S 60²3'14'’W, 850 m.s.n.m., fr., 22. II. 1997, U. Guardia \& Surubi 253 (DAV 152949, USZ).

3. Croton campanulatus Caruzo \& Cordeiro, Brittonia 60(3): 261-264. 2008. (Anexo 1). Tipo: Brasil, Rio de Janeiro, Itatiaia, Parque Estadual do Itatiaia, estrada para a piscina do

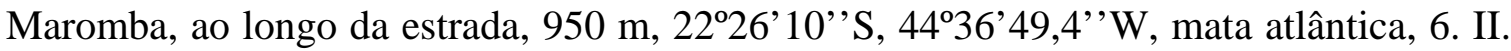
2006, M.B.R. Caruzo, R. Riina \& N. Camps 93 (holótipo: SP!; isótipos: K!, NY!, SPF!, WIS!). (Figs. 3 A-F, 11 A-K).

Árvores 4-5m alt., látex avermelhado, tricomas lepidotos subinteiros; ramos cilíndricos; ramos jovens fortemente estriados, lepidotos, tricomas lepidotos subinteiros, rufo-argênteos. Folhas inteiras, discolores, ovais, ápice acuminado, base arredondada a truncada; lâmina 3,5--17,5x1,5--9,5cm, margem inteira; face adaxial esparsamente lepidota, tricomas lepidotos subinteiros, alvo-prateados, face abaxial densamente lepidota, rufo-argêntea, tricomas lepidotos subinteiros, alvo-prateados, tricomas lepidotos subinteiros rufo-argênteos principalmente sobre as nervuras; nervação pinada, camptódroma, broquidódroma, nervuras terciárias percurrentes, inconspícuas; pecíolo 0,7--9cm, 1 par de glândulas acropeciolares, pateliformes, estipitadas; estípulas linearlanceoladas, 3--5mm compr., caducas. Inflorescências 4--12cm, terminais, laxas; raque achatada, estriada, lepidota, rufo-argêntea; címulas contíguas, as proximais bissexuadas, 1--2 flores masculinas e 1 flor feminina, as distais masculinas, ca. 3 flores; brácteas ca. 4--9mm compr., inteiras, oval-lanceoladas, profilos 1--2mm compr., lanceolados. Flores masculinas 8--9mm compr., campanuladas, gamossépalas, pediceladas; pedicelo 2--3mm compr.; cálice ca. 4mm compr., lepidoto externamente, tricomas lepidotos subinteiros, rufo-argênteo, glabro internamente; lobos do cálice 5, unidos até a metade, ca. $2 \mathrm{~mm}$, inteiros, iguais, valvares, triangulares a ovais, ápice agudo; pétalas ca. 5mm compr., 
espatuladas, ápice obtuso a arredondado, lepidotas externamente, tricomas estreladolepidotos, vilosas nas margens; 5-segmentado; estames ca. 25, filetes subulados, vilosos na base, anteras elipsóides; receptáculo viloso, tricomas simples. Flores femininas 8-10mm compr., campanuladas, sésseis a curtamente pediceladas; cálice 7--9mm compr., lepidoto externamente, tricomas lepidotos subinteiros, rufo-argênteos, glabro internamente; lobos do cálice 5, 7--9mm compr., inconspicuamente unidos na base, quincunciais, largamente ovais, ápice agudo a acuminado; pétalas reduzidas a glândulas ovóides; disco inteiro, profundamente 5-lobado; ovário globoso, lepidoto, tricomas lepidotos subinteiros; estiletes 4-fidos, levemente unidos na base, inclusos, recobertos por tricomas lepidotos subinteiros. Fruto ca. $1,5 \mathrm{~cm}$, globoso, liso, lepidotos, tricomas lepidotos subinteiros, lobos do cálice conspicuamente acrescentes, inflados no fruto jovem, não revolutos no fruto maduro; sementes ca. 6--8mm, globoso-elipsóides; testa lisa.

Ocorre no Brasil nos Estados de Minas Gerais e Rio de Janeiro em floresta pluvial montana, entre 900 e 1500 m de altitude. Foi coletada com flores nos meses de janeiro a maio, setembro, novembro e dezembro, e frutos em abril, maio, agosto, novembro e dezembro.

Croton campanulatus é uma espécie endêmica do maciço do Itatiaia, na Serra da Mantiqueira. Na mesma região também é encontrado C. organensis Baill., outra espécie de Cleodora, e C. vulnerarius Baill., espécie lenhosa da seção Cyclostigma Griseb.

Dentre as espécies de Cleodora, Croton campanulatus é mais semelhante a $C$. hemiargyreus Müll.Arg., dele diferindo principalmente pela coloração do indumento (rufo-argênteo em C. campanulatus vs prateado em C. hemiargyreus), margem foliar (inteira em C. campanulatus vs denteada em C. hemiargyreus), número de estames (25 em C. campanulatus vs 15 C. hemiargyreus), além de outras características vegetativas e florais (ver Tab. 4).

Outra espécie da seção que pode ser confundida com Croton campanulatus é $C$. salutaris. De fato, várias coleções de C. campanulatus encontravam-se erroneamente identificadas como C. salutaris, mas as duas espécies distinguem-se pela forma e ornamentação dos ramos (lisos e cilíndricos em C. campanulatus vs. costados e angulosus em C. salutaris), número de estames (ca. 25 em C. campanulatus vs ca. 15 em C. salutaris) e cálice das flores femininas (campanulado em C. campanulatus vs ampuliforme em C. salutaris). 
Material examinado: BRASIL. Minas Gerais: Bocaína de Minas, distrito de Mirantão, margem esquerda do rio Preto, fazenda Mauá, cerca de 1500 msm, fl., 9. I. 1988, R.B. Pineschi 348 (GUA 33605); Piedade do Rio Grande, córrego das águas limpas, fr., 17. XI. 1990, A. Souza s.n. (R 182858). Rio de Janeiro: Itatiaia, 20. I. 1873, Glaziou 6679 (P); Itatiaia, fl., fr., 30. V. 1935, Brade 14650 (RB 26111, MG, RUCA); Itatiaia, fl., 08. I. 1947, A.P. Duarte \& E. Pereira s.n. (MG 49548, RB 60829); Itatiaia, Parque Nacional de Itatiaia, Três Picos, 1200 m, 27. III. 1948, Cunha Mello s.n. (RB); Itatiaia, P. Nacional, 950 m alt., fl., 4. III. 1962, E. Pereira 6974 (MBM, HB 15858); Itatiaia, Donati, fl., 20. IV. 1962, A. Castellanos 23418 (GUA 1566); Itatiaia, Hotel Donati, fr., 21. IV. 1962, H.E. Strang 411 (GUA 1536); Itatiaia, Hotel Donati, fl., IX. 1964, H.E. Strang s.n. (GUA 4468); Itatiaia, Parque Nacional de Itatiaia, Três Picos, 1200msm, $22^{\circ} 15^{\prime}-22^{\circ} 28^{\prime} \mathrm{S}$ e $44^{\circ} 34^{\prime}-44^{\circ} 45^{\prime} \mathrm{W}$, fl., 27. III. 1995, R. Guedes et al. 2536 (RB 348829); Itatiaia, Parque Nacional de Itatiaia, Ponte do Maromba, $22^{\circ} 15^{\prime}-22^{\circ} 28$ 'S e

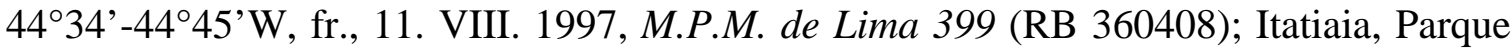
Nacional de Itatiaia, Trilha do Hotel Simon para os três picos, $22^{\circ} 15^{\prime}-22^{\circ} 28^{\prime}$ S e $44^{\circ} 34^{\prime}$ 44²5’W, fl., 09. XI. 1997, L. Sylvestre et al. 918 (RB 333946); Itatiaia, Parque Nacional de Itatiaia, Trilha do Hotel Simon para os três picos, $1200 \mathrm{msm}, 22^{\circ} 15^{\prime}-22^{\circ} 28^{\prime} \mathrm{S}$ e $44^{\circ} 34^{\prime}$ 44²5’W, fr., 18. V. 1999, A. Quinet 201 (RB); Itatiaia, Parque Estadual do Itatiaia, entre a piscina do Maromba e a ponte do Maromba, as margens do rio Campo Belo, $1100 \mathrm{msm}$, 22 $2^{\circ} 15^{\prime}-22^{\circ} 28^{\prime}$ S, $44^{\circ} 34^{\prime}-44^{\circ} 45^{\prime} \mathrm{W}$, mata atlântica, fl., 06. II. 2006, M.B.R. Caruzo, R. Riina \& N. Camps 94 (SP, SPF, WIS); Itatiaia, Parque Estadual do Itatiaia, estrada para a

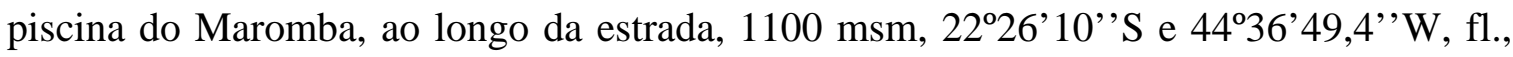
fr., 18. XI. 2008, M.B.R. Caruzo \& L.R. Lima 123 (SP); Parque Nacional de Itatiaia, fl., 05. III. 1948, Cunha Mello s.n. (RB 66479); Rezende, Parque Nacional de Itatiaia, perto do Museu e do abrigo n² 21, fl., 18. X. 1977, V.F. Ferreira \& Briolanjo 157 (RB 180401, SP 382692); Serra da Mantiqueira, Itatiaia, National Park, $N$ of Itatiaia, roads to and environments of Maromba falls, 900 m, 5. IX. 1973, Ehrendorfer \& Gottsberger 7390522.40 (DAV); Visconde de Mauá, trilha para a cachoeira do Alcantilado, fl., 16. XI. 2007, L.R. Lima \& R.R. Rodrigues 469 (SP 399322).

4. Croton croizatii Steyerm., Fieldiana Bot. 28(2): 312. 1952. Tipo: Venezuela, Mérida, “between Hacienda Agua Blanca above La Azulita and Río Capaz, altitude 975 meters”, 25. IV. 1944, J.A. Steyermark 56124 (holótipo: F!; isótipos: NY!, VEN!). (Figs. 12 A-E). 
Arbustos a árvores 4--10m alt., látex acastanhado, tricomas lepidotos subinteiros, estrelado-lepidotos e adpresso-estrelados; ramos cilíndricos; ramos jovens estriados, flocosos, tricomas lepidotos subinteiros, estipitados. Folhas inteiras, fortemente discolores, elípticas a ovais, ápice acuminado a longamente acuminado, base subcordada a cordada; lâmina 5--16,5x3--9cm, margem inteira a inconspicuamente serrilhada, geralmente com glândulas; face adaxial glabrescente, com esparsos tricomas estreladolepidotos, geralmente porrectos, face abaxial lepidota, argêntea, com pontuações ferrugíneas esparsas sobre a lâmina e nervuras, tricomas lepidotos subinteiros; nervação pinada, camptódroma, broquidódroma, nervuras terciárias percurrentes, oblíquas, levemente sinuosas; pecíolo 1--3cm, com 1 par de glândulas basilaminares, pateliformes, sésseis; estípulas 2--3mm compr., inteiras, ovais, ápice agudo a acuminado. Inflorescências 5--15cm compr., laxas, ramificadas, terminais ou axilares; raque achatada, estriada, flocosa, tricomas estrelado-lepidotos, estipitados; címulas contíguas, as proximais femininas, unifloras, as distais masculinas, unifloras; brácteas 2--6 mm compr., ovais, margem inteira ou lobada, ápice agudo a acuminado, profilos 2--4mm compr., lineares. Flores masculinas ca. $1 \mathrm{~cm}$, campanuladas, pediceladas; pedicelo ca. 5mm; cálice ca. 4mm, lepidoto externamente, argênteo-ferrugíneo, com tricomas lepidotos subinteiros, glabro internamente; lobos do cálice 5, unidos até a metade, ca. $2 \mathrm{~mm}$, inteiros, iguais, valvares, triangulares, ápice agudo, vilosos na margem; pétalas ca. 4mm, lanceoladas, ápice arredondado, vilosas externamente; disco 5-segmentado; estames ca. 15, filetes subulados, vilosos na base, anteras elipsóides; receptáculo viloso, tricomas simples. Flores femininas ca. $7 \mathrm{~mm}$, campanuladas, pediceladas; pedicelo ca. 2mm; cálice ca. 5mm, lepidoto externamente, argênteo-ferrugíneo, com tricomas lepidotos subinteiros, glabrescente internamente; lobos do cálice 5, unidos na porção basal, ca. 5mm compr., inteiros, iguais, reduplicado-valvares, largamente ovais, ápice agudo a curtamente acuminado, ás vezes com uma nervura central proeminente, evidente principalmente no fruto maduro; pétalas ausentes; disco inteiro, rasamente 5-lobado; ovário subgloboso, hirto-tomentoso, tricomas adpresso-estrelados, porrectos; estiletes multífidos, unidos na base, inteiros até a metade, inclusos, recobertos por tricomas adpresso-estrelados. Fruto ca. 1cm, subgloboso, trígono, liso, adpresso-estrelados, porrectos, lobos do cálice inconspicuamente acrescentes; sementes ca. $5 \mathrm{~mm}$, subglobosas; testa verruculosa. 
Ocorre na Colômbia e Venezuela, nas florestas pluviais das encostas inferiores da Cordilheira Oriental e Central dos Andes, entre 800 e 1670 m de altitude. Foi coletada com flores em janeiro, abril, maio, junho e novembro, e com frutos em janeiro, maio, junho, agosto e novembro.

Dentre as espécies de Cleodora, Croton croizatii é mais semelhante a C. orinocensis, espécie amazônica das florestas de terra firme do Brasil, Colômbia e Venezuela, da qual se distingue por suas inflorescências laxas e com címulas basais unissexuadas (vs. congestas, com címulas basais bissexuadas em C. orinocensis) e estiletes multífidos (vs. tetrafidos em C. orinocensis).

Material examinado: COLÔMBIA. MAgDALENA: Alrededores de San Javier, 1300 m, fl., fr., 21. I. 1959, R.R. Castañeda 7008 (COL 79782). ToLiMA: Venadillo, Vereda San Antonio, Finca Los Alpes, Cordillera Central, vertiente oriental, 1670 m, 7. VIII. 1980, J.M. Idrobo et al. 10689 (COL 217480); Venadillo, Vereda San Antonio, Finca Los Alpes, Cordillera Central, vertiente oriental, 1670 m, 7. VIII. 1980, J.M. Idrobo et al. 10699 (COL 277674). VENEZUELA. BARINAS: De Altamira a Calderas, 850-1000 m, fl., fr., 30. V. 1957, L. Bernardi 6861 (MER 7966). FalCón: Cerro Socopo, east side above Socopito, $10^{\circ} 30^{\prime} \mathrm{N}, 7^{\circ} 45^{\prime}$ W, fr., 28. VI. 1979, R. Liesner et al. 8273 (VEN 166618). Mérida: 11 km from Caño Zancudo along road to La Azulita, 800 m, fl., fr., 2. IX. 1965, F.J. Breteler 4575 (COL 112201, MER, VEN 66348, US 2582986); Blanquillio, fl., 29. VI. 1955, Bernardi 2333 (MER 7951). TÁchIRA: A lo largo de la carretera San Cristóbal-La Florida, entre el Salto del Indio y Macanillo, 1200-1300 m, fr., 10. IX. 1984, J. Bono 4229 (VEN 312034). ZuLIA: Lagunillas, cuenca del Embalse Burro Negro (Pueblo Viejo), laderas occidentales de la Serrania de Ziruma o El Empalado, a lo largo del río Grande, unos 13 km al norte del Embalse, 10²5’ N, 7049’W, 550-600 m, fl., 1-5. IV. 1982, G.S. Bunting et al. 11224 (VEN 378128).

5. Croton fragrans Kunth, Nov. Gen. Sp. 2: 81. 1817. Tipo: "Crescit locis calidis, frondosis prope Honda Novogravatensium, in ripa Magdalenae et in via ad urbem Guaduas in radicibus montis El Sargento", Humboldt s.n. (holótipo: G!). (Figs. 3 H-I, 4 A-C, 12 F-K).

Nomes populares: “almizolero”, “sarna” 
Arbustos a arvoretas, 1,5--3,5m alt., látex incolor, tricomas multiradiados, rosulados e estrelados; ramos quadrangulares; ramos jovens estriados, tomentosos, com tricomas multiradiados e rosulados. Folhas inteiras, discolores, ovais, ápice acuminado a longamente acuminado, base arredondada a obtusa; lâmina 8--21x3--12cm, margem serrilhada a miudamente serrilhada, com glândulas; face adaxial pubescente a esparsamente pubescente, tricomas simples e estrelados, face abaxial densamente pubescente a pubescente, tricomas estrelados e multiradiados; nervação pinada, craspedódroma, mista, nervuras terciárias percurrentes, oblíquas, levemente sinuosas; pecíolo 0,8--1,7 cm compr., com 1(2) pares de glândulas acropeciolares, pateliformes, curtamente estipitadas; estípulas 6--10 mm compr., profundamente laceradas, largamente ovais. Inflorescências 8--18 cm compr., laxas; raque cilíndrica, estriada, tomentosa, tricomas estrelados e multiradiados; címulas contíguas, as proximais bissexuadas, 1 flor masculina e 1 flor feminina, as distais masculinas, trifloras; brácteas 4--7mm compr., laceradas, ovais, ápice acuminado, profilos 2-4mm compr., linear-lanceolados. Flores masculinas 0,8--1,1cm, subcampanuladas, longamente pediceladas; pedicelo 4--6mm; cálice 3--5mm, densamente pubescente externamente, tricomas multiradiados e rosulados, glabro internamente; lobos do cálice 5, unidos até a metade, ca. 2mm, inteiros, iguais, valvares, ovais, ápice agudo, vilosos na margem; pétalas 4--5mm, espatuladas, ápice arredondado, ondulado, recortado, vilosas nas margens; disco 5-segmentado; estames ca. 15, filetes subulados, vilosos nas margens, anteras elipsóides; receptáculo viloso, tricomas simples. Flores femininas 6--8mm, campanuladas, curtamente pediceladas; pedicelo 2-3mm; cálice 4--5mm, densamente pubescente externamente, tricomas multiradiados e rosulados, glabro internamente; lobos do cálice 5, unidos na porção basal, 3--4mm compr., inteiros, iguais, reduplicado-valvares, triangulares, ápice acuminado; pétalas ausentes; disco rasamente 5-lobado; ovário subgloboso, recoberto por glândulas digiformes; estiletes multifidos, unidos na base, inclusos, inteiros no terço inferior, multifidos, recobertos por glândulas digiformes. Fruto 1--1,5cm, subgloboso, trígono, liso, recoberto por glândulas digiformes, lobos do cálice conspicuamente acrescentes, inflados nos frutos jovens; sementes $4--5 \mathrm{~mm}$, subglobosas; testa costada.

Ocorre na Colômbia, Venezuela e Panamá em florestas pluviais das encostas inferiores dos Andes, e costa caribenha da Colômbia e Panamá, em florestas estacionais, do nível do mar até $800 \mathrm{~m}$ de altitude. Foi coletada com flores em janeiro, e de abril a dezembro, e com frutos de abril a novembro. 
A espécie pode ser reconhecida no campo por seus ramos quadrangulares, folhas ovais com margem serrilhada e estípulas largamente ovais e profundamente laceradas. Dentre as espécies das seção Cleodora, Croton fragrans mais assemelha-se a $C$. fragrantulus, dele diferenciando-se pelos ramos (quadrangulares em C. fragrans vs cilíndricos em C. fragrantulus), estípulas (ovais e profundamente laceradas em $C$. fragrans vs lineares em C. fragrantulus), pelos lobos do cálice das flores femininas (unidos na porção basal em $C$. fragrans vs unidos até a metade em $C$. fragrantulus) e ramos dos estiletes (multifidos em $C$. fragrans vs tetrafidos em $C$. fragrantulus).

Webster (1993) posicionou Croton fragrans na seção Lasiogyne, principalmente pela prefloração reduplicado-valvar das flores femininas, característica desta seção. Apesar de apresentar o tipo de prefloração que Webster considerou típica das Lasiogyne, C. fragrans emergiu juntamente com as outras espécies de Cleodora (Cap. 1) e, além disso, compartilha com as Cleodora várias características morfológicas, como folhas com glândulas na base, inflorescências com címulas basais bissexuadas e estiletes unidos na base formando uma "coroa”.

Pela semelhança entre as espécies, algumas coleções de Croton fragrans do Panamá foram erronemente identificadas como C. hoffmannii. Essas duas espécies diferenciam-se pelos ramos (quadrangulares em $C$. fragrans vs cilíndricos em C. hoffmannii), margem das estípulas (profundamente laceradas em C. fragrans vs inteira em C. hoffmannii), prefloração das flores femininas (reduplicado-valvares em $C$. fragrans vs imbricadas em C. hoffmannii) e lobos do cálice nos frutos (conspicuamente acrescentes e inflados em $C$. fragrans vs inconspicuamente acrescentes e não inflados em C. hoffmannii).

Material examinado: PANAMÁ. CANAL Zone: Espave forest along Albrook-Ft. Clayton dump road, fl., 5. VIII. 1963, J.A. Duke \& H.W. Mussell 6624 (MO, WIS); K-9 road in Canal Zone at bridge, fr., 17. VII. 1959, W.L. Stern et al. 977 (COL 116001); Road C2C on Cerro Luisa, fl., 7. VI. 1970, T.B. Croat 10782 (MO 2029031). Darien: Trail from Pinogama to Yaviza, fl., 8. VII. 1962, J.A. Duke 5157 (MO 1811476). Panamá: Camino a Nuevo Emperador. Cerca de Arraiján, VIII. 1969, A. de Rodríguez 17 (MO 2042717). SAN Blas: Aligandi, fr., 25. VI. 1965, J.D. Dwyer 6812 (MO 1881207).

COLÔMBIA. Cartagena, fr., 1919, B. Heriberto 128 (US 1036893); Cartagena, fl., 1920, B. Heriberto 350 (US 1044433); S. proc., s.d., J.C. Mutis 813 (US 1563770); S. 
proc., fr., s.d., J.C. Mutis s.n. (US 1563097); Plants os Santa Maria, fl., 1898-1901, H.H. Smith 363 (WIS, US 532913); Espinal to Cuamo, 350-400 m, fr., 21. VII. 1917, F.W. Pennell \& H.H. Rusby 181 (US 1041264). ANTIOQUIA: Alrededores de la Coqueta, municipio de Tamesis, a unos 800 m de altura, fl., 5. IV. 1955, M. de Garganta 2006 (US 2816070); La Pintada, alt. 800 m, III. 1963, S. Espinal T. 890 (COL 100870); Fredonia, Pto. Iglesias, fl., 24. VI. 1940, B. Tomas 822 (US 1800013); La Pintada, cerca a puente Iglesias, 5²7’ N, 75³9’W, alt. 750-800 m, fl., alt. 600-700 m, 09. V. 2001, J.C. Marrugo G 92 (COL476494); La Pintada, Hacienda Mone Negro, 547’N, 75³9’W, alt. 750-800 m, fl., 06. VIII. 2001, J.A. Perez Z. et al. 1724 (COL 476435). ATLANTico: Sabanalarga, carretera a Molinegro, 50 m, fl., VI. 1938, A. Dugand 1198 (US 1743044). BoLívar: Carretera Sincelejo a Tolú, en Sabanas, alt. 0-30 m, fl., 03. VI. 1950, H. Garcia-Barriga 13460 (COL 37184, US 2045311); Cerro de Maco, 600 m altitud, fr., 22. VIII. 1984, H. Cuadres V. 1870 (COL 312364); San Martin de Loba, Lands of Loba, fl., IV-V. 1916, H.M. Curran 187 (US US 537211); San Martin de Loba, Lands of Loba, fl., fr., IV-V. 1916, H.M. Curran 51 (US 537360). CHocó: Acandí, Ogiento de Unguía, Reserva Indígena Cuna de Arquía, 100 m alt., fl., 11. VI. 1976, L.E. Forero 331 (COL 176962); Hacienda Sautatá, fl., fr., 22. VI. 1957, R. Romero-Castañeda 6325 (COL 81691); Parque Nacional Natural Los Katíos sector Sautatá alrededores, fl., fr., 14. V. 1982, S. Zuluaga R. 828 (COL 294302); Riosucio, Parque Natural Nal. Los Raytes, Camino Sautatá-Tilupo, 70 m alt., fl., fr., 04. VII. 1976, M. León 192 (COL 271619, MO 2478650). CundinAmARCA: Guaduas, carretera a Guaduero, alt. 1000 m, fl., XII. 1952, L.U. Uribe 2389 (COL 39713). Huila: Below Boca Saldaña, 400 m, fl., 13. VIII. 1917, H.H. Rusby \& F.W. Pennell 1198 (US 1041652). MAgdalenA: Alrededores del la quebrada "El Cedro”, 350-400 m.s.n. fl., X. 1979, L.M. Moreno B. 450 (COL 211777); Sierra Nevada de Santa Marta, Parque Nacional Tayrona, fl., fr., 20. VI. 1983, C. Barbosa et al. 1802 (COL 269249); Roadside 5 km north of Bercerril, altitude about 140 m, fl, 17. IX. 1943, O. Haught 3681 (COL 22117, US 1708523). NORTE DE SANTANDER: Mariquita, hillside scrub along Fresno rd., fairly dry, c. 300 m, fl., 22. VII. 1957, P.J. Crub et al. 44 (COL 85596). Tolima: Mariquita, alt. 500 m, fl., fr., 09. XI. 1938, O. Haugth 2426 (COL 6897, MO 1188217, US 1707059); Mariquita, en el bosque del acueducto, 550 m alt., fl., fr., 26. XI. 1956, L.U. Uribe \& M. Villarreal 2852 (COL 50294); Mariquita, hillside scrub along Fresno rd., fairly dry, 300 m, fl., 22. VII. 1957, P.J. Grubb et al. 44 (US 2279108); Mariquita, bosque 2 km SO del pueblo, alt. 550 m, fl., fr., 26.XI. 1984, $R$. Bernal et al. 794 (COL 294922); Valle del Alto Magdalena, La Chamba, alt. 400 m, fl., 
01. IX. 1962, L.U. Uribe 4130 (COL 95305). VENEZUELA. Amazonas: Selva húmeda, a lo largode la carretera hacia Cerro Morrocoy, 3-4 km. Al Oest de San Juan de Manapiare, 5ำ' $18^{\prime}, 66^{\circ} 10^{\prime} \mathrm{W}, 200$ m, fl., 20. VI. 1977, J.A. Steyermark et al. 113936 (VEN, MO 2672485). BARINAs: Barinas, carretera Barrancas, fr., 23. VII. 1966, L.M. Berti 1040 (MER 27988, PORT 13037); Barinas, 15 km N of Barinas, 5 km NW of El Pescado on road from La Yuca, forest along river, 847’ N, 70¹4’ W, 200-250 m, fl., 28. IV. 1981, R. Liesner \& M. Guariglia 11510 (MO, VEN 163867); Barinas, 15 km N of Barinas, $5 \mathrm{~km} \mathrm{NW}$ of El Pescado on road from La Yuca, forest along river, 8 $47^{\prime} \mathrm{N}$, 70¹4’W, 200-250 m, fl., 28. IV. 1981, R. Liesner \& M. Guariglia 11511 (MO, VEN 163858, WIS); Barrinas, caño Morrocoy, San Sylvestre, 9 km aguas abajo de la descarga, 132 m.s.n.m., 3. XI. 2001, J. Farreras \& I. Schargel 394 (PORT 86619); Barrancas, río La Yuca, fl., 1. V. 1975, J. Bautista B. 3771 (MER 47816); Barrancas, fl., 1. VI. 1980, A. Quintero \& C. Hernandez P. 2268 (MER 32866); Bosque Caimital - Barrancas, s.d., Veillon 63 (US 2654214, VEN 89072); Caimital, distrito Obispos, 7 km al sur de la población de Barrancas, 170 m, fr., 14. X. 1961, L. Ruiz-Terán \& L. Marcano-Berti 766 (MER 7950); Carretera Barrancas - Ospino, fl., 24. V. 1984, L. Valverde \& O. Calderon 164 (MER 39480); Caserio, San José, carretera Barinas - Barrancas, fl., 5. VI. 1980, P. Salcedo \& J. Rodriguez 237 (MER 31754); Ticoporo Forest Reserve, 8¹5’ N, 7045’ W, 350 m, fr., 15. VII. 1964, F.J. Breteler 4018 (COL 112121, CUVC, IAN 125456, MBM 61674, MER, MO 2417069, US 2466006). BolívaR: Cedeño, area de pequeña mineria “El Guaniamo”, 6²7’N, 6552’W, 300 m.s.n.m., fl., V. 1993, W. Diaz 1656 (VEN 375053); Cedeño, tramo carretero a Guaniamo, inmediaciones del Fundo Pueblo Nuevo, fr., 20. VIII. 1997, C.E.B. de Rojas \& F. Rojas 5692 (MY, MO, VEN 373026); Danto Machado, Caño Mezcla, zona cercana al vaso del Guri, 220 m.s.n.m., 9. I. 1983, C. Hernandez \& G. Picon 14 (MER 39045); Danto Machado, Caño Mezcla, zona cercana al vaso del Guri, 220 m.s.n.m., fl., 12. I. 1983, C. Hernandez \& G. Picon 57 (MER 39044);

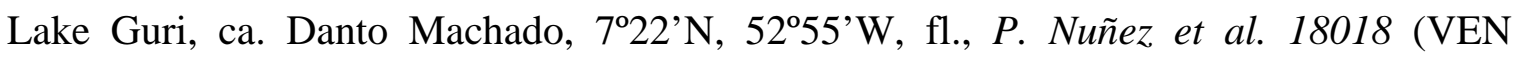
396818); Mata Negra, al Sur de El Tigre, 100 m, fl., 19. VI. 1940, L. Williams 13393 (US 1800615); Piar, Isla en el lago de Guri (Sector Danto Manchado) Bosques medios tropófitos en lomerio. 40 km al S de la Presa R. Leoni, 7³5’ N, 6258’ W, 270 m, fl., 25. VII. 1991, G. Aymard \& M. Norconk 9387 (MO 4281134, PORT 43287, VEN 350412). CARAвово: El Naipe, 500 m, fr., 14. IX. 1939, L. Williams 12203 (US 1778045). CoJEDES: Carretera Valencia - San Carlos, Sector El Apamate, Tinaquillo, $47 \mathrm{~km}$ antes de San Carlos, 9 54'13"N, 68 18'31.5"W, 430 m, 07. XII. 2008, R. Riina et al. 1824 
(VEN); El Socorro, cercanías hacienda Guayabal, dto. Tinaco de edo. Cojedes, 200 msm, fl., 3. VI. 1978, C.M.B. de Rojas 2214 (VEN 148441); Estrada Valencia - San Carlos, setor El Apamate, Tinaquillo, $47 \mathrm{~km}$ antes de San Carlos, próximo a uma casa ao lado da estrada, 9 54'13"N, 68 18'31.5"W, 430 m, 07. XII. 2008, M.B.R. Caruzo et al. 125 (SP); San Carlos, fr., VI. 1946, I. Velez 2764 (US 1905350); San Carlos, via Cacao, 3 km de Los Colorados, al lado de la carretera em zona de bosque deciduo, fr., 30. VIII. 1971, G.S. Bunting 4520 (VEN 296497); Via La Sierra, fl., VIII. 1975, F.D. Chitty 3328 (VEN 106889). Distrito Federal: Caracas, Reforested hills of the Caracas Botanical Gardens, 870-980 m, fl., 30. IX. 1974, P.E. Berry 298 (VEN 168930). LARA: 30 km SW of Barquisimetro near road to Cerrata, lowland rain forest, secundary growth, fr., 22. VII. 1979, W. Meijer et al. 290 (F 2100892, MO). Portuguesa: Araure, a $10 \mathrm{~km}$ de La Lúcia hacia el sitio de Los Tanques, 300 m, fr., 29. VI. 1982, J.A. Casadiego \& J.G. Campos 402 (PORT 13036); Guanare, terrenos de la UNELLEZ, 94’N, 6949’W, 260 m.s.m., fl. 24. XI. 1980, F. Ortega \& B. Stergios 1111 (MO 2995163, PORT 887); Guanare, terrenos de la UNELLEZ, 94’N, 6949’W, fl., 11. IX. 1981, G. Aymard 158 (PORT 888); Guanare, terrenos de la UNELLEZ, 94’N, 69²4’’W, fl., 23. IX. 1981, G. Aymard \& F. Ortega 538 (PORT 894); Guanare, terrenos de la UNELLEZ, 94’’N, 69²49’W, fl., 6. VI. 1983, B. Stergios 5575 (PORT 7652); Guanare, lecho del rio Guanare, mesa de Cavacas, fl., 7. V. 1985, G. Aymard 356 I (PORT 12339); Mesa de Cavacas, entrada para o Campus da UNELLEZ, fr., 07. XII. 2008, M.B.R. Caruzo et al. 126 (SP); Mesa de Cavacas, entrada al Campus de la UNELLEZ, 07. XII. 2008, R. Riina et al. 1827 (VEN); Payara, fl., 30. V. 1979, F. Ortega 659 (PORT 8218); San Genaro de Boconoito, Carretera Guanare - Las Panelas, 100 m.s.m., fl., 2. VI. 1993, C.E.B. de Rojas et al. 4893 (MY, MO 5698118). YARACUY: A lo largo de la carretera entre Urama y San Felipe, fl., 30. VI. 1953, L. Aristeguieta \& F. Pannier 1799 (NY, VEN). ZuLIA: Carretera LaraZulia, a $200 \mathrm{mt}$ del desvio hacia Churuguarita, Distrito Miranda, fr., 23. XI. 1983, O. Zambrano-Luiz Alfonzo 1393 (VEN 274677); Cerca de El Venado, aldea en Km 85 de la carretera Maracaibo-Corora (Ed. Lara), en finca de Jesús Salas, , en bosque remanente de árboles grandes y siempre verdes, alt. 150-175 m, fl., 19. VII. 1977, G.S. Bunting \& L. Aristeguieta 5185 (VEN 166217); Jesús Maria Semprún, sector Los Manueles, 10-15km al NE de Casigua El Cubo, 30-60 m.s.n.m., 849’N, 72²9’W, fr., XI. 2001, A. Fernández 17936 (US 3439359); Límite Dtt. Bolívar-Baralt: a lo largo del río Misoa, em sitio 10 km al suroeste del empalme de las carreteras Maracaibo-Carora-Valera, 0,5-1 km de la carretera a lo largo del camino que sube hasta las torres de transmisión, em bosque 
siempre húmedo, 150-175 m, fl., 18. VI. 1977, G.S. Bunting \& L. Aristeguieta 5181 (VEN 166297); Mara, sandstone wooded bluffs along Río Socuy (northwest side), west of Cerro Caracara, $5 \mathrm{~km}$ southwest of Corpozulia campamento Socuy, $10^{\circ} 54^{\prime} \mathrm{N}, 72^{\circ} 20^{\prime} \mathrm{W}$, 80-90 m, fl., 2. VI. 1980, J.A. Steyermark et al. 123092 (F 2102470, VEN 165927); Mara, gravel and sand bars along Río Cachirí, bordered by riverine forest, just north of Hacienda Salamanca, 10 km (by air) southwest of El Paraíso, 1046'30’’N, 72²0'W, 150 m, fl., 6. VI. 1980, J.A. Steyermark et al. 123472 (F 2102469, MO, PORT 37848); Mara, cuenca del río Guasare, alrededores del Destacamento Guasare ํำ (La Yolanda), em las laderas del cerro ca. $5 \mathrm{~km}$. Al SSE del Destacamento, entre el caño Indio y la fila arriba de su orilla izquierda, en bosque húmedo ahora alterado, 1052'10' ' $\mathrm{N}, 72^{\circ} 29^{\prime} 30^{\prime}$ ' $\mathrm{W}, 250$ 300 m, fl., 16. XI. 1982, G.S. Bunting et al. 12410 (HERZU, MO 3390327, VEN 313294); Perijá, fr., 1917, E. Tejera 5 (US 897603); Sierra de Perijá, Caño Las Piscinas, VII. 1975, 730 m, F.D. Chitty 3251 (VEN 109359); Sierra de Perijá, rio palmas, 450 m.s.n.m., fl., 1976, J.O. Zambrano 302 (PORT 23762).

6. Croton fragrantulus Croizat, Darwiniana 6: 466. 1944. Croton paniculatus Müll.Arg. nom. illeg. Tipo: Peru, “prope Chacahuani”, Ruiz s.n. (holótipo: G!). (Figs. 13 A-E).

Arvoretas, 5--6m, tricomas estrelados, multiradiados e adpresso-estrelados; ramos cilíndricos; ramos jovens achatados, conspicuamente estriados, pubescentes, tricomas multiradiados, alvos. Folhas inteiras, levemente discolores, ovais, ápice agudo a acuminado, base cuneada a levemente truncada; margem miudamente serrilhada, com glândulas; lâmina 4,5--11 x 3--8cm; face adaxial glabrescente, esparsos tricomas estrelados e adpresso-estrelados, face abaxial pubescente, tricomas estrelados e adpressoestrelados, raro multiradiados; nervação pinada, camptódroma, broquidódroma, nervuras terciárias percurrentes, oblíquas, levemente sinuosas; pecíolo 1--3cm, 1 par de glândulas acropeciolares, pateliformes, sésseis; estípulas lineares, ca. $1 \mathrm{~mm}$ compr., caducas. Inflorescências 5--14cm, laxas, falsamente ramificadas; raque achatada, conspicuamente estriada, pubescente, tricomas multiradiados; címulas contíguas, as proximais bissexuadas, 1--2 flores masculinas e 1 flor feminina, as distais masculinas, 2--3 flores; brácteas ca. 3mm, inteiras, lineares; profilos ca. $1 \mathrm{~mm}$, lineares. Flores masculinas ca. $6 \mathrm{~mm}$, subcampanuladas, pediceladas; pedicelo ca. $2 \mathrm{~mm}$; cálice ca. $4 \mathrm{~mm}$, pubescente externamente, alvo, tricomas multiradiados, glabro internamente; lobos do cálice 5, unidos até a metade, ca. 2mm, inteiros, iguais, levemente imbricados, largamente ovais, 
ápice agudo, margem vilosa; pétalas ca. 4mm, estreito-ovais, ápice arredondado, vilosas externamente, tricomas simples, glabras internamente, margem vilosa; disco 5segmentado; estames ca. 15, filetes subulados, vilosos, tricomas simples, anteras elipsóides; receptáculo viloso, tricomas simples. Flores femininas 6--8mm, campanuladas, pediceladas; pedicelo 2--3mm; cálice ca. 4mm, pubescente externamente, alvo, tricomas estrelados e multiradiados, glabro internamente; lobos do cálice 5, unidos até a metade, ca. $2 \mathrm{~mm}$, inteiros, iguais, levememente imbricados, estreito-ovais, ápice agudo a acuminado, margem vilosa, presença de vincos na porção basal; pétalas ausentes; disco inteiro, profundamente 5-lobado; ovário subgloboso, piloso, tricomas multiradiados; estiletes 4-fidos, unidos na base, inteios até a metade, segmentos exsertos, recobertos por tricomas multiradiados até a metade; receptáculo viloso, tricomas multiradiados. Fruto não observados.

Ocorre disjuntamente no Peru, em um vale andino na região de Huánaco, de onde é referido seu tipo, e na região Chiquitana da Bolívia, em florestas estacionais, entre 400 e 600 m de altitude. No Peru é conhecida apenas por sua coleção tipo. Foi observada com flores nos meses de outubro e novembro.

Croton fragrantulus assemelha-se morfologicamente a C. rottlerifolius mas pode ser distinto desta última (Tab. 5) por apresentar ramos jovens e raque da inflorescência achatados e conspicuamente estriados (vs. ramos jovens e raque da inflorescência cilíndricos e levemente estriados em C. rottlerifolius), inflorescências falsamente ramificadas (vs. não ramificadas em C. rottlerifolius) e flores masculinas subcampanuladas com uma nervura central bem evidente nos lobos do cálice (vs flores masculinas campanuladas e sem nervura central evidente).

Material examinado: BOLÍVIA. SANTA Cruz: Nuflo Chaves, 14 km (by air) NW of San Javier, gap through range and slope on west side, Las Lajas, “El Chupadero”, 16010’S, 62³6’W, fl., 30. XI. 1990, M. Nee 40099 (NY, WIS); Nuflo Chaves, Careterra San Ignacio de Velasco - Santa Cruz $50 \mathrm{~km}$ al oeste de Concepción opuosto del desvio San Ramoncito, Modelo de desarollo Lechero, fl., 16. X. 1995, P.F. Foster 424 (MO, USZ).

7. Croton hemiargyreus Müll.Arg., Linnaea 34: 81. 1865. Tipo: Brasil, Minas Gerais, Caldas, Regnell 402 (lectótipo: S!, designado por Caruzo \& Cordeiro 2007; isólectótipos: 
G!, GH!, K!, NY!, P!, R!, US!, WU!); Widgren 339 (síntipo: A!, GH!). (Figs. 4 D-G, 13 F-I).

= Croton hemiargyreus var. gymnodiscus Müll.Arg. Fl. Bras. 11(2): 88. 1873. Tipo:

Brasil, Rio de Janeiro, Schott 4650 (holótipo: W!; isótipo G-DC!). (sinônimo proposto por Govaerts et al., 2000).

Arbustos a árvoretas 1,5--10m alt., látex incolor, tricomas lepidotos subinteiros e dentado-lepidotos porrectos; ramos cilíndricos; ramos jovens estriados, lepidotos, argênteos, lepidotos subinteiros. Folhas inteiras, discolores, ovais a cordiformes, ápice acuminado a longamente acuminado, base arredondada a cordada; lâmina 3--18x1,5-$13 \mathrm{~cm}$; margem inconspicuamente a conspicuamente serrilhada, geralmente com glândulas nas margens; face adaxial glabrescente, tricomas lepidotos subinteiros, esparsos, argênteos, face abaxial densamente lepidota, argêntea, tricomas lepidotos subinteiros; nervação pinada, camptódroma, broquidódroma, nervuras terciárias percurrentes, oblíquas, levemente sinuosas a convexas; pecíolo 1--9cm compr., 1 par de glândulas acropeciolares, pateliformes, estipitadas; estípulas ca. 8mm compr., linear-lanceoladas, caducas. Inflorescências 4--10cm compr., laxas; raque achatada, estriada, lepidota, tricomas lepidotos subinteiros; címulas contíguas, as proximais bissexuadas, 1--2 flores masculinas e 1 flor feminina, as distais masculinas, ca. 3 flores; brácteas 2--4mm compr., inteiras, oval-lanceoladas, profilos lanceolados. Flores masculinas ca. $7 \mathrm{~mm}$ compr., campanuladas, pediceladas; pedicelo ca. 4mm compr.; cálice ca. 3mm compr., lepidoto externamente, alvo, tricomas lepidotos subinteiros, glabro internamente; lobos do cálice 5, unidos até a metade, ca. $2 \mathrm{~mm}$ compr., inteiros, iguais, valvares, triangulares, ápice agudo, margem vilosa; pétalas ca. 3mm compr., espatuladas, ápice arredondado, vilosas nas margens; 5-segmentado; estames ca. 15, filetes subulados, vilosos, tricomas simples, anteras globoso-elipsóides; receptáculo viloso, tricomas simples. Flores femininas ca. 6mm comrp., campanuladas, curtamente pediceladas; pedicelo ca. 1mm compr.; cálice ca. $5 \mathrm{~mm}$ compr., lepidoto externamente, alvo-argênteo, tricomas lepidotos subinteiros, glabros internamente; lobos do cálice 5, unidos na base, ca. $3 \mathrm{~mm}$ compr., inteiros, iguais, carnosos, quincunciais, largamente ovais, ápice agudo, margem revoluta; pétalas reduzida a glândulas elipsóides; disco inteiro, profundamente 5-lobado; ovário globoso, lepidoto, tricomas dentado-lepidotos porrectos; estiletes 4(6)-fidos, unidos na base, inteiros no terço inferior, exsertos, tricomas dentado-lepidotos na base. Fruto ca. 1,5cm compr., globoso, liso, lepidoto, tricomas dentado-lepidotos porrectos, lobos do cálice 
conspicuamente acrescentes, conspicuamente revolutos no fruto maduro, pedicelo conspicuamente acrescente; sementes ca. $6 \mathrm{~mm}$ compr., globoso-elipsóides; testa levemente costada.

Ocorre disjuntamente no Brasil em floresta de brejo de altitude em Pernambuco, e floresta pluvial montana em Minas Gerais e São Paulo, entre 920 e 1030 m de altitude. Do Rio de Janeiro só é conhecida da coleção tipo de C. hemiargyreus var. gymnodiscos, que não possui indicação de localidade. Foi coletada com flores nos meses de janeiro, março, abril e dezembro, e frutos no mês de janeiro e abril.

A espécie é reconhecida no campo pelas folhas cordiformes discolores, fortemente prateadas na face adaxial.

Croton hemiargyreus assemelha-se a C. campanulatus e C. salutaris, mas diferenciase dessas duas espécies por várias características (Tab. 4; comentários em $C$. campanulatus).

Na Flora brasiliensis, Müller (1873) descreveu Croton hemiargyreus var. gymnodiscus para o Rio de Janeiro com base em diferenças de densidade do indumento, que aqui são reconhecidas como parte da variabilidade da espécie, levando-nos a concordar com o sinônimo proposto por Govaerts (2000).

Material examinado: BRASIL. Pernambuco: Brejo da Madre de Deus, Mata do

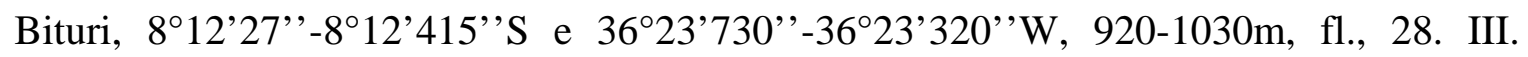
2000, L.M. Nascimento \& A.G. da Silva 362 (PEUFR, SP 355097); Brejo da Madre de

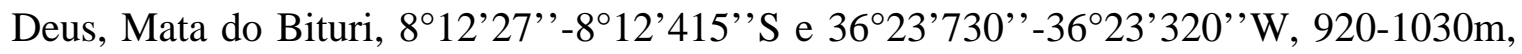
fl., fr., 27. IV. 2000, L.M. Nascimento \& A.G. da Silva 400 (PEUFR, RB 379530, SP 355135); Brejo da Madre de Deus, Mata do Bituri, 8¹2'27' '-8¹2'415'’'S e 36²3'730'’36²3’320’’W, 920-1030m, fl., 15. I. 2001, L.M. Nascimento \& A.G. da Silva 473 (JPB 27527, PEUFR, RB 379544, SP 355161); Brejo da Madre de Deus, Estrada de terra para o engenho da mata do Bituri, segunda entrada após a ponte sobre o rio (após sítio do Sr. Jurandir), 89'S e 36²2’W, 800msm, fl., 08. IV. 2008, M.B.R. Caruzo \& D.A. Ferro 116 (SP). Minas Gerais: Caldas, fr., s.d., A.F. Regnell I 402 (R 100780, S); Caldas, Estrada de terra a 500m do trevo da entrada para Caldas, ao lado direito sentido Poços de Caldas, 21'53'13,3’'S e 46²1'29,5’’W, 1170msm, fr., 25. I. 2007, M.B.R. Caruzo et al. 114 (SP 392151); Caldas, Pocinhos do Rio Verde, estrada da INB (Indústria Nuclear Brasileira), Mata úmida de grota, ca. $1400 \mathrm{~m}$ alt., fl., fr., 24. XI. 2009, I. Cordeiro \& S.A. Nicolau 3229 (SP); Poços de Caldas, 2150’20’’s e 46³3’53’’W, Faz. Chiqueirão, fl., 3. XII. 
1981, H.F. Leitão $F^{o}$ et al. 1578 (UEC 26124). SÃo PAUlo: Águas da Prata, estrada de

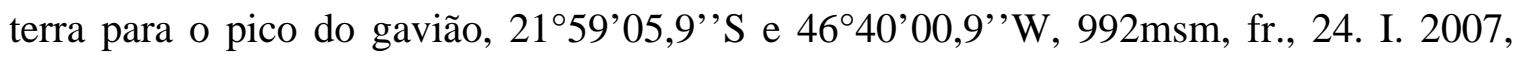
M.B.R. Caruzo et al. 112 (SP 392153); Águas da Prata. Próximo a Divisa entre São Paulo e Minas Gerais. Rodovia para São Roque da Fartura, na beira da estrada ao lado direito, sentido São Roque da Fartura, 2150'55,4'’S e 4641'08,3'’W, 1474msm, fr., 24. I. 2007, M.B.R. Caruzo et al. 113 (SP 392152); São Roque, 2331'26,7"S e 4706'45"W, VII. 1993, E.C. Leite \& A. Oliveira 56 (ESA).

8. Croton heterocalyx Baill., Adansonia 4: 324. 1864. Croton umbrinus Müll.Arg. Linnaea 34: 86. 1865. Tipo: Brasil, Bahia, Blanchet 2959, 3717. nom. superfl. Tipo: Brasil, Bahia, Jacobina, Blanchet 3717 (holótipo: P!; isótipos: G, NY!). (Figs. 5 A-E, 14 A-E).

Arbustos ca. 2--4m alt., látex incolor; tricomas estrelados, multiradiados e dendríticos; ramos cilíndricos, ramos jovens lisos, flocosos, com tricomas dendríticos e multiradiados. Folhas inteiras, levemente discolores, ovais a cordiformes, ápice curtamente acuminado, base arredondada a cordada; lâmina 3,5--15x2--9cm; margem serrilhada, com glândulas, face adaxial esparsamente pubescente, tricomas estrelados, face abaxial pubescente, tricomas multiradiados; nervação pinada, camptódroma, broquidódroma; nervuras terciárias percurrentes, oblíquas, levemente sinuosas; pecíolo 0,6--2,5cm compr., pubescentes, tricomas estrelados alvos e ferrugíneos, com 1 par de glândulas basilaminares, pateliformes, sésseis; estípulas ca. 0,5mm compr., inteiras, linear-lanceoladas, caducas. Inflorescências 6--13cm compr., laxas; raque cilíndrica, lisa, pubérula, tricomas dendríticos e estrelados; címulas contíguas, as proximais bissexuadas, muitas vezes falsamente unissexuadas, 1 flor feminina e 1 flor masculina, as distais masculinas, ca. 3 flores; brácteas ca. 4mm compr., inteiras, linear-lanceoladas, profilos ca. 1mm compr., lineares. Flores masculinas ca. $7 \mathrm{~mm}$, cupuliformes, longamente pediceladas; pedicelo ca. 4mm compr.; cálice ca. 3mm compr., pubescente externamente, enegrescido, tricomas estrelados e multiradiados, glabro internamente; lobos do cálice 5 , unidos até a metade, ca. 1,5mm compr., iguais, inteiros, quincunciais, ovais, ápice agudo, margem vilosa; pétalas ca. 3mm compr., espatuladas, ápice arredondado, revoluto, vilosas na base externamente, tricomas simples, glabras internamente, margem vilosa; disco 5segmentado; estames ca. 15, exsertos; filetes lineares, vilosos, unidos na base; anteras elipsóides; receptáculo viloso, tricomas simples. Flores femininas ca. $8 \mathrm{~mm}$, 
ampuliformes, curtamente pediceladas; pedicelo ca. 1mm compr.; cálice ca. 6mm compr., pubescente externamente, enegrescido, tricomas estrelados e multiradiados, glabro internamente; lobos do cálice 5, ca. $7 \mathrm{~mm}$ compr., inconspicuamente unidos na base, inteiros, iguais, quincuncinais, ovais a largamente ovais, ápice agudo, nervura central bem evidente, com uma faixa de tricomas mais escuros na porção mediana, margem vilosa; pétalas ausentes; disco 5-segmentado; ovário globoso, velutino, tricomas estreladoporrectos e mutiradiados, ferrugíneos; estiletes multifidos, unidos na base, inteiros até a metade, ramificando-se a partir deste ponto, segmentos exsertos, recobertos por tricomas estrelados, alvos, exsertos. Fruto ca. 1,2cm compr., elipsóide, liso, tricomas estrelados e multiradiados; lobos do cálice persistentes, acrescentes; sementes ca. $7 \mathrm{~mm}$ compr., subglobosas, testa levemente costada.

Ocorre disjuntamente no Brasil nas florestas estacionais nos Estados da Bahia e Minas Gerais, e nas florestas de restinga do Espírito Santo, desde o nível do mar até cerca de $900 \mathrm{~m}$ de altitude. Foi coletado com flores nos meses de janeiro a março, agosto e setembro, e com frutos em janeiro, fevereiro, março, abril e agosto.

Croton heterocalyx pode ser reconhecido no campo pelas folhas ovais a cordiformes, de margem serrilhada, que ficam voltadas para baixo, além dos ramos jovens densamente recobertos por indumento castanho.

Baillon (1864) descreveu as inflorescências de C. heterocalyx como unissexuadas na base, enquanto Müller (1873) considerou-as bissexuadas. Dentre todas as coleções analisadas, apenas uma apresentava um botão masculino junto a flor feminina, nas demais coleções, as címulas basais eram unicamente femininas, em virtude das flores masculinas cedo secarem e caírem, sendo aqui denominadas falsamente unissexuadas.

Entre as espécies de Cleodora, Croton heterocalyx é mais semelhante a $C$. sphaerogynus, espécie que também ocorre nas restingas do Espírito Santo, mas dela diferencia-se pelos ramos jovens cilíndricos e lisos (vs achatados e estriados em $C$. sphaerogynus), folhas ovais a cordiformes (vs oval-lanceoladas a elípticas em $C$. sphaerogynus) e flores masculinas cupuliformes (vs campanuladas em C. sphaerogynus).

Moreno et al. (2009) estudaram a composição química e atividade antimicrobiana do óleo essencial das folhas de Croton heterocalyx e encontraram boa atividade contra a bactéria gram-positiva Staphylococcus aureus e os fungos Aspergillus niger e Candida albicans, evidenciando um potencial medicinal nessa espécie. 
Material examinado: BRASIL. BAHIA: 1844, M. Blanchet 316 (P); Santa Cruz Cabrália, 16¹6’S e 39¹W, fl., 28. VIII. 1999, S. dos S. Lima et al. 2 (ALCB 42495); Eunápolis, 16²2’00'’S e 39³4’00'’W, Alt. 200m, fl., fr., 14. III. 1997, M.L. Guedes et al. 4630 (ALCB 29733, MBM 274973); Morro do Chapéu, entre as Faz. Pau D’Arco e Efigênia, próximo a divisa da Bacia do Rio Utinga, $11^{\circ} 56^{\prime}$ 'S e $41^{\circ} 02^{\prime} \mathrm{W}$, fr., 01. IV. 1986, A.C. Sarmento \& H.P. Bautista 844 (HRB 24248, RB 269974); Morro do Chapéu, Rodovia BA 052 sentido Morro do Chapéu, aproximadamente 70Km da entrada da

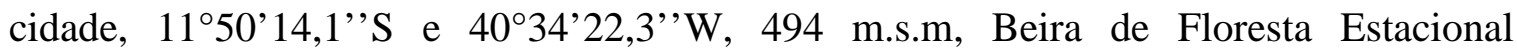
Semidecidual, fl., 23. IX. 2006, M.B.R. Caruzo et al. 105 (HUEFS 112835, SP 392159); Morro do Chapéu, Rodovia BA 426 sentido Bonito, estrada de terra sentido duas barras.

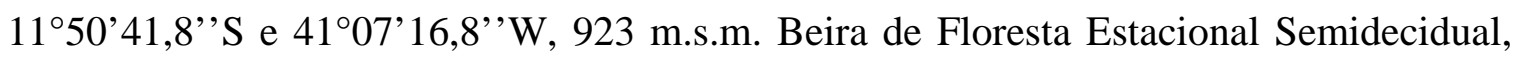
24. IX. 2006, M.B.R. Caruzo et al. 107 (HUEFS 112837, SP 392161); Morro do Chapéu, Rodovia BA 426 sentido Bonito, estrada de terra sentido duas barras. 1150’41,8'’S e 4107’16,8’’W, 923 m.s.m. Beira de Floresta Estacional Semidecidual, fl., 24. IX. 2006, M.B.R. Caruzo et al. 108 (HUEFS 112838, SP 392160); Piemonte da Diamantina, Miguel Calmon, Entorno do Parque Sete Passagens, ponto 223, próximo ao rancho do Sr. Isaias,

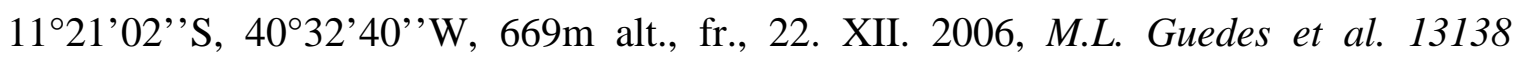
(ALCB 75783, MBM 344036); Tapiramutá, VIII. 1972, fl., fr., G. Pinto s.n. (ALCB 2142, CEPEC 60502, HRB 311037). EsPírito SANTO: Piuma, roadside at base of Morro do Agá, ca. 5 km S of Piuma on Rod. ES-60, 2052’S e 4046’W, fl., fr., 18. I. 1993, J.A. Kallunki \& J.R. Pirani 325 (MO 569669, NY, SP 262506, SPF 81411, WIS). MINAS GERAIS: Salto da Divisa, Estação Repetidora de Salto da Divisa, 1,9 km S of road from Salto da Divisa to Itajimirim, 7,1 km E of Salto da Divisa, 1601'43'’S, 3955'17'’W, fl., fr., 31. I. 2004, W.W. Thomas et al. 13720 (CEPEC 102292, SP 378907, NY).

9. Croton hoffmannii Müll.Arg., Linnaea 34: 86. 1865. C. hoffmannii var. incanus Müll.Arg., Linnaea 34: 86. 1865. Tipo: Costa Rica, C. Hoffmann 547 (holótipo: B†, foto F!, lectótipo MO!, aqui designado). (Figs. 5 F-G, 14 F-K).

= Croton hoffmannii var. viridis Müll.Arg. Linnaea 34: 86. 1865. Tipo: Costa Rica, $C$. Hoffmann 548 (holótipo: B†, foto F!). (sinônimo proposto por Govaerts et al., 2000). = Croton longiradiatus Lanj. Euphorb. Surinam. 2(1): 33. 1931. Tipo: Suriname, Brownsberg, B.W. 6711 (holótipo: U!; isótipos: L!, P!). syn. nov. 
Arvoretas a arbustos, 1,5--8m, tricomas estrelados e multiradiados; ramos cilíndricos; ramos jovens levemente estriados, pubescentes, castanhos, tricomas multiradiados, alvos, esparsos tricomas multiradiados, castanhos. Folhas inteiras, levemente discolores, ovais a cordiformes, raramente oval-lanceoladas, ápice agudo a acuminado, base cuneada a cordiforme; margem inconspicuamente serrilhada a serrilhada, com glândulas; lâmina 6--22 x 2--18cm; face adaxial glabrescente, tricomas simples, estrelados principalmente sobre as nervuras, face abaxial pubescente a esparsamente pubescente, tricomas multiradiados, estrelados, raro adpresso-estrelados; nervação pinada, camptódroma, broquidódroma, nervuras terciárias percurrentes, oblíquas, retas a levemente sinuosas; pecíolo 0,4--8cm, 1 par de glândulas acropeciolares, pateliformes, sésseis; estípulas 2--6mm, inteiras, lineares a linear-lanceoladas. Inflorescências 11--52cm, laxas, pendentes, terminais, mais raramente axilares, geralmente falsamente ramificadas; raque cilíndrica, levemente estriada, pubescente, tricomas estrelados; címulas contíguas, as proximais bissexuadas, 1--2 flores masculinas e 1 flor feminina, as distais masculinas, 2--4 flores; brácteas $0,2--1 \mathrm{~cm}$, inteiras, lineares a lanceoladas, caducas; profilos 1--4mm, lineares. Flores masculinas 0,6--1cm, campanuladas, pediceladas; pedicelo 2--6mm; cálice ca. 4mm, pubescente externamente, alvo, tricomas estrelados, glabro internamente; lobos do cálice 5, unidos até a metade, ca. $2 \mathrm{~mm}$, inteiros, iguais, valvares, ovais a triangulares, ápice agudo, margem vilosa; pétalas 3--5mm, espatuladas, ápice recortado, ondulado, pubescentes externamente, tricomas estrelados, glabras internamente; disco 5-segmentado; estames 15--17, filetes subulados, vilosos na base, tricomas simples, anteras sagitadas; receptáculo viloso, tricomas simples. Flores femininas 0,8--1,2cm, campanuladas, pediceladas; pedicelo 2-5mm, geralmente espesso e anguloso na porção apical; cálice 5--7mm, pubescente externamente, tricomas estrelados e multiradiados, alvos, castanhos principalmente no centro dos lobos do cálice e na base do cálice próximo ao receptáculo, glabro internamente; lobos do cálice 5, unidos até a metade, 2,5--3,5mm, inteiros, iguais, imbricados, romboidais, algumas vezes com as laterais de textura diferente, ápice agudo a curtamente acuminado, margem vilosa; pétalas ausentes; disco inteiro, rasamente 5-lobado; ovário subgloboso, pubescente a hirsuto, tricomas estrelados e estrelado-porrectos, castanhos; estiletes 4-fidos, unidos na base, inteiros no terço inferior, segmentos levemente exsertos, recobertos por tricomas estrelados até a metade; receptáculo densamente viloso, tricomas simples. Fruto 1,5-2,8cm, subgloboso, trígono, liso, pubescente, tricomas castanhos, estrelados; lobos do 
cálice persistentes, inconspicuamente acrescentes, pedicelo conspicuamente acrescente; sementes 5--7mm, romboidais a subglobosas; testa costada.

Croton hoffmannii ocorre na Costa Rica, Suriname (aqui conhecida apenas pelo material tipo de um dos seus sinônimos, C. longiradiatus), Guiana Francesa e Brasil, em florestas pluviais e estacionais, entre 200 e 1300 m de altitude. A espécie foi coletada com flores em fevereiro, abril a agosto, outubro e dezembro, e com frutos em março, agosto a outubro e dezembro.

Müller (1865) descreveu Croton hoffmannii com duas variedades, var. incana (considerada a variedade típica) e var. viridis, com base nas diferenças de densidade e coloração do indumento de apenas duas coleções, que aqui consideramos como parte da variabilidade da espécie, estando portanto de acordo com a sinonimização proposta por Govaerts et al. (2000), que propôs $C$. hofmannii var. viridis como sinônimo de $C$. hoffmannii, não sendo reconhecidas variedades para esta espécie no presente trabalho.

A espécie pode ser reconhecida em sua área de ocorrência pelo indumento castanho que recobre principalmente as partes jovens, pelas folhas ovais a cordiformes, de margens serrilhadas e suas inflorescências laxas, algumas vezes axilares, geralmente falsamente ramificadas.

Dentre as espécies de Cleodora, Croton hoffmannii é mais semelhante a $C$. rottlerifolius, espécie das florestas estacionais do Brasil e Bolívia. Além da disjunção entre suas distribuições, as espécies também diferenciam-se pelos tricomas (estrelados e adpresso-estrelados em C. rottlerifolius vs multiradiados em C. hoffmannii), pela posição das inflorescências (sempre terminais em $C$. rottlerifolius vs algumas vezes axilares em C. hoffmannii), pétalas das flores masculinas (ápice inteiro em C. rottlerifolius vs recortado em C. hoffmannii) e frutos (globoso-elipsóide em C. rottlerifolius vs subgloboso e trígono em C. hoffmannii) (ver Tab. 5).

Como o holótipo de Croton hoffmannii foi destruído, uma duplicata depositada no Herbário do Missouri Botanical Garden foi selecionada como lectótipo.

Material examinado: COSTA RICA. Bords des ruisseaux à La Verbena prés Alajnelita, 1000 m, fl., fr., VIII. 1894, A. Conduz 8859 (US 936037); Buissons á la Uruca, prés San José, fl., VI. 1896, A. Conduz 10134 (US 936146); Envions de San José, 1135 m, fl., V. 1891, H. Pittier 4103 (US 391932); La Gloria de Juan Viñas, fl., 4-6. VI. 1911, H. Pittier 3663 (NY, US 678725). Alajuela: Alajuela, fr., 1918, W.W. \& H.E. Rowlee 270 (US 1036405). CARTAgo: Agua Caliente del Llano, fl., 11. V. 1906, A.M. Brenes 
s.n. (NY); Al borde de la quebrada que limita el valle del Guarco por el Sur, unos 500 metros al Este de San Isidro del Tejar, 1400 m, fl., 30. VI. 1964, A. Jiménez M. 2012 (CR, F, NY); Along the road, 2.6 km west of Paraíso towards Cachí, fl., 12. VI. 1970, J.L. Luteyn 725 (DUKE, MICH 1159249); Cantón de Paraíso, Cuenca de Reventazón, entre Cartago e Paraíso, carretera al Jardin Lankaster, 950'25'’N, 8353'11'’W, 1233 m, fr., 23. IX. 1996, A. Rodríguez 1568 (CR 238889, MO); Cantón de Paraíso, Cuenca de Reventazón, entre Cartago e Paraíso, carretera al Jardin Lankaster, 950'25'N, 8353’11’’W, 1233 m, fl., 30. X. 1997, A. Rodríguez 2655 (CR 234962, MO); Cantón de Paraíso, along the driveway through the coffee plantation uphill from the Hotel Tapanti Media, approximately where the road leaves the coffee plantation and enters secondary vegetation, 947’19.6N, 8350’30.6W, 1080 m, fl., 15. IV. 2006, B. Van Ee \& M. Van Ee 598 (MICH, WIS); Carretera a Orosi, fl., 31. V. 1984, R. Hernandéz 840531-3 (CR 104492); Cartago, 1330 m, fl., 17. VII. 1971, R.W. Lent 2009 (NY); Dulce Nombre, 1400 m, 27. II. 1924, P.C. Standley 35860 (US 1227271); Florencia, Turrialba, 500-600 m, fl., 13. VII. 1965, A. Jiménez M. 3290 (CR, F, NY); From 3 km SE of Cartago, 1200 m, 10. VIII. 1967, R.J. Taylor 4228 (NY); Hedgerous c. $7 \mathrm{~km} \mathrm{SE}$ of Cartago on road to Lankester Gardens, alt. 4100 ft., 950’N, 8353’W, fl., 20. VII. 1977, G.L. Webster 22124 (CR 219435, DAV 106024, MO 3644575, NY); Jardim Lankaster, Concavas, Cartago, fl., 7. VII. 1977, L.J. Poreda \& D. Mora 1670 (DAV 76877); Navarrito, 1400 m, fr., 1. IX. 1927, R.T. Rojas 240 (US 1405853); Patches of secondary forest above Quebrada Cascajal, 1.5 km S of Guatuso, 1530 m, fl., 23. VII. 1967, R.W. Lent 1109 (NY); Scrub on reddish soil, 0,5 mi W of Paraíso, alt. c. 4100 ft., fl., 14. VII. 1962, G.L. Webster 12298a (DAV 49282, NY, MICH 1159896); Scrub on reddish soil, 0,5 mi W of Paraíso, alt. c. 4100 ft., fl., 14. VII. 1962, G.L. Webster 12298g (DAV 84456); Valle de Orosi, En ribeira del Rio Aguacaliente, 1000 m, fr., 7. X. 1964, A. Jiménez M. 2438 (CR, F, NY). SAN Jose: Along the Río María Aguilar, near San José, 1200 m, fl., 25. III. 1924, P.C. Standley 38956 (US 1228454); Arbu au bord du Rio Torres á San Francisco de Guadalupe, 1170 m, fl., XII. 1893, A. Conduz 8454 (US 936038); Cantón de Santa Ana, Vale del Tárcoles, Alto Las Palomas, Parche de bosque secundario lado izq. carretera, 956’N, 84¹0’W, 1100 m, fl., 6. VI. 1994, Q. Jiménez 1576 (CR 186023); Cerca Rio Virilla, San Jose, fl., 16. VI. 1935, A.M. Brenes 20562 (NY); Collected along a small stream about $1 \mathrm{~km}$ southeast of Patarra, forest along the stream with upland pastures away from the stream, the rock here is limestone, 1150 m, fr., 24. XII. 1974, J. Taylor 17602 
(US 2770783); Entre Pedernal y Candelarita, 900 m, fl., 29. V. 1966, A. Jiménez M. 3968 (CR, F, NY).

GUIANA FRANCESA. GUYANE: Saül, tropical moist forest, 33’N, 531'' W, 200400 m, fr., 26. III. 1983, S. Mori et al. 15388 (MO 3095614, NY, P); Saül, Grand Boeuf Mort Trail, scenic overlook, the overlook spur located on $\mathrm{N}$ part of trail near Rout de Bélizon entrance (see fig. 3 in Guide to the Vascular Plants of Central French Guiana, part 1), non-flooded moist forest, $3^{\circ} 37^{\prime} \mathrm{N}, 53^{\circ} 12^{\prime} \mathrm{W}, 300 \mathrm{~m}$, fl., 14. II. 1998, S.A. Mori et al. 24778 (NY 189727). SURINAME. s. proc., Brownsberg, B.W. 6711 (U, L, P). BRASIL. RoRAIMA: arredores do marco divisor no. 10, mata de terra firme, $700 \mathrm{~m}$, fr., 4. IX. 1979, N.A. Rosa \& O.C. Nascimento 3275 (INPA, K, MG 73299, NY).

10. Croton organensis Baill., Adansonia 4: 324. 1864. Tipo: Brasil, "Serra dos Orgaos”, V. 1839, Guillemin cat. 938 (holótipo: P!). (Figs. 6 A-H, 15 A-C).

= Croton platycladus Müll.Arg., Linnaea 34: 123. 1865. Tipo: Brasil, Bahia, Lhotsky s.n. (lectótipo: G!, aqui designado); Brasil, Bahia, Limmingh s.n. (síntipo: G!). (sinônimo proposto por Müller, 1873).

= Croton oxyphyllus Müll.Arg., Fl. Bras. 11(2): 100. 1873. Tipo: Brasil, Rio de Janeiro, “in silvis primaevis prope Bananal, altitud. 800-1000 ped. supra maré”, Martius 318 (holótipo: M!). syn. nov.

Árvores 4--15m, látex incolor, tricomas simples, estrelados e dendríticos; ramos conspicuamente achatados, estriados; ramos jovens flocosos a tomentosos, tricomas dendríticos. Folhas inteiras, discolores, oval-lanceoladas a elípticas, ápice acuminado a longamente acuminado, raramente agudo, base subcordada, obtusa a cuneada, margem irregularmente serrilhada, com glândulas nos dentes, lâmina 7--26(30) x 2,5--10cm; face adaxial esparsamente pubescente, tricomas simples, tricomas estrelados concentrados na nervura central, face abaxial pubescente, alva, tricomas estrelados; nervação pinada, camptódroma, eucamptódroma, nervuras secundárias paralelas entre si, bem evidentes, nervuras terciárias percurrentes, oblíquas, retas; pecíolo ca. 2,5cm, 1 par de glândulas basilaminares, maculares, inconspícuas, esverdeadas, recobertas por tricomas estrelados; estípulas lineares, ca. $1 \mathrm{~cm}$. Inflorescências 7--22cm, laxas, pendentes; raque achatada, estriada; címulas contíguas, as proximais bissexuadas, 1 flor masculina e 1 flor feminina, as distais masculinas, ca. 2 flores; brácteas inteiras, linear-lanceoladas, ca. $5 \mathrm{~mm}$, profilos 
lineares. Flores masculinas ca. 1,5cm, subcampanuladas, longamente pediceladas; pedicelo ca. $7 \mathrm{~mm}$; cálice ca. $5 \mathrm{~mm}$, pubescente externamente, alvo-esverdeado, tricomas estrelados, glabro internamente; lobos do cálice 5, unidos apenas na porção basal, ca. $4 \mathrm{~mm}$, inteiros, iguais, valvares, romboidais, ápice agudo a obtuso, margem vilosa; pétalas ca. 4mm, oblongas, ápice obtuso, vilosas nas margens; disco 5-segmentado; estames ca. 15; filetes filiformes, vilosos na base, anteras globoso-elipsóides; receptáculo viloso, tricomas simples. Flores femininas ca. 1,5cm, ampuliformes, pediceladas; pedicelo 2-3mm compr.; cálice ca. 7mm, pubescente externamente, ferrugíneo na base, esverdeado no ápice, tricomas estrelados, glabro internamente; lobos do cálice 5, ca. 6mm, unidos na base, inteiros, iguais, quincuncinais, romboidais, ápice obtuso; pétalas ausentes; disco 5segmentado; ovário globoso, pubescente, tricomas estrelados; estiletes multifidos, unidos na base, exsertos. Fruto ca. 2,5cm, elipsóide, liso, pubescente; lobos do cálice persistentes, inconspicuamente acrescentes; sementes ca. $1 \mathrm{~cm}$, subglobosas; testa costada.

Ocorre no Brasil nos Estados Minas Gerais, Rio de Janeiro e São Paulo em floresta pluvial montana, nas Serras do Mar e Mantiqueira, entre 800 e 1300 m de altitude. A coleção proveniente da Bahia, tipo de seu sinônimo Croton platycladus, representaria um padrão de disjunção bastante incomum, entretanto não foi encontrada nenhuma outra coleção da Bahia, um indício de que talvez a proveniência da coleção tipo não fosse correta. Foi observada com flores nos meses de outubro e dezembro, e com frutos nos meses de janeiro, fevereiro, abril, novembro e dezembro.

Durante a análise dos protólogos e coleções tipo de Croton platycladus e C. oxyphyllus, verificou-se a grande semelhança morfológica entre os binômios citados e $C$. organensis, pricipalmente no que se refere aos ramos jovens achatados, nervação foliar eucamptódroma e flores femininas ampuliformes, sendo possível verificar que ambos devem ser considerados sinônimos de C. organensis.

A espécie pode ser reconhecida por seus ramos e folhas recobertos de tricomas estrelados ferrugíneos, ramos jovens conspicuamente achatados e folhas com nervuras secundárias, bem salientes e paralelas entre si.

Em suas localidades de ocorrência, Croton organensis pode ocorrer em simpatria com outras duas espécies de Cleodora, C. campanulatus e C. salutaris. No entanto, é muito distinta destas pelo tricoma do indumento (estrelado em $C$. organensis vs lepidoto em $C$. campanulatus e C. salutaris), folhas (oval-lanceoladas a elíptcas em C. organensis vs ovais 
em C. campanulatus e C. salutaris) e padrão de nervação secundária (eucamptódroma em $C$. organensis vs broquidódroma em C. campanulatus e C. salutaris).

Na maioria das coleções de Croton organensis, foram observadas apenas címulas unissexuais, possivelmente em virtude das címulas proximais estarem incompletas, pela falta de flores estaminadas, que cedo secam e caem. No entanto, no campo foram observadas címulas proximais bissexuadas. As glândulas foliares são inconspícuas, principalmente no material herborizado, pois são maculares e por vezes recobertas pelo indumento.

Webster (1993) posicionou Croton organensis Baill. na seção Cyclostigma subseção Sampatik G.L.Webster, apesar da espécie não possuir indumento de tricomas adpressoestrelados, flores femininas distintamente pediceladas e estiletes 2-fidos, como descreveu para Sampatik. No entanto, assim como já observado por Caruzo (2005), as flores femininas subsésseis, com lobos do cálice distintamente imbricados e estiletes multifidos unidos na porção basal, indicariam uma melhor posição da espécie em Cleodora, atualmente corroborada pelos estudos filogenéticos de Cyclostigma (Riina et al., 2009) e Cleodora (Cap. $1)$.

Material examinado: BRASIL. BAHIA: s. proc., Lhotsky s.n. (G); s.proc., Limmingh s.n. (G). Minas Gerais: Antônio Carlos, Faz. Borda do Campo, fl., fr., XII. 1963, L. Roth 2530 (CESJ, GUA 42013, SPF); Camanducaia, nativo em mata nas proximidades da Vila Montes-Verdes, fr., 19. XI. 1979, H.F. Leitão Filho \& R.C. Barros 10671 (SP 162915, UEC 22121); Camanducaia-Monte-Verde, fl., 19. X. 2002, L. Meireles s.n. (SP 363269); Delfim Moreira, São Francisco dos Campos, fr., 12. VI. 1950, M. Kuhlmann 2507 (SP 75881); Juiz de Fora, fl., 24. X. 1970, PLK \& Urbano 9516 (CESJ, HCES, RB 251152, SPF, UFJF); Passa Vinte, distrito de Carlos Euler, Usina Elétrica de Paes Leme, fr., 15. XI. 2000, A. Salino \& L.C.N. Melo 5917 (BHCB 57039, MBM 274631); Paraíso,

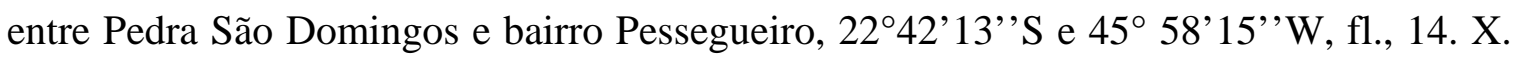
2000, G.S. França \& J.R. Stehmann 140 (BHCB 53755); Sapucaí Mirim, fl., 26. X. 1950, M. Kuhlmann 2579 (MG 152552, SP 200317). Rio DE JANEIRO: Parque Nacional de Itatiaia, trail in Forest near Véu da Noiva, fall in upper Rio Maromba, fr, 3. II. 1997, J.C. Lindeman \& J.H. de Haas 4202 (MBM 136649, RB); Itatiaia, 8. I. 1941, N. D. Ramos 157 (PNI 1081, RB 84218); Itatiaia, 2. XI. 1941, N. D. Ramos 430 (PNI 1329, RB 84217); Parque Nacional de Itatiaia, 16. X. 1947, Jocelino s.n. (RB 62075); Itatiaia, Parque Nacional de Itatiaia, Ponte do Maromba, próximo a margem do rio Campo Belo, 8. XI. 1993, L. Sylvestre et al. 912 (RB 333876); Itatiaia, Parque Nacional de Itatiaia, Visconde de Mauá, trilha a partir da Fazenda do CPRM, fl., 6. X. 1995, S.J. Silva Neto et 
al. 785 (RB 365750, SP 383900); Itatiaia, Parque Estadual do Itatiaia, estrada para a piscina do Maromba, ao longo da estrada, 1100 msm, 22²6'10', e 44³6'49,4'’W, fl., fr., 18. XI. 2008, M.B.R. Caruzo \& L.R. Lima 122 (SP); Nova Friburgo, Reserva Ecológica Municipal de Macaé de Cima, margens do rio Macaé, fl., $22^{\circ} 00^{\prime S}$ e $42^{\circ} 03^{\prime} \mathrm{W}$, 26. X. 1989, C.M.B. Correia et al. 65 (MG 146228, RB, SP 266217); Nova Friburgo,

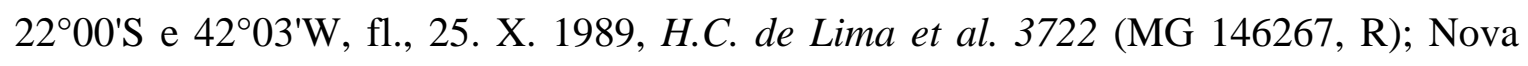
Friburgo, Reserva Ecológica Municipal de Macaé de Cima, caminho para a parcela I,

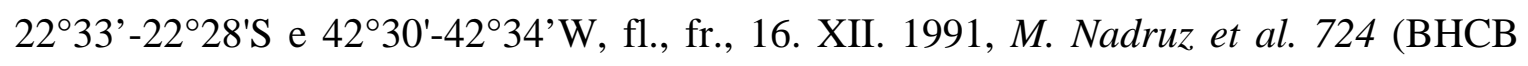
24356); Nova Friburgo, Estrada para Nova Friburgo, próximo ao Km 65, 1040 msm, 22²2'34,3’’s e 42³2'56,6’’W, fr, 04. II. 2006, M.B.R. Caruzo et al. 90 (SP 384409, WIS); Nova Iguaçu, Rebio, Tinguá, estrada do Ouro, próximo ao portão para Santana de

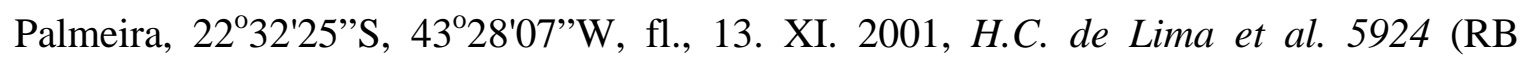

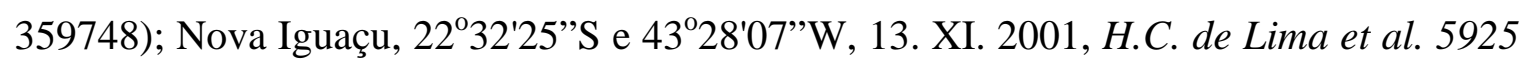
(R, RB 360171); Rezende, Visconde de Mauá, III. 2001, A.Q. Lobão 555 (SPF, WIS);

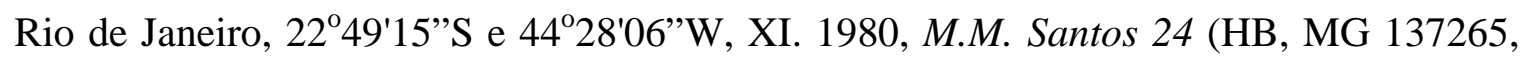
RB 209190); Serra dos Órgãos, 7. X. 1865, Glaziou s.n. (RB 82960); Teresópolis, fl., 15. X. 1921, E.W.D. \& M.M. Holway 1221 (US 1188940); Teresópolis, Granja Comarí, 850 msm, fl., 28. X. 1962, G. Pabst \& A. Abendroth 7160 (HB, US 2436237); Teresópolis, Parque Nacional da Serra dos Órgãos, 22. X. 1987, A. Souza et al. 308 (R). SÃo PAUlo: Bananal, Serra da Bocaína, estrada para a Pousada da Terra, mata baixa, seca, $22^{\circ} 48^{\prime S}$, 442ㄱ'W, elev. ca. 1209 m, fr., 15. XII. 2006, L.R. Lima et al. 418 (SP 390621); Campos do Jordão, P.E. Instituto Florestal, região do Paiol, fr., 29. I. 1986, M.J. Robim 392 (SP 237472, SPSF); Campos do Jordão, fl., 26. X. 2004, M.B.R. Caruzo et al. 72 (SP 370627, SPF, WIS); Cunha, Parque Estadual da Serra do Mar - Núcleo Cunha, fl., 14. X. 1992, S. Buzato \& M. Sazima 27206 (UEC 59420); Cunha, Estação experimental da Serra do Mar - Núcleo Cunha - Trilha da Barra do Rio, 12. XII. 1996, fl., fr., A.R. Ferretti et al. 32 (ESA, SP 368924, UEC); Cunha, Parque Estadual da Serra do Mar, Núcleo Cunha-Indaiá, trilha do Rio Paraibuna, 2314'47"S e 4501'24"W, fr., 14. II. 2000, I. Cordeiro 2010 (SP 341053, WIS); Cunha, Parque Estadual da Serra do Mar, Núcleo Cunha-Indaiá, trilha do Rio Bonito, após o sítio Campo grande, Foresta Ombrófila Densa, (SAD69, Zona 23, 497404S, 7428842W, m), 29. I. 2004, árvore 9m de altura e 47+32+44cm de perímetro à altra do peito, matriz 2574, fr., N.M. Ivanauskas, R.F. Lorza, D. de Souza, B. Lopes 5076 (SPSF 34344, MBM 308029); Cunha, Parque Estadual da Serra do Mar, Núcleo CunhaIndaiá, trilha do Rio Bonito, fr., 30. XI. 2004, M.B.R. Caruzo et al. 82 (SP 372143, SPF, 
WIS); Piquete, Alto da Serra da Mantiqueira às margens da Rod. BR-459 entre os dois pontos da polícia rodoviária, fr., 14. II. 1994, G.F. Arbocz 148 (SP 269868); Reserva Florestal da Bocaína, 1300msm, Posses, 7. V. 1968, D. Sucre et al. 2986 (RB 138966); Santo Antônio do Pinhal, Sítio Matão, fr., 05. XI. 2006, R.B. Torres et al. 1801 (IAC 48918, SP 398155); Santos, fr., 3. I. 1968, T. Sendulsky 800 (MG 15534, SP 106047); Procedência ignorada, Cultivada no Jardim Botânico de São Paulo, fr., 27. XII. 1965, J.R. Mattos 13229 (MG 152570, SP 155782); São Paulo, Cultivada no Jardim Botânico de São Paulo, fr., 30. XII. 1974, J.R. Mattos 16178 (MG 159327, SP 156096); São Paulo, Parque Estadual das Fontes do Ipiranga, Instituto de Botânica, Jardim Botânico, fr., 15. XII. 1976, L.B. Noffs et al. 12 (BHCB 39884, MG 152596, SP 204078); São Paulo, Parque Estadual das Fontes do Ipiranga, Jardim Botânico, fl., 14. X. 1977, fl., M. Kirizawa et al. 299 (BHCB 39885, MG 152521, SP 204173); São Paulo, Parque Estadual das Fontes do Ipiranga, Jardim Botânico, fr., 13. I. 1978, J.H.M. Nascimento et al. 6 (CEPEC 65932, MG 152585, SP 204057); São Paulo, Parque Estadual das Fontes do Ipiranga, Jardim Botânico, fr., 02. II. 1978, M. Kirizawa et al. 323 (SP 204340).

11. Croton orinocensis Müll.Arg., Fl. Bras. 11(2): 135. 1873. Tipo: Venezuela, Amazonas, “Habitat ad flumen Orenoco prope Maypuré”, Spruce 3723 (holótipo: G ; isótipos: BM, K!, P! e W, Foto F! no herbário MICH). (Figs. 7 A-E, 15 D-H).

= Croton badiocalyx Croizat, Caldasia 2(7): 127. 1943. Tipo: Colômbia, Los Llanos, Boyacá, “Orocué, alt. 140 m”, 12. V. 1939, O. Haught 2823 (holótipo A!; isótipo: COL!, NY!, US!). syn. nov.

Arbustos a árvores 1-10m alt., látex acastanhado, tricomas adpresso-estrelados, estrelado-lepidotos e dendríticos; ramos cilíndricos; ramos jovens lisos, flocosos, tricomas dendríticos. Folhas inteiras, fortemente discolores, elípticas, ápice acuminado, base subcordada a cordada; lâmina 3-16,5x1,5-7,5cm, margem inteira a inconspicuamente serrilhada, geralmente com glândulas; face adaxial glabrescente, tricomas simples, face abaxial lepidota, argêntea, pontuações rufo-argênteas sobre as nervuras, tricomas adpresso-estrelados e estrelado-lepidotos; nervação pinada, camptódroma, broquidódroma, nervuras terciárias percurrentes, oblíquas, levemente sinuosas; pecíolo 0,7-2,7cm, 1 par de glândulas basilaminares, pateliformes, sésseis; estípulas ca. $2 \mathrm{~mm}$, inteiras, triangulares. Inflorescências 2,5-4cm compr., congestas; raque cilíndrica, estriada, pubescente, tricomas estrelados; címulas contíguas, as proximais geralmente 
bissexuadas, 1 flor masculina e 1 flor feminina, as distais masculinas, unifloras; brácteas 3-7mm compr., margem incisa, com glândulas, ovais, ápice acuminado, profilos 2-4mm compr., linear-lanceolados. Flores masculinas ca. $7 \mathrm{~mm}$, campanuladas, pediceladas; pedicelo ca. 3mm; cálice ca. 4mm, lepidoto externamente, rufo-ferrugíneo, tricomas adpresso-estrelados, glabro internamente; lobos do cálice 5, unidos até a metade, ca. 2mm, inteiros, iguais, valvares, triangulares, ápice agudo, vilosos na margem; pétalas ca. 4mm, linear-lanceoladas, ápice arredondado, vilosas externamente; disco 5-segmentado; estames ca. 15, filetes subulados, ciliados, anteras elipsóides; receptáculo viloso, tricomas simples. Flores femininas $0,6-1 \mathrm{~cm}$, campanuladas, pediceladas; pedicelo 23mm; cálice 4-8mm, lepidoto externamente, rufo-ferrugíneo, tricomas adpressoestrelados, glabrescente internamente; lobos do cálice 5, unidos na porção basal, 3-7mm compr., inteiros, iguais, imbricados, ovais, ápice agudo a acuminado; pétalas ausentes; disco 5-segmentado; ovário globoso, hirto-tomentoso, tricomas estrelados longamente estipitados; estiletes 4-fidos, unidos na base, inclusos, inteiros até a metade, recobertos por tricomas estrelados. Fruto ca. $1 \mathrm{~cm}$, subgloboso, verruculoso, tricomas adpressoestrelados, lobos do cálice inconspicuamente acrescentes; sementes ca. 4mm, subglobosas; testa costada.

Espécie amazônica das florestas pluviais de terra firme da Colômbia, Venezuela e Brasil, entre 70 e $300 \mathrm{~m}$ de altitude.

É proposta aqui a sinonimização de Croton badiocalyx sob C. orinocensis, pois a análise dos protólogos e das coleções tipo desses dois binômios revelou que referem-se a uma mesma espécie, caraterizada pelo hábito arbóreo ou arbustivo, indumento foliar lepidoto, flores femininas campanuladas e estiletes 4-fidos, unidos na base.

Algumas coleções de Croton orinocensis do Brasil encontravam-se identificadas como C. spruceanus. Essas duas espécies são muito semelhantes vegetativamente, mas se diferenciam pelas inflorescências (congestas em $C$. orinocensis vs laxas em $C$. spruceanus), flores femininas (campanuladas em C. orinocensis vs urceoladas em $C$. spruceanus) e lobos do cálice nos frutos (inconspicuamente acrescentes em $C$. orinocensis vs conspicuamente acrescentes em C. spruceanus).

Material examinado: COLÔMBIA. MetA: Orocué, Rio Meta, fl., 3. XI. 1933, J. Cuatrecasas 4399 (US 1774014). VENEZUELA. AMAzonas: 14 km of Samariapo on road to Puerto Ayacucho, alt. 100m, fr., 29. VI. 1975, A. Gentry \& P. Berry 14581 (MO 
4281130); $23 \mathrm{~km}$ NE of Puerto Ayacucho and $10 \mathrm{~km}$ E of the highway, hills and base of hills, near Cachama, elev. 90 m, 551’N, 67²4’W, fl., 17-19. IV. 1978, G. Davidse \& O. Huber 15335 (DAV 8389, MO 2714564, VEN 133969); Atures, forested areas and igneous outcrops along río Coromoto, at Tobogán de La Selva, 35 km southeast of Puerto Ayacucho, 522’ N, 67³3’W, alt. 150 meters, fl., 14. V. 1980, J.A. Steyermark et al. 122514 (VEN 251998); Atures, carretera Pto. Ayacucho - Samariapo, km 37, laja 0,5 km al este de la carretera, 5²2'N, 67 40'W, fl., 4. V. 1992, A. Gröger 325 (MO 04600960, TFVA 9572, VEN 284336); Atures, Samariapo, Estrada Puerto Ayacucho-Samariapo, aproximadamente $14,5 \mathrm{~km}$ ao lado esquerdo da estrada sentido Puerto Ayacucho, 5'29’24,2’’N e 67³6’21,1'’W, 76m, fr., 04. XII. 2008, M.B.R. Caruzo et al. 124 (SP); Carretera Pto. Ayacucho hacia Samariapo, Cerro Tigrito, entre Platanillal y Guayabal al oeste de la carretera, 5²3’N e 67²41’W, 06. I. 1993, A. Gröger 672 (MO 04600959, TFVA 9442, VEN 292542); Laja a 14.6 Km N de Samariapo, Borde inferior de la laja a orillas de caño, En ecotono bosque ribereño-laja, 5 29'24.2"N, 67 36'21.1"W, 76 m, fr., 4. XII. 2008, R. Riina et al. 1818 (VEN, TFVA); Simariapo, antes de sabana de Tigre, fr., 21. VI. 2007, Y. Lira 80 (VEN 391720); Tobogan de la Selva, parte inferior de la laja, ca de la entrada al balneario, Vegetación secundaria al borde del bosque, 5²3'13.4"N, 67 36'56.6"W, 80 m, 4. XII. 2008, R. Riina et al. 1819 (VEN, TFVA). BRASIL. PARÁ: Alemquer, fl., 26. XII. 1903, A. Ducke s.n. (MG 4896); Alemquer, fl., fr., 27. XII. 1903, A. Ducke s.n. (INPA, MG 4914); BR 163, km 1350, 11 km north of rio Ariri, fl., 24. XI. 1877, G.T. Prance et al. 25726 (INPA, MG 60326, NY, RB 244631); Lageira, airstrip on Rio Maicuru. Near airstrip, 17. VII. 1981, 055’S, 54²6’W, 800 ft., J.J. Strudwick et al. 3080 (INPA, MG, NY); Monte Alegre, Ramal Água Preta, fl., 16. II. 1997, M.F.F. Silva et al. 2475 (MG 164764); Ourilândia do Norte, projeto Pinkaiti, aldeia Aúkre, fr., 3. II. 1999, M.R. Cordeiro \& C. Baider 2890 (IAN 169711); Rio Maicuru, proximidades da pista de pouso do Lageiro, $1^{\circ} 00^{\prime}$ S, 54³0’W, fr., 18. VII. 1981, J. Jangoux \& B.G.S. Ribeiro 1478 (INPA, MG 122456, NY, SP 320899, WIS); Rio Tapajós, aeroporto de Jacareacanga, fl., 30. I. 1952, J.M. Pires 4045 (IAN, UB 46867, US 2221359); Sete Varas airstrip on Rio Curua, 5492’W e 095'S, fr., 4. VIII. 1981, J.J. Strudwick et al. 4088 (INPA, MG 94995, MO 3122944, NY, US 3502867). Mato Grosso: Fazenda Cachimbo, sub. Base Projeto Radam, fl., 27. XI. 1976, M.R. Cordeiro 1205 (INPA, MG, NY, RB 244560); Matupá, Agropecuária Cachimbo, estrada vicinal E-60, cerca de 33 km ENE (em linha reta), de Matupá, rio Peixotinho, 105'S, 54²4'’'W, fr., 23. IV. 1997, V.C. Souza et al. 15428 (ESA 43376, MT, PEUFR); Matupá, MT 322, em beira de estrada de 
chão, lado esquerdo, em mata de galeria, 10¹6’36,8' 'S, 54²47’32,1'’W, 330 m.s.m, fl., 23. XI. 2004, R. Tsuji et al. 873 (HPL 2700, IAC 45577).

12. Croton pseudofragrans Croizat, Caldasia 2(7): 126. 1943. Tipo: Colombia, “Comisaría del Putumayo: - Selva higrófila del Rio Putumayo, en las margines del afluente ezquierda Piñuña Negro, alt. 240m. -”, Cuatrecasas 10700 (holótipo: A!; isótipos: U!, US!). (Figs. 16 A-E).

Arbustos escandentes ca. 2,5--4m, tricomas estrelados, adpresso-estrelados e estrelado-lepidotos; ramos cilíndricos, ramos jovens levemente achatados, estriados, flocosos, tricomas estrelado-lepidotos, alvos e castanhos. Folhas inteiras, discolores, cordiformes, ovais a oval-lanceoladas, ápice longamente acuminado, base cordada a arredondada; lâmina 7,5--23x3,5--9cm; margem inteira, sem glândulas, face adaxial esparsamente pubescente, tricomas estrelados, face abaxial pubescente, tricomas adpresso-estrelados, raro esparssos estrelados; nervação pinada, camptódroma, broquidódroma; nervuras terciárias percurrentes, oblíquas, levemente sinuosas; pecíolo 0,8--3cm, pubescentes, geralmente enegrescidos, tricomas estrelado-lepidotos, castanhos, 1 par de glândulas basilaminares, pateliformes, sésseis; estípulas caducas. Inflorescências 1,5--8cm compr., axilares; raque cilíndrica, lisa, pubérula, tricomas estrelado-lepidotos, castanhos; címulas contíguas, congestas, as proximais unissexuadas, femininas, unifloras, as distais masculinas, unifloras; brácteas 5--10mm, profundamente 3-lobadas, profilos 2--4mm, linear-lanceolados. Flores masculinas $7--8 \mathrm{~mm}$, campanuladas, pediceladas; pedicelo ca. $4 \mathrm{~mm}$; cálice 2--4 mm, pubescente externamente, tricomas estrelado-lepidotos, glabro internamente; lobos do cálice 5, unidos até a metade, 1,5--2 mm, iguais, inteiros, valvares, estreito-ovais, ápice agudo, margem vilosa; pétalas ca. $3 \mathrm{~mm}$, espatuladas, ápice agudo, vilosas nas margens, tricomas simples, glabras internamente, margem vilosa; disco 5-segmentado; estames ca. 25, exsertos; filetes lineares, vilosos na base; anteras estreito-elipsóides; receptáculo viloso, tricomas simples. Flores femininas $0,7--1 \mathrm{~cm}$, campanuladas, pediceladas; pedicelo 3--4mm compr.; cálice 4--6mm, pubescente externamente, enegrescidos, tricomas estrelado-lepidotos externamente, castanhos, alguns alvos esparsos, glabro internamente; lobos do cálice 5, 4-6mm, inconspicuamente unidos na base, inteiros, iguais, imbricados, ovais a largamente ovais, algumas vezes com as laterais de textura diferente, ápice agudo a acuminado, margem vilosa, algumas vezes com a vilosidade extendendo-se ate quase a metade dos lobos, ficando uma faixa de tricomas castanhos na parte mediana; pétalas ausentes; disco 
inteiro, rasamente 5-lobado; ovário subgloboso, pubescente, tricomas adpresso-estrelados; estiletes 4-fidos, unidos na base, ramificando-se a partir do terço inferior, segmentos inclusos, recobertos por tricomas adpresso-estrelados, alvos. Fruto 0,7--1cm, subgloboso, liso, esparssos tricomas adpresso-estrelados; lobos do cálice persistentes, não acrescentes; sementes ca. 5mm compr., subglobosas, testa levemente costada.

Ocorre na Colômbia, Equador e Peru, em floresta pluvial de terra firme da Amazônia ocidental e encostas inferiores do Andes, entre 180 e 1050 m de altitude.

A espécie é muito distinta das outras Cleodora, sendo a única de hábito escandente, que também é raro nas outras seções de Croton, com brácteas profundamente lobadas, estames em número de 25 e lobos do cálice das flores femininas vilosos até quase a metade, com uma faixa de tricomas castanhos na porção mediana e alvos nas laterais.

Material examinado: ECUADOR. Reserva Ecológica Tiputini, fl., 14. IV. 2005, C. Woodward \& T. Rooney s.n. (MICH, WIS). NAPO: Parque Nacional Yasuní, río Tivacuno, en unión con el río Tiputini, 0045'S, 76²0'W, 220 m, fr., 1. IV. 1988, F. Coello 213 (MO 4238224); Tiputini Biodiversity Station, río Tiputini, about 25 km (via air) east of confluence with río Tivacuno, on harpia trail at 850 m, alt. 200-300 m, fl., 6 . III. 1998, R.J. Burnham 1651 (DAV 148856, MICH 1196966, MO 4935538). Sucumbios: Gonzalo Pizarro Canton, Campo Bermejo 6 Norte, $1 \mathrm{~km}$ al norte del Campo, $30 \mathrm{~km}$ al noroeste de Lago Agrio, suelo rojo colinado, vegetación secundaria de 2-3 años, bosque húmedo premontano, transectos, $00^{\circ} 14^{\prime} \mathrm{N}, 7^{\circ} 13^{\prime} \mathrm{W}, 1050 \mathrm{~m}$, fl., 31. III. 1990, C.E. Cerón et al. 9414 (MO, QCNE, WIS). PERU. Loreto: Alto Amazonas, Andoas, río pastaza, near Ecuador border, 248’S, 76²8’W, alt. 210 m, fl., 14. VIII. 1980, A. Gentry et al. 29678 (AMAZ 11651, F, MO, MICH); Alto Amazonas, Andoas, campamento petrolero, río pastaza, no. de Iquitos, $2^{\circ} 55^{\prime} \mathrm{S}, 76^{\circ} 25^{\prime} \mathrm{W}$, alt. ca. $210 \mathrm{~m}$, fl., 21. XI. 1980, R. Vásquez \& N. Jaramillo 832 (AMAZ 12879, F 2098279, MICH, MO); Alto Amazonas, Andoas, 255’S, 76²5’W, alt. 180 m, fl., 09. IX. 1983, R. Vásquez 4449 (AMAZ 19871, F 2097890, MICH, MO).

13. Croton rottlerifolius Baill., Adansonia 4: 327. 1864. Tipo: Brasil, Minas Gerais, 1838, Claussen 788 (holótipo: P!; isótipo: G, foto F!). (Figs. 16 F-H).

= Croton warmingii Müll.Arg., Fl. bras. 11(2): 105. 1873. Tipo: Brasil, Minas Gerais, Uberaba, Regnell 1077 (lectótipo: UPS, designado por Caruzo \& Cordeiro, 2007; 
duplicata: S); Brasil, Minas Gerais, Lagoa Santa, Warming 1649 (síntipo: C!, G-DC!); Brasil, Minas Gerais, Riedel 1381, 1382 (síntipos: LE). (sinônimo proposto por Caruzo \& Cordeiro, 2007).

Arvoretas a arbustos, 2,5--6m, látex incolor, tricomas estrelados e adpressoestrelados; ramos cilíndricos; ramos jovens levemente estriados, pubescentes, tricomas estrelados, alvos, esparsos tricomas estrelados enegrecidos. Folhas inteiras, discolores, ovais a largamente ovais, ápice agudo, base cuneada a levemente truncada; margem inteira a miudamente serrilhada, com glândulas; lâmina 5,5--18,5 x 3,5--17,5cm; face adaxial glabrescente, tricomas simples, face abaxial pubescente a esparsamente pubescente, tricomas adpresso-estrelados, porrectos; nervação pinada, camptódroma, broquidódroma, nervuras terciárias percurrentes, oblíquas, retas a levemente sinuosas; pecíolo 2--8cm, 1 par de glândulas acropeciolares, pateliformes, sésseis, alaranjadas; estípulas ca. 2mm, inteiras, lineares. Inflorescências ca. $18 \mathrm{~cm}$, laxas, pendentes, ás vezes ramificadas; raque cilíndrica, levemente estriada, pubescente, tricomas estrelados; címulas contíguas, as proximais bissexuadas, ca. 2 flores masculinas e 1 flor feminina, as distais masculinas, ca. 2 flores; brácteas ca. 2mm, inteiras, lineares a lanceoladas; profilos ca. $1 \mathrm{~mm}$, lineares. Flores masculinas ca. $6 \mathrm{~mm}$, campanuladas, pediceladas; pedicelo ca. 3mm; cálice ca. 3mm, pubescente externamente, alvo, tricomas estrelados, glabro internamente; lobos do cálice 5 , unidos até a metade, ca. 1,5mm, inteiros, iguais, valvares, levemente imbricados, ovais, ápice agudo, margem vilosa; pétalas ca. 3mm, oblongo-lanceoladas, ápice obtuso, tricomas simples externamente, glabras internamente, margem vilosa; disco 5-segmentado; estames ca. 15, filetes filiformes, vilosos, tricomas simples; anteras elipsóides; receptáculo viloso, tricomas simples. Flores femininas ca. $7 \mathrm{~mm}$, campanuladas, pediceladas; pedicelo ca. $2 \mathrm{~mm}$, geralmente espesso e anguloso na porção apical; cálice ca. 5mm, pubescente externamente, calcáreo-esverdeado, tricomas estrelados, algumas vezes com uma faixa central de tricomas castanhos, glabro internamente; lobos do cálice 5, unidos até a metade, ca. 2,5mm, inteiros, iguais, imbricados, ovais a romboidais, algumas vezes com as laterais de textura diferente, ápice agudo a obtuso, margem vilosa; pétalas ausentes; disco inteiro, rasamente 5-lobado; ovário globoso, piloso, tricomas estrelados; estiletes 4-fidos, unidos na base, segmentos exsertos, base recoberta por tricomas estrelados; receptáculo viloso, tricomas simples. Fruto ca. 1,5cm, subgloboso, liso, pubescente, calcáreo na base, nigrescente no ápice, 
tricomas estrelados; lobos do cálice persistentes, inconspicuamente acrescentes; sementes ca. $6 \mathrm{~mm}$, oblongas; testa lisa a inconspicuamente verruculosa.

Espécie endêmica do Brasil, nos Estados da Bahia, Minas Gerais, São Paulo e Mato Grosso do Sul, em floresta estacional. Foi coletada com flores nos meses de janeiro, março, setembro a dezembro, e com frutos nos meses de janeiro a abril e outubro a dezembro.

Croton rottlerifolius pode ser reconhecido pelo indumento enegrecido presente nos ramos e ápice dos frutos e pelas flores masculinas e femininas campanuladas, com lobos do cálice imbricados.

Dentre as espécies da seção Cleodora, Croton rottlerifolius mais assemelha-se a $C$. fragrantulus, espécie de florestas estacionais da Bolívia e Peru e C. hoffmannii, espécie de florestas pluviais e estacionais da América Central e norte da América do Sul, diferindo destas por várias características (Tab. 5; ver comentários em C. fragratulus e C. hoffmannii).

Material examinado: BRASIL. s.proc., s.d., Riedel (P); Lagoa Santa, fl., s.col. (P); Lagoa Santa, s.d., fl., fr., Warming 1649 (G). BАНIA: Rui Barbosa, Serra do Orobó, Fazenda Santa Maria, 12²0'1'’S e 40²8’45’’W, 20. XII. 2002, fl., L.P. Queiroz et al. 10005 (HUEFS 91323, SP 392157). Minas Gerais: Araguari, fr., 15. XII. 2006, P.O. Rosa et al. 231 (HUFU 46765, SP 399744); Araguari, fl., 21. XI. 2007, G.M. Araújo \& A.E. Gusson s.n. (HUFU 49144, SP 399743); Faz. do Rasgão, 3km de Paraopeba, mata virgem, arbusto da mata, 15. II. 1958, E.P. Heringer 5911 (UB 40340); Lagoa Santa, Warmingii 1649 (G-DC); Vale do rio Araguaia, 1854'45'’-1908'15'’06S e 4802'30'’4743’15’’W, I. 1993, fr., A.L.P. Mota 1513 (VIC 22276); Vale do rio Araguaia,

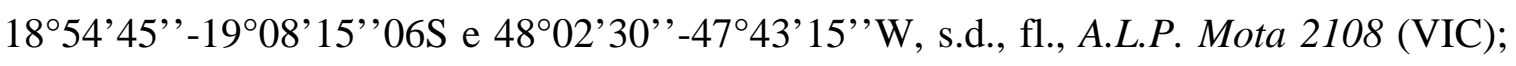
Pains, Fazenda Amoroso, MG 439 Km 16, 20²2'55.5'’-20²3'05.7'’S e 45³9'04.2'’45³8'57.7’'W, atl. 650-700m, arbusto na borda da mata calcária secundária, fl., 08. XII. 2003, P.H.A. Melo \& G.P. Santos 984 (BHCB 88393, SP 370580); Pedrinópolis, fr., 05. III. 1988, J.R. Stechmann et al. s.n. (CETEC NP 1374, SP 226977); Poços de Caldas, fazenda cachoeira, 21.XI.1940, capoeira, muito frequente, fl. Alva, arbusto 2,5m alt., Mello Barreto 11130 (BHCB 35876, HB 28848, US 2438461), Santana do Riacho, Km 101 ao longo da rodovia Belo Horizonte - Conceição do Mato Dentro, afloramento de rochas calcáreas, mata mesófila, fl., 06. XI. 1980, J.R. Pirani et al. CFSC 6692 (SP 
259143, SPF 43934, WIS); Santana do Riacho, 19¹8'27"S e 4336'50"W, III. 2002, fr., L.R. Lima et al. 139 (SPF 150862, WIS); Santana do Riacho, Cardeal Mota, Serra do Cipó, APA Morro da Pedreira, 19¹8'19.3"S e 43³6'50"W, 920 m, fr., 17. I. 2007, J.R. Pirani et al. 5559 (SP 401906, SPF 5559); Uberlândia, s.d., fl., A.L.P. Mota et al. 1482 (SP 392268, VIC 22276); Uberlândia, Fazenda Buriti, mata decídua, fl., 02. X. 1993, G.M. Araújo et al. 1048 (MG 159139, SP 266620, HUFU 7557); Uberlândia, UHE de Miranda, área 24, fl., s.d., A.L.P. Mota et al. 1482 (SP 392268, VIC 22276); Uberlândia, fl., 25. XI. 1994, A.L.P. Mota 2292 (SP 392263, VIC 23818). Mato Grosso do Sul: Corumbá, Morro Bocaína, 1902’08'’S, 57³8'11'’W, fl., 4. IX. 1998, K.C.R. Proença et al. 36 (COR 5681); Terenos, BR 362, 16. XII. 1990, fr., U.M. Resende et al. 285 (CGMS, PEUFR 38257). SÃo PAulo: Águas da Prata, estrada de terra para o pico do gavião, 2159’05,9’’S e 4640’00,9’’W, fr., 24. I. 2007, M.B.R. Caruzo et al. 111 (SP 392151); Bauru, Reserva Florestal de Bauru, floresta mesófila semidecídua, fl., 18. XII. 1980, O. Cavassan 09 (UEC 295227); Botucatu, XII. 1987, J.L.C. Gabriel s.n. (HRCB 10902); Brotas, Fazenda Limoeiro, mata mesófila, fr., 06. I. 1997, S.N. Pagano et al. 153 (HRCB, SP 369093); Campinas, Fazenda Santa Elisa, semi-deciduous Forest, alt. 650m, 2252’'S, 4704’W, fl., 10. X. 1984, G.L. Webster \& J.Y. Tamashiro 25380 (DAV, MBM 153990, MICH, MO 4323549, UEC 40519, UB); Campinas, fl., fr., 17. XI. 1989, R.B. Torres s.n. (IAC 32080, SP 360460); Campinas, Faz. Sta. Elisa, fl., 03. XI. 1992, R.B. Torres s.n. (IAC 32035, SP 360461); Campinas, Remanescente Florestal da fazenda Santa Elisa, Centro Experimetal de Campinas, Instituto Agronômico de Campinas, Floresta Estacional Semidecidual atingida por incêndios, $22^{\circ} 55^{\prime}$ S e $47^{\circ} 05^{\prime} \mathrm{W}, 19$. X. 1997, fl., fr., A.S. Penha et al. s.n. (ESA 60334, MBM 269252, UEC, UNIP); Campinas, Instituto Agronômico de Campinas, mata da Fazenda Santa Elisa, fl. fr., 31. III. 2004, M.B.R. Caruzo et al. 56 (SP 369871, WIS); Campinas, Instituto Agronômico de Campinas, mata da Fazenda Santa Elisa, fl., 04. XI. 2004, M.B.R. Caruzo et al. 75 (SP 372148, SPF, WIS); Campinas, Instituto Agronômico de Campinas, mata da Fazenda Santa Elisa, em fragmento de mata próximo a cerca da fazenda, fr., 21. II. 2006, R. Riina \& M.B.R. Caruzo 1534 (MICH, SP 384394, WIS); Charqueada, V. 1993, K.D. Barreto et al. 514 (ESA); Comissao Geographica e Geologica da Provincia de S. Paulo, fl., Löfgren 447 (P); Corumbataí,

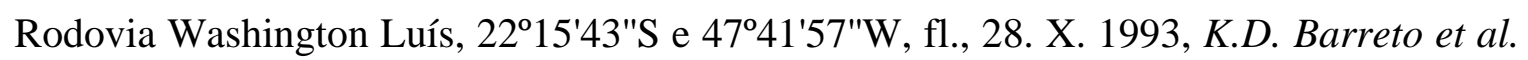
1524 (ESA 25689, FUEL, HUEFS, SP 369784); Monte Alegre, Amparo, Faz. Sta. Isabel, fr., 5. IV. 1943, M. Kuhlmann 582 (SP 49832); Monte Alegre do Sul, Fazenda Benati, fr., 17. III. 1995, L.C. Bernacci et al. 1350 (IAC 30216, SP 279725, SPF, UEC 74411, WIS); 
Piracicaba, Mata do sítio São Luís, 22³3'11,7"S e 47³9'15,6"W, fr., 05. I. 1994, K.D. Barreto et al. 1714 (ESA 18311, MG 158979, SP 291902); Prov. S. Paulo, fl., Mósen 4374 (P, S); Ribeirão Preto, Reserva da Fazenda Fortaleza, 7644727S e 0213265W, fl., 04. XII. 2000, O. Kotchetkoff-Henriques et al. 381 (IAC 43455, SP 366832); Ribeirão Preto, Mata Santa Tereza, Estação Ecológica de Ribeirão Preto, 7650285S e 0204280W, fl., 19. I. 2001, O. Kotchetkoff-Henriques \& V.G. Laguna 384 (IAC 43457, SP 366833); Ribeirão Preto, Morro do Piripau, 7660866S e 02220609W, fl., 04. I. 2002, $O$. Kotchetkoff-Henriques \& A. Furlan 400 (IAC 43464, SP 366834); São Pedro, serra de São Pedro, fl., fr., 22. XII. 1965, J.R. Mattos \& N.F. Mattos 13032 (SP 118339, WIS); São Pedro, fl., 07. XI. 1991, S. Gandolfi s.n. (ESA 11097, SP 292079); São Pedro, fr., 30. XI. 1992, S. Gandolfi s.n. (ESA 11098, SP 292078); Teodoro Sampaio, Parque Estadual do Morro do Diabo, fl., 08. XII. 1994, G.A.D.C. Franco 1322 (HRCB, SP 279734, SPF, UEC 873229, WIS).

14. Croton rufolepidotus Caruzo \& Riina, sp. inéd. (Anexo 2). Tipo: Colombia, Antioquia, Tarazá, Corrigimiento El 12, camino El 12-Barroblanco, km 4 N.O. Medellín, 210 km en troncal del Caribe, bht/bmht, $7^{\circ} 30^{\prime} \mathrm{N}, 7^{\circ} 16^{\prime} \mathrm{W}, 25$. V. 1987, R. Callejas, J. Betancur \& F.J. Roldán 3611 (holótipo: MO!; isótipos: DAV!, HUA!). (Figs. 17 A-H).

Árvores 6--10m alt., tricomas simples, estrelados, lepidotos subinteiros; ramos cilíndricos; ramos jovens lisos, lepidotos, tricomas lepidotos subinteiros. Folhas inteiras, discolores, estreitamente ovais a oval-elípticas, ápice agudo a acuminado, base arredondada a levemente cordada; lâmina 3--11,5x1--4,5cm, margem inteira, ás vezes com glândulas; face adaxial glabra, raramente tricomas esparsos sobre a nervura central, face abaxial lepidota, rufo-argêntea, tricomas lepidotos subinteiros de margem alva e centro rufo-ferrugíneo; nervação pinada, camptódroma, broquidódroma, nervuras terciárias inconspícuas; pecíolo 0,5--1,5cm compr., 1 par de glândulas basilaminares, pateliformes, curtamente estipitadas; estípulas 0,5--1,5cm compr., inteiras, auriculadas, ápice caudado, caducas. Inflorescências 2,5--6,5cm compr., laxas; raque cilíndrica, estriada, lepidota, tricomas lepidoto-subinteiros; címulas contíguas, as proximais femininas, unifloras, as distais masculinas, 1--2 flores; brácteas 3--5mm compr., inteiras, lineares, profilos inconspícuos. Flores masculinas 1--1,5cm compr., campanuladas, pediceladas; pedicelo ca. $6 \mathrm{~mm}$ compr.; cálice ca. 4mm compr., lepidoto externamente, rufo-ferrugíneo, tricomas lepidoto-subinteiros, glabro internamente; lobos do cálice 5, 
unidos até a metade, ca. 2mm compr., inteiros, iguais, valvares, triangulares, ápice agudo, vilosos nas margens; pétalas ca. 4mm compr., espatuladas, ápice ondulado, levemente recortado, densamente vilosas externamente; disco 5-segmentado; estames 15--25, filetes subulados, vilosos na base, anteras estreito-elipsóides; receptáculo viloso, tricomas simples. Flores femininas 1--1,5cm compr., ampuliformes, longamente pediceladas; pedicelo 4--6mm; cálice 6--8mm, lepidoto externamente, rufo-ferrugíneo, tricomas lepidotos-subinteiros, glabro internamente; lobos do cálice 5, levemente unidos na porção basal, 6--8mm compr., inteiros, iguais, quincunciais, oval-lanceolados, ápice acuminado; pétalas ausentes; disco inteiro, rasamente 5-lobado; ovário subgloboso, trígono, lepidoto, tricomas lepidotos subnteiros; estiletes multifidos, unidos na base, inteiros até a metade, segmentos exsertos, recobertos em quase toda a extensão por tricomas lepidotos subinteiros. Fruto ca. 1,5cm, subgloboso, trígono, lepidoto, liso, tricomas lepidotos subinteiros, lobos do cálice inconspicuamente acrescentes; sementes não observadas.

Espécie endêmica de Antioquia, Colômbia, onde cresce em florestas secundárias pluviais das encostas inferiores dos Andes, entre 180 e 300 metros de altitude. Foi coletada com flores e frutos nos meses de maio, julho e novembro.

Croton rufolepidotus pode ser facilmente reconhecido vegetativamente por suas folhas com indumento de coloração rufo-argêntea e estípulas auriculadas.

Dentre as outras espécies da seção Cleodora, Croton rufolepidotus mais assemelha-se a C. salutaris Casar., espécie da floresta Atlântica do sudeste do Brasil (ver comentários em C. salutaris).

Material examinado: COLÔMBIA. AnTIOQUiA: Tarazá, Corregimiento El Doce, 210 km NNE of Medellín, Carretera El Doce-Barro Blanco, near entrance to Hacienda Las Mercedes, rd. outside of finca, $7^{\circ} 30^{\prime}$ N, $7^{\circ} 16^{\prime}$ W, fl., fr., 25. VII. 1987, W.W. Thomas \& C.J. Castaño C. 5525 (COL, MO, NY); Tarazá, Corregimiento El 12, Vía El 12-Doce-

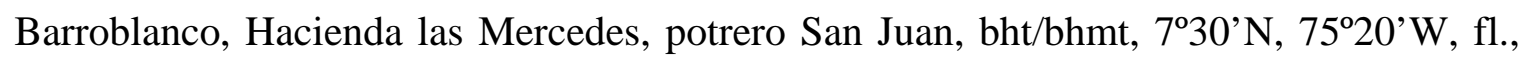
fr., 7. XI. 1987, R. Callejas, F.J. Roldán, A.L. Arbeláez \& D.L. Echeverry 5425 (F, HUA).

15. Croton salutaris Casar., Nov. stirp. bras. 10: 89. 1845. Tipo: Brasil, Rio de Janeiro, “Serra dos Orgaos”, Casaretto 856 (Holótipo: C; Isótipo: G-DC!). (Figs. 7 F-I, 18 A-F). 
= Croton urceolatus Baill. Adansonia 4: 299. 1864. Tipo: Brasil, Sellow s.n. (lectótipo: P!, aqui designado); Brasil, Minas Gerais, “ bords du Persicaba à Itajá, cat. B ${ }^{1}$, n. 601, 691”, A. St.-Hilaire (síntipos: P). (sinônimo proposto por Müller, 1873).

Nome popular: cambraia, sangue-de-drago.

Árvores 3--15m alt., látex avermelhado, tricomas lepidotos subinteiros; ramos conspicuamente angulosos, estriados, com cristas agudas nas partes mais velhas; ramos jovens cilíndricos, lepidotos, tricomas lepidotos subinteiros. Folhas inteiras, fortemente discolores, ovais, mais raramente cordiformes, ápice acuminado, base truncada a arredondada, mais raramente cordada; lâmina 4--20x2--13cm, margem inteira; face adaxial esparsamente lepidota, tricomas lepidotos subinteiros porrectos, rufo-argêntea face abaxial densamente lepidota, tricomas lepidotos subinteiros, rufo-argêntea; nervação pinada, camptódroma, broquidódroma, nervuras terciárias percurrentes, oblíquas, levemente sinuosas; pecíolo 0,5--15cm compr., 1 par de glândulas acropeciolares, pateliformes, estipitadas, raramente curtamente estipitadas; estípulas 4-8mm, linearlanceoladas. Inflorescências 7--19cm compr., laxas, eretas; raque achatada, estriada, lepidota; címulas contíguas, as proximais bissexuadas, ca. 2 flores masculinas e 1 flor feminina, as distais masculinas, ca. 4 flores; brácteas ca. 1mm compr., subuladas, profilos inconspícuos, recobertos por tricomas lepidotos subinteiros. Flores masculinas ca. $4 \mathrm{~mm}$, campanuladas, pediceladas; pedicelo ca. $2 \mathrm{~mm}$ compr.; cálice ca. $2 \mathrm{~mm}$ compr., lepidoto externamente, argênteo, tricomas lepidotos subinteiros, glabro internamente; lobos do cálice 5, unidos até a metade, ca. 1mm compr., inteiros, iguais, valvares, ovais, ápice agudo; pétalas ca. 2mm compr., lanceoladas, ápice obtuso a arredondado, vilosas nas margens; disco 5-segmentado; estames ca. 15, filetes subulados, glabrescentes, anteras elipsóides; receptáculo viloso, tricomas simples. Flores femininas ca. $8 \mathrm{~mm}$, ampuliformes, pediceladas; pedicelo ca. 3mm compr.; cálice ca. $5 \mathrm{~mm}$ compr., lepidoto externamente, rufo-argênteo, tricomas lepidotos subinteiros, glabro internamente; lobos do cálice 5, ca. 5mm compr., inconspicuamente unidos na base, carnosos na base, inteiros, iguais, quincunciais, ovais, ápice agudo; pétalas reduzidas à glândulas ovóides; disco 5-segmentado; ovário subgloboso, lepidoto, tricomas lepidotos subinteiros; estiletes 4-fidos, unidos na base, inteiros no terço inferior, segmentos exsertos, recobertos por tricomas lepidotos subinteiros castanhos. Fruto ca. 1cm compr., elipsóide, liso, lepidotos, tricomas lepidotos subinteiros alvo-prateados e castanhos; lobos do cálice 
persistentes, inconspicuamente acrescentes; sementes ca. 7mm compr., elipsóides; testa lisa.

Endêmica do Brasil, nos Estados de Minas Gerais, Espírito Santo, Rio de Janeiro e São Paulo em floresta pluvial montana e matas ciliares, entre 700 e 950 m de altitude.

Foi coletada com flores nos meses de janeiro, março, abril, julho, agosto, novembro e dezembro, e com frutos nos meses de fevereiro, março, abril, julho, agosto e novembro.

A espécie distingue-se das outras da seção Cleodora por seu látex avermelhado, copioso e ramos caracteristicamente angulosos, que chegam a formar cristas nas partes mais velhas.

Segundo Pio Corrêa (1975), por sua ação cicatrizante, o látex da casca de Croton salutaris é utilizado na medicina popular no tratamento de úlceras.

Croton salutaris Baill. possui características que foram atribuídas por Webster (1993) às seções Cyclostigma Griseb. e Cleodora (Klotzsch) Baill, como címulas basais bissexuadas, pétalas reduzidas nas flores femininas e estiletes multifidos, apesar do indumento lepidoto típico presente na espécie não ser referido para nenhuma dessas seções. Entretanto, como já observado por Caruzo (2005), o número de estames (ca. 15) e os lobos do cálice das flores femininas conspicuamente imbricados, além dos estiletes unidos na base, são indícios morfológicos para o posicionamento da espécie na seção Cleodora, corroborado pela hipótese filogenética da seção (Cap. 1).

Dentre as espécies de Cleodora, Croton salutaris é mais semelhante a $C$. campanulatus (ver comentários em C. campanulatus).

Outra espécie semelhante a Croton salutaris é C. rufolepidotus, endêmica da Colômbia, da qual difere pelo ramos jovens (angulosos em C. salutaris vs cilíndrico em C. rufolepidotus) e estípulas (linear-lanceoladas em C. salutaris vs auriculadas em $C$. rufolepidotus), além de características florais como a textura dos lobos do cálice das flores femininas e número de divisões dos estiletes (Tab. 4).

Croton salutaris é a única espécie da seção Cleodora indicada pela legislação da Secretaria do Meio Ambiente do Estado de São Paulo para o reflorestamento de áreas degradadas (SMA 47 de 27 de novembro de 2003).

Material examinado: BRASIL. ESPíRITO SANTO: Alegre, II. 2000, V.C. Souza et al. 23650 (ESA). MinAS GERAIS: Serra da Piedade, s.d., Warming s.n. (US 289458); 
Araponga, Serra do Brigadeiro, margens do córrego do Boné, 15. IV. 1989, G.A.P. de Melo 28 (SP 392272, VIC 10835) incluir no banco de dados; Carangola, Morro da Torre, 204' S e 4204'W, fl., 06. XII. 1988, L.S. Leoni s.n. (SP 245736, GFJP 555); Lima Duarte, São José dos Alpes, Fazenda da Serra, Mato do Alfredo, fl., fr., III. 1995, V.C. de Almeida 170 (GUA 45057); Juiz de Fora, Mata do Poço Dantas, fl., fr., 14. IV. 1977, J.A. Silva 16370 (CESJ); Juiz de Fora, Museu Mariano Procópio, 17. X. 1986, s.col., s.n. (RB 280564); Juiz de Fora, X. 1986, L. Krieger \& Beatriz 21322 (CESJ, GUA 38872); Juiz de Fora, Poço D’Antas, fl., 11. II. 1988, F.R.S. Pires \& V.L.A. Garcia s.n. (CESJ, MG 152589, SP 221501); Juiz de Fora, Poço D’Anta, fl., 2. III. 1989, Sérgio \& Orlando 24585 (CESJ, GUA 38873, SP); Juiz de Fora, Campos da UFJF, estrada de terra que liga ao Dom Orione, fl., 22. I. 1993, M. Eiterer \& D. Sette de Almeida 124 (RB 395810, CESJ 26351, MBM 291038, UB); Juiz de Fora, Mata do Morro do Redentor, V. 1993, R.G. Silveira \& M.L.G. Lisboa s.n. (CESJ 27762); Juiz de Fora, Morro do Imperador, fl., 1. III. 2002, D.S. Pifano \& R.M. Castro 327 (CESJ 36684, RB 395319, SP 360707); Ouro Preto, Parque Estadual do Itacolomi, 5. I. 1994, fl., M.B. Roschel \& S. Dias s.n. (OUPR 1281); Ouro Preto, 29. I. 1997, M.B. Roschel \& J. Craig 468 (OUPR 6621); Serra do Espinhaço, Slender tree $4 \mathrm{~m}$ tall, leaning on other trees, flowers white, near river, southeastern drainage of Pico Itambé, about 5km directly west and north of Santo Antônio de Itambé, elev. 950m, hillsides with second growth Forest and bracken-covered campo, sloping down to river with blocky sandstone and sandy soil, fl., fr., 9. II. 1972, W.R. Anderson et al. 35686 (R 139631, NY, MBM 65349, UB 38927, US 2934234, VEN 174889); Viçosa, road to São Miguel, just beyond km. 4, in cut-over woods on slope, 690m, 4. IV. 1930, Y. Мexia 4563 (MICH, MO 1068985, US 1617912, WIS); Viçosa, road to São Miguel, on slope near Km. 5 at border of forest, 720m, 29. X. 1930, Y. Mexia 5237 (MICH, MO 1067090, US 1618042); Viçosa, Fazenda Octavio Pacheco, 19. I. 1935, J.G. Kuhlmann s.n. (SP 392269, VIC 2333). Rio DE JANEIRO: Nova Friburgo, Reserva Ecológica Municipal Macaé de Cima, Estrada para Hotel Faz. São João, 2200'S e 4203'W, fl., 27. XII. 1989, M. Nadruz et al. 516 (RB 146241, SP 266223, SPF); Nova Friburgo, 22 00 'S e 4203'W, I. 1991, S.V.A. Pessoa et al. 550 (RB, SPF); Nova Friburgo, estrada para Nova Friburgo, rodovia RJ 116, 500m da entrada para Lumiar, próximo ao Km 73, 22²0’0,0’' S e 42³0’56,8’’W, fl., 04. II. 2006, M.B.R. Caruzo et al. 89 (SP 384408, WIS); Petrópolis, Carangola, XII. 1943, O.C. Góes \& Dionísio 955 (MG 49615); Rio de Janeiro, Corcovado, G.H. Langsdorff s.n. (LE, US 1574027); Serra dos Órgãos, VII. 1940, A.C. Brade 16487 (RB 143304, MG 149610, RUCA); Teresópolis, fl., II. 
1943, H. Vellozo s.n. (R 38390); Teresópolis, fl., II. 1943, s.c. s.n. (R 99249); Teresópolis, Posse section of Teresópolis, hills with secondary vegetation, fl., 27. I. 1982, L.R. Landrum 4203 (NY, MBM 84166, MO 3095636, US 3313977); Teresópolis, Serra dos Órgãos, Vale das Yuccas, fl., III. 1982, M.R. Barbosa \& Tokitika 299 (GUA 21944); Teresópolis, rua Sloper, próximo a praça dos namorados, mata perturbada dentro da

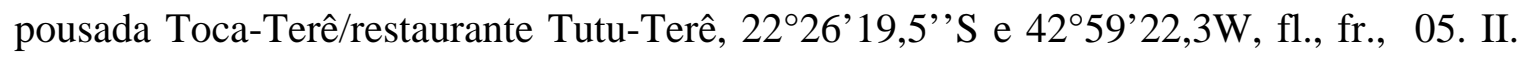
2006, M.B.R. Caruzo et al. 91 (SP 384410, WIS). SÃo PAulo: Cunha, Parque Estadual Serra do Mar, ao longo do Rio Paraibuna, fl., 31. III. 1994, J.B. Baitello 638 (HRCB, SP 279762, SPF, UEC); Cunha, Parque Estadual da Serra do Mar, Núcleo Cunha-Indaiá, fl., fr., 30. XI. 2004, M.B.R. Caruzo et al. 81 (SP, SPF, WIS); Jundiaí, Serra do Japi, sentido Eloy Chaves, próximo a represa do Dae, 30. XI. 1968, D. Coelho \& J. Lima s.n. (INPA 25926, UEC 28650); Jundiaí, Serra do Japi, sentido Eloy Chaves, próximo a represa do Dae, 8. XII. 1998, fl., E.R. Pansarin 381 (UEC 103440); Mogi das Cruzes, Parque Municipal da Serra do Itapety, fl., fr., 26. III. 1993, P.L.B. Tomasulo \& Silva 210 (SP); São José do Barreiro, Parque Nacional da Bocaína, fl., fr., 18. VII. 1994, L. Rossi \& E.L.M. Catharino 1577 (SP, SPF, UEC); São José dos Campos, 28. II. 1909, A. Löfgren 264 (RB 4219); São José dos Campos, 2304’30’’S e 4556’15’’W, 9. I. 1986, fl., A.F. Silva \& C. Capellari Jr. 1347 (CEPEC 50962, UEC); São José dos Campos, 2304’30’’S e 4556’15’’W, 11. I. 1986, A.F. Silva \& C. Capellari Jr. 13161 (MG, UEC); São José dos Campos, 2304'30’'s e 4556’15’’W, 13. I. 1986, fl., A.F. Silva \& C. Capellari Jr. 379 (CEPEC 51149, RB 409803, UEC); São Paulo, Parque do Estado e Jardim Botânico, (cultivada), fl., 26. XII. 1933, F.C. Hoehne s.n. (HB 52070, SP 31388, SPF 83197, US 2857622); São Paulo, nativa no Jardim Botânico e Parque do Estado, fl., fr., 16. IV. 1947, J.S. Silva 285 (CEPEC 65938, MG 152518, SP 122750, SPF); São Paulo, Bairro Sapopemba, Aterro Sanitário São João, fr., 01. VIII. 2005, W. Ribeiro s.n. (SP 377131); São Pedro, 22²9'59,7"S e 4755'14,8"W, fl., fr., 10. VIII. 1994, K.D. Barreto et al. 2843 (ESA, SP 369771); Serra da Cantareira, São Paulo, fl., 14. VII. 1933, M. Koscinsky s.n. (SP 30785). Paraná: Adrianópolis, Parque Estadual das Lauráceas, 9. I. 2000, fl., I. Isernhagen 235 (UPCB 44333).

16. Croton sphaerogynus Baill., Adansonia 4: 326. 1864. Tipo: Brasil, Rio de Janeiro, 1835, Gaudichaud 1139 (lectótipo: P!, designado por Caruzo \& Cordeiro 2007); Brasil, Minas Gerais, 1842, Claussen 79 (síntipo: P!), Claussen 2004 (síntipo: P). (Figs. 9 A-E, 19 F-J). 
= Cleodora sellowiana Klotzsch, Arch. Naturgesch. 7: 197. 1841. (sinônimo proposto por Müller, 1866).

= Croton pachycalyx Müll.Arg., Linnaea 34: 109. 1865. Tipo: Rio de Janeiro, Gaudichaud 1139 (lectótipo: P!, aqui designado), Riedel s.n. (síntipo), Luschnath (B síntipo), Widgren 487 (sintipo). (sinônimo proposto por Müller, 1866).

Arbustos 1,5--3m, látex incolor; tricomas estrelados, estrelado-porrectos e adpressoestrelados; ramos achatados, estriados, ramos jovens hirsutos, tricomas adpressoestrelados, geralmente porretos. Folhas inteiras, levemente discolores, oval-lanceoladas a elípticas, ápice agudo, base conspicuamente cordada a auriculada, lobos geralmente sobrepostos; lâmina 4--25x2--10cm, margem miudamente serrilhada a serrilhada, raramente denteadas, com glândulas, ferrugíneas, face adaxial e abaxial esparsamente hirsutas a glabrescentes, tricomas adpresso-estrelados, porrectos, face abaxial esparsamente hirsutas a glabrescentes, tricomas adpresso-estrelados, porrectos; nervação pinada, camptódroma, broquidódroma; nervuras terciárias percurrentes, oblíquas, levemente sinuosas; pecíolo 0,5--3cm, 1 par de glândulas basilaminares, globosas, acastanhadas, sésseis; estípulas 3--5mm compr., inteiras, lineares. Inflorescências 3-$25 \mathrm{~cm}$ compr., laxas, pendentes; raque achatada, estriada, flocosa, tricomas adpressoestrelados; címulas contíguas, as proximais bissexuadas, ca. 4 flores masculinas e 1 flor feminina, as distais masculinas, ca. 4 flores; brácteas ca. 4 mm compr., lanceoladas a lineares, profilos ca. 1mm compr., lineares. Flores masculinas ca. 6mm compr., campanuladas, pediceladas; pedicelo ca. 3mm compr.; cálice ca. $2 \mathrm{~mm}$ compr., pubescente externamente, alvo, tricomas estrelados e adpresso-estrelados, glabro internamente; lobos do cálice 5, unidos até a metade, ca. 1mm compr., iguais, inteiros, valvares, ovais a levemente romboidais, ápice agudo, margem vilosa; pétalas ca. $2 \mathrm{~mm}$ compr., ovais a oval-lanceoladas, ápice agudo a arredondado, revoluto, margem vilosa; disco 5segmentado; estames ca. 16; filetes subulados, glabros, anteras globoso-elipsóides; receptáculo viloso, tricomas simples. Flores femininas ca. $5 \mathrm{~mm}$ compr., ampuliformes, curtamente pediceladas, pedicelo ca. 1mm compr.; cálice ca. 4mm compr., esparsamente pubescente externamente, glauco, tricomas estrelados e adpresso-estrelados, glabro internamente; lobos do cálice 5, ca. 4mm compr., unidos na base, reflexos, inteiros, iguais, quincunciais, carnosos, romboidais, ápice agudo, margem vilosa; pétalas ausentes; disco 5-segmentado; ovário globoso, recoberto por tricomas tricomas estrelados a adpresso-estrelados, geralmente porrectos; estiletes 4-fidos, unidos até a metade, 
segmentos exsertos, recobertos por tricomas estrelados a adpresso-estrelados. Fruto ca. 7mm compr., globoso, liso, recoberto por tricomas estrelados e adpresso-estrelados; lobos do cálice persistentes, inconspicuamente acrescentes; sementes ca. $4 \mathrm{~mm}$ compr., globosas; testa levemente verruculosa.

A espécie pode ser reconhecida no campo pelas folhas dispostas disticamente nos ramos e recobertas por indumento esparso, geralmente hirsuto.

Ocorre no Brasil nos Estados da Bahia, Espírito Santo, Rio de Janeiro e São Paulo em floresta de restinga e floresta pluvial baixo montana, desde o nível do mar até $750 \mathrm{~m}$ de altitude Foi coletada com flores e frutos nos meses de janeiro, fevereiro, março, maio, junho, outubro, novembro e dezembro, e com frutos nos meses de janeiro, fevereiro, março, junho e novembro.

As coleções de Croton sphaerogynus examinadas são todas provenientes das florestas de restinga da costa do Brasil, entretanto, dois dos síntipos de C. sphaerogynus citados no protólogo são de Minas Gerais, Clausen 79 e 2004, datadas de 1842. Dessas, apenas foi localizada Clausen 79, que não possui nenhuma referência à data de coleta. Nenhuma outra coleção dessa espécie foi encontrada em Minas Gerais, levando-nos a crer que pode ter havido um erro na etiqueta em relação à procedência da coleção, uma vez que as coleções de Clausen não estão regularmente datadas e numeradas.

Croton sphaerogynus foi incluída na Lista oficial de espécies da Flora ameaçada de extinção do Estado de São Paulo (SMA, 2004) na categoria Em Perigo (EN) em virtude de sua distribuição geográfica restrita no estado, ocorrência desconhecida em unidades de conservação e ocorrência em floresta de restinga, formação vegetal não protegida por legislação específica.

Material examinado: BRASIL. BAHIA: Ilhéus, fl., fr., 8. II. 1982, L.A. Mattos Silva et al. 1460 (CEPEC 28993, SPF 43572); Ilhéus, ca. 6 Km ao W do Distrito de Olivença, na estrada Olivença/Vila Brasil, 1445’'S e 39²’W, 30. III. 1995, fl., fr., J.G. Jardim et al. 632 (CEPEC 64198); Ilhéus, 1468’39’’s e 39²’6', 19. II. 2004, fl., fr., C.S. de Sant'Ana et al. 1122 (CEPEC 102423); Maraú, 22. XI. 1971, fl., fr., T.S. Santos 2206 (CEPEC 8129); Maraú, Rod. BR 030, trecho Ubaitaba/Maraú, 45-50km a leste de Ubaitaba, ca. $50 \mathrm{~m}$ alt., $14^{\circ} 11^{\prime} \mathrm{S}$ e $39^{\circ} 1^{\prime} \mathrm{W}$, fl., fr., 12-13. VI. 1979, S.A. Mori et al. 11970 (RB 375482, CEPEC 17120). EsPíRITo SANTo: Guarapari, 6 km N of Guarapari, 20³7'S, 40²9'W, fl., fr., 24. II. 1988, W.W. Thomas et al. 6131 (NY, MO, SP 236551, SPF, WIS); Santa Tereza, estrada de Sta. Tereza a Nova Lombardia, sitio do Sr. 
Alcebíades, 700 a 750m, 4. II. 1985, A. Peixoto et al. 3444 (MO); Santa Teresa, Santo Antônio, terreno do Boza, altitude 800m, fl., 08. 12. 1998, L. Kollmann et al. 1254 (MBML 8277); Santa Teresa, Santo Antônio, terreno do Boza, altitude 750 m, fl., fr., 14. I. 1999, L. Kollmann \& E. Bausen 1559 (MBML 9660). RIO DE JANEIRO: Matas da mesa do Imperador, D. Federal, (Rio de Janeiro), 14. XII. 1944, P. Occhioni 168 (RB 51052); Morro do Corcovado, Distrito Federal, 18. XII. 1945, Altamiro \& Walter 176 (R, RB 54904); Estado da Guanabara, D. Federal, Vista Chinesa, IX. 1958, E. Pereira 431 (RB); Rio de Janeiro, 23. IX. 1958, fl., E. Pereira et al. 4343 (RB 107922, US 2433947); Parque Nacional da Tijuca, Vista Chinesa, na beira da estrada, $28^{\circ} 58^{\prime} \mathrm{S}$ e $43^{\circ} 15^{\prime} \mathrm{W}$, fl., fr., 21. XI. 1987, S. Ginzbarg \& M. Emmerich 654-3 (LL, TEX, US 3516656); Rio de Janeiro (antiga Guanabar), estrada da Vista Chineza, fl., 7. XI. 1966, E.F. Guimarães \& D. Sucre 83 (CEPEC 77440, F, K, LIL, MBM 228137, MBML, MG, R, RB 132507); “Estado da Guanabara, estrada da Vista Chinesa”, (Rio de Janeiro), fl., 11. X. 1967, D. Sucre 1657 (HB, R, RB 136773, SP 382691); "Estado da Guanabara, D. Federal, Vista Chinesa”, (Rio de Janeiro), IX. 1958, E. Pereira 4323 (HBR, RB, RFA, US 2433947); “Guanabara, Vista Chinesa, mesa do Imperador”, (Rio de Janeiro), 16. X. 1972, J. Almeida de Jesus 2023 (RB 248324); Angra dos Reis, Ilha Grande, R.B.E. da Praia do Sul, fl., VI. 1984, D.S. Pedrosa $1122^{A}$ \& H.Q. Boudt Fernandes 931 (GUA 27378); Angra dos Reis, Ilha Grande, Res. Biol. Est. da Praia do Sul, fl., 13. XII. 1992, D. Araujo 5849 (GUA 26159); Angra dos Reis, Ilha Grande, Reserva Biológica Estadual da Praia do

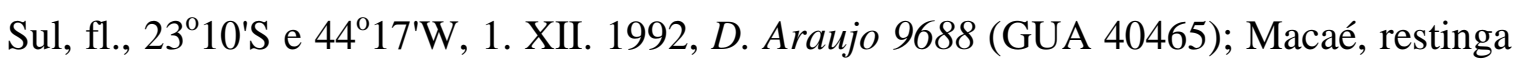
de Cabiúnas, no caminho para Lagoa Comprida, 22. XI. 86, A. Souza 1560 \& E. Pena 127 (R); Macaé, loteamento Lagomar, mata de restinga, remanescente periodicamente inundável, fl., 29. XI. 1994, C. Farney \& D. Araujo 3434 (GUA 43621, RB 311030); Macaé, restinga de Carapebus: ca. de 2km da lagoa, 29. II. 1996, A.S. Oliveira et al. 3859 (R); Morro Queimado, X. 1946, A.P. Duarte \& E. Pereira 358 (RB); Rio de Janeiro, Corcovado, s.d., Duarte e Paulo 409 (RB 59046); Rio de Janeiro, Morro Dois Irmãos, fl., 26. IX. 1946, A.P. Duarte 314 (RB 59040, SP 382695); Rio de Janeiro, Corcovado, 05. XI. 1946, Duarte e Paulo 790 (RB 59036); Rio, Horto Florestal, 27. XII. 1926, S.G. Kuhlmann 251 (RB 111122); Rio, matas da Vista Chinesa, 10. I. 1942, E. Pereira 42 (RB 46257); Rio de Janeiro, entre a Vista Chinesa e o Jardim Botânico, s.d., J. de Saldanha, Ex. Herb. J. de Saldanha 4238 (RB 255209); Rio de Janeiro, fl., IX. 1915, F.C. Hoehne s.n. (MG 159089, SP 25051); Rio de Janeiro (Guanabara, Horto), XII. 1919, P. Campos Porto s.n. (RB 10401); Rio de Janeiro, XII. 1926, J.G. Kuhlmann 251 (RB); Rio de 
Janeiro (Distrito Federal), XII. 1944, P. Occhioni 168 (RB); Rio de Janeiro (Morro Queimado), X. 1946, A. Edmundo 358 (RB); Rio de Janeiro, fl., 20. XI. 1955, E. Pereira 1893 (RB 94047, SP 382696); Rio de Janeiro (antiga Guanabar), estrada da vista Chinesa, 07. XI. 1966, E. Guimarães \& D. Sucre 83 (R, K, CEPEC, F, MBML, MG 160213, LIL, RB, MBM); Rio de Janeiro (Mata do Rumo), I. 1969, D. Sucre 4467 \& P.I.S. Braga 1344 (RB); Rio de Janeiro, Rio das Ostras, na restinga, 7. IV. 1971, fl., fr., L. Krieger 10484 (CESJ, RB 228632); Rio de Janeiro, P.N. Tijuca, mesa do Imperador, ca. 2250'S e 43²0’W, elev. ca. 400-650m, 12. XII. 1977, L.R. Landrum 2052 (RB 413773); Rio de Janeiro, P.N. Tijuca, estrada D. Castorina acima da Vista Chineza, 14. XII. 1983, fl., C. Farney \& H.C. Lima 387 (CEPEC 38341, K, INPA 140058, NY, RB 238548); Rio de Janeiro (Vista Chineza), fl., fr., 21. XI. 1987, S. Ginzbarg \& M. Emmerich 654-1 (RB 265866, SP 218075); Rio de Janeiro, horto florestal, fl., 26. IX. 1991, L.C. Giordano et al. 1170 (CEPEC 72195, K, F, RB 293433); Rio de Janeiro, horto florestal, caminho da torre, 12. XI. 1991, A. Machado \& M. Nadruz 07 (RB 295401); Rio de Janeiro, grotão, subindo na encosta em direção ao pico do morro, floresta ombrófila densa degradada, $\mathrm{X}$. 1992, R. Marquete 693 (K, F, RB 300026); Rio de Janeiro, X. 1994, P. Botelho et al. 07 (RB); Rio de Janeiro, Morro dois Irmãos, X. 2000, C. Farney \& C.E.R. Sampaio 4233 (RB); Rio de Janeiro, Parque Nacional da Tijuca, vertente Leste, entre 500 e 670m, trilha da Mesa do Imperador-Morro Queimado, fl., 13. XI. 2000, C.L. de Oliveira \& M.C. Vianna 1698 (GUA 46872); Rio de Janeiro, Parque Nacional da Tijuca, Alto da Boa Vista, aproximadamente $100 \mathrm{~m}$ do mirante da vista Chineza, $400 \mathrm{msm}, 22^{\circ} 58^{\prime 2} 24,2^{\prime}$ 's e 43¹4'59,7'’W, fr., 03. III. 2006, M.B.R. Caruzo et al. 88 (SP 384407, WIS); Rio de Janeiro, Parque Nacional da Tijuca, Alto da Boa Vista, aproximadamente 100m do mirante da Vista Chineza, 600msm, 2258'24,2'’S e 4314'59,7'’W, fl., 18. XI. 2008, M.B.R. Caruzo \& L.R. Lima 121 (SP); Teresópolis, X. 1987, A. Souza et al. 308 (R 183219). São Paulo: Bertioga, Riviera de São Lourenço, X. 1999, S.E. Martins 565 (SP); Bertioga, Riviera de São Lourenço, fl., 7. X. 2004, M.B.R. Caruzo et al. 65 (SP 370367, WIS); Bertioga, Riviera de São Lourenço, fl., 7. X. 2004, M.B.R. Caruzo et al. 66 (SP 370366, WIS); Bertioga, Riviera de São Lourenço, fl., 7. X. 2004, M.B.R. Caruzo et al. 67 (SP 370365, WIS); Cananéia, Parque Estadual da Ilha do Cardoso, restinga, fr., 23. I. 2003, R.G. Udulustch et al. 1520 (ESA 88476, SP 378809); Ilha Comprida, X. 1999, P.G. Carrasco et al. 71 (HRCB); Ilha do Cardoso, XI. 2004, M.P. Sandrini et al. s.n. (SPF 166656); Itanhaém, vila Suarão, loteamento, fl., 15. XI. 1996, M. Kirizawa 3318 (SP 300932); Itanhaém, 2412'5'’S e 4651'28'’W, fl., 28. 8. VI. 1998, F. França \& E. 
Melo 2584 (HUEFS 34467, SP 360199); Itanhaém, próximo a saída do Balneário Gaivota, beirando a SP 055, restinga arbórea, próximo a rodovia, 24¹4'19'’S, 465'31'’W, elev. 27, 24. X. 2007, R.C. Forzza et al. 4800 (RB 458577, SP 412809); Praia Grande, X. 1898, A. Löfgren in CGG 4202 (SP); “São Paulo, by road S. PauloSantos, lower slope, (São Paulo-Santos), 22. X. 1966, J.C. Lindeman \& J.H. Haas 3202 (RB, MBM 136623, UB).

17. Croton spruceanus Benth., Hooker's J. bot. Kew gard. misc. 6: 375. 1854. Tipo: Brasil, Amazonas, “Among inundated rocks at the falls of San Gabriel”, Jan-Aug 1852, Spruce 2205 (holótipo: K!, isótipos: NY!, MO!, P!). (Figs. 9 F-I, 18 G-M).

= Croton calycularis Huber, Bull. Soc. bot. Geneve 6: 181. 1914 publ. 1915. Tipo: Brasil, “Hab. In silvis editis ad fl. Cumina-mirim”, 13. XII. 1906, A. Ducke s.n. (holótipo: MG 7946!; isótipo: RB!). (sinônimo proposto por Secco, 2008).

Arbustos ca. 3m alt., látex incolor, tricomas estrelados, adpresso-estrelados, estrelado-lepidotos e dendríticos; ramos cilíndricos; ramos jovens levemente estriados, flocosos, tricomas dendríticos, alvos. Folhas inteiras, discolores, elípticas a ovais, raramente oval-lanceoladas, ápice acuminado a longamente acuminado, base arredondada; lâmina 4--16x0,7--8,5cm; margem inconspicuamente serrilhada, com glândulas; face adaxial glabrescente, tricomas simples, tricomas estrelados sobre a nervura central, face abaxial pubescente, calcárea, tricomas adpresso-estrelados porrectos, alvos; nervação pinada, camptódroma, broquidódroma, nervuras terciárias percurrentes, oblíquas, levemente sinuosas; pecíolo 0,3--2,5cm, 1 par de glândulas basilaminares, pateliformes, sésseis, alaranjadas; estípulas subuladas, ca. 3mm. Inflorescências 4-$18 \mathrm{~cm}$, laxas; raque levemente achatada, estriada, flocosa, tricomas dendríticos; címulas contíguas, as proximais bissexuadas, 1 flor masculina e 1 flor feminina, as distais masculinas, unifloras; brácteas ca. 2mm compr., inteiras, linear-lanceoladas, profilos inconspícuos. Flores masculinas 0,6--1cm, campanuladas, pediceladas; pedicelo 1-4mm; cálice ca. 4mm, pubescente externamente, ferrugíneos, tricomas adpressoestrelados e estrelado-lepidotos, glabro internamente; lobos do cálice 5, unidos até a metade, ca. 2mm, inteiros, iguais, inconspicuamente imbricados, ovais a triangulares, ápice agudo, margem vilosa; pétalas ca. $5 \mathrm{~mm}$, elípticas a oblongas, ápice obtuso a arredondado, ondulado, vilosas externamente; disco 5-segmentado; estames ca. 15, filetes 
subulados, vilosos na base, anteras elipsóides; receptáculo viloso, tricomas simples. Flores femininas ca. $1,1 \mathrm{~cm}$, urceoladas, pediceladas; pedicelo ca. $4 \mathrm{~mm}$; cálice ca. $7 \mathrm{~mm}$, pubescente externamente, ferrugíneo, tricomas adpresso-estrelados e estrelado-lepidotos, glabro internamente; lobos do cálice 5, unidos até quase o ápice, ca. 1mm compr., inteiros, iguais, inconspicuamente imbricados, ovais, ápice agudo; pétalas ausentes; disco inteiro, rasamente 5-lobado; ovário globoso, tricomas adpresso-estrelados e estreladolepidotos; estiletes unidos até a metade, 4-fidos (bibífidos), sendo a segunda divisão dos segmentos apenas no ápice dos estiletes, inclusos, recobertos por tricomas estrelados e adpresso-estrelados até a metade. Fruto ca. $1,8 \mathrm{~cm}$, subgloboso, levemente verruculoso, tricomas adpresso-estrelados e estrelado-lepidotos, lobos do cálice conspicuamente acrescentes, inflados no fruto jovem, revolutos no fruto maduro; sementes ca. $6 \mathrm{~mm}$, elipsóides; testa costada.

Espécie das florestas pluviais de terra firme e inundáveis da região amazônica e encostas dos Andes (Equador, Colômbia, Venezuela, Bolívia e Brasil.), com grande amplitude altitudinal, ocorrendo de 50 a até aproximadamente 1800 m de altitude. Foi encontrada com flores de janeiro a junho e de agosto a dezembro, com frutos de fevereiro a junho, agosto a outubro e dezembro.

A espécie pode ser reconhecida por suas folhas discolores, voltadas para baixo, elípticas a ovais e de base arredondada, além das inflorescências eretas lobos do cálice conspicuamente acrescentes e inflados no fruto jovem.

Os estiletes bibífidos de Croton spruceanus, denominação usada por Lima \& Pirani (2008) para espécies da Seção Lamprocroton, onde os dois ramos de cada estilete são divididos apenas próximo do ápice, foram descritos por Müller $(1866,1873)$ como bífidos.

Material examinado: COLÔMBIA. CAucA: B/grande, Corr. Ceilán, Vereda Bocaemonte, via Hda. La Luciana, 1680 m, 25. V. 1982, fl., fr., M. Monsalve 61 (MO 3591421); Cali, Villa Carmelo, 1700 m alt., fl., fr., 15. V, 1982, H. Murphy 393 (COL 259236, NY, US 2963350); Ceylon “La Luciana”, government owed recuperating property, alt. 1300, fl., fr., 25. V. 1982, H. Murphy 466 (COL 265805, MO 3046092, NY, US 2971751); Cauca Valley, Oak grove, east of, alt. 1600-1700 m, fl., 27. VI. 1922, F.W. Pennell \& E.P. Killip 7249 (NY); Quebrada Silencio, 2 km. Below source, 16 km. W. of Timba, drainage of Río Timba, 35’N, 76²7’W, 1550m, fl., F.R. Fosberg 20483 (NY, 
US 2108692). CundinamarCA: Camino de herradura antiga de Guaduas a Villeta, entre Guaduas y el Alto del Trigo, alt. 1100-1800m, fl., 10. XI. 1945, H. Garcia-Barriga 11815 (GH, US 1854654). VENEZUELA. Amazonas: Atabapo, río Cunucunuma, comunidad de Culebra, fl., 5. IV. 1992, J. Perez \& M. Sosa 91 (VEN 377102). MÉRIDA: Tucupido del río Camburitohacia Santa Maria de Caparo, distrito Arzobispo Chacón, fr., 4. VIII. 1973, S. López-Palacios \& J.A. Bautista B. 3209 (MER 3116). ZuLiA: Lagunillas, cuenca del Embalse Burro Negro (Pueblo Viejo), laderas occidentales de la Serrania de Ziruma o El Empalado, a lo largo del río Grande, unos $13 \mathrm{~km}$ al norte del Embalse, aprox. Lat. $10^{\circ} 25^{\prime} \mathrm{N}$., Long. 7049’O., en bosque siempreverde original, Altura 550-600 m., 1-5. IV. 1982, G.S. Bunting et al. 11184 (HERZU, NY). BRASIL. AmAzonAs: Região do Rio Jarí, estrada entre Planalto A e Braço, fl., 22. I. 1969, N.T. Silva 1667 (DAV 105763, MO 5103791); Rio Jamary, cach. Samoel, fr., IX. 1918, J.G. Kuhlmann 2106 (RB 10430); Rio Marauia, afl. do R. Negro, 11. VI. 1976, fr., L.R. Marinho 510 (IAN 152704); Serra do Jacamim, Rio Negro, fl., 6. III. 1936, A. Ducke s.n. (DAV 70644, RB 35702). PARÁ: BR 163, Cuiabá-Santarém highway, km 1131, vicinity of Igarapé Natal, fl., 15. XI. 1977, G.T. Prance et al. 25420 (MG 60027, MO 5696927, NY); Capanema, rio Quatipuru, in vicinity of Mirasselvas, ca. $30 \mathrm{~km}$ by road west of Bragança, elev. $50 \mathrm{~m}$, ca. $1^{\circ} 04^{\prime} \mathrm{S}$ e 4659’W, fr., 9. IV. 1980, G. Davidse et al. 18100 (DAV 103840, INPA, MG 95735, MO 5696536, NY, US 3195279); Capanema, estrada para a vila de Mirasselvas, entrada na estrada Capanema-Bragança, próximo a uma Igreja, a aproximadamente $10 \mathrm{~km}$ de Capanema, fl., fr., 4. III. 2006, M.B.R. Caruzo \& R. Riina 101 (SP 384400, WIS); Faro, Castanhal da Boa Vista, estéril, fr., 31. I. 1910, A. Ducke s.n. (MG 10567, P, RB 169); Mata do Rio Cuminá-Mirim, afluente do Trombetas, fl., 13. XII. 1906, A. Ducke s.n. (MG 7946, MO 1678070, RB 2418); Monte Alegre, 26. III. 1924, J.G. Kuhlmann 1767 (RB 20656, US 2820645); Oriximiná, estrada oriximiná Obidus e estrada do BEC km 70, próximo ao Rio Cuminá-Mirim, fl., 14. IX. 1980, C.A. Cid et al. 2544 (INPA 96971, MG 77913, US 2985004); Quatipuru, região de Santarém Novo, 6. IV. 1963, fr., W. Rodrigues 5130 (INPA 13796); Rio Guamá, São Miguel, I. 1945, fl., R. de L. Fróes 20267 (IAN 16229, US 2279549); Santarém, Rio Maíca, Serra de Taperinha, fl., fr., 5. II. 1968, M. Silva 1364 (MG 35460, SP 111046). MATo Grosso: source of the Jatuarana River, Machado River region, fl., XII. 1931, B.A. Krukoff 1666 (MICH). RonDôNIA: Falls of Madeira, fl., X. 1886, H.H. Rusby 2632 (GH); Falls of Madeira, fl., X. 1886, H.H. Rusby 2622 (US 206981); Trail north of Rio Madeira from 2km below confluence of Rio Abunã, fl., fr., 12. XII. 1968, G.T. Prance et al. 8314 (INPA 25112, MG 39408, MO 
5696901, NY). ACrE: Acrelândia, BR-364, Kim 85, fazenda do Sr. Natalício Gomes Silva, 9`57’57’’S, 67²4’00W, fr., 11. II. 2000, I.S. et al. 251 (NY, WIS); Boa Esperança, Abumau, fl., 22. X. 1923, J.G. Kuhlmann 187 (DAV 70598, MG, MICH, RB 20650, SP 382690, US); Cruzeiro do Sul, Rio Branco, Igarapé Formoso, 08³6’S e 73¹0W, 11. X. 1987, fl., M.C. Ferreira \& P. Araújo 50 (HRBN 24695, INPA 161327, RB 365209); Rio Branco, Rio Branco-Porto Velho Highway, between km 22-37, 8. II. 1979, fr., B.W. Albuquerque et al. 1344 (DAV 150486); Sena Madureira, trail west of Rio Iaco from São Caetano, 18km above Sena Madureira, 8. X. 1968, fl., G.T. Prance et al. 7933 (A, C, COL, G, INPA 24731, K, M, MG 39251, MICH, MO, NY, P, S, U, US, VEN); Varadouro do São Luiz, fl., 26. X. 1923, J.G. Kuhlmann 723 (MG, RB 20655, SP 382693). EQUADOR. Morona-SANTiAgo: La Mision, Salesiano, $5 \mathrm{~km}$ al S del Rio Bomboiza y cerca la carretera Zamora-Gualaquiza, 800 m, fl., fr., 31. X. 1985, M.A. Baker \& J. Zaruma 6493 (MO 329651). BOLÍVIA. Pando: Madre de Dios, Puerto Candelaria, along the Rio Madre de Dios, 21 km (by air) WSW of Riberalta, $11^{\circ} 2^{\prime} \mathrm{S}$, 66¹5’W, 125 m, fl., 19. VIII. 1985, M. Nee 31420 (MO 42535337, NY). SANTA CruZ: Guarayos, $40 \mathrm{~km}$ al SW de rio San Matín, $14^{\circ} 30^{\circ} \mathrm{S}, 62^{\circ} 06^{\prime} \mathrm{W}, 200 \mathrm{msnm}$, fl., 26 Oct - 05 nov 1992, I.G. Vargas et al. 1774 (USZ); Velasco, Parque Nacional Noel Kempff Mercado, pei de monte, bosque húmedo alto, dosel de 20-35 m, emergentes hasta $45 \mathrm{~m}$, 14³4'33’’S, 6049’50’’W, 200 m, fl., 23. X. 1993, T. Killeen et al. 5925 (MO, USZ); Velasco, Parque Nacional Noel Kempff Mercado, bosque seco en la pendiente de la serrañia de Caparuch Substrato duricosta ferruginosa e latosol, 14³3'46”'S, 6046'18'’W, 300 m, fl., 8. XI. 1993, A. Jardim et al. 74 (LPB, MO 5032320, USZ 7938); Velasco, Parque Nacional Noel Kempff Mercado, Senda de Geobol, 15 km SE del campamento Los Fierros, bosque húmedo tropical con dosel de 20-25 m y emergentes hasta 40 m, 14³5'16'’'S, 6047’48'’W, 300 m, fl., 20. XI. 1994, T. Killeen 7147 (USZ); Velasco, Parque Nacional Noel Kempff Mercado, a 15 km Del Campamento Los Fierros, 14³7’02'’'S 6050'05'’W, 200 m, fr., 3. III. 1997, S. Jimenez et al. 1127 (DAV 152952, MO 5903018, USZ).

18. Croton stellatoferrugineus Caruzo \& Cordeiro, sp. inéd. (Anexo 3). Tipo: Brasil, Minas Gerais, Santo Antônio do Itambé, Estrada para as cachoeiras e para a ponte de pedra, próximo a ponte, $18^{\circ} 27^{\prime} 16,2^{\prime \prime}$ 's e 4318’29,4’’W, 750 msm, fl., 25. VI. 2008, 
M.B.R. Caruzo, L.R. Lima, S.E. Martins \& A.L. Santos 120 (holótipo: SP!; isótipo: MICH!, SPF!). (Figs. 8 A-G, 19 A-E).

Arbustos 1--3m, látex incolor; tricomas estrelados e multiradiados; ramos achatados, estriados, ramos jovens flocosos, tricomas estrelados e mais raramente multiradiados ou dendríticos. Folhas inteiras, levemente discolores, estreitamente ovais a oval-lanceoladas, ápice agudo, base levemente cordada; lâmina 5--15x2--7cm, margem miudamente serrilhada a serrilhada, com glândulas, ferrugíneas, face adaxial esparsamente pubescente, tricomas estrelados, face abaxial pubescente, tricomas multiradiados; nervação pinada, camptódroma, broquidódroma; nervuras terciárias percurrentes, oblíquas, levemente sinuosas; pecíolo 0,5--2cm, 1 par de glândulas basilaminares, globosas, acastanhadas, sésseis; estípulas ca. $5 \mathrm{~mm}$ compr., inteiras, lineares. Inflorescências 5--20cm compr., laxas, pendentes; raque achatada, estriada, flocosa, tricomas estrelados e multiradiados; címulas contíguas, as proximais femininas, unifloras, as distais masculinas, 1-2 flores; brácteas 0,4--1 cm compr., foliáceas, com um par de glândulas na base, conspicuamente acrescentes nos frutos, profilos 1-3mm compr., lineares. Flores masculinas ca. $5 \mathrm{~mm}$ compr., campanuladas, pediceladas; pedicelo ca. $2 \mathrm{~mm}$ compr.; cálice ca. $2 \mathrm{~mm}$ compr., pubescente externamente, ferrugíneo, tricomas estrelados e multiradiados, glabro internamente; lobos do cálice 5, unidos até a metade, ca. $1 \mathrm{~mm}$ compr., iguais, inteiros, valvares, ovais a levemente romboidais, ápice agudo, margem vilosa; pétalas ca. $2 \mathrm{~mm}$ compr., ovais a oval-lanceoladas, ápice agudo a arredondado, revoluto, margem vilosa; disco 5-segmentado; estames ca. 15; filetes subulados, glabros, anteras globosoelipsóides; receptáculo viloso, tricomas simples. Flores femininas ca. $5 \mathrm{~mm}$ compr., campanuladas, sésseis; cálice ca. 4mm compr., pubescente externamente, ferrugíneo, tricomas estrelados e multiradiados, glabro internamente; lobos do cálice 5, ca. 3mm compr., unidos até a metade, inteiros, iguais, quincunciais, levemente carnosos na base, romboidais, ápice agudo, com parte central recoberta por tricomas estrelados e multiradiados, ferrugíneos, laterais recobertas por tricomas estrelados e multiradiados, alvos, margem vilosa; pétalas ausentes; disco 5-segmentado; ovário globoso, tricomas estrelados; estiletes 8-fidos, unidos na base, segmentos exsertos, recobertos por tricomas estrelados. Fruto 7-10mm compr., globoso, liso, tricomas estrelados; lobos do cálice persistentes, inconspicuamente acrescentes; sementes 4-5mm compr., subglobosas; testa lisa. 
A espécie pode ser reconhecida no campo principalmente pelo indumento pubescente denso, fortemente ferrugíneo. Croton stellatoferrugineus é endêmico do Pico do Itambé, na porção mineira da Cadeia do Espinhaço, ocorrendo a cerca de 800 m altitude, em floresta estacional. Foi coletada com flores e frutos em fevereiro e junho.

Entre as espécies de Cleodora, Croton stellatoferrugineus é mais semelhante a $C$. sphaerogynus, sendo as principais diferenças entre essas duas espécies a densidade e coloração do indumento, tipo de tricomas, forma das brácteas e flores femininas, grau de união dos lobos das flores femininas e número de divisões dos estiletes (Tab. 6). Além disso, essas duas espécies ocorrem em habitats distintos, sendo C. stellatoferrugineus uma espécie de floresta estacional e C. sphaerogynus de floresta de restinga.

Outra espécie da seção que apresenta certa semelhança com Croton stellatoferrugineus é C. heterocalyx, no entanto diferem na forma das folhas (estreitoovais a oval-lanceoladas C. stellatoferrugineus vs ovais a cordiformes em $C$. heterocalyx), ramos jovens (cilíndrico em C. stellatoferrugineus vs achatado em $C$. heterocalyx), brácteas (folíáceas em C. stellatoferrugineus vs não folíaceas em $C$. heterocalyx) e flores masculinas (campanuladas em C. stellatoferrugineus vs cupuliformes em C. heterocalyx).

Material examinado: BRASIL. MINAS GERAIS: Serra do Espinhaço, south-eastern drainage of Pico do Itambé, about 5km directly west and north of Santo Antônio do Itambé, fl., fr., 9. II. 1972, W.R. Anderson et al. 35673 (MBM 65350, NY, UB, US 2934235, VEN 174930); Santo Antônio do Itambé, ponte de pedra sobre o riacho mãed’água, 18³3’8.4’’S e 43²0’15.8’’W, 811 m, fr., 18. II. 2009, I. Cordeiro et al. 3033 (SP).

\section{Táxons excluídos de Croton sect. Cleodora}

1. Croton maracayuensis Chodat \& Hassl. Bull. Herb. Boissier II 5: 492. 1905. Tipo: Paraguai, "ad marginem silvarum Ipê hu, Sierra de Maracayu”, Hassler 5178 (holótipo: G, foto F!; isótipo: K!, NY!, S)

Croton maracayuensis foi sinonimizado a Croton floribundus Spreng. por Govaerts et al. (2000).

Webster (1993) incluiu Croton floribundus na seção Argyroglossum Baill., posicionamento mantido na revisão dessa seção por Gomes (2006). Em Croton floribundus as folhas não apresentam glândulas na junção da lâmina com o pecíolo, as címulas basais da inflorescência são unissexuadas, sendo as flores masculinas rotáceas e 
não imbricativas, e as flores femininas com sépalas não imbricativas e com pétalas reduzidas a estruturas filiformes, características que excluem a espécie da seção Cleodora.

2. Croton velutinus Baill. Adansonia 4: 325. 1864. Tipo: Brasil, Bahia, Jacobina, Blanchet 3660 (holótipo: P!; isótipo: K!, M, foto F!)

Croton velutinus Baill. foi incluído por Baillon (1864) em sua seção Stolidanthus.

Webster (1993) excluiu a espécie da seção Cleodora (sin. seção Stolidanthus) e não a mencionou para nenhuma das outras seções do gênero. De fato, Croton velutinus é um subarbusto, com folhas desprovidas de glândulas no pecíolo, com inflorescências de címulas basais unissexuadas, flores masculinas com menos de 15 estames e flores femininas de prefloração valvar, características que excluem essa espécie de Croton sect. Cleodora. Considerando tais características, o melhor posicionamento para $C$. velutinus seria a seção Medea (Klotzsch) Baill. 


\section{Lista de coletores}

S.col.: R 99249 (15), RB 15872 (2), RB 280564 (15), SP 13822 (7); Aguilar, R.: 6256 (1); Albuquerque, B.W.: 1344 (17); Albuquerque, J.M.: IAN 165013 (2); Almeida, V.C.: 170 (15); Almeida de Jesus, J.: 2023 (16); Altamiro: 176 (16); Anderson, W.R.: 35673 (18), 35686 (15); Araquistain, M.: 3000 (1), 3084 (1), 3134 (1); Araújo, G.M.: 1048 (13), HUFU 49144 SP 399743 (13); Arbocz, G.F.: 148 (10); Aristeguieta L.: 1799 (5); Araujo, D.: 5849 (16), 9688 (16); Arvigo, R.: 626 (1); Aymard, G.: 158 (5), 356 I (5), 538 (5), 9387 (5); Baitello, J.B.: 638 (15); Baker, M.A.: 6493 (17); Barbosa, C.: 1802 (5); Barbosa, M.R.: 299 (15); Barreto, K.D.: 514 (13), 1524 (13), 1714 (13), 2843 (15); Barth, O.M.: I 175 (3); Bartlett, H.H.: 16350 (1), 16554 (1), 16840 (1); Bautista B., J.: 3771 (5); Bello, E.: 2274 (1), 2305 (1); Bernal, R.: 794 (5); Bernacci, L.C.: 1350 (13); Bernardi, L.: 2333 (4), 6861 (4); Berry, P.E.: 298 (5); Berti, L.M.: 1040 (5); Bevilaqua, A.: MG 49545 RB 24882 US 24882 (2); Black, G.A.: 47-1705 (2); Blanch, L.C.: 126 (2), 193 (2), 1193 (2); Blanchet, M.: 316 (8); Bono, J.: 4229 (4); Boom, B.: 6339 (2); Botelho, P.: 7 (16); Brade, A.C.: 14650 (3), 16487 (15); Brenes, A.M.: 20562 (9); Breteler, F.J.: 4018 (5), 4575 (4); Brewer, S.W.: 93 (1), 292 (1); Bunting, G.S.: 4520 (5), 5181 (5), 5185 (5), 7310 (2), 11184 (17), 11224 (4), 12410 (5); Burnham, R.J.: 1651 (12); Buzato, S.: 27206 (10); Cabrera, E.: 5216 (1), 5252 (1); Calderon, G.M.: 1730 (1); Callejas, R.: 3611 (14), 5425 (14); Campos Porto, P.: RB 10401 (16); Carballo, G.: 493 (1); Carpenter, J.B.: 394 (1); Carrasco, P.G.: 71 (16); Caruzo, M.B.R.: 56 (13), 65 (16), 66 (16), 67 (16), 72 (10), 75 (13), 81 (15), 82
(10), 88 (16), 89 (15), 90 (10), 91 (15), 93 (3), 94 (3), 95 (2), 96 (2), 98 (2), 101 (17), 105 (8), 107 (8), 108 (8), 111 (13), 112 (7), 113 (7), 114 (7), 116 (7), 120 (18), 121 (16), 122 (10), 123 (3), 124 (11), 125 (5), 126 (5); Casadiego, J.A.: 402 (5); Castañeda, R.R.: 6325 (5), 7008 (4); Castellanos, A.: 23418 (3); Castillo, A.: 1386 (2), 3469 (2); Cavalcante, P.: 1772 (2), 1933 (2), 2333 (2); Cavassan, O.: 9 (13); Cerón, C.E.: 9414 (12); Chitty, F.D.: 3251 (5), 3328 (5); Christopherson, E.D.: 194 (1); Cid, C.A.: 2544 (17); Coelho, D.: INPA 25926 UEC 28650 (15); Coello, F.: 213 (12); Cook, O.F.: 580 (1); Conduz, A.: 8454 (9), 8859 (9), 10134 (9); Contreras, E.: 6306 (1), 9880 (1), 9881 (1), 10121 (1), DAV 40476 (1); Cordeiro, M.R.: 969 (2), 1205 (11), 1378 (2), 2890 (11); Cordeiro, I.: 2010 (10), 2033 (18), 3229 (7); Córdoba, J.J.: 151 (1), 1009 (1); Correia, C.M.B.: 65 (10); Corrêa, L.: MG 165738 (2); Cortês, A.: 78 (2); Costa, M.: 285 (2); Croat, T.B.: 10782 (5), 24445 (1); Croizat: F 1426209 (2); Crub, P.J.: 44 (5); Cuadres V., H.: 1870 (5); Cuatrecasas, J.: 4399 (11); Cunha Mello: RB 66479 (3); Curran, H.M.: 51 (5), 187 (5); Daly, D.C.: 435 (2), 1756 (2); Davidse, G.: 15303 (2), 15334 (2), 15335 (11), 18100 (17), 18139 (2); Delprete, P.: 5156 (1); Diaz, W.: 1656 (5); Domingos: IAN 170278 (2); Duarte: 409 (16), 790 (16); Duarte, A.P.: 314 (16), 358 (16), MG 49548 RB 60829 (3); Ducke, A.: 2246 (2), DAV 70644 RB 35702 (17), MG 4896 (11), MG 4914 (11), MG 7946 MO 1678070 RB 2418 (17), MG 10567 RB 169 (17), MG 16904 (2), RB 7432 US 1617625 (2), RB 10275 (2), RB 10279 US 161726 (2), RB 24883 (2); Dugand, A.: 1198 (5); Duke, J.A.: 5157 (5), 6624 (5); Dwyer, J.D.: 6579 (1), 
6812 (5), 10801 (1), 11073 (1), 11113 (1), 12505 (1), 15176 (1); E.W.D.: 1221 (10); Ebinger, J.E.: 213 (1); Edmundo, A.: 358 (16); Ehrendorfer, F.: 73905-22.40 (3); Eiterer, M.: 124 (15); Espinal T., S.: 890 (5); Faria, S.M.: 2115 (2); Farias, C.: INPA 199547 (2); Farney, C.: 387 (16), 3434 (16), 4233 (16); Farreras, J.: 394 (5); Feddema, C.: 2104 (1); Fernández, A.: 17936 (5); Ferreira, M.C.: 50 (17); Ferreira, V.F.: 157 (3); Ferretti, A.R.: 32 (10); Flender, A.: 292 (1); Fittkau: INPA 12782 (2); Fosberg, F.R.: 20483 (17); Forero, L.E.: 331 (5); Forzza, R.C.: 4800 (16); Foster, P.F.: 424 (6); França, F.: 2584 (16); França, G.S.: 140 (10); Franco, G.A.D.C.: 1322 (13); Frazão, A.: RB 10348 (15); Freitas, C.A.A.: 119 (2); Fróes, R.: 1701 (2), 11537 (2); Fróes, R.L.: 20267 (17); Gabriel, J.L.C.: HRCB 10902 (13); Gallardo, G.: 131 (1); Gandolfi, S.: ESA 11097 SP 292079 (13), ESA 11098 SP 292078 (13); Garcia-Barriga, H.: 11815 (17), 13460 (5); Garganta, M.: 2006 (5); Gentry, A.: 7840 (1), 8439 (1), 14276 (2), 14581 (11), 29678 (12); Gentle, P.H.: 2113 (1), 2613 (1), 2835 (1), 2979 (1), 3324 (1), 4761 (1), 6749 (1), 8851 (1); Giordano, L.C.: 1170 (16); Ginzbarg, S.: 654-1 (16), 654-3 (16); Glaziou: RB 82960 (10); Góes, O.C.: 955 (15); González, J.: 358 (1); González, L.: 2272 (1); Grayum, M.H.: 3282 (1), 3528 (1), 5511 (1), 5883 (1); Gröger, A.: 325 (11), 672 (11); Grubb, P.J.: 44 (5); Guardia, U.: 253 (2); Guedes, M.L.: 4630 (8), 13138 (8); Guedes, R.: 2536 (3); Guillen, J.: 265 (2), 268 (2); Guimarães, E.F.: 83 (16); Haber, W.A.: 1688 (1), 1851 (1), 11240 (1); Hammel, B.: 11862 (1); Harmon, W.E.: 2838 (1); Hartshorn, G.S.: 2260 (1); Hatschbach, G.: 63776 (2); Haught, O.: 2426 (5), 3681 (5);
Hazlett, D.: 7089 (1); Heriberto, B.: 128 (5), 350 (5); Heringer, E.P.: 5911 (13); Hernandez C.: 14 (5), 57 (5); Hernández, H.: 100 (1); Hernandéz, R.: 840531-3 (9); Hoehne, F.C.: HB 52070 SP 31388 SPF 83197 US 2857622 (15), MG 159089 SP 25051 (16); Holdridge, L.R.: 2505 (1); Holm, R.W.: 62 (1); Hopkins, M.J.G.: 653 (2), 722 (2), 847 (2); Howard, R.: 626 (1); I.S.: 251 (17); Idrobo, J.M.: 10689 (4), 10699 (4); Isernhagen, I.: 235 (15); Ivanauskas, N.M.: 5076 (10); Jacobs, B.: 3096 (1); Jangoux, J.: 1051 (2), 1478 (11); Jardim, A.: 74 (17); Jardim, J.G.: 632 (16); Jimenez, S.: 1127 (17); Jiménez, Q.: 1576 (9); Jiménez M., A.: 2012 (9), 2438 (9), 3290 (9), 3968 (9); Jocelino: RB 62075 (10); Johnson, E.P.: 118 (1); Kallunki, J.A.: 325 (8); Kenoyer, L.A.: 411 (1); Kernan, C.: 1200 (1); Killeen, T.: 5917 (2), 5925 (17), 7147 (17), 8119 (2); Kirbride, J.H.: 1666 (1); Kirizawa, M.: 299 (10), 323 (10), 3318 (16); Knapp, S.: 4667 (1); Kollmann, L.: 1254 (16), 1559 (16); Kotchetkoff-Henriques, O.: 381 (13), 384 (13), 400 (13); Koscinsky, M.: SP 30785 (15); Krieger, L.: 10484 (16), 21322 (15); Krukoff, B.A.: 1666 (17); Kuhlmann, J.G.: 187 (17), 251 (16), 723 (17), 1767 (17), 2106 (17), SP 392269 VIC 2333 (15); Kuhlmann, M.: 582 (13), 2507 (10), 2579 (10); Kuhlmann, S.G.: 251 (16); Landrum, L.R.: 2052 (16), 4203 (15); Langsdorff, G.H.: US 1574027 (10); Lao, E.A.: 20 (1), 170 (1); Leitão-Filho, H.F.: 1578 (7), 10671 (10); Leite, E.C.: 56 (7); Léon B.: 104 (1); Leon, J.: 1639 (1), 1673 (1); León, M.: 192 (5); Leoni, L.S.: GFJP 555 SP 245736 (15); Lent, R.W.: 1109 (9), 2009 (9), 3380 (1); Liesner, R.: 8273 (4), 11510 (5), 11511 (5); Lima, H.C.: 3722 (15), 5924 (10), 5925 (10); Lima, J.: 704 (2); Lima, L.R.: 139 
(13), 418 (10), 469 (3); Lima, M.P.M.: 399

(3); Lima, S.S.: 2 (8); Lindeman, J.C.: 172 (2), 3202 (16), 4202 (10); Lins, E.A.M.: 311 (2); Little Jr., L.L.: 20002 (1); Lobão, A.Q.: 555 (10); Lobo, M.G.: 329 (2); Lobo, M.G.A.: 21 (2); Löfgren, A.: 264 (15), in CGG 447 (13), in CGG 4202 (16); LópezPalacios, S.: 3209 (17); Lundell, C.L.: 453 (1), 19885 (1), 20092 (1); Luteyn, J.L.: 725 (9); Machado, A.: 7 (16); Magaña, M.A.: 3060 (1); Marinho, L.R.: 510 (17); Marquete, R.: 693 (16); Marrugo G., J.C.: 92 (5); Martínex S., E. M.: 23466 (1); Martínez-Calderon, G.: 27 (1); Martins, S.E.: 565 (16); Mattos, J.R.: 13229 (10), 16178 (10); Maxon, W.R.: 6521 (1), 6798 (1); Milliken, W.: 79 (2); Martinelli, G.: 10798 (3); Mattos, J.R.: 13032 (13); Mattos Silva, L.A.: 1460 (16); Meijer, W.: 290 (5); Meireles, L.: SP 363269 (10); Melo, G.A.P.: 28 (15); Melo, P.H.A.: 984 (13); Mello Barreto: 11130 (13); Mexia, Y.: 4563 (15), 5237 (15); Miller, J.S.: 1191 (1); Miranda, F.: 6636 (1); Molina R., A.: 5556 (1), 7222 (1), 30610 (1); Monsalve, M.: 61 (17); Morales, J.F.: 515 (1); Moreno B., L.M.: 450 (5); Mori, S.: 613 (2), 6030 (1), 15388 (9); Mori, S.A.: 11970 (16), 24778 (9); Morillo, G.: 7370 (2); Mósen, H.J.: 4374 (13); Mota, A.L.P.: 1482 (13), 1513 (13), 2108 (13), 2292 (13); Muniz, F.H.: 220 (2); Murphy, H.: 393 (17), 466 (17); Mutis, J.C.: 813 (5), US 1563097 (5); Nadruz, M.: 516 (15), 724 (10); Nascimento, J.H.M.: 6 (10); Nascimento, L.M.: 362 (7), 400 (7), 473 (7); Nascimento, O.C.: 913 (2); Nee, M.: 11081 (1), 24746 (1), 26703 (1), 31420 (17), 40099 (6); Nevers, G.: 5806 (1); Noffs, L.B.: 12 (10); Nuñez, P.: 18018 (5); Occhioni, P.: 168 (16), 8941 (3), RB 51052 (16); Oliveira, A.S.: 3859 (16);
Oliveira, C.L.: 1698 (16); Oliveira, E.: 5104 (2); Ortega, F.: 659 (5), 1111 (5); PLK: 9516 (10), 12524 (2), 12688 (2); Pabst, G.: 7160 (10); Pagano, S.N.: 153 (13); Pansarin, E.R.: 381 (15); Pedrosa, D.S.: $1122^{\mathrm{A}}$ (16); Peixoto, A.: 3444 (16); Penha, A.S.: ESA 60334 MBM 269252 (13); Pennell, F.W.: 181 (5), 7249 (17); Pereira, E.: 42 (16), 431 (16), 1893 (16), 4323 (16), 4343 (16), 6974 (3); Perez, J.: 91 (17); Perez Z., J.A.: 1724 (5); Pessoa, S.V.A.: 550 (15); Pifano, D.S.: 327 (15); Pineschi, R.B.: 348 (3); Pinto, G.: ALCB 2142 CEPEC 60502 HRB 311037 (8); Pirani, J.R.: 5559 (13), in CFSC 6692 (13); Pires, F.R.S.: MG 152589 SP 221501 (15); Pires, J.M.: 4045 (11), 6517 (2); Pires, M.J.: 877 (2), 1478 (2); Pittier, H.: 3513 (1), 3663 (9), 3698 (1), 4103 (9), 8568 (1); Poreda, L.J.: 1670 (9); Poveda, L.J.: 43 (1); Prance, G.T.: 1262 (2), 7933 (17), 8314 (17), 25420 (17), 25726 (11); Proença, K.C.R.: 36 (13); Queiroz, L.P.: 10005 (13); Quinet, A.: 201 (3); Quintero, A.: 2268 (5); Ramos, N.D.: 157 (10), 430 (10); Rawitscher: SPF 16201 (3); Regnell, A.F.: I 402 (7); Resende, U.M.: 285 (13); Ribeiro, W.: SP 377131 (15); Riina, R.: 1534 (13), 1818 (11), 1819 (11), 1824 (5), 1827 (5); Rios, M.: 711 (2); Rivera, G.: 1470 (1); Robim, M.J.: 392 (10); Robleto, W.: 574 (1); Rodrigues, E.: SP 319378 (2); Rodrigues, W.: 5130 (17); Rodrigues, W.A.: INPA 2107, MG 21876, UB 46855 (2); Rodríguez, A.: 17 (5), 1568 (9), 2655 (9); Rodriguez, R.S.: INPA 11507 MG 3380 (2); Roe, K.: 1433 (1); Rojas, C.E.B.: 4893 (5), 5692 (5); Rojas, C.M.B.: 2214 (5); Rojas, E.: 68 (1); Rojas, R.T.: 240 (9); Rosa, N.A.: 2410 (2), 2532 (2), 3275 (9); Roschel, M.B.: 468 (15), OUPR 1281 (15); Rossi, L.: 1577 (15); Roth, L.: 2530 (10); Ruiz-Terán, L.: 766 (5); Rusby, 
H.H.: 1198 (5), 2622 (17); Salcedo, P.: 237 (5); Saldanha, J.: 4238 (16); Salino, A.: 5917 (10); Samp., A.: 4057 (3); Sánchez, P.: 493 (1); Sandrini, M.P.: SPF 166656 (16); Sant'Ana, C.S.: 1122 (16); Santos, M.: INPA 213337 (2); Santos, M.M.: 24 (10); Santos, T.S.: 2206 (16); Sarmento, A.C.: 844 (8); Schalzel, R. J.: 718 (1); Schipp, W.A.: 205 (1), 336 (1); Secco, R.S.: 618 (2), 773 (2), 902 (2); Sendulsky, T.: 800 (10); Sérgio: 24585 (15); Sevilha, A.C.: 1776 (2); Shattuck: 929 (1), 952 (1); Silva, A.F.: 379 (15), 1347 (15), 13161 (15); Silva, A.S.: 101 (2); Silva, J.A.: 435 (2), 16370 (15); Silva, J.S.: 285 (15); Silva, M.: 1364 (17); Silva, M.F.F.: 2475 (11); Silva, M.G.: 5660 (2); Silva, N.T.: 177 (2), 1667 (17); Silva Neto, S.J.: 785 (10); Silveira, R.G.: CESJ 27762 (15); Smith, H.H.: 363 (5); Sobrinho, A.F.S.: INPA 218867 (2); Solano, D.: 118 (1); Souza, A.: 308 (10), 1560 (16), R 182858 (3); Souza, J.E.C.: INPA 213339 (2); Sousa, M.: 2751 (1); Souza, V.C.: 15428 (11), 23650 (15); Standley, P.C.: 23949 (1), 28718 (1), 29942 (1), 30204 (1), 30968 (1), 31436 (1), 31611 (1), 31683 (1), 35860 (9), 38956 (9), 40967 (1), 52629 (1), 53661 (1); Stechmann, J.R.: NP 1374 SP 226977 (13); Stergios, B.: 5575 (5); Stern, W.L.: 977 (5); Steyermark, J.A.: 113936 (5), 122472 (2), 122514 (11), 123092 (5), 123472 (5); Strang, H.E.: 411 (3), DAV 73838 GUA 4466 (3); Strudwick, J.J.: 3080 (11), 3989 (2), 4088 (11); Sucre, D.: 1657 (16), 2986 (10), 4467 (16); Sullivan, G.A.: 134 (1); Sylvestre, L.: 912 (10), 918 (3); Taylor, J.: 17602 (9); Taylor, R.J.: 4228 (9); Tenorio L., P.: 14433 (1); Thomas, W.W.: 5525 (14), 6131 (16), 13720 (8); Timaná, M.: 2664 (2), 2843 (2); Toledo, M.: 1318 (6); Tomas, B.: 822 (5); Tomasulo, P.L.B.: 210
(15); Torres R.B.: 1801 (10), IAC 32035 SP 360461 (13), IAC 32080 SP 360460 (13); Tsuji, R.: 873 (11); Udulustch, R.G.: 1520 (16); Uribe, L.U.: 2389 (5), 2852 (5), 4130 (5); Valverde, L.: 164 (5); Valverde, L.: 1169 (2); Valverde, O.: 1154 (1); Van Ee, B.: 342 (1), 595 (1), 598 (9); Vargas, I.G.: 1774 (17), 1778 (2); Vargas, O.: 161 (1); Vásquez, R.: 832 (12), 4449 (12); Veillon: 63 (5); Vellozo, H.: R 38390 (15); Vieira, G.: 398 (2); Vieira, M.G.: 864 (2); Vilhena, R.: 1011 (2); Villegas H., A.: 20 (1); Von Wedel, H.: 2524 (1); Von Tuerckheim, H.: 390 (1), 467 (1), US 398429 (1), US 936109 (1); Yuncker, T.G.: 4516 (1); W.W.: 270 (9); Ward, D.B.: 7923 (1); Warming: 1649 (13), US 289458 (15); Webster, G.L.: 12298a (9), 12298g (9), 12691 (1), 12754 (1), 15423 (1), 16400 (1), 16446 (1), 16769 (1), 16880 (1), 17890 (1), 21888 (1), 22124 (9), 25380 (13); Wendt, T.: 2508 (1); Wiley, J.R.: 7 (1); Williams, L.: 8934 (1), 12203 (5), 13393 (5); Wood, J.R.I.: 15138 (6); Zarucchi, J.L.: 2655 (2); Zambrano-Luiz Alfonzo, O.: 1393 (5); Zambrano, J.O.: 302 (5); Zamora V., N.: 766 (1); Zuluaga R., S.: 828 (5). 


\section{Referências Bibliográficas}

Baillon, H. 1858. Etude générale du groupe des Euphorbiacées. Victor Masson, Paris.

Baillon, H. 1864. Euphorbiaceés Americaines. Adansonia 4:257-377.

Barroso, G.M.; Morim, M.P.; Peixoto, A.L.; Ichaso, C.L.F. 1999. Frutos e sementes: morfologia aplicada à sistemática de dicotiledôneas. Editora UFV, Viçosa.

Bentham, G. 1854. On the North Brazilian Euphorbiaceae in the collections of Mr. Spruce. Hooker's Journal of Botany and Kew Garden Miscellany 6: 321-377.

Bentham, G. 1880. Euphorbiaceae. In G. Bentham \& J.D. Hooker (eds) Genera plantarum ad exemplaria imprimis in herbariis kewensibus servata definita. 3:239-340. Lovell Reeve \& Co, Londres.

Berry, P.E. 2002. Croton Research Network. Madison: University of Wisconsin-Madison. Disponível em: <http://botany.wisc.edu/croton/>.

Berry, P.E.; Cordeiro, I.; Wiedenhoeft, A.C.; Vitorino-Cruz, M.A. \& Lima, L.R. 2005a. Brasiliocroton, a new crotonoid genus of Euphorbiaceae s.s. from eastern Brazil. Systematic Botany 30(20):357-365.

Berry, P.E.; Hipp, A.L.; Wurdack, K.J.; Van Ee, B. \& Riina, R. 2005b. Molecular phylogenetics of the giant genus Croton and tribe Crotoneae (Euphorbiaceae sensu stricto) using ITS and trnL-trnF DNA sequence data. Amer. J. Bot. 92 (9):1520-1534.

Bridson, G.D.R. \& Smith, E.R. 1991. Botanico-Periodicum-Huntianum/Supplementarum. Hunt Institute for Botanical Documentation. Carneige Mellon University. Pittsburgh.

Burger, W. \& Huft, M. 1995. Flora costaricensis: Euphorbiaceae. Fieldiana 36:1-169.

Caruzo, M.B.R. 2005. Estudo taxonômico e biogeográfico do gênero Croton L. (Euphorbiaceae) no estado de São Paulo, Brasil. Dissertação de Mestrado. Instituto de Biociências, Universidade de São Paulo, São Paulo.

Caruzo, M.B.R. \& Cordeiro, I. 2007. Sinopse da tribo Crotoneae Dumort. (Euphorbiaceae s.s.) no Estado de São Paulo, Brasil. Hoehnea 34: 571-585.

Caruzo, M.B.R.; Riina, R.; Cordeiro, I. \& Berry, P.E. 2008. Croton campanulatus (Euphorbiaceae s.s.), a new species from the Brazilian Atlantic rain forest. 60(3): 261264.

Carvalho, J.C.T.; Silva, M.F.C.; Maciel, M.A.M.; Pinto, A.C.; Nunes, D.S.; Lima, R.M.; Bastos J.K. \& Sarti, S.J. 1996. Investigation of anti-inflammatory and antinociceptive activities prototype of trans-dehydrocrotonin, a 19-nor-clerodane diterpene from Croton cajucara. Part 1. Planta Med 62: 402-404. 
Chase, W.M.; Zmarzty, S., Lledó; M.D., Wurdack; K.J., Swensen; S.M. \& Fay, M.F. 2002. When in doudt, put in Flacourtiaceae: a molecular phylogenetic analysis base don plastid rbcL DNA sequences. Kew Bulletin 57: 141-181.

Cordeiro, I. 1989. Euphorbiaceae. Flora Fanerogâmica do Parque Estadual das Fontes do Ipiranga (São Paulo, Brasil). Hoehnea 16: 11-29.

Cordeiro, I. 1992. Flora da Serra do Cipó, Minas Gerais: Euphorbiaceae. Bol. Bot. Univ. São Paulo 13:169-217.

Cordeiro, I. 1993. Revisão taxonômica de Julocroton Mart. (Euphorbiaceae). Tese de Doutorado. Universidade de São Paulo, São Paulo.

Corner, E.J.H. 1976. The seeds of dicotyledons, v. 1. Cambridge University Press, Cambridge.

Croizat, L. 1940. Thirty-five new species of american Croton. J. Arnold. Arbor. 21: 76107.

Croizat, L. 1941. Preliminaries for the study of Argentine and Uruguayan species of Croton. Darwiniana 5: 417-462.

Cruden, R.W. 1988. Temporal dioecism: systematic breadth, associated traits, and temporal patterns. Botanical Gazette 149: 1-15.

Davis, G. 1966. Systematic embriology of angiosperms. Wiley \& Sons, New York.

Ferguson, A.M. 1901. Crotons of the United States. Annual Rep. Missouri Bot. Gard. 12:33-73.

Forster, P.I. 2003. “A taxonomic revision of Croton L. (Euphorbiaceae) in Australia”. Austrobaileya 6(3): 349-436.

Gillespie, L.J. 1993. Euphorbiaceae of the Guianas: annotated species checklist and key to genera. Brittonia 45(1): 56-94.

Giulietti, A.M. \& Pirani, J.R. 1988. Patterns of geographic distribution of some plant species from the Espinhaço Range, Minas Gerais and Bahia, Brazil. In W.R. Heyer \& P.E. Vanzolini (eds.) Proceedings of a workshop on neotropical distribution patterns. Academia Brasileira de Ciências. Rio de Janeiro.

Gomes, A.P.S. 2006. Revisão das espécies sul-americanas de Croton L. subgen. Croton sect. Argyroglossum Baill. (Crotonoideae-Euphorbiaceae). Tese de doutorado. Universidade Federal Rural de Pernambuco, Brasil. 
Govaerts, R., Frodin, D.G. \& Radcliffe-Smith, A. 2000. World Checklist and Bibliography of Euphorbiaceae (and Pandaceae). Kew, Royal Botanic Gardens. v. 2. 921p.

Grisebach, A.H.R. 1864. Croton. In Flora of the British West Indian Islands. London. pp. 37-42.

Grynberg, N.F.; Echevarria, A.; Lima, J.E.; Pamplona, S.S.R.; Pinto, A.C. \& Maciel, M.A.M. 1999. Anti-tumour activity of two 19-nor-clerodane diterpenes, trans-dehydrocrotonin and trans-crotonin, from Croton cajucara. Planta Med 65: 687-689.

Hickey, L.J. 1973. Classification of the architecture of dicotiledonous leaves. Amer. J. Bot. 60(1):17-33.

Hiruma-Lima, C.A.; Gracioso, J.S.; Bighetti, E.J.; Grassi-Kassisse, D.M.; Nunes, D.S. \& Brito, A.R. 2002. Effect of essential oil obtained from Croton cajucara Benth. on gastric ulcer healing and protective factors of the gastric mucosa. Phytomedicine 9(6):523-529.

Jablonski, E. 1965. Botany of the Guayana highlands-part VI: Euphorbiaceae. Mem. New York Bot. Gard. 12:150-169.

Lemos, T.L.G.; Machado, M.I.L.; Menezes, J.E.S.A. \& Sousa, C.R. 1999. Essential oil of Croton cajucara Benth. J. Essent. Oil Res. 11: 411-412.

Lima, L. R. 2001. O gênero Croton L. (Euphorbiaceae) na Cadeia do Espinhaço, Minas Gerais - Brasil. Dissertação de Mestrado. Instituto de Biociências, Universidade de São Paulo, São Paulo.

Lima, L.R. \& Pirani, J.R. 2008. Revisão taxonômica de Croton sect. Lamprocroton (Müll.Arg.) Pax (Euphorbiaceae s.s.). Biota Neotropica 8(2): 21-75.

Linnaeus, C. 1753. Species plantarum. Laurentii Salvii, Stockolm.

Lopes, D.; Bizzo, H.R.; Sa-Sobrinho, A.F. \& Pereira, M.V.G. 2000. Linalool-rich essential oil from leaves of Croton cajucara Benth. J. Essent. Oil Res. 12: 705-708.

Mcneill, J.; Barrie, F.R.; Burdet, H.M.; Demoulin, V.; Hawksworth, D.L.; Marhold, K.; Nicolson, D.H.; Prado, J; Silva, P.C.; Skog, J.E.; Wiersema, J. H. \& Turland, N. J. (eds.). 2007. International Code of Botanical Nomenclature (Vienna Code) adopted by the Seventeenth International Botanical Congress Vienna, Austria, July 2005. Gantner, Ruggell. 181p.

Moreno, P.R.; Lima, M.E.L.; Caruzo, M.B.R.; Torres, D.S.C.; Cordeiro, I.; Young, M.C.M. 2009. Chemical Composition and Antimicrobial Activity of the Essential Oil 
from Croton heterocalyx Baill. (Euphorbiaceae s.s.) Leaves. The Journal of Essential Oil Research 21: 190-192.

Mori, S.A.; Silva, L.A.M.; Lisboa, G. \& Coradin, L. 1989. Manual de manejo do herbário fanerogâmico. 2 ed. Centro de Pesquisas do Cacau. Ilhéus. Bahia.

Müller, J. 1865/66. Euphorbiaceae. Linnaea 34: 1-224.

Müller, J. 1866. Euphorbiaceae exceto suborfo Euphorbieae. In Prodomus Systematics Universalis Regni Vegetabilis (De Candolle, A.P. ed.) 15(2): 189-1286.

Müller, J. 1873. Euphorbiaceae. In Flora Brasiliensis (Martius, C. F. P. \& Eichler, A. G. eds.) 11(2):293-750, pl. 43-104.

Murillo-A., J. 1999. Composición y distribucíon del género Croton (Euphorbiaceae) en Colombia, con cuatro especies nuevas. Caldasia 21(2): 141-166.

Payne, W.W. 1978. Plant hair terminology. Brittonia 32(2):239-255.

Pax, F. \& Hoffman, K. 1931. Euphorbiaceae. In Die natürlichen Pflanzenfamilien (A. Engler \& K. Prantl. eds.) 19:11-233.

Pio-Corrêa, M. 1975. Dicionário das Plantas Úteis do Brasil e das Exóticas Cultivadas, v.6. Ministério da Agricultura, Rio de Janeiro.

Radford, A. E. 1986. Fundamentals of Plant Systematics. New York, Harper \& Row. 498p.

Riina, R., Berry, P.E. \& Van Ee, B.W. 2009. Molecular phylogenetics of the dragon's blood Croton section Cyclostigma (Euphorbiaceae): a polyphyletic assemblage unraveled. Syst. Bot. 34, 360-374.

Secco, R. de S. 2008. Sinopse das espécies de Croton L. (Euphorbiaceae) na Amazônia brasileira: um ensaio taxonômico. 1ํㅗㄹ ed. Belém: Museu Paraensi Emilio Goeldi. 169p.

Souza-Brito, A.R.M.; Rodríguez, J.A.; Hiruma-Lima, C.A.; Haun, M. \& Nunes, D.C. 1998. Antiulcerogenic activity of trans-dehydrocrotonin from Croton cajucara. Planta Med 64: 126-129.

Stafleu, F.A. \& Cowan, R.S. 1973-1988. Taxonomic Literature, v.1-7. Ed. Bohn, Scheltema \& Holkema, Utrech.

Stearn, W. T. 1992. Botanical Latim. $4^{\mathrm{a}}$ ed. Portland: Oregon, Timber Press. 546p.

Thiers, B. [continuously updated]. Index Herbariorum: A global directory of public herbaria and associated staff. New York Botanical Garden's Virtual Herbarium. http://sweetgum.nybg.org/ih/

Weberling, F. 1989. Morphology of flowers and inflorescences. Cambridge University Press, Cambridge. 
Venkata-Rao, C. 1971. Anatomy of the inflorescence of some Euphorbiaceae. Bot. Notes. 124:39-64.

Webster, G. L. 1967. The genera of Euphorbiaceae in the Southeastern United States. J. Arnold Arb. 48: 303-357.

Webster, G.L. 1975. Conspectus of a new classification of the Euphorbiaceae. Taxon 24 (5/6): 593-601.

Webster, G.L. 1992. Realignments in americam Croton (Euphorbiaceae). Novon 2: 269273.

Webster, G. L. 1993. A provisional synopsis of the sections of the genus Croton (Euphorbiaceae). Taxon 42:793-823.

Webster, G. L. 2001. Synopsis of Croton and Phyllanthus (Euphorbiaceae) in Western Tropical Mexico. Contr. Univ. Michigan Herb. 23:353-388.

Webster, G.L. \& Huft, M.J. 1988. Revised synopsis of panamanian Euphorbiaceae. Ann. Missouri Bot. Gard. 75: 1087-1144.

Webster, G. L.; Del-Arco-Aguilar, M.J. \& Smith, B.A. 1996. Systematic distribution of foliar trichome types in Croton (Euphorbiaceae). Bot. J. Linn. Soc. 121: 41-57.

Webster, G.L.; Berry, P.E.; Ambruster, W.S.; Esser, H.J.; Gillespie, L.J.; Hayden, W.J.; Levin, G.A.; Secco, R.S. \& Heald, S.V. 1999. Euphorbiaceae. In Flora of the Venezuelan Guayana. (Berry, P.E.; Steyermark, J.A.; Holst, B.K. \& Yatskievych, K. eds.). Missouri Botanic Gardn Press, St. Louis, Missouri. v. 5. pp. 72-228. 
Tabela 1. Expedições de coleta.

\begin{tabular}{|c|c|c|}
\hline Localidade & $\begin{array}{c}\text { Data } \\
\text { (mês/ano) }\end{array}$ & $\begin{array}{l}\text { Espécies } \\
\text { coletadas }\end{array}$ \\
\hline $\begin{array}{l}\text { Brasil, Rio de Janeiro, Município de Rio de } \\
\text { Janeiro, Parque Nacional da Tijuca. }\end{array}$ & II/2006 & C. sphaerogynus \\
\hline $\begin{array}{l}\text { Brasil, Rio de Janeiro, Município de Nova } \\
\text { Friburgo. }\end{array}$ & II/2006 & $\begin{array}{l}\text { C. salutaris } \\
\text { C. organensis }\end{array}$ \\
\hline $\begin{array}{l}\text { Brasil, Rio de Janeiro, Município de } \\
\text { Teresópolis. }\end{array}$ & II/2006 & C. salutaris \\
\hline $\begin{array}{l}\text { Brasil, Rio de Janeiro, Município de Itatiaia, } \\
\text { Parque Estadual do Itatiaia. }\end{array}$ & II/2006 & C. campanulatus \\
\hline $\begin{array}{l}\text { Brasil, Pará, Belém, Embrapa, Centro de } \\
\text { Pesquisa Agroflorestal da Amazônia Oriental. }\end{array}$ & III/2006 & C. cajucara \\
\hline $\begin{array}{l}\text { Brasil, Pará, Município de Capanema, Vila de } \\
\text { Mirasselvas }\end{array}$ & III/2006 & $\begin{array}{l}\text { C. cajucara } \\
\text { C. spruceanus }\end{array}$ \\
\hline Brasil, Bahia, Município de Morro do Chapéu. & IX/2006 & C. heterocalyx \\
\hline Brasil, Minas Gerais, Município de Caldas. & $\mathrm{I} / 2007$ & C. hemiargyreus \\
\hline Brasil, São Paulo, Município de Águas da Prata. & $\mathrm{I} / 2007$ & $\begin{array}{l}\text { C. rottlerifolius } \\
\text { C. hemiargyreus }\end{array}$ \\
\hline $\begin{array}{l}\text { Brasil, Pernambuco, Município de Brejo da } \\
\text { Madre de Deus. }\end{array}$ & IV/2008 & C. hemiargyreus \\
\hline $\begin{array}{l}\text { Brasil, Minas Gerais, Município de Santo } \\
\text { Antônio do Itambé. }\end{array}$ & VII/2008 & C. stellatoferrugineus \\
\hline $\begin{array}{l}\text { Brasil, Rio de Janeiro, Município de Rio de } \\
\text { Janeiro, Parque Nacional da Tijuca. }\end{array}$ & $\mathrm{XI} / 2008$ & C. sphaerogynus \\
\hline $\begin{array}{l}\text { Brasil, Rio de Janeiro, Município de Itatiaia, } \\
\text { Parque Estadual do Itatiaia. }\end{array}$ & $\mathrm{XI} / 2008$ & $\begin{array}{l}\text { C. campanulatus } \\
\text { C. organensis }\end{array}$ \\
\hline $\begin{array}{l}\text { Venezuela, Amazonas, Município de } \\
\text { Samariapo. }\end{array}$ & XII/2008 & C. orinocensis \\
\hline Venezuela, Cojedes, Valencia-San Carlos. & XII/2008 & C. fragrans \\
\hline Brasil, Bahia, Município de Morro do Chapéu. & II/2009 & C. heterocalyx \\
\hline $\begin{array}{l}\text { Brasil, Minas Gerais, Município de Santo } \\
\text { Antônio do Itambé. }\end{array}$ & II/2009 & C. stellatoferrugineus \\
\hline
\end{tabular}


Tabela 2. Espécies da seção Cleodora sensu Webster (1993) e seu posicionamento nos sistemas de Baillon e Müller.

\begin{tabular}{|c|c|c|c|}
\hline Webster (1993) & Baillon (1864) & Müller (1866) & Müller (1873) \\
\hline C. calycularis Huber & - & 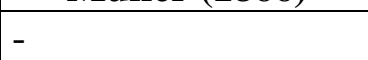 & $(2-1)$ \\
\hline C. cajucara Benth. & Sect. Cleodora & $\begin{array}{l}\text { Sect. Eucroton, } \\
\text { subsect. Eutropia }\end{array}$ & $\begin{array}{l}\text { Sect. Eucroton, } \\
\text { subsect. Eutropia, } \\
\text { série Cyclostigma }\end{array}$ \\
\hline $\begin{array}{l}\text { C. hemiargyreus } \\
\text { Müll.Arg. }\end{array}$ & - & $\begin{array}{l}\text { Sect. Eucroton, } \\
\text { subsect. Cyclostigma }\end{array}$ & $\begin{array}{l}\text { Sect. Eucroton, } \\
\text { subsect. Eutropia, } \\
\text { série Eutropia }\end{array}$ \\
\hline C. heterocalyx Baill. & Sect. Stolidanthus & $\begin{array}{l}\text { Sect. Eucroton, } \\
\text { subsect. Cyclostigma }\end{array}$ & $\begin{array}{l}\text { Sect. Eucroton, } \\
\text { subsect. Eutropia, } \\
\text { série Cyclostigma }\end{array}$ \\
\hline C. hoffmannii Müll.Arg. & - & $\begin{array}{l}\text { Sect. Eucroton, } \\
\text { subsect. Cyclostigma }\end{array}$ & - \\
\hline $\begin{array}{l}\text { C. maracayuensis } \\
\text { Chodat \& Hassl. }\end{array}$ & - & - & - \\
\hline C. seputubensis Hoehne & - & - & - \\
\hline C. sphaerogynus Baill. & Sect. Stolidanthus & $\begin{array}{l}\text { Sect. Eucroton, } \\
\text { subsect. Eutropia }\end{array}$ & $\begin{array}{l}\text { Sect. Eucroton, } \\
\text { subsect. Eutropia, } \\
\text { série Cyclostigma }\end{array}$ \\
\hline
\end{tabular}


Tabela 3. Espécies da seção Cleodora sensu Caruzo e seu posicionamento nos sistemas de Baillon, Müller e Webster

\begin{tabular}{|c|c|c|c|c|}
\hline $\begin{array}{c}\text { Croton sect. Cleodora } \\
\text { sensu Caruzo }\end{array}$ & Webster (1993) & Baillon (1864) & Müller (1866) & Müller (1873) \\
\hline $\begin{array}{l}\text { C. billbergianus } \\
\text { Müll.Arg. }\end{array}$ & & & $\begin{array}{l}\text { Sect. Eucroton, } \\
\text { subsect. Eutropia }\end{array}$ & - \\
\hline C. cajucara Benth. & Sect. Cleodora & Sect. Cleodora? & $\begin{array}{l}\text { Sect. Eucroton, } \\
\text { subsect. Eutropia }\end{array}$ & $\begin{array}{l}\text { Sect. Eucroton, } \\
\text { subsect. Eutropia, } \\
\text { série Cyclostigma } \\
\end{array}$ \\
\hline $\begin{array}{l}\text { C. campanulatus Caruzo } \\
\text { \& Cordeiro }\end{array}$ & - & - & - & - \\
\hline C. croizatii Steyerm. & - & - & - & - \\
\hline C. fragrans Kunth & Sect. Lasiogyne & - & $\begin{array}{l}\text { Sect. Eucroton, } \\
\text { subsect. Lasiogyne }\end{array}$ & - \\
\hline C. fragrantulus Croizat & - & - & - & - \\
\hline $\begin{array}{l}\text { C. hemiargyreus } \\
\text { Müll.Arg. }\end{array}$ & Sect. Cleodora & - & $\begin{array}{l}\text { Sect. Eucroton, } \\
\text { subsect. Cyclostigma }\end{array}$ & $\begin{array}{l}\text { Sect. Eucroton, } \\
\text { subsect. Eutropia, } \\
\text { série Eutropia } \\
\end{array}$ \\
\hline C. heterocalyx Baill. & Sect. Cleodora & $\begin{array}{l}\text { Sect. } \\
\text { Stolidanthus }\end{array}$ & $\begin{array}{l}\text { Sect. Eucroton, } \\
\text { subsect. Cyclostigma }\end{array}$ & $\begin{array}{l}\text { Sect. Eucroton, } \\
\text { subsect. Eutropia, } \\
\text { série Cyclostigma } \\
\end{array}$ \\
\hline C. hoffmanii Müll.Arg. & Sect. Cleodora & - & & $\begin{array}{l}\text { Subsec. } \\
\text { Cyclostigma }\end{array}$ \\
\hline C. organensis Baill. & $\begin{array}{l}\text { Sect. } \\
\text { Cyclostigma }\end{array}$ & $\begin{array}{l}\text { Sect. } \\
\text { Stolidanthus }\end{array}$ & $\begin{array}{l}\text { Sect. Eucroton, } \\
\text { subsect. Eutropia }\end{array}$ & $\begin{array}{l}\text { Sect. Eucroton, } \\
\text { subsect. Eutropia, } \\
\text { série Cyclostigma }\end{array}$ \\
\hline C. orinocensis Müll.Arg. & - & - & $\begin{array}{l}\text { Sect. Eucroton, } \\
\text { subsect. Cyclostigma }\end{array}$ & - \\
\hline $\begin{array}{l}\text { C. pseudofragrans } \\
\text { Croizat }\end{array}$ & - & - & - & - \\
\hline C. rottlerifolius Baill. & $\begin{array}{l}\text { Sect. } \\
\text { Cyclostigma }\end{array}$ & $\begin{array}{l}\text { Sect. } \\
\text { Stolidanthus }\end{array}$ & $\begin{array}{l}\text { Sect. Eucroton, } \\
\text { subsect. Cyclostigma }\end{array}$ & $\begin{array}{l}\text { Sect. Eucroton, } \\
\text { subsect. Eutropia, } \\
\text { série Cyclostigma }\end{array}$ \\
\hline $\begin{array}{l}\text { C. rufolepidotus Caruzo } \\
\text { \& Riina sp.nov.ined. }\end{array}$ & - & - & - & - \\
\hline C. salutaris Casar. & - & $\begin{array}{l}\text { Sect. } \\
\text { Palanostigma }\end{array}$ & $\begin{array}{l}\text { Sect. Eucroton, } \\
\text { subsect. Eutropia }\end{array}$ & $\begin{array}{l}\text { Sect. Eucroton, } \\
\text { subsect. Cleodora, } \\
\text { série } \\
\text { Argyrocroton }\end{array}$ \\
\hline C. sphaerogynus Baill. & Sect. Cleodora & $\begin{array}{l}\text { Sect. } \\
\text { Stolidanthus }\end{array}$ & $\begin{array}{l}\text { Sect. Eucroton, } \\
\text { subsect. Eutropia }\end{array}$ & $\begin{array}{l}\text { Sect. Eucroton, } \\
\text { subsect. Eutropia, } \\
\text { série Cyclostigma }\end{array}$ \\
\hline C. spruceanus Benth. & - & $\begin{array}{l}\text { Sect. } \\
\text { Argyroglossum }\end{array}$ & $\begin{array}{l}\text { Sect. Eucroton, } \\
\text { subsect. Eutropia }\end{array}$ & $\begin{array}{l}\text { Sect. Eucroton, } \\
\text { subsect. Cleodora, } \\
\text { série Medea }\end{array}$ \\
\hline $\begin{array}{l}\text { C. stellatoferrugineus } \\
\text { Caruzo \& Cordeiro } \\
\text { sp.nov. ined. }\end{array}$ & - & - & - & - \\
\hline
\end{tabular}


Tabela 4. Principais diferenças entre Croton campanulatus, C. hemiargyreus, C. salutaris e C. rufolepidotus.

\begin{tabular}{|c|c|c|c|c|}
\hline Características & $\begin{array}{c}\text { C. } \\
\text { campanulatus }\end{array}$ & C. hemiargyreus & C. salutaris & C. rufolepidotus \\
\hline $\begin{array}{l}\text { Coloração do } \\
\text { Indumento }\end{array}$ & rufo-argênteo & prateado & rufo-argênteo & rufo-argênteo \\
\hline Tipo de Tricomas & lepidoto & lepidoto & $\begin{array}{l}\text { lepidoto- } \\
\text { porrecto }\end{array}$ & Lepidoto \\
\hline $\begin{array}{l}\text { Tipo de margem } \\
\text { foliar }\end{array}$ & inteira & serrilhada & inteira & Inteira \\
\hline Forma da estípula & $\begin{array}{l}\text { linear- } \\
\text { lanceolada }\end{array}$ & linear-lanceolada & $\begin{array}{l}\text { linear- } \\
\text { lanceolada }\end{array}$ & Auricular \\
\hline $\begin{array}{ll}\text { Número } & \text { de } \\
\text { estames }\end{array}$ & ca. 25 & са. 15 & са. 15 & $15-25$ \\
\hline Forma da flor $q$ & campanulada & campanulada & ampuliforme & ampuliforme \\
\hline $\begin{array}{l}\text { Textura dos lobos } \\
\text { do cálice da flor } \\
+\end{array}$ & foliáceo & carnoso & carnoso & Foliáceo \\
\hline $\begin{array}{l}\mathrm{N}^{\mathrm{o}} \text { de divisões } \\
\text { dos estiletes }\end{array}$ & 4-fidos & 4(6)-fidos & 4-fidos & Multífidos \\
\hline Altitude & Acima de $900 \mathrm{~m}$ & Acima de $900 \mathrm{~m}$ & $700-950 \mathrm{~m}$ & Até 300 m \\
\hline
\end{tabular}

Tabela 5. Principais diferenças entre Croton fragrantulus, C. hoffmannii e $C$. rottlerifolius.

\begin{tabular}{|c|c|c|c|}
\hline Características & C. fragrantulus & C. hoffmannii & C. rottlerifolius \\
\hline Tipo de Tricomas & $\begin{array}{l}\text { estrelados, } \\
\text { multiradiados }\end{array}$ & $\begin{array}{l}\text { estrelados e } \\
\text { multiradiados }\end{array}$ & $\begin{array}{l}\text { estrelados e } \\
\text { adpresso-estrelados }\end{array}$ \\
\hline $\begin{array}{l}\text { Âmbito dos ramos } \\
\text { jovens }\end{array}$ & $\begin{array}{l}\text { achatados, } \\
\text { conspicuamente } \\
\text { estriados }\end{array}$ & $\begin{array}{l}\text { cilíndricos, } \\
\text { levemente estriados }\end{array}$ & $\begin{array}{l}\text { cilíndricos, } \\
\text { levemente estriados }\end{array}$ \\
\hline Forma das anteras & elipsóides & sagitadas & elipsóides \\
\hline Forma da flor $\hat{\sigma}$ & subcampanulada & campanulada & campanulada \\
\hline $\begin{array}{l}\text { Ápice das pétalas da } \\
\text { flor } \widehat{\sigma}\end{array}$ & arredondado & recortado, ondulado & obtuso \\
\hline Forma do fruto & não observados & subgloboso, trígono & $\begin{array}{l}\text { globoso-elipsóide, } \\
\text { não trígono }\end{array}$ \\
\hline
\end{tabular}


Tabela 6. Principais diferenças entre Croton sphaerogynus e C. stellatoferrugineus.

\begin{tabular}{|c|c|c|}
\hline Características & C. sphaerogynus & C. stellatoferrugineus \\
\hline $\begin{array}{l}\text { Densidade do indumento } \\
\text { foliar (face abaxial) }\end{array}$ & $\begin{array}{l}\text { esparsamente hirsuto a } \\
\text { glabrescente }\end{array}$ & pubescente \\
\hline Tipo de Tricomas & $\begin{array}{l}\text { estrelado-porrectos, } \\
\text { adpresso-estrelados }\end{array}$ & estrelados, multiradiados \\
\hline Base das folhas & $\begin{array}{l}\text { cordada a auriculada, lobos } \\
\text { sobrepostos }\end{array}$ & $\begin{array}{l}\text { levemente cordada, lobos } \\
\text { não sobrepostos }\end{array}$ \\
\hline Brácteas & $\begin{array}{l}\text { brácteas não foliáceas, sem } \\
\text { glândulas na base }\end{array}$ & $\begin{array}{l}\text { brácteas foliáceas, com um } \\
\text { par de glândulas na base }\end{array}$ \\
\hline Forma da flor $q$ & ampuliforme & campanulada \\
\hline Lobos do cálice da flor + & $\begin{array}{l}\text { unidos apenas na base, } \\
\text { reflexos }\end{array}$ & $\begin{array}{l}\text { unidos até a metade, não } \\
\text { reflexos }\end{array}$ \\
\hline $\begin{array}{l}\text { Coloração do indumento } \\
\text { do cálice da flor } q\end{array}$ & glauco & ferrugíneo \\
\hline $\begin{array}{l}\text { Número de divisões dos } \\
\text { estiletes }\end{array}$ & 4-fidos & multífidos \\
\hline Habitat & floresta de restinga & $\begin{array}{l}\text { floresta estacional } \\
\text { semidecidual }\end{array}$ \\
\hline Distribuição & SP, RJ, ES, BA & $\begin{array}{l}\text { MG, endêmica da Serra do } \\
\text { Espinhaço }\end{array}$ \\
\hline
\end{tabular}




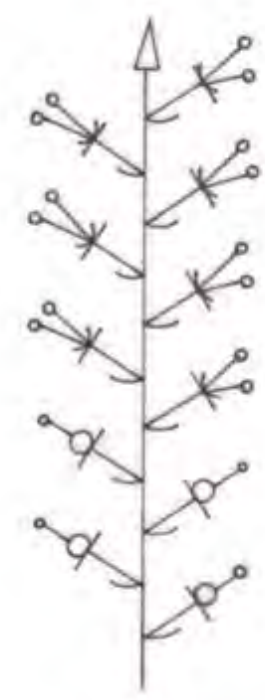

Padrão 1

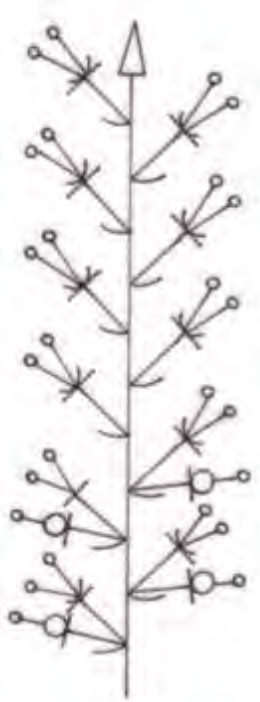

Padrão 2

\section{Legenda: $\forall$ Flormasculina if Flor feminina}

Figura 1: Esquema dos padrões de inflorescências encontrados nas espécies de Croton sect. Cleodora (modificado de Caruzo, 2005). 

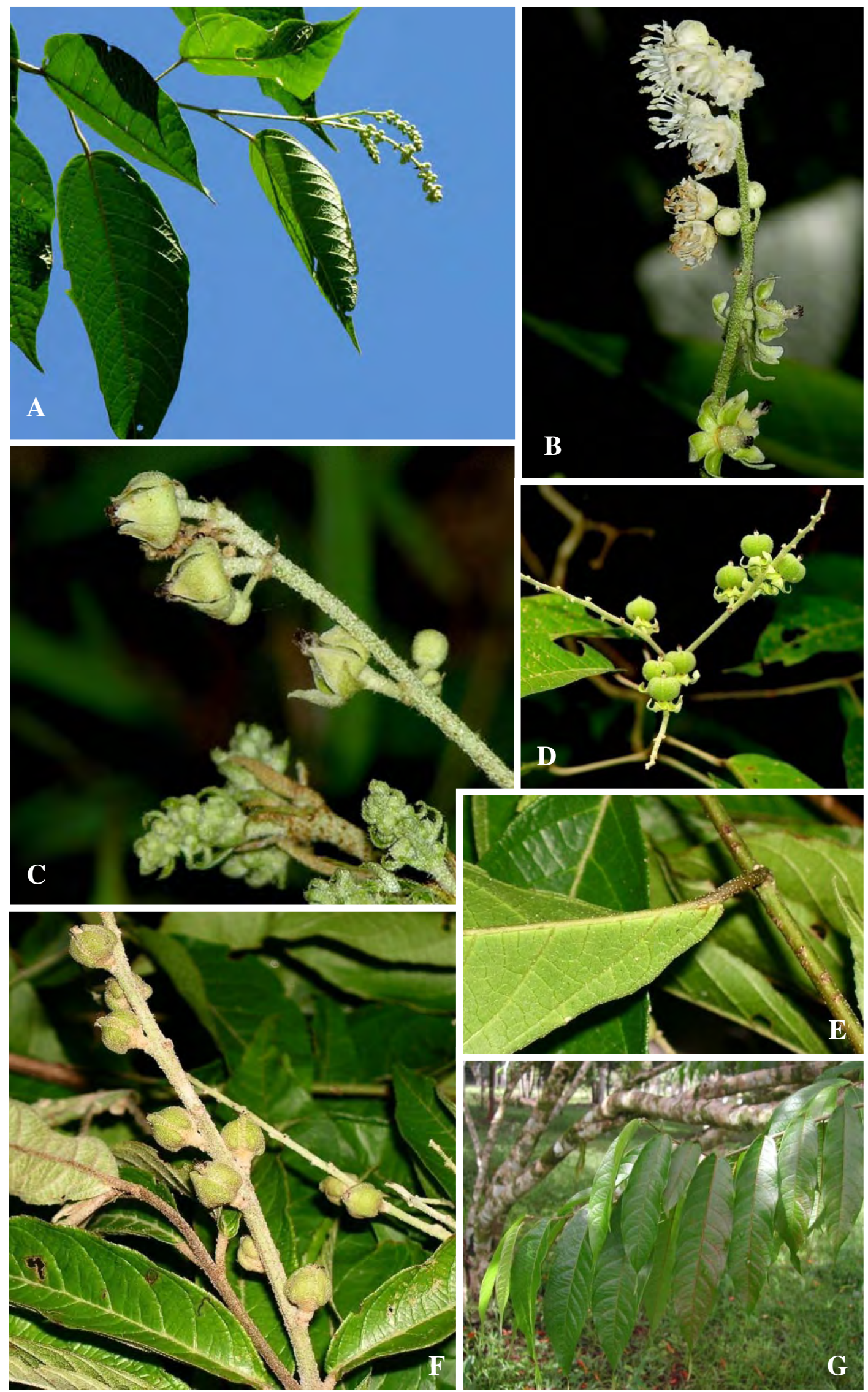

Figura 2. A-D: Croton billbergianus. A: Inflorescência, B: Flores, C: Frutos jovens . D. Frutos maduros com lobos do cálice revolutos. E-G: Croton cajucara. E: Glândula foliar basilaminar macular, F: Frutos, G: Folhas (Fotos A-D: J. González; E-F: R. Riina; G: M.B.R. Caruzo). 

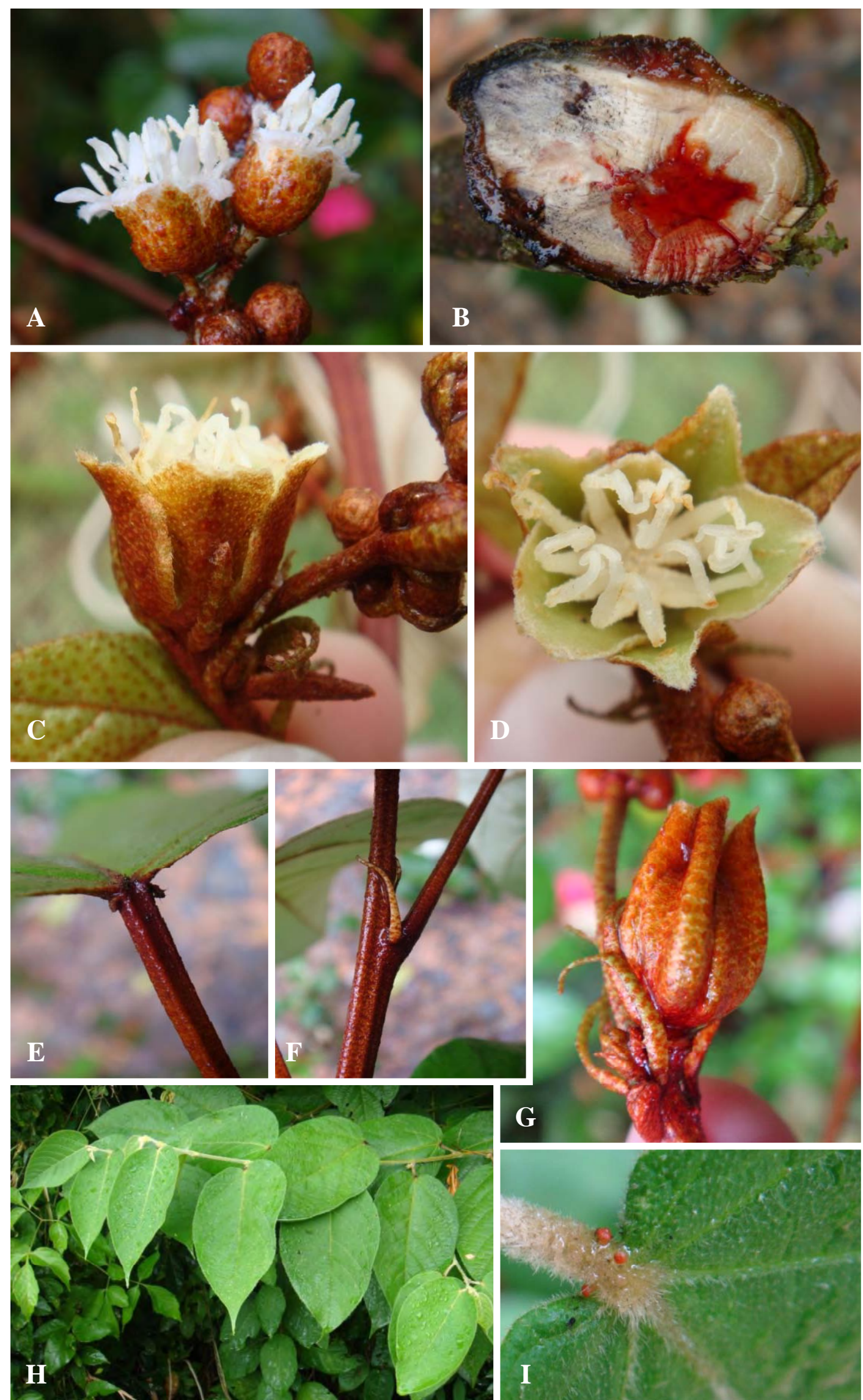

Figura 3. A-F: Croton campanulatus. A: Flor masculina, B: Látex, C: Flor feminina. D. Flor feminina, detalhe dos estiletes unidos, E: glândulas acropeciolares, F: estípula, G: fruto jovem. H-I: Croton fragrans. H: ramo estéril, I: Glândulas acropeciolares. (Fotos AI: M.B.R. Caruzo). 


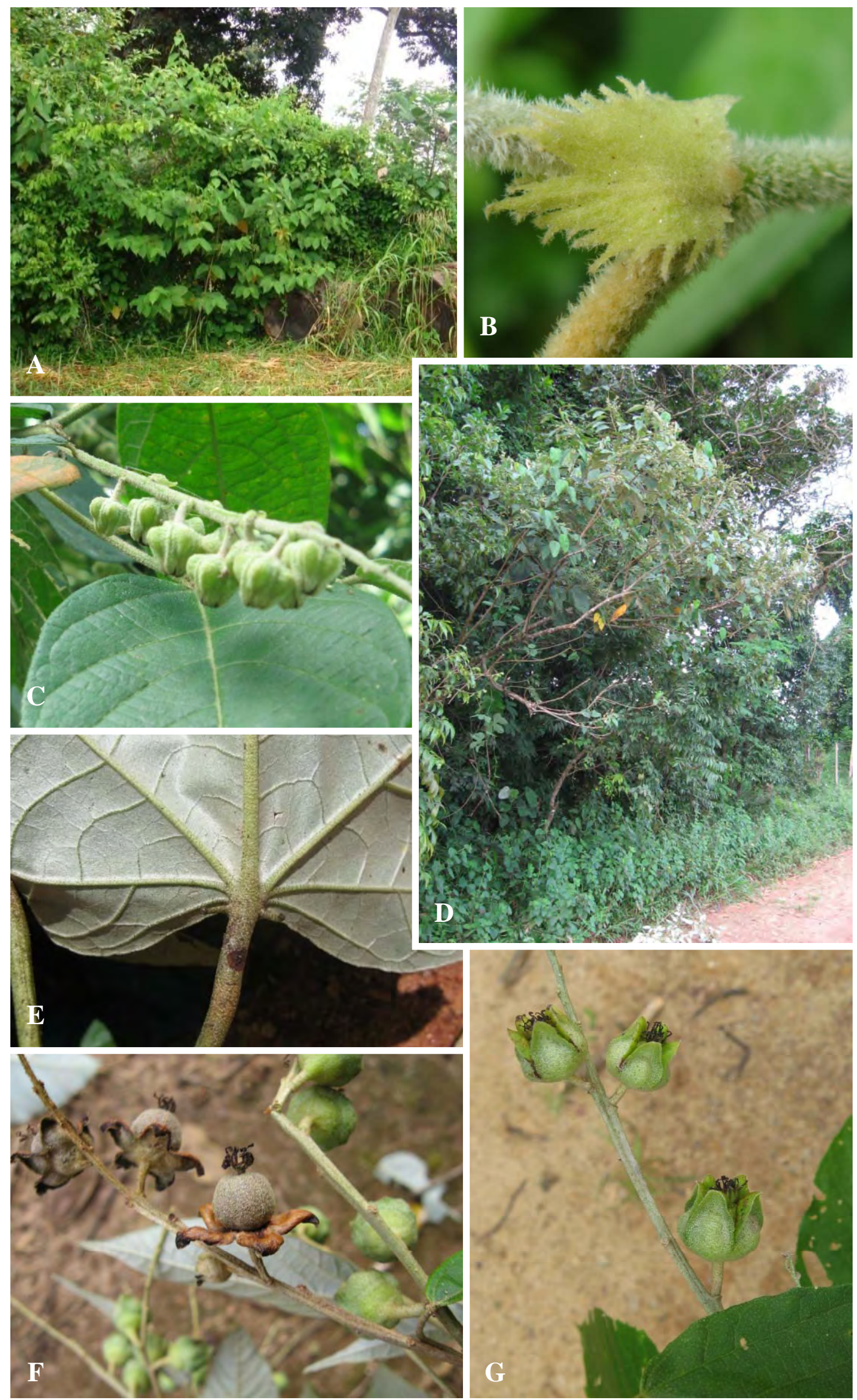

Figura 4. A-C: Croton fragrans. A: habito, B: estípula com margem lacerada, C: frutos. DG: Croton hemiargyreus. D: habito, E: Glândulas acropeciolares, F: fruto maduro, G: fruto jovem. (Fotos A-B: M.B.R. Caruzo; C: C. Reyes; D-G: M.B.R. Caruzo). 

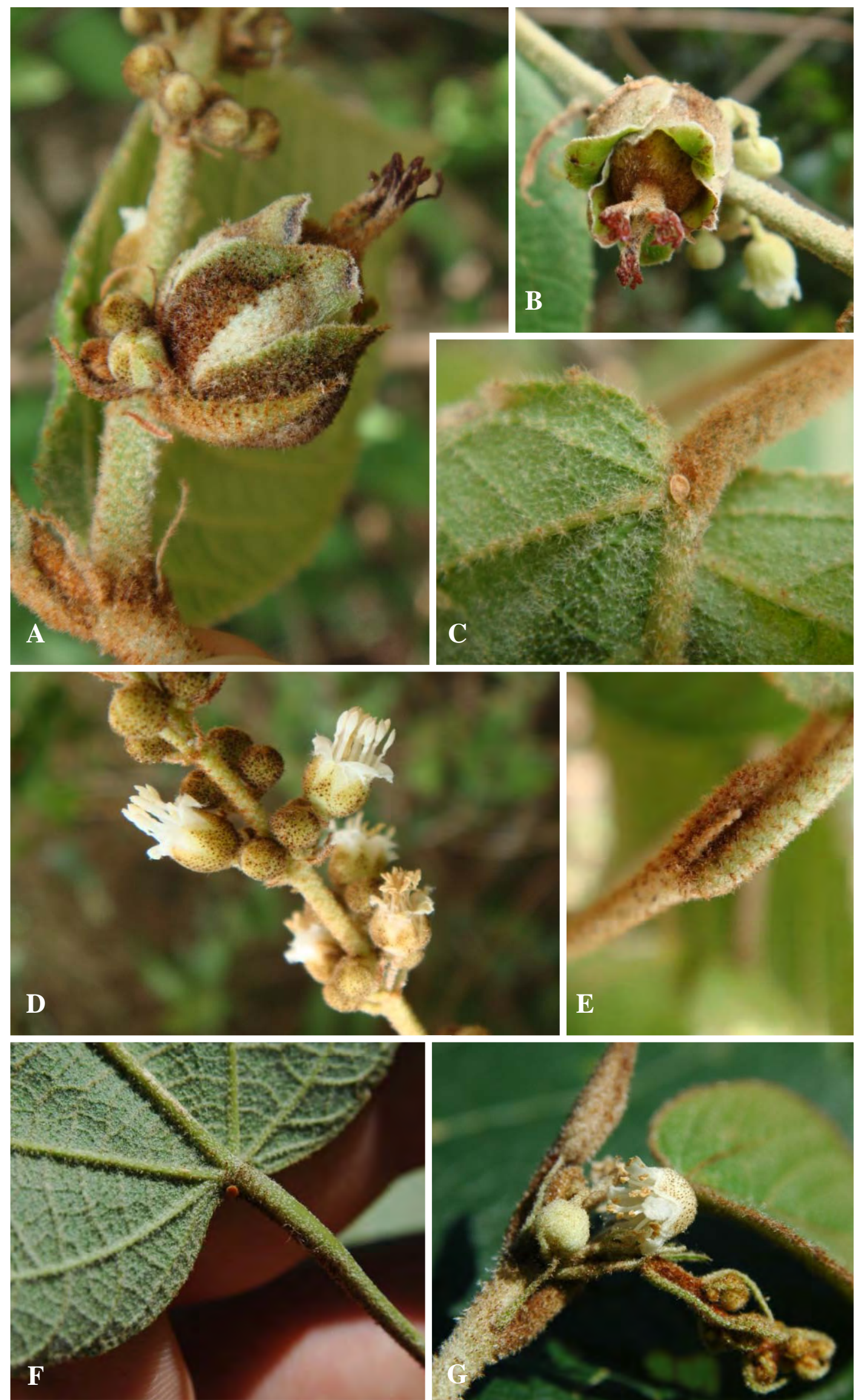

Figura 5. A-E: Croton heterocalyx. A: fruto, B: fruto, detalhe dos estiles unidos, C: glândula foliar basilaminar, D: flores masculinas, E: estípula. F-G: Croton hoffmannii. F: glândulas acropeciolares, G: flor masculina (Fotos A-E: M.B.R. Caruzo; G: B. Van Ee). 

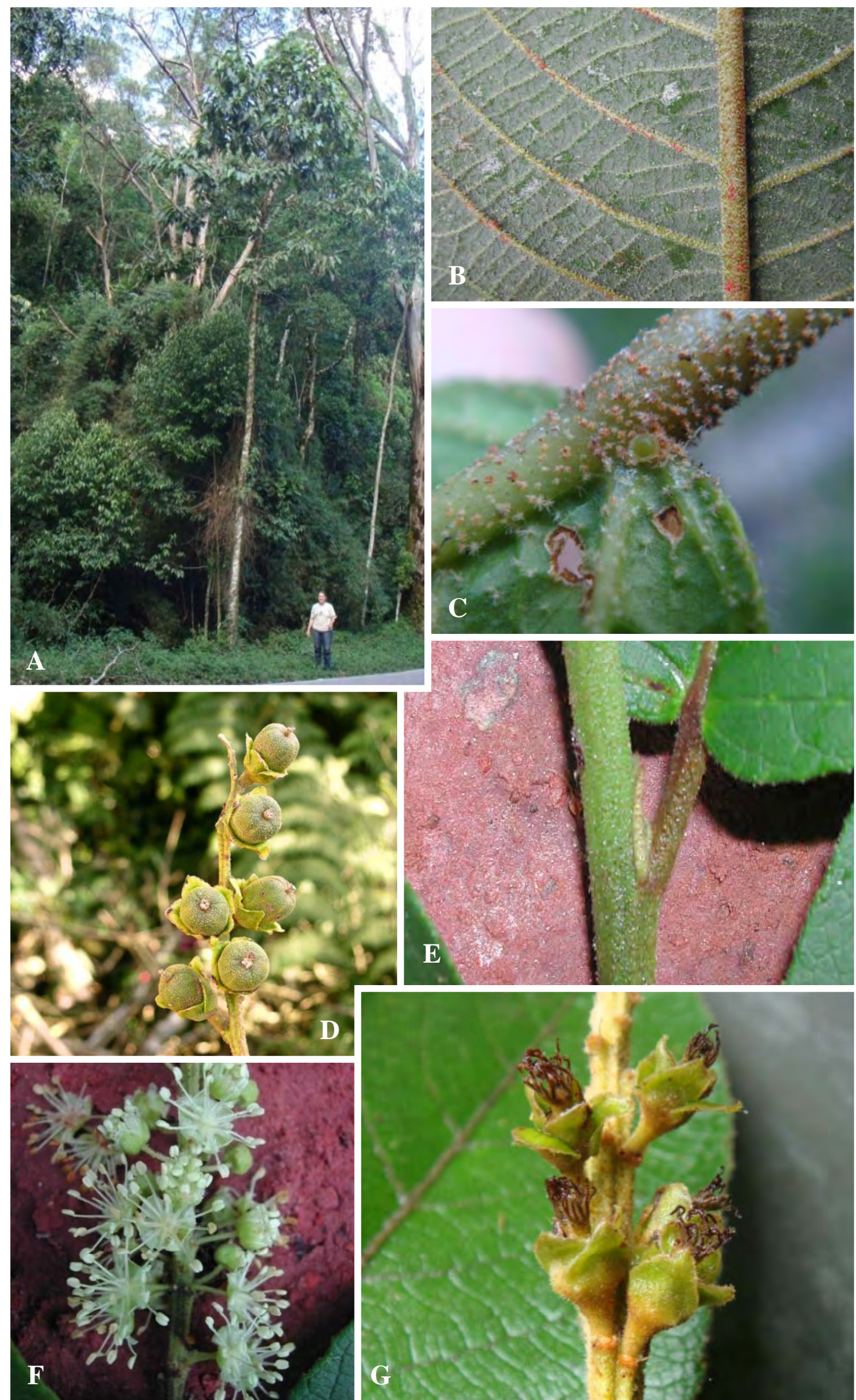

Figura 6. A-H: Croton organensis. A: habito, B: nervuras tercárias percurrentes, C: glândula foliar basilaminar, D: frutos maduros, E: estípula, F: : flores masculinas; G: frutos jovens (Fotos A-C: M.B.R. Caruzo; D: R. Riina; E-F: M.B.R. Caruzo). 

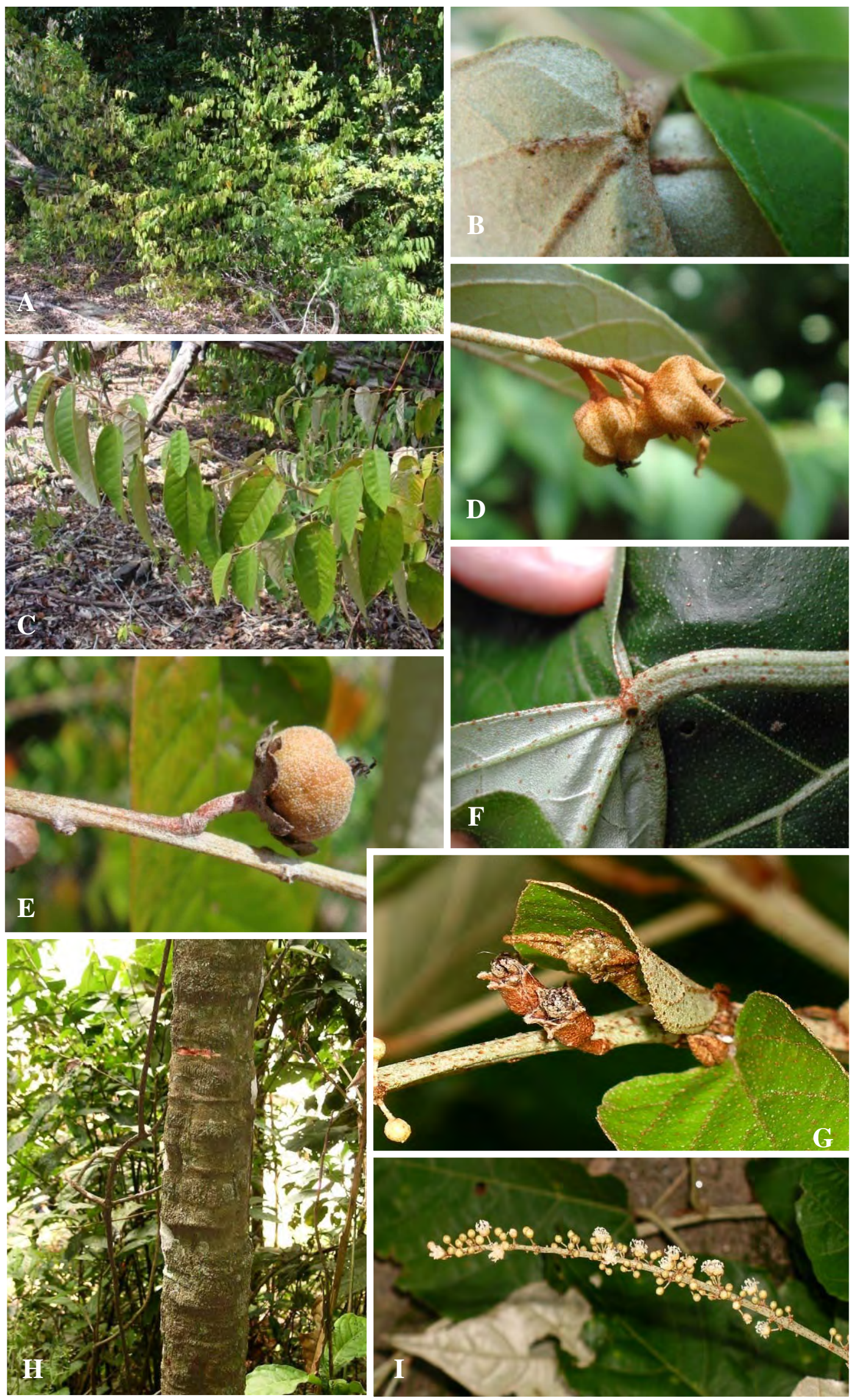

Figura 7. A-E: Croton orinocensis. A: habito, B: glândula foliar basilaminar, C: ramo, D: frutos jovens, E: fruto maduro. F-I: Croton salutaris. F: glândula foliar basilaminar, G: tronco costado; H: fruto jovem; I: flores masculinas (Fotos A-E: M.B.R. Caruzo; F: I. Cordeiro; G-I: R. Riina). 

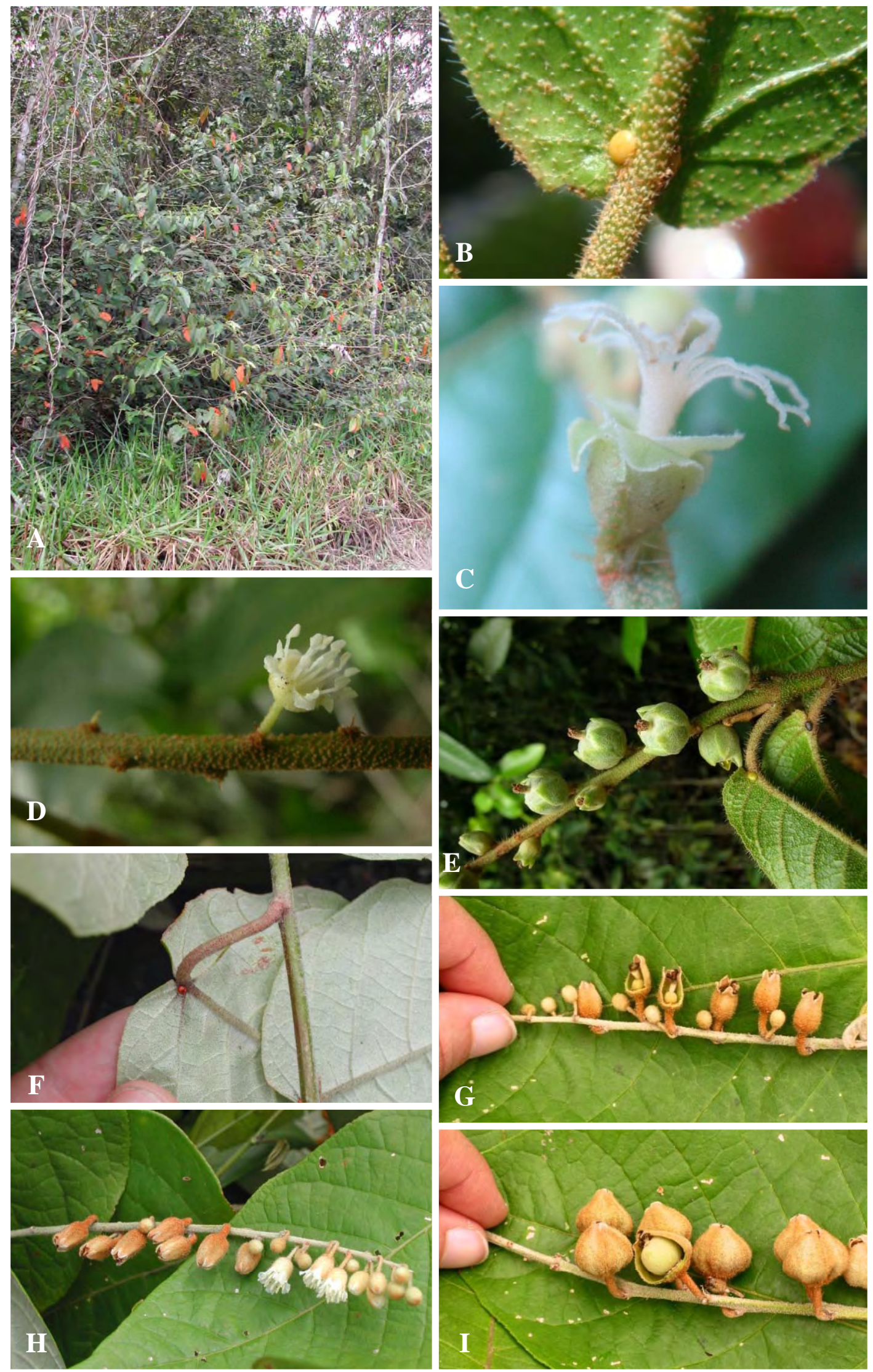

Figura 8. A-E: Croton sphaerogynus subsp. sphaerogynus. A: habito, B: glândula foliar basilaminar, C: flor feminina, evidenciando estiletes unidos formando uma "coroa", D: flor masculina, E: frutos maduros, F-I: C. spruceanus. F: glândula foliar basilaminar, G: frutos jovens, H: inflorescência, I: frutos maduros, evidenciando cálice inflado (Fotos A-D: M.B.R. Caruzo, E-G: R. Riina). 

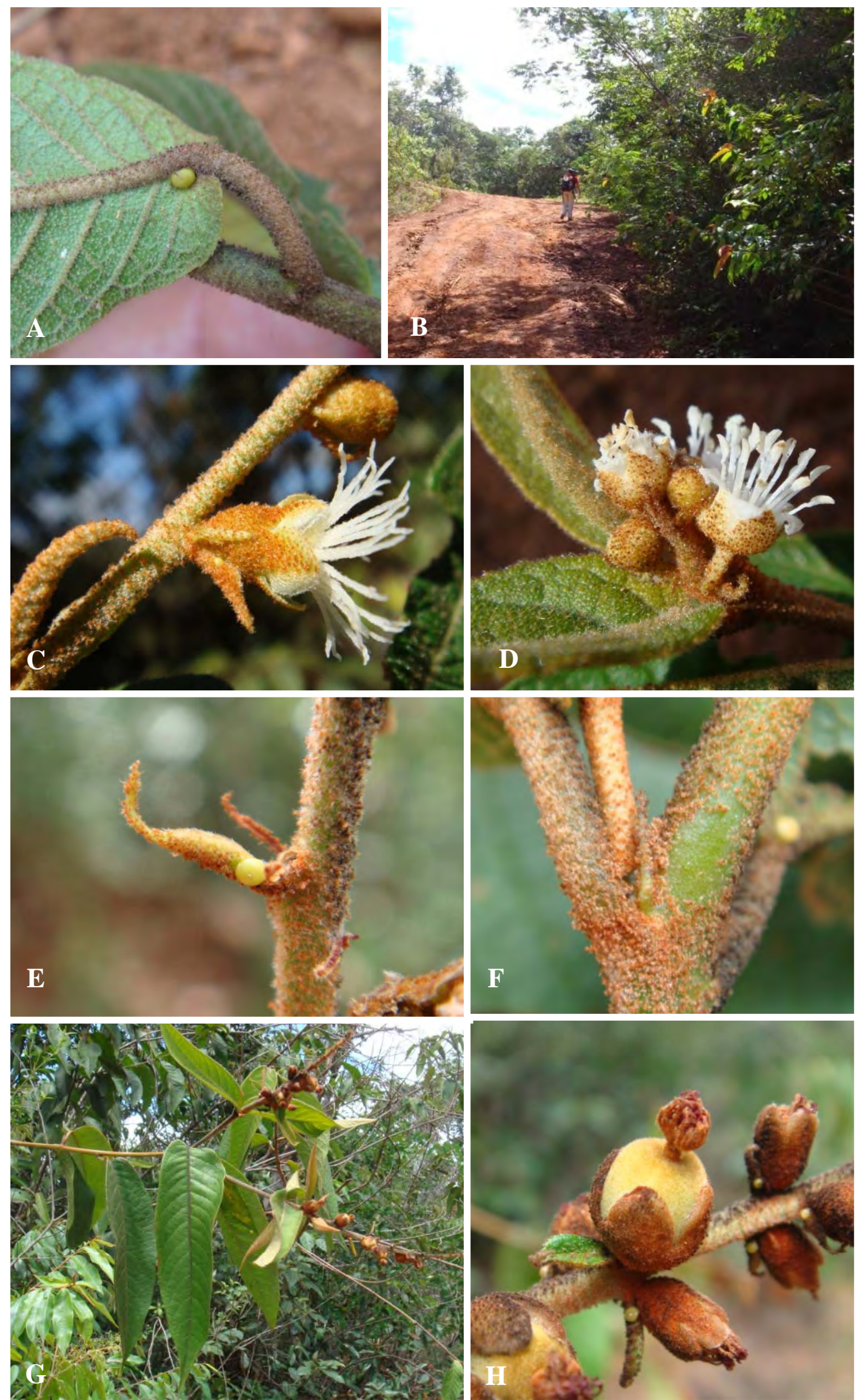

Figura 9. A-H: Croton stellatoferrugineus. A: glândula foliar basilaminar, B: habito, C: flor feminina, D: flor masculina, E: bráctea foliácea com glândula na base, F: estípula, G: ramo; H: fruto maduro (Fotos A-H: M.B.R. Caruzo). 


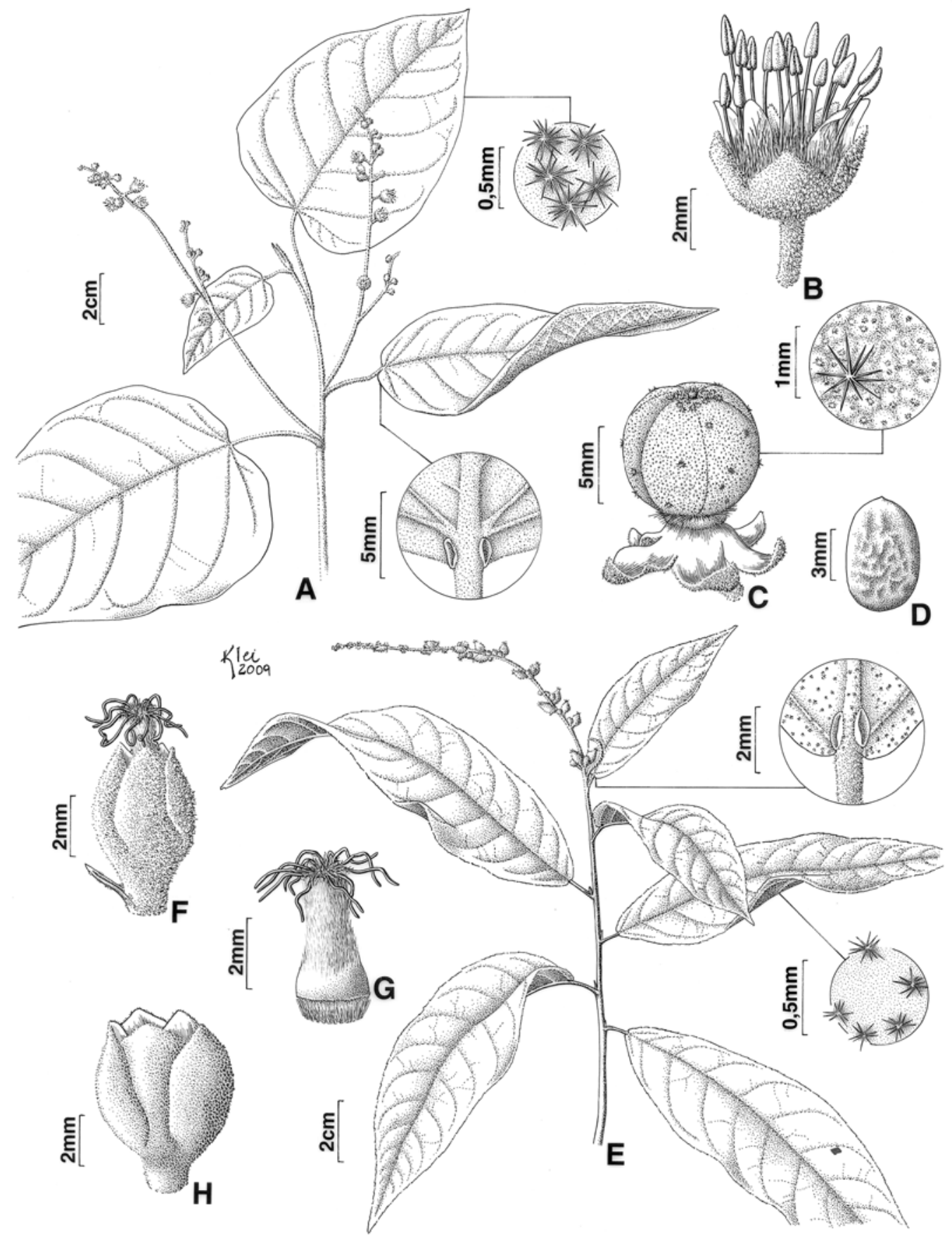

Figura 10. A-D: Croton billberganus. A: ramo, detalhe dos tricomas foliares e nectários extraflorais (Hernadez, 100), B: flor masculina (Hernadez, 100), C: fruto (Carballo, 493), D: semente (Carballo, 493). E-H: Croton cajucara. E: ramo, detalhe dos tricomas foliares e nectários extraflorais (Zarucchi et al., 2655), F: flor feminina (Rodriguez, s.n.), G: gineceu (Rodriguez, s.n.), H: fruto (Caruzo \& Riina, 98). 


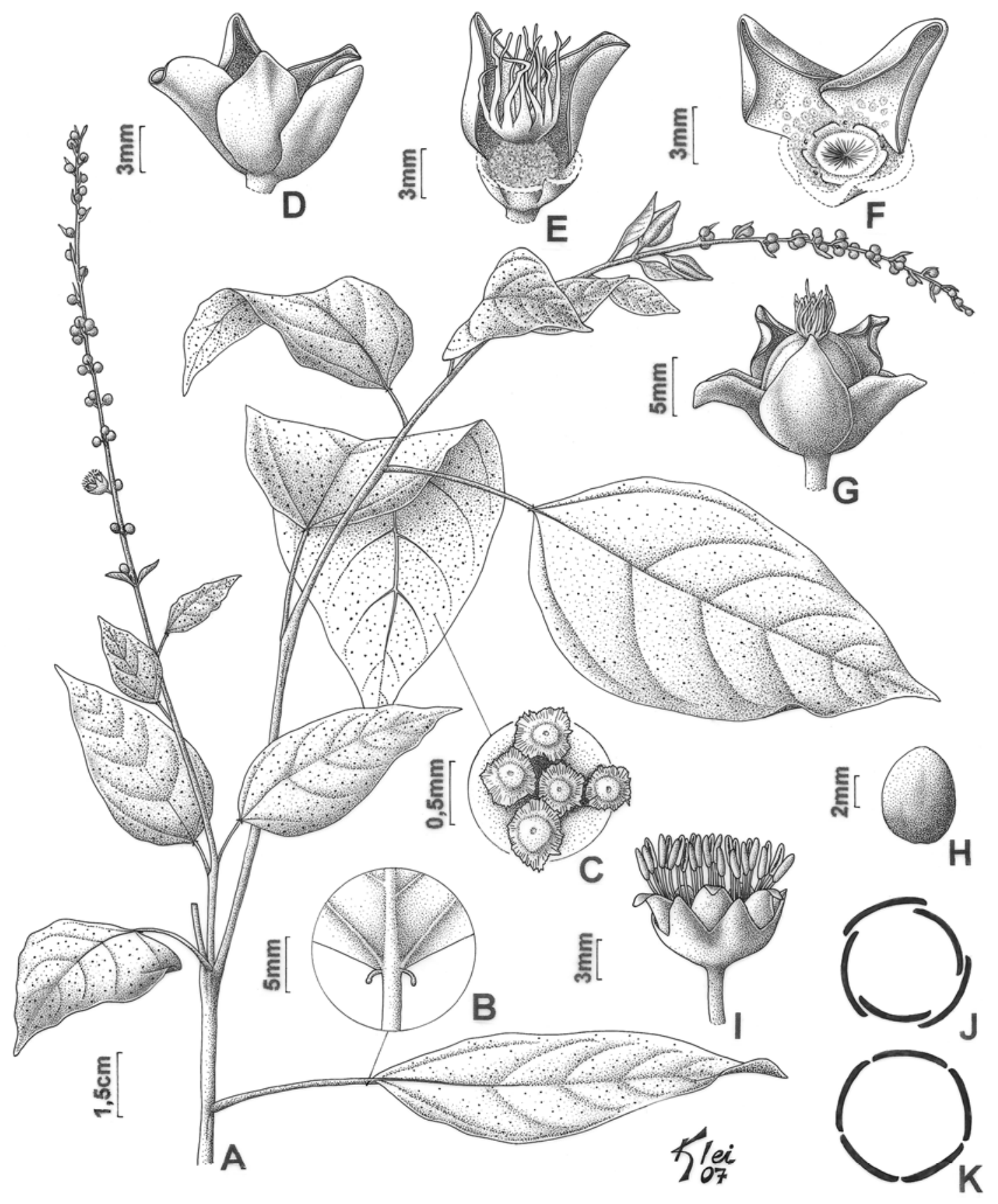

Figura 11. A- K: Croton campanulatus. A: ramo, B: glândula acropeciolar, C: tricomas lepidotos subinteiros, D: flor feminina, E: detalhe do gineceu, F: detalhe do disco na base do ovário, G: fruto, H: semente, I: flor masculina, J: esquema da prefloração quincuncial da flor feminina, $\mathrm{K}$ : esquema da prefloração valvar da flor masculina. (Caruzo et al., 93). 


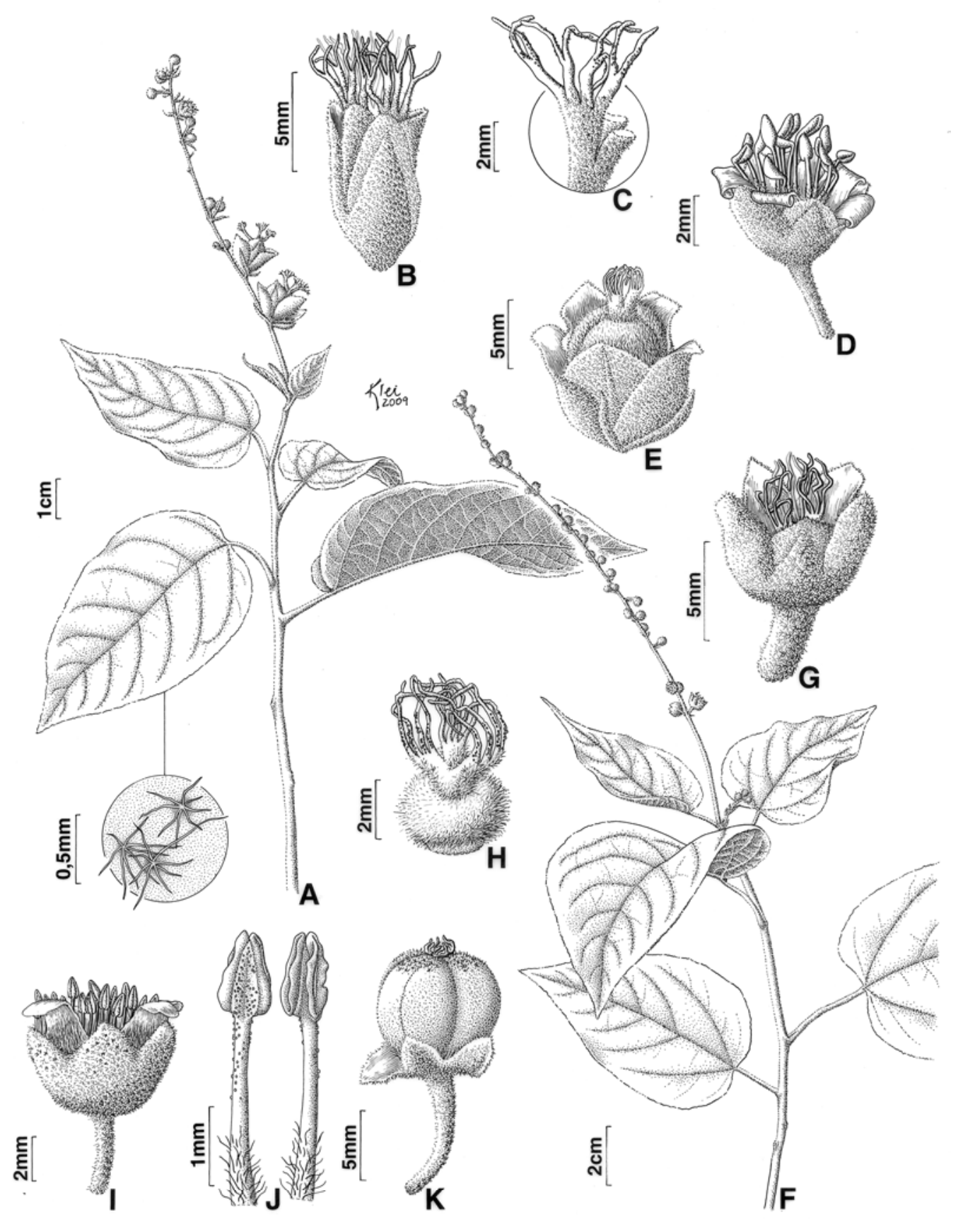

Figura 14. A-E. Croton heterocalyx. A: ramo, com detalhe dos tricomas foliares estrelados (Caruzo et al., 108), B: flor feminina (Caruzo et al., 108), C: detalhe dos ramos dos estiletes (Caruzo et al., 108), D: flor masculina (Caruzo et al., 108), E: fruto (Caruzo et al. 108). F-K. Croton hoffmannii. F: ramo (Luteyn, 725), G: flor feminina (Luteyn, 725), H: gineceu (Luteyn, 725), I: flor masculina (Luteyn, 725), J: estame (Luteyn, 725), K: fruto (Mori, 15388). 


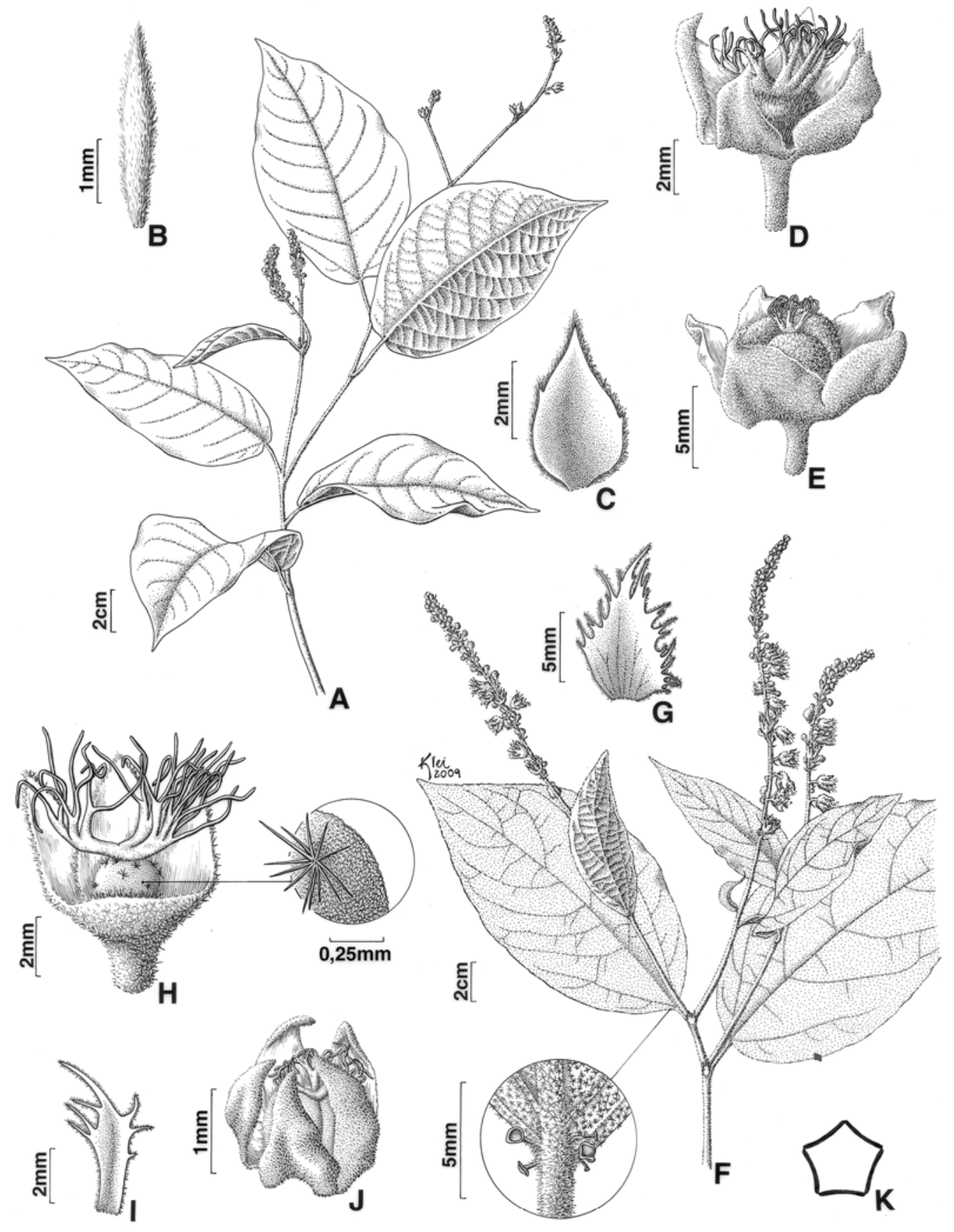

Figura 12. A-E: Croton croizatii. A: ramo (Breteler, 4575), B: estípula (Breteler, 4575), C: bráctea (Breteler, 4575), D: flor feminina (Breteler, 4575), E: fruto (Breteler, 4575). F-K: Croton fragrans. F: ramo, detalhe dos nectários extraflorais (Léon, 192), G: estípula (Caruzo et al. 136), H: flor feminina, detalhe do gineceu (Liesner \& Guariglia, 11511), I: bráctea (Liesner \& Guariglia, 11511), J: fruto (Breteler, 4018), K: esquema da prefloração reduplicado-valvar da flor feminina. 


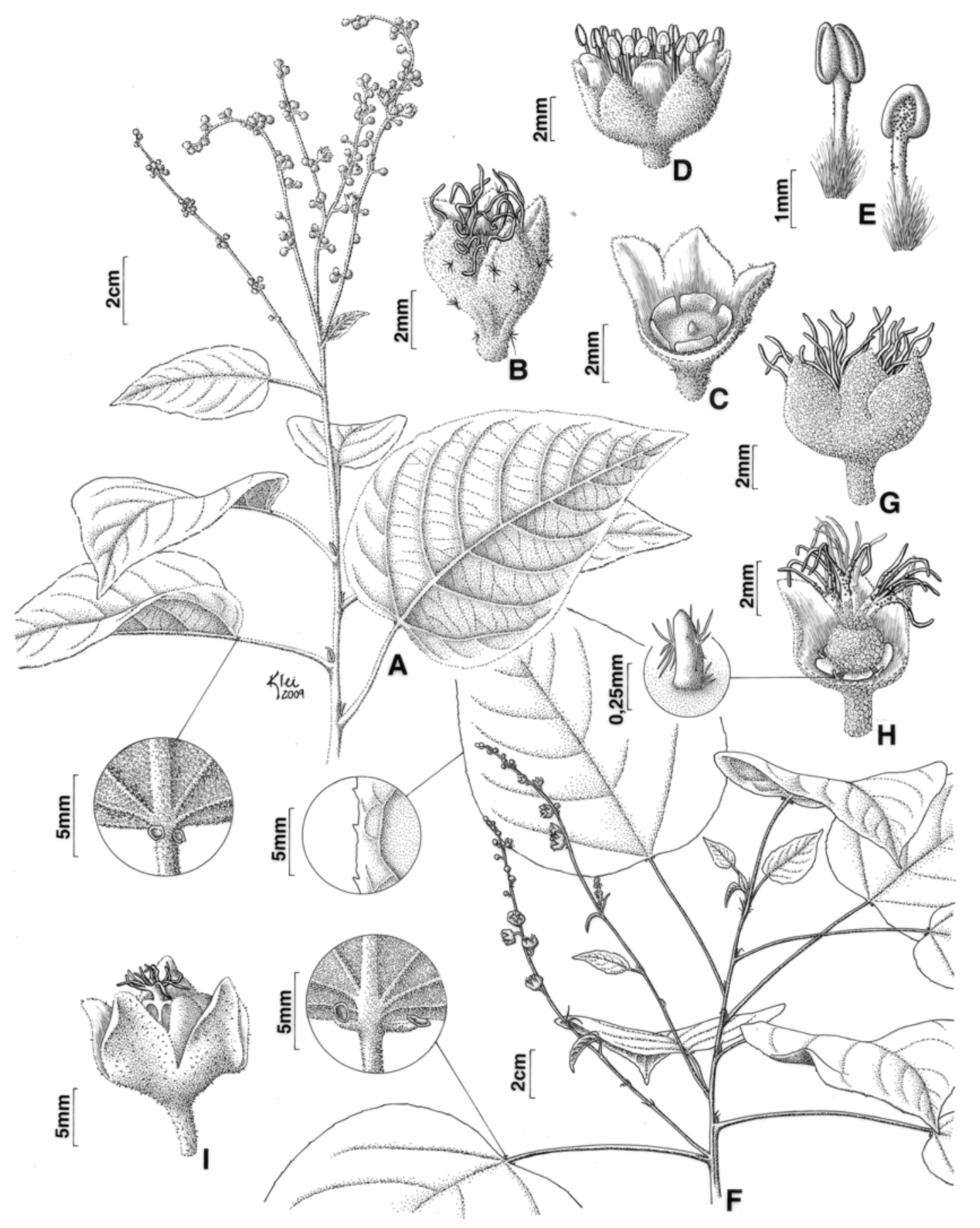

Figura 13. A-E. Croton fragrantulus. A: ramo, detalhe das glândulas acropeciolares (Nee, 40099), B: flor feminina (Nee, 40099), C: detalhe do disco nectarífero da flor feminina (Nee, 40099), D: flor masculina (Foster, 424), E: estame, vista dorsal e ventral (Foster 424). F-I. Croton hemiargyreus. F: ramo, detalhe das glândulas acropeciolares e da margem foliar serrilhada (Caruzo et al., 116), G: flor feminina (Caruzo et al., 116), $\mathrm{H}$ : detalhe do gineceu e pétala reduzida a glândula (Caruzo et al., 116), I: fruto (Caruzo et al., 114). 


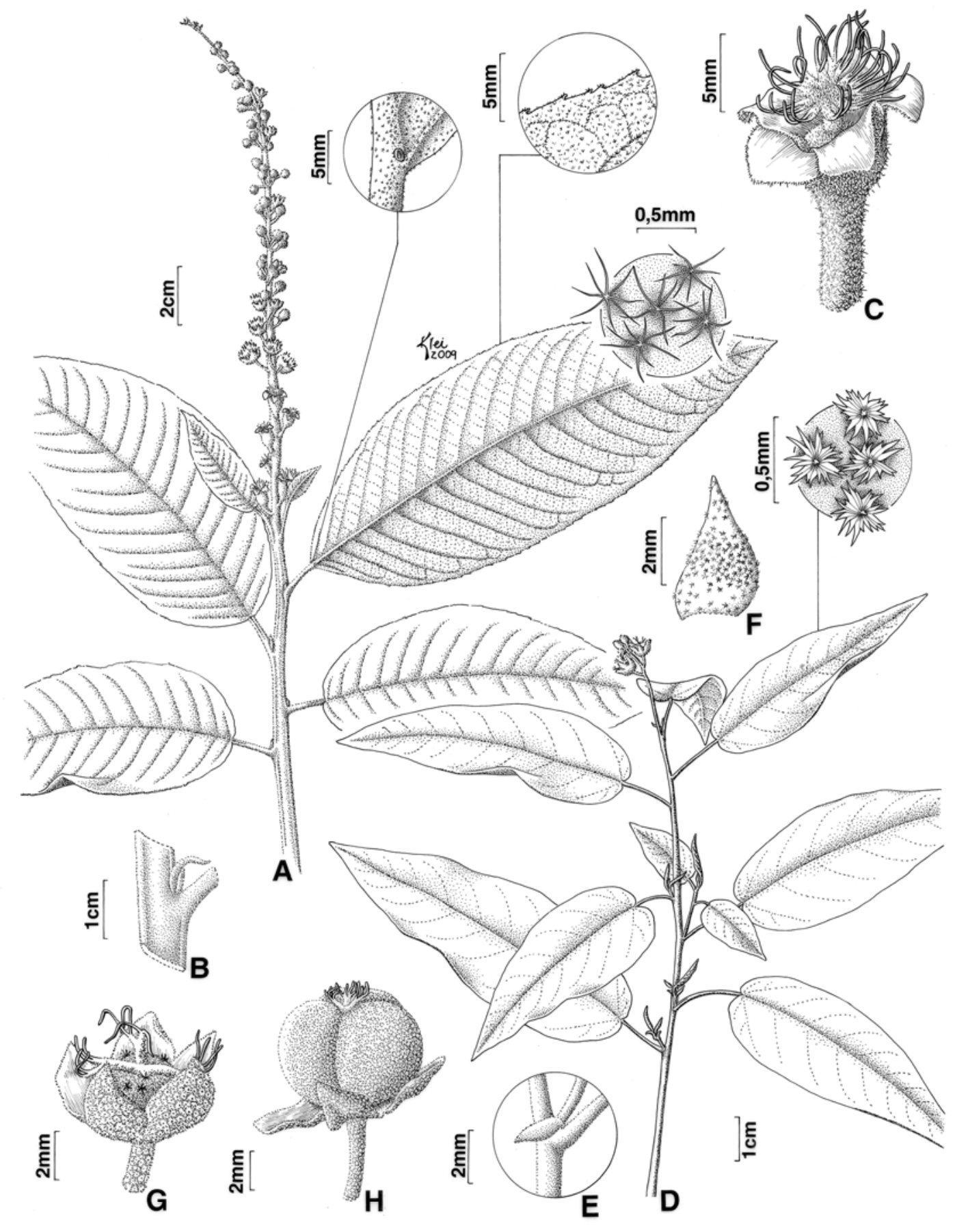

Figura 15. A-C. Croton organensis. A: ramo, detalhe da glândula basilaminar e da margem foliar serrilhada (Caruzo et al. 72), B: detalhe do ramo achatado e da estípula (Caruzo et al. 72), C: flor feminina (Caruzo et al. 72). D-H. Croton orinocensis. D: ramo, detalhe dos tricomas foliares (Gentry \& Berry, 14581), E: estípula (Gentry \& Berry, 14581), F: bráctea (Gentry \& Berry, 14581), G: fruto jovem (Gentry \& Berry, 14581), H: fruto maduro (Gentry \& Berry, 14581). 


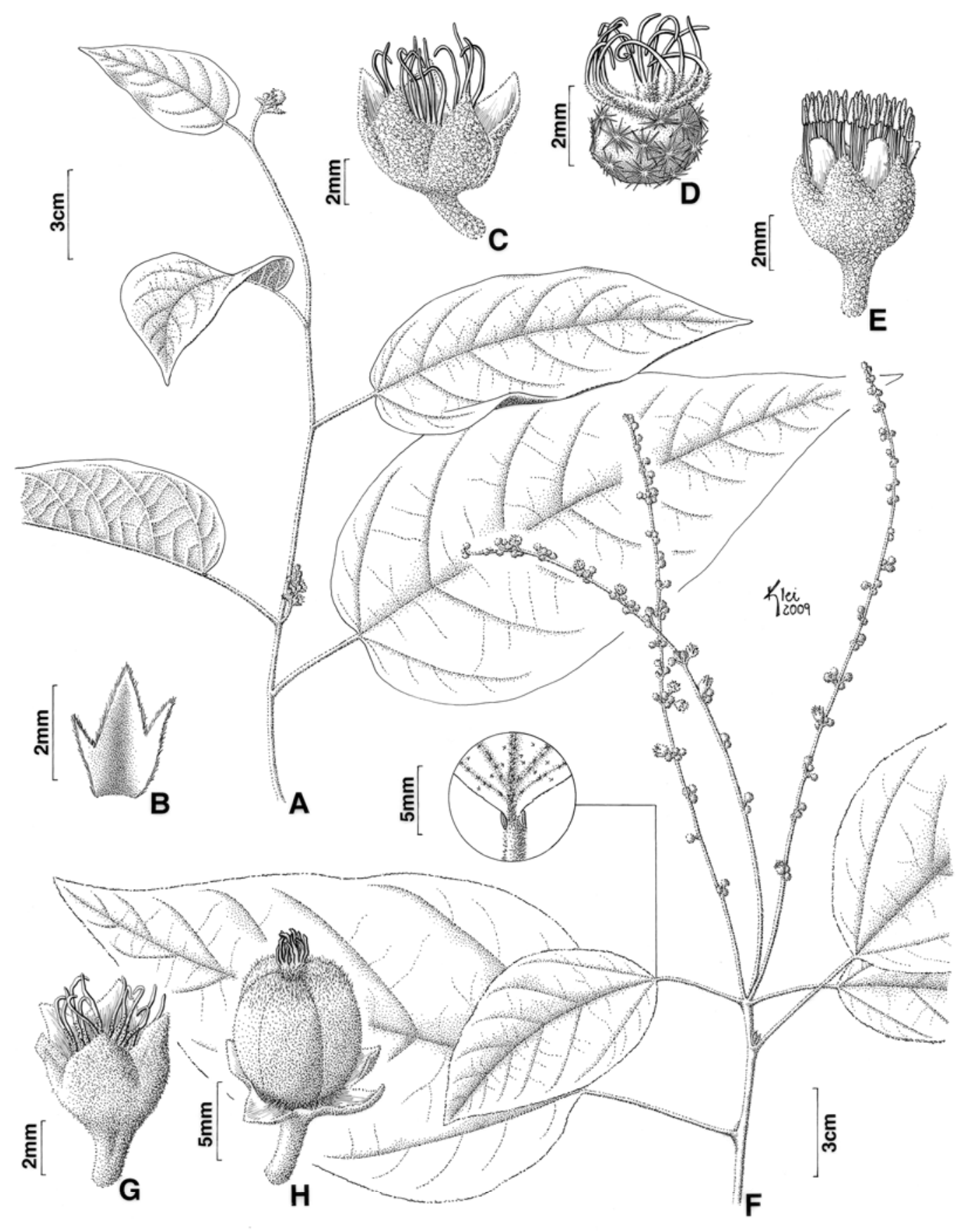

Figura 16. A-E. Croton pseudofragrans. A: ramo (Coello, 213), B: bráctea 3-lobada (Coello, 213), C: flor feminina (Coello, 213), D: gineceu (Coello, 213), E: flor masculina (Coello, 213). F- H. Croton rottlerifolius. F: ramo, detalhe das glândulas acropeciolares (Melo \& Santos, 984), G: flor feminina (Melo \& Santos, 984), H: fruto (Caruzo 


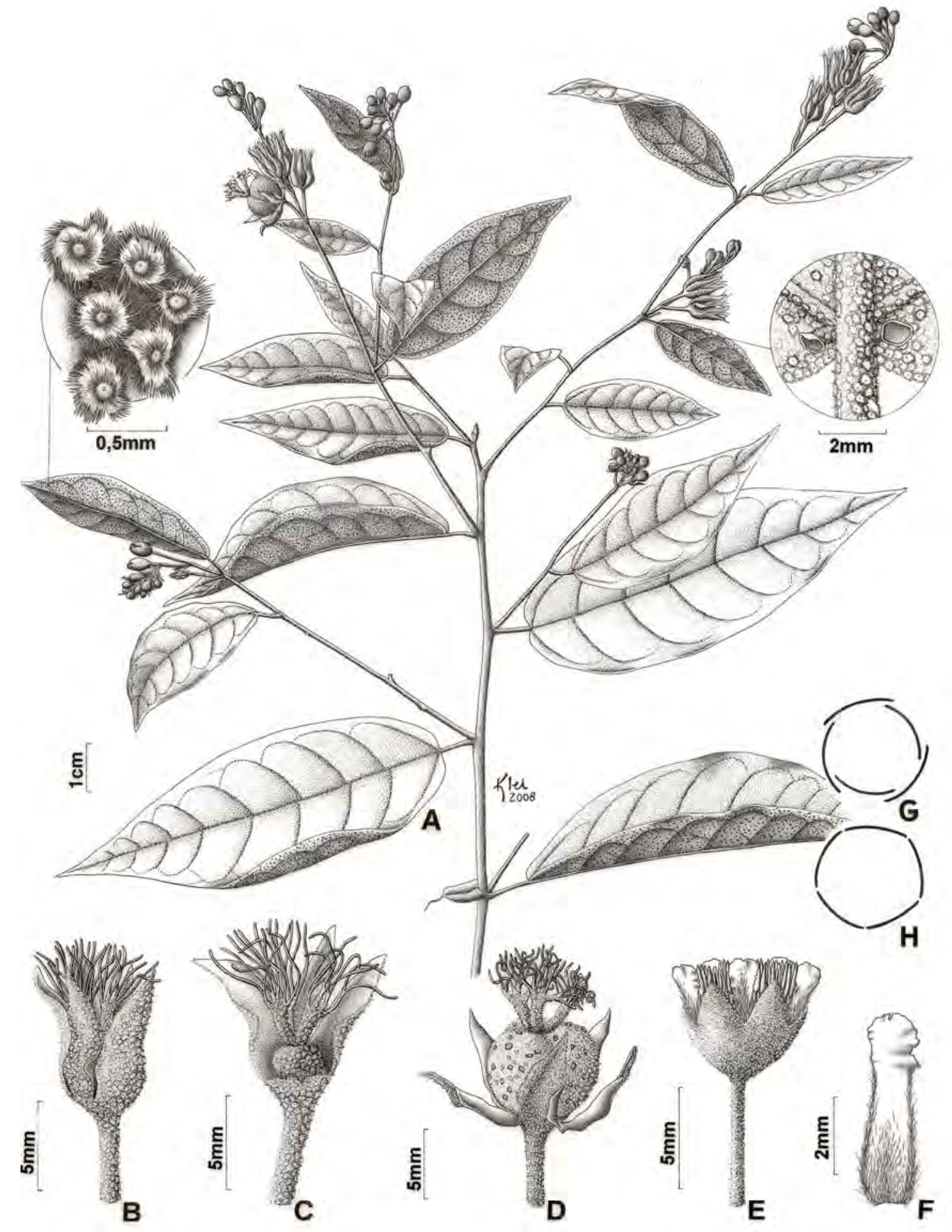

Figura 17. A-H. Croton rufolepidotus. A: ramo, detalhe das glândulas basilaminares, B: flor feminina, C: detalhe do gineceu, D: fruto, E: flor masculina, F: pétala da flor masculina com ápice recortado, G: esquema da prefloração quincuncial da flor feminina, H: esquema da prefloração valvar da flor masculina. (Callejas et al., 3611). 


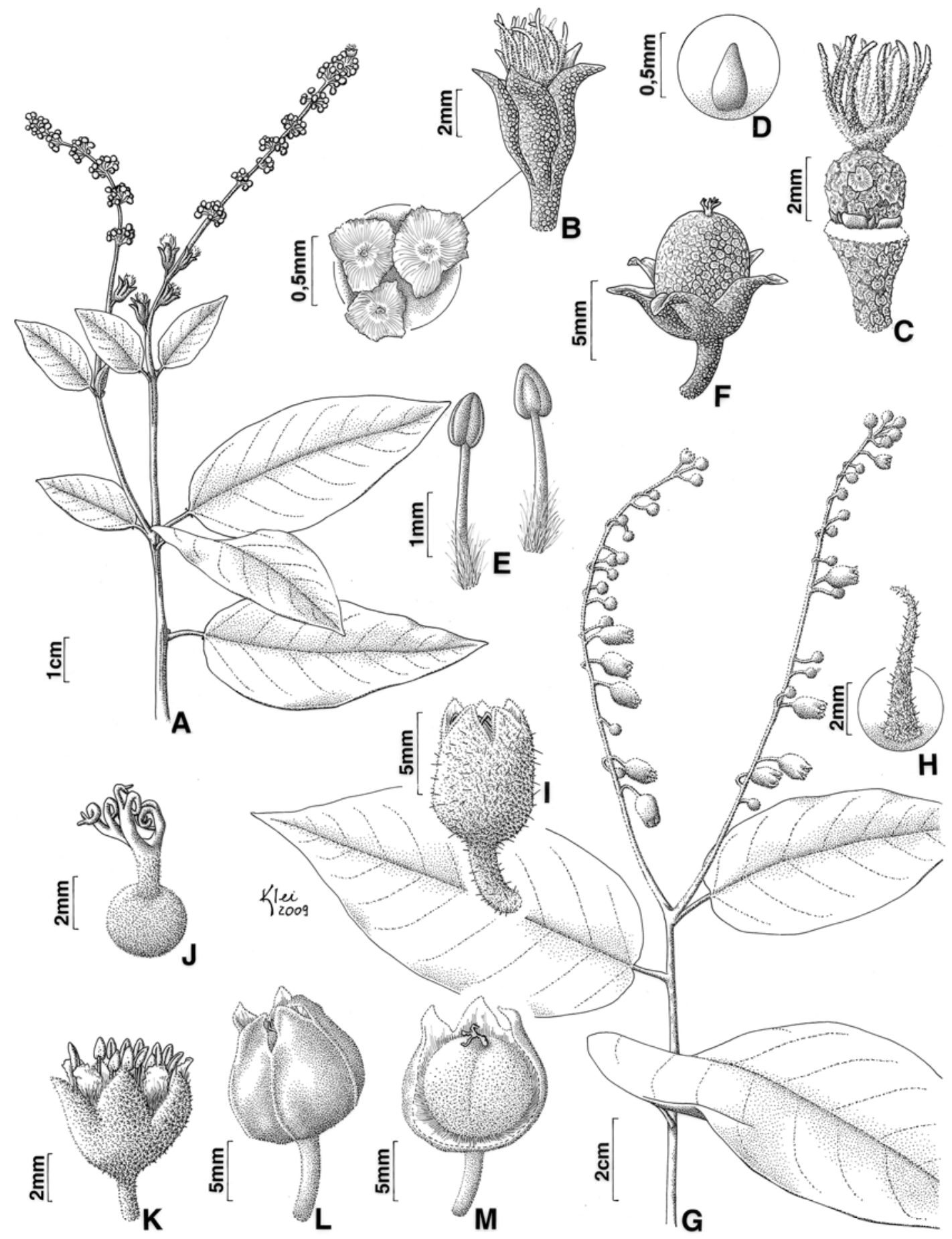

Figura 18. A-F. Croton salutaris. A: ramo (Pifano \& Castro, 327), B: flor feminina, detalhe dos tricomas lepidotos subinteiros no cálice (Pifano \& Castro, 327), C: gineceu (Pifano \& Castro, 327), D: detalhe da pétala feminina redudia à glândula (Pifano \& Castro, 327), E: estame, vista dorsal e ventral (Pifano \& Castro, 327), F: fruto (Caruzo et al., 81). G-M. Croton spruceanus. A: ramo (Caruzo \& Riina, 101), H: bráctea (Caruzo \& Riina, 101), I: flor feminina (Caruzo \& Riina, 101), J: gineceu (Caruzo \& Riina, 101), K: flor masculina (Caruzo \& Riina, 101), L: fruto recoberto com lobos do cálice inflados (Caruzo \& Riina, 101), M: fruto (Caruzo \& Riina, 101). 


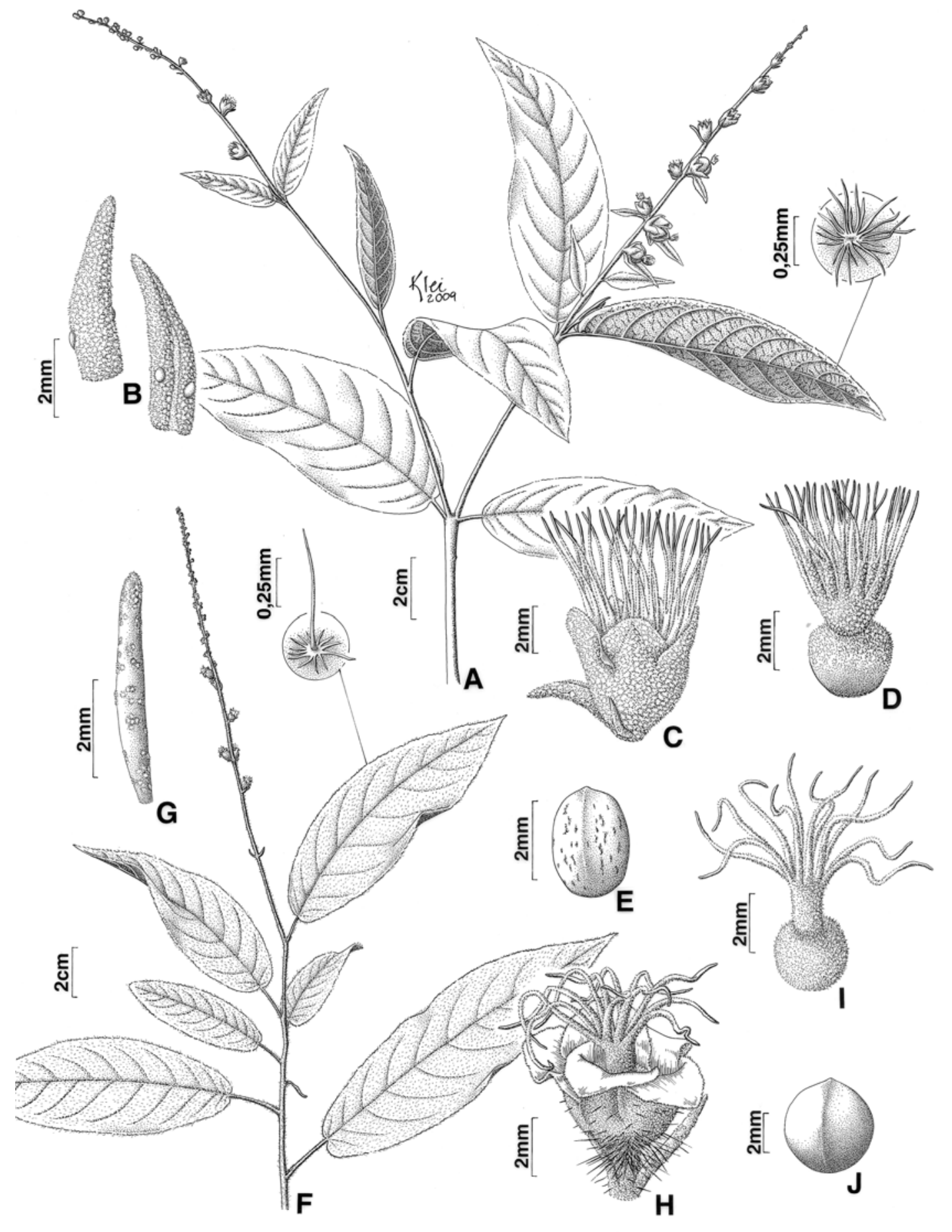

Figura 19. A-E. Croton stellatoferrugineus. A: ramo, com detalhe dos tricomas foliares (Cordeiro et al. 3033), B: bráctea (Caruzo et al., 120), C: flor feminina (Caruzo et al., 120), D: gineceu (Caruzo et al., 120), E: semente (Caruzo et al., 120), F: . F-J. Croton sphaerogynus. F: ramo, detalhe do tricoma foliar (Caruzo \& Lima, 121), G: bráctea (Caruzo \& Lima, 121), H: flor feminina (Caruzo \& Lima, 121), I: gineceu (Caruzo \& Lima, 121), J: semente (Caruzo \& Lima, 121). 
CAPítulo 3 


\title{
Tricomas foliares em Croton sect. Cleodora (Euphorbiaceae) ${ }^{1}$
}

Resumo. (Tricomas foliares em Croton sect. Cleodora (Euphorbiceae). O indumento foliar das espécies de Croton sect. Cleodora é caracteristicamente formado por tricomas lepidotos, com 2/3 das espécies apresentando principalmente os do subtipo adpressoestrelado e 1/3 lepidoto-subinteiro. Tricomas simples também são encontrados em aproximadamente $40 \%$ das espécies, entretanto apenas na face adaxial das folhas. O estudo demonstrou que o indumento não é decisivo para a caracterízação da seção, uma vez que tricomas semelhantes aos encontrados em Cleodora ocorrem também em espécies pertencentes a várias das seções de Croton, porém é útil na circunscrição das espécies, uma vez que apresenta-se constante entre as populações de cada uma delas.

Palavras chave: tricomas foliares, Croton, Euphorbiaceae

\begin{abstract}
Foliar trichomes of Croton sect. Cleodora (Euphorbaceae)). The foliar indument of Croton sect. Cleodora is characterized by lepidote trichomes, with 2/3 of the species presenting appressed-stellate, and 1/3 with lepidote-subentire. Simple trichomes are also found in around $40 \%$ of the species, but only on the upper surface of the leaves. This study showed that the indument is not decisive in the caracterization of the section, once the same types of trichomes found in Cleodora occur also in many others species belonging to different sections of Croton, nevertheless it is useful for circumscribing species, once it is invariable among populations of each species.
\end{abstract}

Key words: foliar trichomes, Croton, Euphorbiaceae

\section{Introdução}

\footnotetext{
1 *Manuscrito a ser submetido à revista Rodriguésia.
} 
Croton L. é o segundo maior gênero das Euphorbiaceae com aproximadamente 1200 espécies (Govaerts et al., 2000) que ocorrem, em sua maioria, nas regiões tropicais do globo. Nos Neotrópicos, o centro de diversidade primário do gênero está localizado no Brasil, onde ocorrem aproximadamente 350 espécies em praticamente todos os tipos de vegetação, mas nitidamente concentradas na parte leste do país, principalmente em vegetações abertas.

O tipo de tricoma do indumento foliar foi utilizado por diversos autores, tanto na circunscrição das espécies, como de táxons infragenéricos de Croton, (Baillon 1858, 1864; Müller, 1866, 1873; Cordeiro, 1993; Webster, 1993; Webster et al., 1996; Lima, 2005).

Müller (1866, 1873) e Baillon $(1858,1864)$ utilizaram o tipo de tricoma do indumento foliar na circunscrição de seções, subseções, séries e espécies do gênero, considerando dois tipos básicos: estrelados, onde os raios são livres, e lepidotos, onde os raios são variavelmente unidos entre si. Entre esses dois tipos básicos, entretanto, há vários intermediários que podem ser utilizados na sistemática do grupo (Webster et al. 1996)

O primeiro trabalho sobre a diversidade de tricomas em Croton é o de Froembling (apud Webster et al. 1996), que estudou a anatomia foliar de 132 espécies e reconheceu cinco tipos básicos de tricomas: 'Schilghaare' (lepidoto), 'Sternhaare' (estrelado), 'Buschelhaare' (fasciculado ou rosulado), 'Morgensternförmige Haare’ (fasciculadoestipitado) e ‘Candelaberhaare’ (dendrítico).

Webster et al. (1996) baseados no trabalho de Froembling, fizeram uma revisão dos tipos de tricomas foliares em Croton e reconheceram oito tipos básicos para o gênero: estrelado, fasciculado, multiradiado, rosulado, dendrítico, lepidoto, papiloso e glandular, indicando, inclusive, uma possível sequência evolutiva para eles. 
Os trabalhos mais recentes sobre indumento em Croton são os de Gordillo \& Matias (2005), que trata de Croton sect. Barhamia (Klotzsch) Baill,, Lima (2005), sobre Croton sect. Lamprocroton (Müll.Arg.) Pax, e Lucena e Sales (2006), que trata de espécies de Croton do litoral e Zona da Mata do Estado de Pernambuco.

Croton sect. Cleodora (Klotzsch) Baill. é Neotropical, com 18 espécies que ocorrem, em sua maioria, disjuntamente entre a floresta Atlântica no Brasil e a floresta Amazônica, e outras, exclusivamente extrabrasileiras, das florestas estacionais do norte da América do Sul e América Central. A seção é composta por espécies de hábito arbóreo ou arbustivo, com látex colorido ou incolor, e flores femininas de prefloração quincuncial e estiletes unidos na base ou até a metade. De acordo com Webster et al. (1993), os representantes da seção Cleodora apresentam tricomas do tipo adpresso-estrelado. No entanto, estudos morfológicos com algumas das espécies da seção Cleodora (Caruzo, 2005), revelaram outros tipos de tricomas, além dos adpresso-estrelados.

O presente trabalho visa analisar e caracterizar os tricomas foliares de Croton sect. Cleodora (Klotzsch) Baill. em uma tentativa de utilizá-los na sistemática do gênero.

\section{Material e Métodos}

Foi analisada a ultra-estrutura dos tricomas presentes em ambas as faces da lâmina foliar de todas as espécies de Croton sect. Cleodora (Kloztsch) Baill. (Tab. 1), através de Microscopia Eletrônica de Varredura (MEV).

Os fragmentos foliares, com aproximadamente $3 \mathrm{~mm}^{2}$, foram extraídos de coleções de herbário, metalizados em banho de ouro e posteriormente observados e fotografados sob microscópio eletrônico de varredura Zeiss, modelo DSM940.

Na tabela 1 encontram-se apenas os materiais selecionados para a captura das imagens, entretanto, para avaliação da variabilidade do indumento, foram examinadas, 
ao estereomicroscópio, todas as coleções disponíveis de espécies da seção, selecionando-se, quando possível, até 3 amostras de cada espécie, para análise em MEV.

Os termos morfológicos utilizados na classificação dos tipos de tricomas foram aqueles contidos em Webster et al. (1996).

\section{Resultados e Discussão}

O indumento foliar das espécies de Croton sect. Cleodora é formado de quatro diferentes tipos principais de tricomas: simples, estrelados, multiradiados e lepidotos. Na tabela 2 encontra-se a caracterização morfológica de cada um deles segundo Webster et al. (1996).

De maneira geral, o tipo de tricoma encontrado nas espécies não varia entre as suas diferentes populações. Já o indumento em ambas as faces das folhas pode apresentar diferentes tipos de tricomas, sendo em geral mais denso nesta última. Outras variações encontradas foram em relação ao tamanho e ao número de raios laterais dos tricomas, como já observaram Gordillo \& Matías (2005) e Lucena \& Sales (2006) em outras espécies do gênero (Tab. 3).

O tipo de tricoma mais comum entre as espécies da seção é o lepidoto, encontrado em cerca de $80 \%$ das espécies, sendo que destas, 2/3 possuem o tipo adpresso-estrelado e 1/3 delas, o lepidoto-subinteiro. Dentre estes últimos, alguns possuem raios unidos de forma regular, formando uma estrutura arredondada, como em Croton campanulatus (Fig. 1E), enquanto em outros, os raios unem-se irregularmente como em Croton rufolepidotus (Fig. 5D). Na face adaxial das folhas de Croton salutaris, os tricomas lepidoto-subinteiros possuem um raio central, sendo este tipo aqui denominado lepidoto-subinteiro porreto (Figs. 6A-B). 
Apenas em duas espécies da seção ocorrem diferentes tipos de tricomas juntos na face abaxial de suas folhas. Em Croton hoffmannii, adpresso-estrelados e multiradiados (Figs. 3C-D) e em C. orinocensis, adpresso-estrelados e estreladolepidotos (Figs. 4C-D).

Tricomas simples foram observados em $40 \%$ das espécies apenas na face adaxial de suas folhas (Figs. 3E, 4A, 5C, 6F) . Tricomas multiradiados e estrelados foram observados em apenas três das espécies estudadas, sendo portanto os menos freqüentes na seção. Em Croton heterocalyx e C. stellatoferrugineus (Figs. 3A-B, 6D) tricomas multiradiados na face abaxial, enquanto em $C$. organensis há tricomas estrelados na face abaxial (Fig. 3F).

Os tricomas característicos da maioria das espécies de Croton sect. Cleodora são os lepidotos, do tipo adpresso-estrelado e lepidoto-subinteiro, mas também ocorrem em menor freqüência os multiradiados e estrelados. O presente estudo demonstrou que, assim como já observado por Gordillo \& Matías (2005) para espécies da seção Barhamia, o indumento foliar não é decisivo para a caracterização da seção, uma vez que tricomas semelhantes aos nela encontrados ocorrem também em outras seções de Croton. Por outro lado, a estabilidade morfológica entre as populações, torna o indumento, no que se refere ao tipo de tricoma formador, importante na circunscrição das espécies da seção.

\section{Referências bibliográficas}

Govaerts, R.; Frodin, D.G. \& Radcliffe-Smith, A. 2000. World Checklist and Bibliography of Euphorbiaceae (and Pandaceae), v. 2. Kew, Royal Botanical Gardens. 921p.

Baillon, H. 1858. Etude générale du groupe des Euphorbiacées. Victor Masson, Paris.

Baillon, H. 1864. Euphorbiaceés Americaines. Adansonia 4:257-377. 
Cordeiro, I. 1993. Revisão taxonômica de Julocroton Mart. (Euphorbiaceae). Tese de Doutorado. Universidade de São Paulo, São Paulo.

Gordillo, M.M. \& Matías, S.E. 2005. Tricomas foliares de Croton sección Barhamia (Euphorbiaceae). Acta Botanica Mexicana 72: 39-51.

Lima, L.R. \& Pirani, J.R. 2008. Revisão taxonômica de Croton sect. Lamprocroton (Müll.Arg.) Pax (Euphorbiaceae). Biota Neotropica 8(2): 21-75.

Lucena, M.F.A. \& Sales, M.F. 2006. Tricomas foliares em espécies de Croton L. (Crotonoideae-Euphorbiaceae). Rodriguésia 57: 11-25.

Müller, J. 1865/66. Euphorbiaceae. Linnaea 34: 1-224.

Müller, J. 1866. Euphorbiaceae exceto suborfo Euphorbieae. In Prodomus Systematics Universalis Regni Vegetabilis (De Candolle, A.P. ed.) 15(2): 189-1286.

Müller, J. 1873. Euphorbiaceae. In Flora Brasiliensis (Martius, C. F. P. \& Eichler, A. G. eds.) 11(2):293-750, pl. 43-104.

Webster, G. L. 1993. A provisional synopsis of the sections of the genus Croton (Euphorbiaceae). Taxon 42:793-823.

Webster, G. L.; Del-Arco-Aguilar, M.J. \& Smith, B.A. 1996. Systematic distribution of foliar trichome types in Croton (Euphorbiaceae). Bot. J. Linn. Soc. 121:41-57. 
Tabela 1. Lista das coleções testemunho

\begin{tabular}{|c|c|c|}
\hline Espécie & Voucher & Herbários \\
\hline Croton billbergianus Müll.Arg. & A. Molina R., 30610 & EAP, MO \\
\hline Croton cajucara Benth. & Caruzo \& Riina, 98 & SP, WIS \\
\hline Croton campanulatus Caruzo \& Cordeiro & Caruzo et al., 93 & $\begin{array}{l}\text { K, NY, SP, } \\
\text { SPF, WIS }\end{array}$ \\
\hline Croton croizatii Steyermark & Breteler, 4575 & $\begin{array}{l}\text { COL, MER, } \\
\text { VEN }\end{array}$ \\
\hline Croton fragrans Kunth & Caruzo et al., 126 & SP \\
\hline Croton fragrantulus Croizat & Foster, 424 & MO, USZ \\
\hline Croton hemiargyreus Müll.Arg. & $\begin{array}{l}\text { Nascimento \& Silva, } \\
362\end{array}$ & PEUFR, SP \\
\hline Croton heterocalyx Baill. & Caruzo et al., 108 & HUEFS, SP \\
\hline Croton hoffmannii Müll.Arg. & $\begin{array}{l}\text { Van Ee \& Van Ee, } \\
\text { 598; Webster et al., } \\
\text { 12298a }\end{array}$ & $\begin{array}{l}\text { DAV, NY, } \\
\text { MICH }\end{array}$ \\
\hline Croton organensis Baill. & Caruzo, 72 & SP \\
\hline Croton orinocensis Müll.Arg. & Prance et al., 25726 & $\begin{array}{l}\text { INPA, MG, } \\
\text { NY, RB }\end{array}$ \\
\hline Croton pseudofragrans Croizat & Burnham, 1651 & $\begin{array}{l}\text { DAV, MICH, } \\
\text { MO }\end{array}$ \\
\hline Croton rottlerifolius Baill. & Cavassan, 9 & UEC \\
\hline Croton salutaris Casar. & Caruzo et al., 89 & SP, WIS \\
\hline Croton sphaerogynus Baill. & Caruzo et al., 88 & SP, WIS \\
\hline $\begin{array}{l}\text { Croton stellatoferrugineus Caruzo \& Cordeiro } \\
\text { sp.nov. ined. }\end{array}$ & Caruzo et al., 120 & SP \\
\hline Croton spruceanus Benth. & Caruzo \& Riina, 101 & SP, WIS \\
\hline $\begin{array}{l}\text { Croton rufolepidotus Caruzo \& } \quad \text { Riina } \\
\text { sp.nov.ined. }\end{array}$ & Callejas, et al., 3611 & $\begin{array}{l}\text { DAV, F, } \\
\text { HUA, MO }\end{array}$ \\
\hline
\end{tabular}


Tabela 2. Tipos de tricomas segundo Webster et al. (1996).

\begin{tabular}{|c|c|}
\hline Tipo básico de tricoma & Subtipos e caracterização \\
\hline Simples & Filiforme. (Fig. 3D) \\
\hline \multirow[t]{2}{*}{ Estrelado } & $\begin{array}{l}\text { Estrelado típico: Apresenta um único verticilo de raios } \\
\text { dispostos no mesmo plano ou levemente deslocados para } \\
\text { cima. Número de raios: aproximadamente seis. (Fig. } 3 F \text { ) }\end{array}$ \\
\hline & $\begin{array}{l}\text { Estrelado-porrecto: Apresenta a mesma estrutura do } \\
\text { estrelado, com um raio central ereto alongado. Número de } \\
\text { raios: aproximadamente seis. (Fig. } 3 \mathrm{~B} \text { ) }\end{array}$ \\
\hline Multiradiado & $\begin{array}{l}\text { Apresenta os raios divergentes. Número de raios: dez ou mais. } \\
\text { (Fig. 3A) }\end{array}$ \\
\hline \multirow[t]{5}{*}{ Lepidoto } & $\begin{array}{l}\text { Lepidoto-subinteiro (lepidoto típico): Tricoma peltado, } \\
\text { escamiforme, com um único verticilo de raios unidos quase } \\
\text { que inteiramente (aproximadamente } 80-100 \% \text { ), onde a região } \\
\text { central é geralmente proeminente (e ornamentada) ou de } \\
\text { coloração distinta dos raios. (Fig. 1D) }\end{array}$ \\
\hline & $\begin{array}{l}\text { Lepidoto- subinteiro porrecto: Apresenta a mesma estrutura } \\
\text { do lepidoto, com um raio central ereto. (Fig. 6B) }\end{array}$ \\
\hline & $\begin{array}{l}\text { Dentado-lepidoto: Apresentam a mesma estrutura do } \\
\text { lepidoto, com uma união menor dos raios (entre 50\% e 80\%). } \\
\text { (Fig. 5D) }\end{array}$ \\
\hline & $\begin{array}{l}\text { Estrelado-lepidoto: Apresentam a mesma estrutura do } \\
\text { lepidoto, com uma união mediana dos raios } \\
\text { (aproximadamente 50\%). (Fig. 4C) }\end{array}$ \\
\hline & $\begin{array}{l}\text { Adpresso-estrelado: Apresentam a mesma estrutura do } \\
\text { lepidoto, com uma pequena união dos raios } \\
\text { (aproximadamente 0-30\%); geralmente possuem um raio } \\
\text { central ereto alongado (Fig. 2B) }\end{array}$ \\
\hline
\end{tabular}


Tabela 3. Tricomas do indumento foliar das espécies de Croton sect. Cleodora.

\begin{tabular}{|c|c|c|c|c|c|}
\hline Espécie & Face foliar & Tipo de tricoma & $\begin{array}{l}\text { No. de } \\
\text { raios }\end{array}$ & Raio central & $\begin{array}{l}\text { Base do raio central } \\
\text { ornamentada }\end{array}$ \\
\hline \multirow[t]{2}{*}{ C. billbergianus } & adaxial & Adpresso-estrelado & $<10$ & Presente & Presente \\
\hline & abaxial & Adpresso-estrelado & $<10$ & Presente & Presente \\
\hline \multirow[t]{2}{*}{ C. cajucara } & adaxial & Ausente & - & - & - \\
\hline & abaxial & Adpresso-estrelado & $\geq 10$ & Presente & Presente \\
\hline \multirow[t]{2}{*}{ C. campanulatus } & adaxial & Lepidoto-subinteiro & $\geq 10$ & Ausente & Ausente \\
\hline & abaxial & Lepidoto-subinteiro & $\geq 10$ & Ausente & Ausente \\
\hline \multirow[t]{2}{*}{ C. croizatii } & adaxial & Simples & - & - & - \\
\hline & abaxial & Lepidoto-subinteiro & $\geq 10$ & Ausente & Ausente \\
\hline \multirow[t]{2}{*}{ C. fragrans } & adaxial & Estrelado & $<10$ & Ausente & Ausente \\
\hline & abaxial & Adpresso-estrelado & $<10$ & Presente & Presente \\
\hline \multirow[t]{2}{*}{ C. fragrantulus } & adaxial & Adpresso-estrelado & $<10$ & Presente & Presente \\
\hline & abaxial & Adpresso-estrelado & $<10$ & Presente & Presente \\
\hline \multirow[t]{2}{*}{ C. hemiargyreus } & adaxial & Lepidoto-subinteiro & $\geq 10$ & Ausente & Ausente \\
\hline & abaxial & Lepidoto-subinteiro & $\geq 10$ & Ausente & Ausente \\
\hline \multirow[t]{2}{*}{ C. heterocalyx } & adaxial & $\begin{array}{l}\text { Estrelado, } \\
\text { geralmente porrecto }\end{array}$ & $<10$ & Ausente & Ausente \\
\hline & abaxial & Multiradiado & $\geq 10$ & Ausente & Ausente \\
\hline \multirow[t]{2}{*}{ C. hoffmannii } & adaxial & Simples & - & - & - \\
\hline & abaxial & $\begin{array}{l}\text { Adpresso-estrelado, } \\
\text { multiradiado }\end{array}$ & $<10$ & $\begin{array}{l}\text { Presente (apenas no } \\
\text { adpresso estrelado) }\end{array}$ & $\begin{array}{l}\text { Presente (apenas no } \\
\text { adpresso estrelado) }\end{array}$ \\
\hline \multirow[t]{2}{*}{ C. organensis } & adaxial & Simples & - & - & - \\
\hline & abaxial & Estrelado & $<10$ & Ausente & Ausente \\
\hline
\end{tabular}




\begin{tabular}{|c|c|c|c|c|c|}
\hline \multirow[t]{2}{*}{ C. orinocensis } & adaxial & Simples & - & - & - \\
\hline & abaxial & $\begin{array}{l}\text { Adpresso-estrelado, } \\
\text { estrelado-lepidoto }\end{array}$ & $\geq 10$ & Presente & Presente \\
\hline \multirow[t]{2}{*}{ C. pseudofragrans } & adaxial & Simples & - & - & - \\
\hline & abaxial & Adpresso-estrelado & $\geq 10$ & Presente & Presente \\
\hline \multirow[t]{2}{*}{ C. rottlerifolius } & adaxial & Simples & - & - & - \\
\hline & abaxial & Adpresso-estrelado & $<10$ & Presente & Presente \\
\hline \multirow[t]{2}{*}{ C. rufolepidotus } & adaxial & Ausente & - & - & - \\
\hline & abaxial & Dentado-lepidoto & $\geq 10$ & Ausente & Ausente \\
\hline \multirow[t]{2}{*}{ C. salutaris } & adaxial & Lepidoto-subinteiro & $\geq 10$ & Presente & Ausente \\
\hline & abaxial & Lepidoto-subinteiro & $\geq 10$ & Ausente & Ausente \\
\hline \multirow[t]{2}{*}{ C. sphaerogynus } & adaxial & Adpresso-estrelado & $\geq 10$ & Presente & Ausente \\
\hline & abaxial & Adpresso-estrelado & $\geq 10$ & Presente & Ausente \\
\hline \multirow[t]{2}{*}{ C. spruceanus } & adaxial & Simples & - & - & - \\
\hline & abaxial & Adpresso-estrelado & $\geq 10$ & Presente & Presente \\
\hline \multirow[t]{2}{*}{ C. stellatoferrugineus } & adaxial & $\begin{array}{l}\text { Estrelado, } \\
\text { geralmente porrecto }\end{array}$ & $<10$ & Presente & Ausente \\
\hline & abaxial & Multiradiado & $\geq 10$ & Ausente & Ausente \\
\hline
\end{tabular}



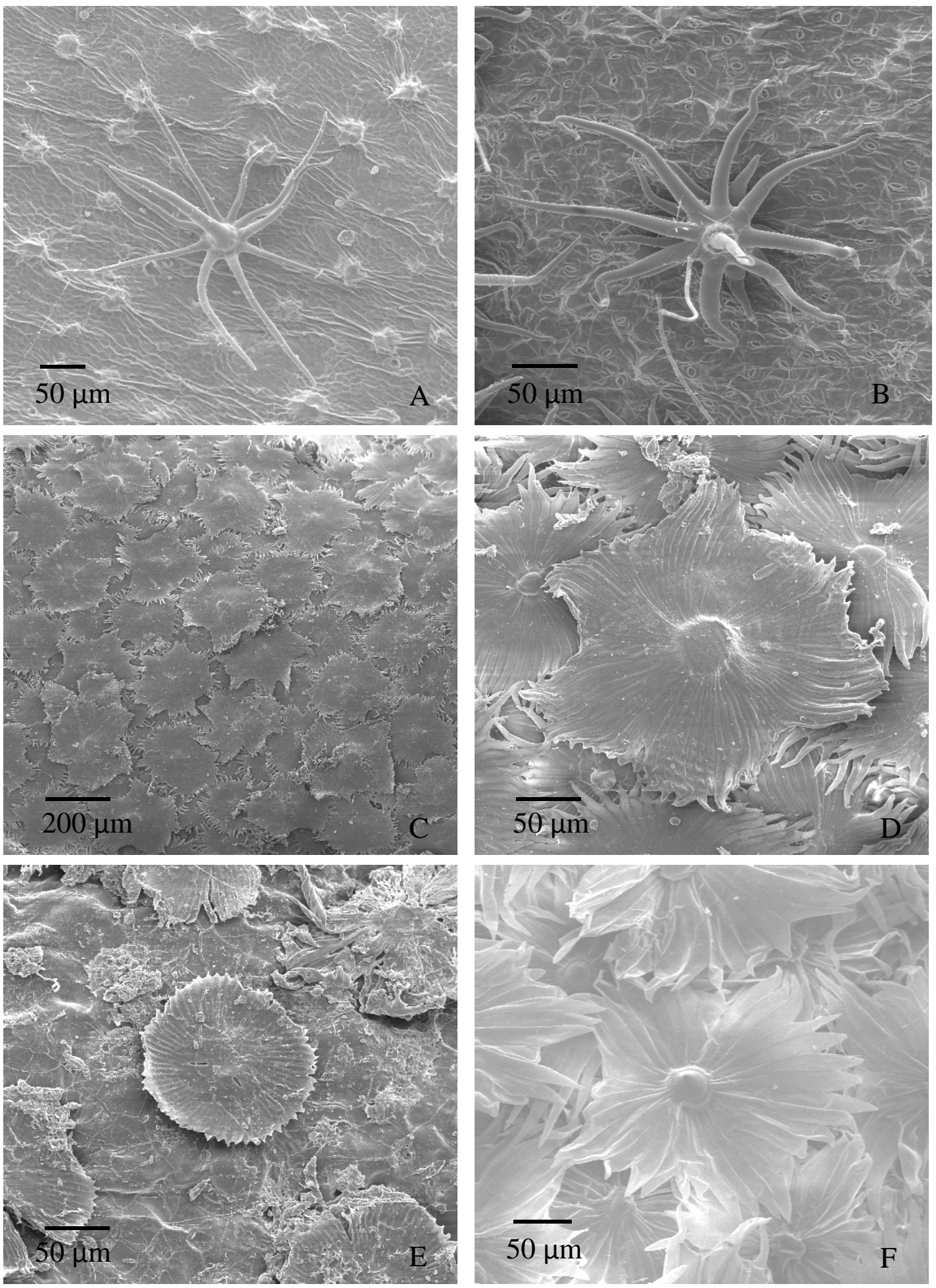

Figura 1. A: Croton billbergianus - tricoma adpresso-estrelado porrecto da face adaxial (Molina R., 30618). B: C. cajucara - tricoma adpresso-estrelado porrecto da face abaxial (Caruzo \& Riina, 98). C-E: C. campanulatus. C- indumento lepidoto da face abaxial, Dtricoma lepidoto-subinteiro da face abaxial, E- tricoma lepidoto-subinteiro da face adaxial (Caruzo et al., 93). F: C. croizatii. F- tricoma lepidoto-subinteiro porrecto da face abaxial (Breteler, 4575). 

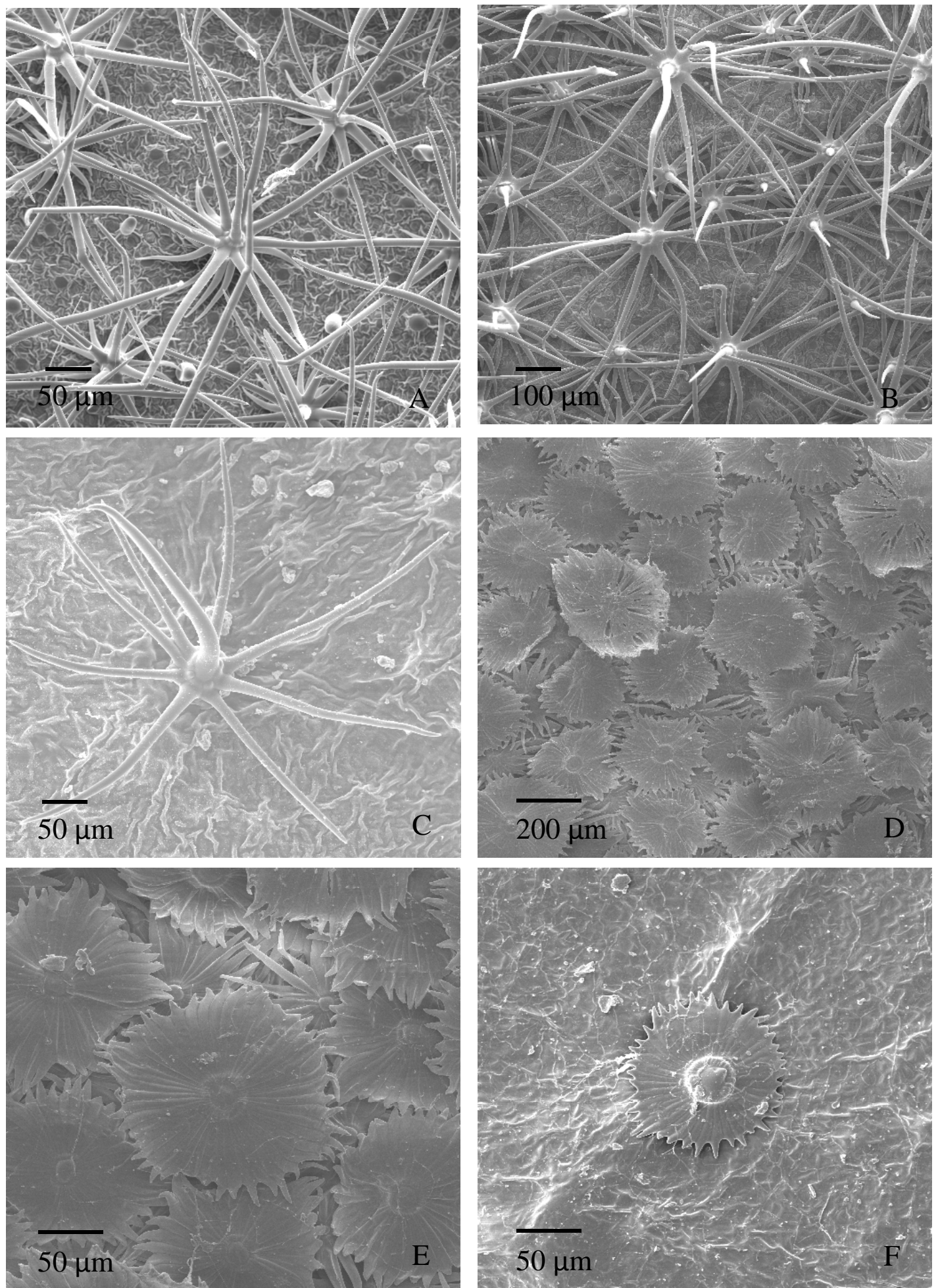

Figura 2. A: Croton fragrans. A - tricoma adpresso-estrelado porrecto da face abaxial (Caruzo et al. 12). B-C: C. fragrantulus. B- tricoma adpresso-estrelado porrecto da face abaxial, C- tricoma adpresso-estrelado porrecto da face adaxial (Foster, 424). D-F: C. hemiargyreus. C- indumento lepidoto da face abaxial, D- tricoma lepidoto-subinteiro da face abaxial, E- tricoma lepidoto-subinteiro porrecto da face adaxial (Nascimento, 362). 

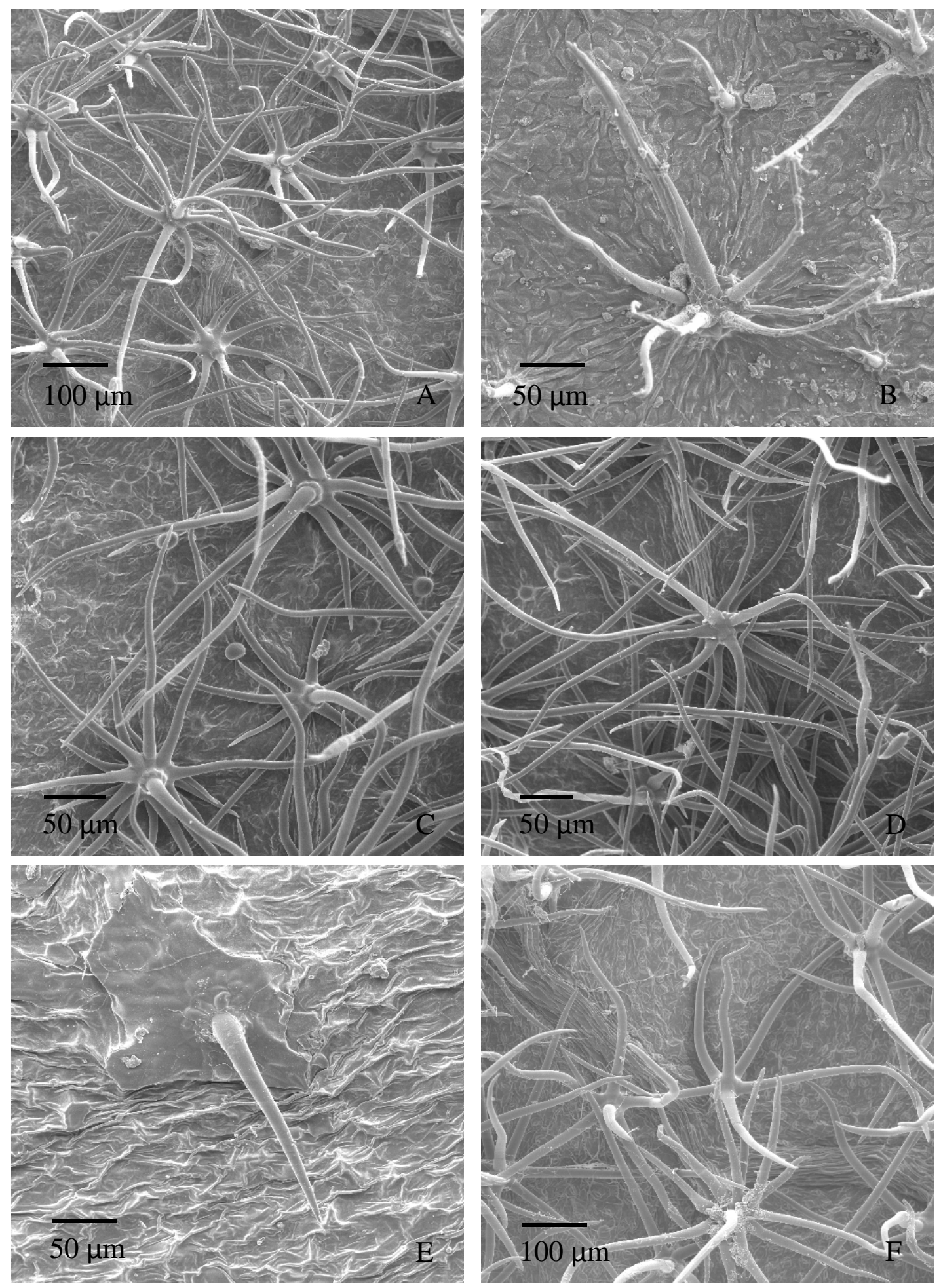

Figura 3. A-B: Croton heterocalyx. A- tricoma multiradiado da face abaxial , B- tricoma estrelado-porrecto da face adaxial da folha (Caruzo et al., 108). C-E: C. hoffmannii. Ctricoma adpresso-estrelado porrecto da face abaxial , D- tricoma multiradiado da face abaxial (Van Ee \& Van Ee 598), E- tricoma simples da face adaxial (Webster et al. 12298a). F: C. organensis. F- tricomas estrelados da face abaxial (Caruzo et al., 72). 

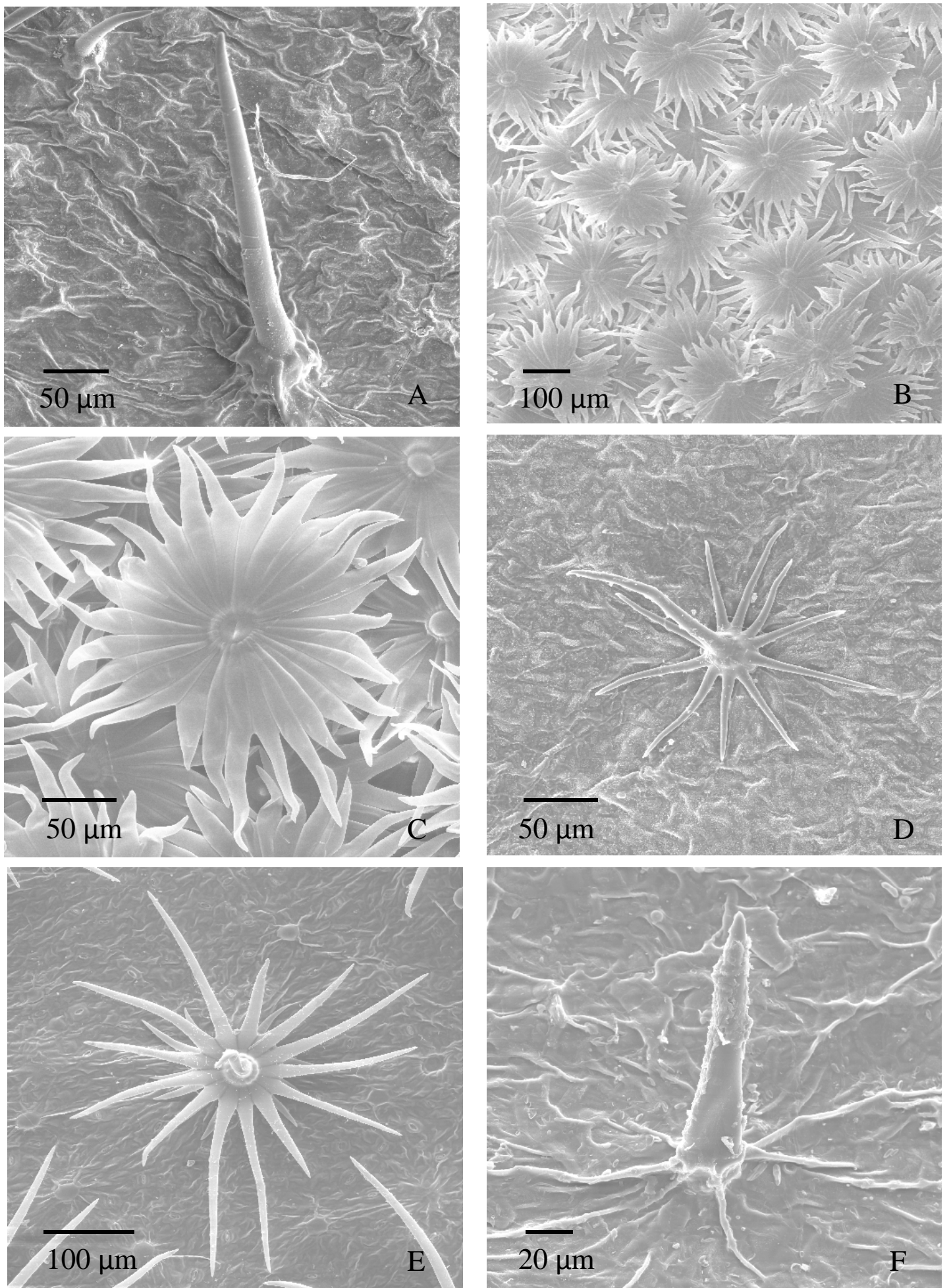

Figura 4. A: Croton organensis. A- tricoma simples na face adaxial (Caruzo et al., 72). B-D: C. orinocensis. B- indumento estrelado-lepidoto da face abaxial, C- tricoma estreladolepidoto na face abaxial da folha, D- tricoma adpresso-estrelado porrecto da face abaxial (Caruzo et al. 124). E-F: C. pseudofragrans. E- tricoma adpresso-estrelado porrecto da face abaxial da folha, F- tricoma simples da face adaxial (Burnham, 1651). 

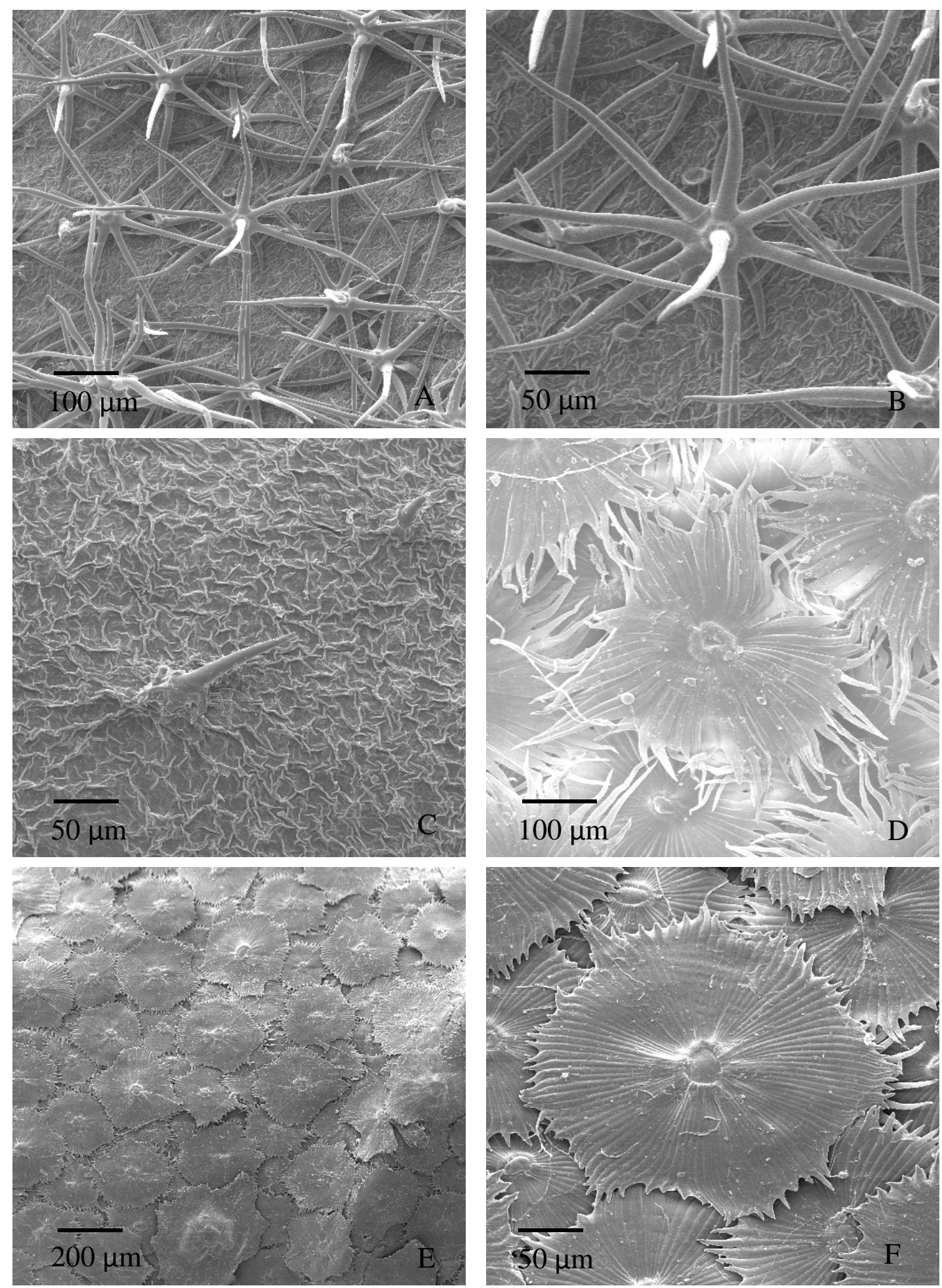

Figura 5. A-C: Croton rottlerifolius. A- tricoma adpresso-estrelado porrecto da face abaxial , B- tricoma adpresso-estrelado porrecto da face abaxial, C- tricoma simples da face adaxial (Cavassan, 9). D: C. rufolepidotus. - tricoma dentato-lepidoto da face abaxial (Callejas et al., 3611). E-F: C. salutaris. E- indumento lepidoto da face abaxial, F- tricoma lepidotosubinteiro da face abaxial (Caruzo et al., 89). 

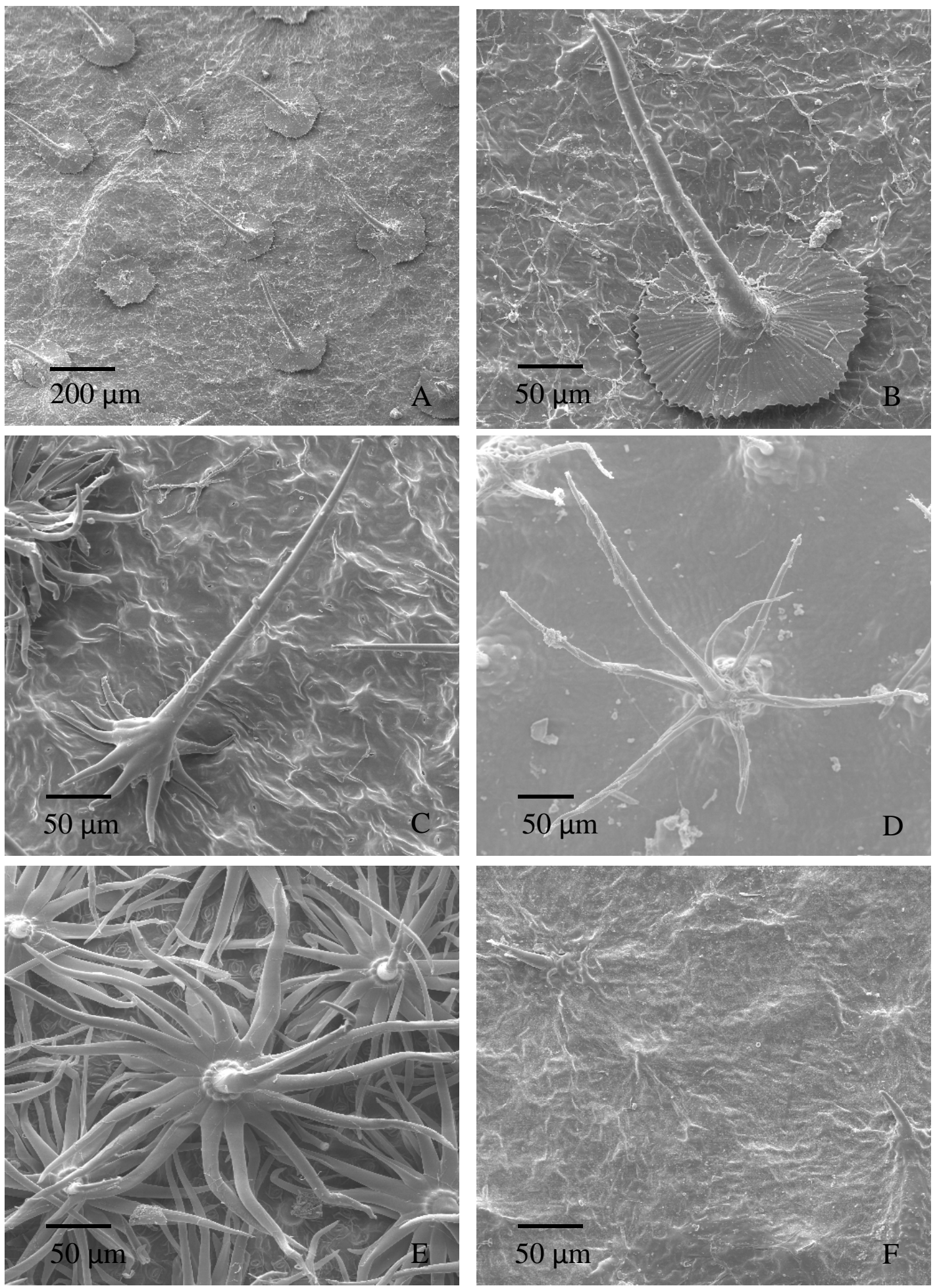

Figura 6. A-B: Croton salutaris. A: tricomas lepidoto-subinteiros porrecto da face adaxial, B: detalhe tricoma lepidoto-subinteiro porrecto da face adaxial (Caruzo et al., 89). C: $C$. sphaerogynus. - tricoma adpresso-estrelado porrecto da face abaxial da folha (Caruzo et al., 88). D: C. stellatoferrugineus. D- tricoma estrelado- porrecto da face adaxial (Caruzo et al., 120). E-F: C. spruceanus. E: tricoma adpresso-estrelado da face abaxial , F: tricoma simples da face adaxial (Caruzo \& Riina, 101). 
CAPÍTULO 4 


\section{Padrões de distribuição geográfica em Croton sect. Cleodora (Euphorbiaceae) ${ }^{1}$}

REsumo. (Padrões de distribuição geográfica em Croton sect. Cleodora (Euphorbiaceae)). Croton sect. Cleodora (Klotzsch) Baill. é composta de 18 espécies florestais, de hábito arbustivo ou arbóreo, que distribuem-se no México, América Central, norte da América do Sul e leste do Brasil. Seus dois centros de diversidade localizam-se nas Serras do Mar e Mantiqueira, no sudeste do Brasil e na região do baixo Rio Amazonas, no norte do Brasil. De acordo com o tipo de vegetação de ocorrência, podemos distinguir na seção espécies endêmicas das seguintes formações: florestas pluviais do México, América Central e norte da América do Sul, florestas pluviais da Amazônia, florestas pluviais da Mata Atlântica e florestas estacionais tropicais do Brasil, Peru e Bolívia.

Palavras-chave: Croton, distribuição geográfica, flora Neotropical

Abstract. (Patterns of geographic distribution in Croton sect. Cleodora (Euphorbiaceae)). Croton sect. Cleodora (Klotzsch) Baill. is formed by 18 species of trees or shrubs, from Mexico, Central America, northern South America, and eastern Brazil. The two centers of diversity of the section are located in the Serras do Mar and Mantiqueira, in southeastern Brazil and in the region of low Amazonas River, in northern Brazil. According to the vegetation of occurrence, species from the section can be: endemic from rain forests of Mexico, Central America and nothern South America, Amazonian rain forests, Atlantic rain forests, and seasonally dry tropical forests from Brazil, Peru and Bolivia.

Key words: Croton, geographic distribution, Neotropical flora

\footnotetext{
${ }^{1}$ Manuscrito a ser submetido à revista Acta Botanica Brasilica
} 


\section{Introdução}

Croton L. é um gênero pantropical com aproximadamente 1223 espécies (Govaerts et. al., 2000). É o segundo maior gênero da família Euphorbiaceae s.s., estando atrás apenas de Euphorbia L. Apesar do gênero ocorrer preferencialmente em regiões tropicais, também são encontradas espécies em áreas subtropicais e temperadas. Na região Neotropical, os principais centros de diversidade do gênero encontram-se nas Antilhas, México e Brasil (Burger \& Huft, 1995). No Brasil, o gênero é representado por cerca de 350 espécies, incluindo ervas, arbustos e árvores, em todos os tipos vegetação, nitidamente concentradas no leste do país, principalmente em áreas de vegetação aberta.

Croton seção Cleodora (Klotzsch) Baill. é exclusivamente neotropical e em sua nova delimitação (Cap. 1, 2), possui 18 espécies, das quais 12 ocorrem no Brasil. O presente trabalho visa reconhecer os padrões de distribuição e os tipos de vegetação de ocorrência das espécies da seção.

\section{Material e Métodos}

A distribuição geográfica das espécies de Croton sect. Cleodora foi determinada com base em aproximadamente 700 coleções, depositadas nos seguintes herbários (herbários com asterisco foram visitados pelo primeiro autor): ALCB*, BHCB*, BOTU, CEN*, CEPEC*, CESJ*, CPAP, COL, CR, EAC, ESA*, ESAL, FUEL, GFJP, GUA*, HAMAB, HB*, HEPH*, HF, HRB*, HRCB*, HUEFS*, HUFU, IAC*, IBGE*, INPA, IPA, JPB, LPB, MAC*, MBM*, MBML, MEXU, MG*, MICH*, MO, MYF*, NY, P, PEUFR, PMA, PMSP*, PORT*, QCA, R*, RB*, SJRP, SP*, SPF*, SPSF*, TEPB, TFAV*, UB*, UEC*, US*, USM, VEN*, VIC, W, WU (siglas segundo o "Index Herbariorum - Part I: the Herbaria of the World”2; Thiers, continuously updated).

As coordenadas geográficas utilizadas na plotagem dos mapas de distribuição geográfica foram obtidas nos rótulos das exsicatas e, na falta destas, através de índices de localidades ('gazetteers') impressos (Houaiss, 1983) ou eletrônicos (IBGE, 1994; Global Gazetteer Version 2.1 (2006) $^{3}$ ), utilizando-se geralmente as coordenadas do município.

Para identificar as áreas de maior riqueza em espécies da seção, foi utilizado o programa DIVA-GIS $5.2^{4}$, onde as ocorrências das espécies foram marcadas por quadrículas de $1^{\circ} \times 1^{\circ}, 5^{\circ} \times 5^{\circ}$ e $10^{\circ} \times 10^{\circ}$ ao longo de toda a área de distribuição da seção.

\footnotetext{
${ }^{2}$ http://sweetgum.nybg.org/ih/

${ }^{3} \mathrm{http}: / /$ www.fallingrain.com/world/

${ }^{4}$ http://www.diva-gis.org/
} 
O estudo da distribuição geográfica das espécies, incluiu também sua classificação com base na distribuição de suas populações na zona tropical ou subtropical, segundo Burkart (1975), sendo para isto analisados os limites norte e sul da distribuição de cada uma das espécies. Segundo a extenção de sua ocorrência, a distribuição das espécies foi classificada como moderadamente ampla, restrita ou muito restrita, conforme em Boechat \& Longhi-Wagner (2000).

O uso do conceito de domínio para florestas Amazônica e Atlântica, bem como da classificação desta última em floresta pluvial montana e submontana, seguiram Rizzini (1997). Alguns dados de altitude e localidades foram checados no Britannica Atlas (1984), bem como em Huber \& Riina (2007).

A abreviação dos nomes de países foram retirados do International Standard Codes of the Representation of Names of Coutries, adotado por Austin \& Huáman (1996).

\section{Resultados e discussão}

Croton sect. Cleodora é formada exclusivamente por espécies neotropicais, que ocorrem em formações florestais úmidas e/ou estacionais. A seção apresenta distribuição disjunta entre o México, América Central, norte e noroeste da América do Sul, incluindo a região Amazônica, e costa leste do Brasil (Fig. 1; Tab. 1).

No Brasil encontra-se o maior número de espécies, 12 das 18 espécies reconhecidas para a seção, sendo oito delas exclusivamente brasileiras (Croton campanulatus, C. hemiargyreus, C. heterocalyx, C. organensis, C. salutaris, C. sphaerogynus, C. stellatoferrugineus e C. rottlerifolius (Tab. 2).

A análise de riqueza revelou duas principais áreas de concentração das espécies da seção (Fig. 2):

1) Região Sudeste do Brasil, principalmente nos Estados de São Paulo, Minas Gerais

e Rio de Janeiro, nas Serras do Mar e Mantiqueira.

2) Região do baixo Amazonas, no noroeste do Estado do Pará, área que coincide com o que Prance (1982) reconheceu como área de endemismo do Rio Trombetas.

A segunda região de concentração de espécies pode ser resultado de um artifício da análise, levando-se em conta o grande esforço de coleta a que foi submetida a área, como mencionam Nelson et al. (1999). Da mesma forma, é no sudeste do Brasil onde concentra-se o maior número de instituições de pesquisa do país, o que também pode estar relacionado à maior concentração de espécies na região. 
Conforme a classificação de Burkart (1975), as espécies da seção são todas megatérmicas, ou seja, com a maioria de suas populações encontradas na região tropical, com limite sul de distribuição próximo ao Trópico de Capricórnio e limite norte próximo ao Trópico de Câncer (Fig. 1).

Levando-se em conta a distribuição e a vegetação, podem ser reconhecidas quatro regiões de ocorrência da seção, com espécies de distribução moderadamente ampla, restrita e muito restrita (Tab 2):

\section{A) Florestas pluviais do México, América Central e norte da América do Sul (Fig. 3,}

\section{$6,7,11,16)$}

A maioria das espécies nesta região possuem distribuição moderadamente ampla. Croton billbergianus Müll.Arg (Fig. 3) ocorre desde o nível do mar até 800 m de altitude, em toda a América Central e parte do México., C. fragrans Kunth (Fig. 7) ocorre nas encostas inferiores dos Andes (Colômbia e Venezuela), Maciço das Guianas na Venezuela, e costa caribenha da Colômbia e Panamá, onde também cresce em florestas estacionais, desde o nível do mar até $800 \mathrm{~m}$ de altitude. Croton hoffmannii Müll.Arg. (Fig. 11) que possui distribuição aparentemente disjunta entre a América Central (Costa Rica) e norte da América do Sul (Roraima, Suriname e Guiana Francesa), entre 200 e $1300 \mathrm{~m}$ de altitude, e também ocorre em florestas estacionais. As duas únicas espécies de distribuição mais restrita nesta região são C. rufolepitodus Caruzo \& Riina (Fig. 16), endêmica de Antioquia, nas encostas inferiores dos Andes na Colômbia, entre 180 e 300 m de altitude e C. croizatii Steyerm. (Fig. 6), das encostas inferiores dos Andes, entre 800 e 1670 m de altitude, na Colômbia e Venezuela.

\section{B) Florestas pluviais do domínio da floresta Amazônica (Fig. 4, 13, 14, 18)}

Aqui estão referidas as espécies cuja distribuição é predominantemente amazônica. Croton cajucara Benth. (Fig. 4) é a espécie amazônica mais comum de Cleodora, tendo sido coletada em toda a amazônia brasileira, e também na Venezuela, Bolívia e Suriname, desde o nível do mar até $850 \mathrm{~m}$ de altitude. Croton spruceanus Benth. (Fig. 18) ocorre na amazônia brasileira e venezuelana e nas encostas inferiores dos Andes, no Equador e Colômbia, entre 50 e aproximadamente $1900 \mathrm{~m}$ de altitude. Croton orinocensis Müll.Arg. (Fig. 13), que juntamente com as duas anteriores tem distribuição moderadamente ampla, ocorre na Colômbia, Venezuela e Brasil, entre 70 e 300 m de altitude. Croton 
pseudofragrans Croizat (Fig. 14) ocorre em uma área mais restrita que as espécies anteriores, nas encostas inferiores do Andes no Equador e amazônia peruana e colombiana, entre 180 e aproximadamente 1000 m de altitude.

\section{C) Florestas pluviais do domínio da Mata Atlântica (Fig. 5, 9, 12, 17, 19)}

As espécies desse grupo possuem distribuição moderadamente ampla, restrita ou muito restrita e ocorrem em sua maioria nas encostas das Serras do Mar e Mantiqueira e nas florestas baixas de restinga.

Croton sphaerogynus Baill. (Fig. 19) possui distribuição moderadamente ampla, ocorrendo nas florestas de restinga da Bahia e São Paulo, e em floresta pluvial baixo montana nas encostas da Serra do Mar e contrafortes, no Rio de Janeiro e Espírito Santo, desde o nível do mar até $750 \mathrm{~m}$ de altitude. Croton salutaris Casar. (Fig. 17) também possui distribuição moderadamente ampla e ocorre em floresta pluvial montana nas encostas das Serras do Mar, Mantiqueira e Espinhaço, em Minas Gerais, Espírito Santo, Rio de Janeiro, São Paulo e Paraná, entre 700 e 950 m de altitude.

Croton organensis Baill. (Fig. 12) possui distribuição restrita, na floresta montana das encostas da Serra do Mar e Mantiqueira, entre 800 e $1300 \mathrm{~m}$ de altitude, nos Estados de Minas Gerais, Rio de Janeiro e São Paulo. Seu sinônimo, C. platycladus Müll.Arg. foi descrito para a Bahia, sendo o tipo a única coleção da espécie encontrada neste estado.

Croton campanulatus Caruzo \& Cordeiro (Fig. 5) possui distribuição muito restrita, sendo endêmica da floresta Montana da Serra do Mar (Itatiaia) e Mantiqueira, entre Rio de Janeiro e Minas Gerais, de 900 a 1500 m de altitude.

Croton hemiargyreus Müll.Arg. (Fig. 9) ocorre disjuntamente entre o sul de Minas Gerais e São Paulo, em floresta montana da Serra da Mantiqueira, e Pernambuco, em floresta de brejo, de 800 a 1000 m de altitude, distribuição disjunta semelhante à referida por Sakuragi (2001) para o gênero Philodendron.

\section{D) Florestas estacionais tropicais da América do Sul (Fig. 8, 10, 15, 19)}

As espécies deste grupo distribuem-se em áreas restritas a moderadamente amplas, dentro da grande área de ocorrência das florestas tropicais estacionais da América do Sul, denominadas “seasonally dry tropical forests” por Pennington et al. (2000).

Croton rottlerifolius Baill. (Fig. 15) é a única com distribuição moderadamente ampla, ocorrendo nos Estados da Bahia, Minas Gerais, São Paulo e Mato Grosso do Sul, 
dentro da área do “arco pleistocênico” (Prado \& Gibbs, 1993), distribuição que vem sendo observada para outros grupos de organismos ocorrentes nestas florestas do Brasil (Prado, 2000; Werneck \& Colli, 2006).

Croton heterocalyx Baill. (Fig. 10) ocorre em floresta estacional, disjuntamente na Bahia (dentro do domínio da Caatinga) e Minas Gerais, e em floresta de restinga na Bahia e Espírito Santo, desde o nível do mar até $900 \mathrm{~m}$ de altitude. Croton fragrantulus Croizat (Fig. 8) ocorre disjuntamente no Peru, na região de Huánaco, em um vale andino, e na região Chiquitana da Bolívia. Croton stellatoferrugineus Caruzo \& Cordeiro (Fig. 19), como as duas espécies anteriores, tem distribuição muito restrita, sendo endêmica da base do Pico do Itambé, na região central da Cadeia do Espinhaço, norte de Minas Gerais.

\section{Considerações finais}

As espécies da seção Cleodora são essencialmente megatérmicas, com todas as suas populações presentes na região neotropical e em sua grande maioria, endêmicas de florestas pluviais, com exceção de Croton fragrans e C. hoffmannii, que também ocorrem em florestas estacionais e apenas quatro espécies ( $C$. fragrantulus, $C$. heterocalyx, $C$. rottlerifolius e C. stellatoferrugineus) exclusivas de florestas estacionais. No Brasil, onde a maioria das espécies da seção ocorre, há duas áreas de diversidade, as encostas das Serras do Mar e Mantiqueira, no Sudeste do país, e a região do baixo Amazonas, no Noroeste do Pará. Há três espécies endêmicas na seção, sendo duas do leste do Brasil e uma da Colômbia.

Alguns dos padrões encontrados nas espécies de Croton sect. Cleodora também já foram referidos para outras espécies, como a disjunção entre floresta pluvial da Mata Atlântica e "brejo de altitude" no Nordeste, encontrado em C. hemiargyreus, e a congruência da distribuição de C. rottlerifolius com o "arco pleistocênico" (Prado \& Gibbs, 1993), bem como a distribuição das outras três espécies de florestas estacionais na área das florestas tropicais estacionais, referida por Pennington (2000).

\section{Referências}

Austin, D.F. \& Huáman, Z. 1996. A synopsis of Ipomoea (Convolvulaceae) in the Américas. Taxon 45(1): 1-38. 
Boechat, S.C. \& Longhi-Wagner, H.M. 2000. Padrões de distribuição geográfica dos táxons brasileiros de Eragrostis (Poaceae, Chloridoideae). Revista Brasileira de Botânica 23(2): 177-194.

Britannica Atlas. 1984. Chicago: Rand McNally \& Company.

Burger, W. \& Huft, M. 1995. Flora costaricensis: Euphorbiaceae. Fieldiana 36: 1-169.

Burkart, A. 1975. Evolution of grasses and grasslands in South América. Taxon 24(1): 5366.

Govaerts, R.; Frodin, D.G. \& Radcliffe-Smith, A. 2000. World Checklist and Bibliography of Euphorbiaceae (and Pandaceae), v. 2. Kew, Royal Botanic Gardens. Jablonski, E. Botany of the Guayana highlands-part VI: Euphorbiaceae. Mem. New York Bot. Gard. 12: 150-169.

Huber,O. \& Riina, R. 1997. Glosario Fitoecológico de las Américas, vol. 1. América del Sur: países hispanoparlantes. Caracas, Venezuela.

Huber, O. \& Riina, R. 2003. Glosario Fitoecológico de las Américas, vol. 2. México, Centroamérica e Islas del Caribe. UNESCO, Paris.

Insituto Brasileiro de Geografia e Estatística (IBGE). 1994. Cadastro de Cidades e Vilas. CDDI. Edição eletrônica.

Nelson, B.W.; Ferreira, C.A. C.; Silva, M.F. da \& Kawasaki, M.L. 1999. Endemism centers, refugia and botanical colletion density in Brazilian Amazonia. Nature 345: 714-716.

Pennington, R.T.; Lewis, G.P. \& Ratter, J.A. 2006. An overview of the plant diversity, biogeography and conservation of Neotropical savannas and seasonally dry forests. In Pennington, R.T.; Lewis, G.P. \& Ratter, J.A. eds. Neotropical savannas and dry forests: diversity, biogeography, and conservation. The Systematics Association Special, Series 69. Boca Raton: CRC Press. 1-29.

Prado, D.E. 2000. Seasonally dry forestsof tropical South America: from forgotten ecosystems to a new phytogeographic unit. Edinburgh Journal of Botany 57: 437461.

Prado, D.E. \& Gibbs, P.E. 1993. Patterns of species distribution in the dry seasonal forests of South America. Annals of the Missouri Botanical Garden 80: 902-927. 
Prance, G.T. 1982. Forests refuges: Evidence from woody angiosperms. In Biological Diversification in the Tropics (G.T. Prance, ed.). New York: ColumbiaUniversity Press. pp. 137-157.

Rizzini, C.T. 1997. Tratado de Fitogeografia do Brasil. Rio de Janeiro: Ed. Âmbito Cultural Ed. Ltda. 747p.

Sakuragui, M. 2001. Biogeografia de Philodendron seção Calostigma (Schott) Pfeiffer (Araceae) no Brasil. Acta Scientiarum 23(2): 561-569.

Werneck, F.P. \& Colli, G.R. 2006. The lizard assemblage from seasonally dry tropical forest enclaves in the cerrado biome, Brazil, and its association with the pleistocenic arc. Journal of Biogeography 33: 1983-1992. 
Tabela1. Distribuição geográfica e habitat das espécies de Croton sect. Cleodora.

\begin{tabular}{|c|c|c|c|}
\hline Distribuição & Ocorrência & Espécie & Habitat \\
\hline \multirow{6}{*}{$\begin{array}{l}\text { Moderadamente } \\
\text { ampla* }\end{array}$} & $\begin{array}{l}\text { México até noroeste da } \\
\text { Colômbia }\end{array}$ & C. billbergianus Müll.Arg. & Floresta pluvial \\
\hline & $\begin{array}{l}\text { Norte e Centro-Oeste do Brasil, } \\
\text { Bolívia até Peru }\end{array}$ & C. cajucara Benth. & Floresta pluvial amazônica \\
\hline & Panamá, Venezuela e Colômbia & C. fragrans Kunth & Floresta pluvial e estacional \\
\hline & $\begin{array}{l}\text { Costa Rica, Norte do Brasil, } \\
\text { Guiana e Suriname }\end{array}$ & C. hoffmannii Müll.Arg. & Floresta pluvial e estacional \\
\hline & $\begin{array}{l}\text { Nordeste, Centro-Oeste e } \\
\text { Sudeste do Brasil }\end{array}$ & C. rottlerifolius Baill. & Floresta estacional \\
\hline & $\begin{array}{l}\text { Norte do Brasil, Bolívia a } \\
\text { Venezuela }\end{array}$ & C. spruceanus Benth. & Floresta pluvial amazônica \\
\hline \multirow[t]{9}{*}{ Restrita** } & Colômbia e Venezuela & C. croizatii Steyerm. & Floresta pluvial \\
\hline & Bolívia e Peru & C. fragrantulus Croizat & Floresta estacional \\
\hline & Nordeste e Sudeste do Brasil & C. hemiargyreus Müll.Arg. & Floresta pluvial montana Atlântica \\
\hline & Nordeste e Sudeste do Brasil & C. heterocalyx Baill. & Floresta estacional \\
\hline & Sudeste do Brasil & C. organensis Baill. & Floresta pluvial montana Atlântica \\
\hline & Norte do Brasil, Venezuela & C. orinocensis Müll.Arg. & Floresta pluvial \\
\hline & Colômbia, Ecuador e Peru & C. pseudofragrans Croizat & Floresta pluvial amazônica \\
\hline & Sudeste do Brasil & C. salutaris Casar. & Floresta pluvial montana Atlântica \\
\hline & Nordeste e Sudeste do Brasil & C. sphaerogynus Baill. & $\begin{array}{l}\text { Floresta pluvial baixo montana Atlântica e } \\
\text { restinga }\end{array}$ \\
\hline Muito restrita*** & $\begin{array}{l}\text { Sudeste do Brasil } \\
\text { Noroeste da Colômbia } \\
\text { Sudeste do Brasil }\end{array}$ & \begin{tabular}{|l|} 
C. campanulatus Caruzo \& Cordeiro \\
C. rufolepidotus Caruzo \& Riina \\
C. stellatoferrugineus Caruzo \& Cordeiro
\end{tabular} & $\begin{array}{l}\text { Floresta pluvial montana } \\
\text { Floresta pluvial } \\
\text { Floresta estacional }\end{array}$ \\
\hline
\end{tabular}

*Moderadamente ampla: acima de $5000 \mathrm{~km}^{2}$; **Restrita: entre aproximadamente 1000 e $4000 \mathrm{~km}^{2}$; ${ }^{* * *}$ Muito restrita: até aproximadamente $200 \mathrm{~km}{ }^{2}$ 
Tabela 2. Distribuição das espécies de Croton sect. Cleodora no Brasil.

\begin{tabular}{|c|c|c|c|c|c|c|c|c|c|c|c|c|c|c|c|c|c|c|c|c|c|c|c|c|c|c|c|}
\hline \multirow[t]{3}{*}{ ESPÉCIE } & \multicolumn{26}{|c|}{ BRASIL } & \multirow{3}{*}{$\begin{array}{l}\text { ÁREAS } \\
\text { EXTRA- } \\
\text { BRASILEIRAS }\end{array}$} \\
\hline & \multicolumn{7}{|c|}{ NORTE } & \multicolumn{4}{|c|}{ CENTRO-OESTE } & \multicolumn{8}{|c|}{ NORDESTE } & \multicolumn{4}{|c|}{ SUDESTE } & \multicolumn{3}{|c|}{ SUL } & \\
\hline & $\mathrm{RR}$ & AP & $\mathrm{AM}$ & $\mathrm{PA}$ & AC & RO & TO & MT & MS & $\mathrm{GO}$ & $\mathrm{DF}$ & MA & PI C & $\mathrm{CE}$ & RN & PB & $\mathrm{PE}$ & AL SE & BA & MG & ES & RJ & SP & PR & SC & RS & \\
\hline C. cajucara Benth. & $\mathrm{X}$ & & $\mathrm{X}$ & $X$ & & $X$ & & $\mathrm{X}$ & & & & $\mathrm{X}$ & & & & & & & & & & & & & & & BOL, VEN, PER \\
\hline $\begin{array}{l}\text { C. campanulatus } \\
\text { Caruzo \& Cordeiro }\end{array}$ & & & & & & & & & & & & & & & & & & & & $\mathrm{X}$ & & $\mathrm{X}$ & & & & & \\
\hline $\begin{array}{l}\text { C. hemiargyreus } \\
\text { Müll.Arg. }\end{array}$ & & & & & & & & & & & & & & & & & $\mathrm{X}$ & & & $\mathrm{X}$ & & $\mathrm{X}$ & $\mathrm{X}$ & & & & \\
\hline C. heterocalyx Baill. & & & & & & & & & & & & & & & & & & & $\mathrm{X}$ & $\mathrm{X}$ & $\mathrm{X}$ & & & & & & \\
\hline $\begin{array}{l}\text { C. hoffmannii } \\
\text { Müll.Arg. }\end{array}$ & $\mathrm{X}$ & & & & & & & & & & & & & & & & & & & & & & & & & & CRI, GUY \\
\hline C. organensis Baill. & & & & & & & & & & & & & & & & & & & & $\mathrm{X}$ & & $X$ & $\mathrm{X}$ & & & & \\
\hline $\begin{array}{l}\text { C. orinocensis } \\
\text { Müll.Arg. }\end{array}$ & & & & $\mathrm{X}$ & & & & & & & & & & & & & & & & & & & & & & & COL, VEN \\
\hline C. rottlerifolius Baill. & & & & & & & & & $\mathrm{X}$ & & & & & & & & & & $\mathrm{X}$ & $\mathrm{X}$ & & & $\mathrm{X}$ & & & & \\
\hline C. salutaris Casar. & & & & & & & & & & & & & & & & & & & & $\mathrm{X}$ & $X$ & $\mathrm{X}$ & $\mathrm{X}$ & & & & \\
\hline $\begin{array}{l}\text { C. sphaerogynus } \\
\text { Baill. }\end{array}$ & & & & & & & & & & & & & & & & & & & $\mathrm{X}$ & $\mathrm{X}$ & $\mathrm{X}$ & $\mathrm{X}$ & $\mathrm{X}$ & & & & \\
\hline C. spruceanus Benth. & & & & $X$ & $\mathrm{X}$ & & & & & & & & & & & & & & & & & & & & & & $\begin{array}{l}\text { BOL, COL, } \\
\text { VEN, ECU }\end{array}$ \\
\hline $\begin{array}{l}\text { C. stellatoferrugineus } \\
\text { Caruzo \& Cordeiro }\end{array}$ & & & & & & & & & & & & & & & & & & & & $\mathrm{X}$ & & & & & & & \\
\hline
\end{tabular}




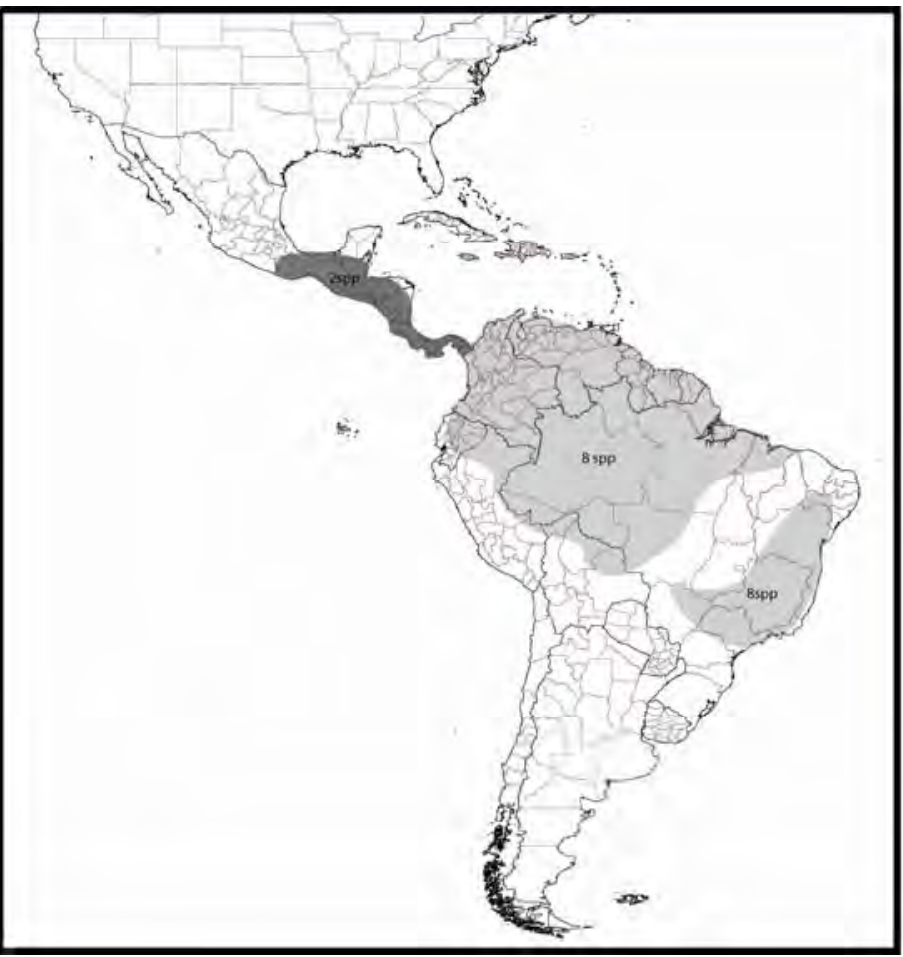

Figura 1. Distribuição total de Croton sect. Cleodora.

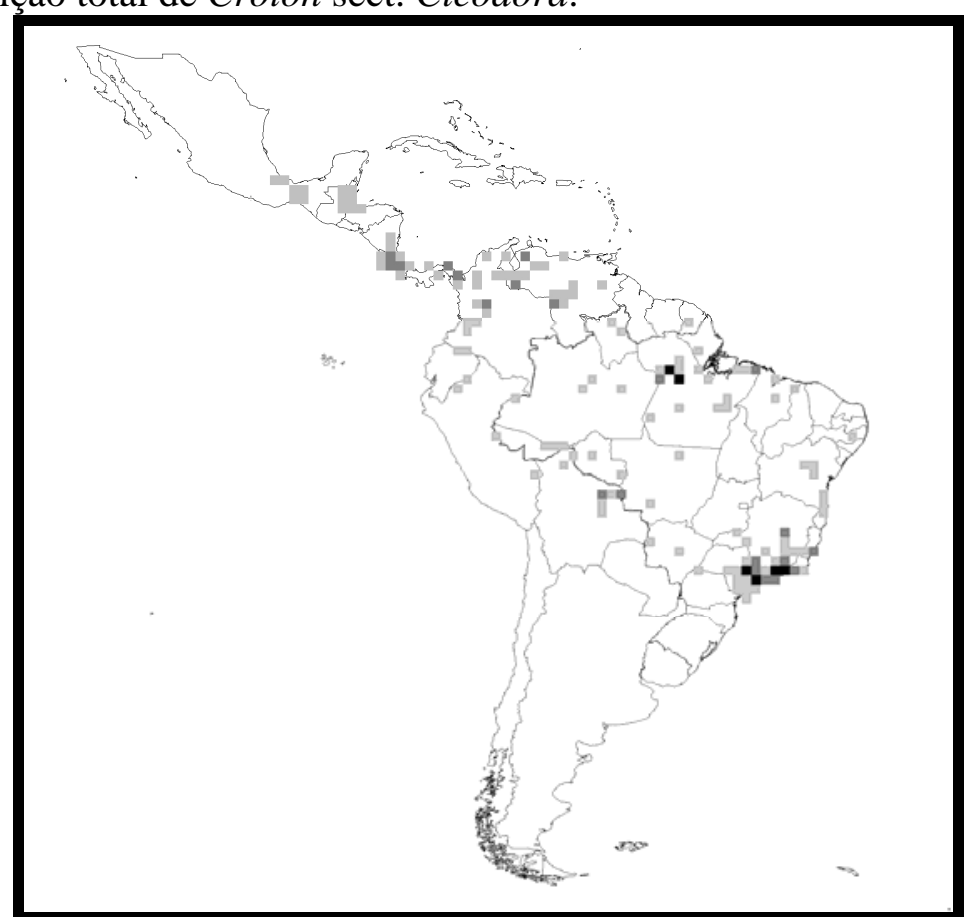

Figura 2. Áreas de maior riqueza de Croton sect. Cleodora. $\square 3$ espécies, espécie. 


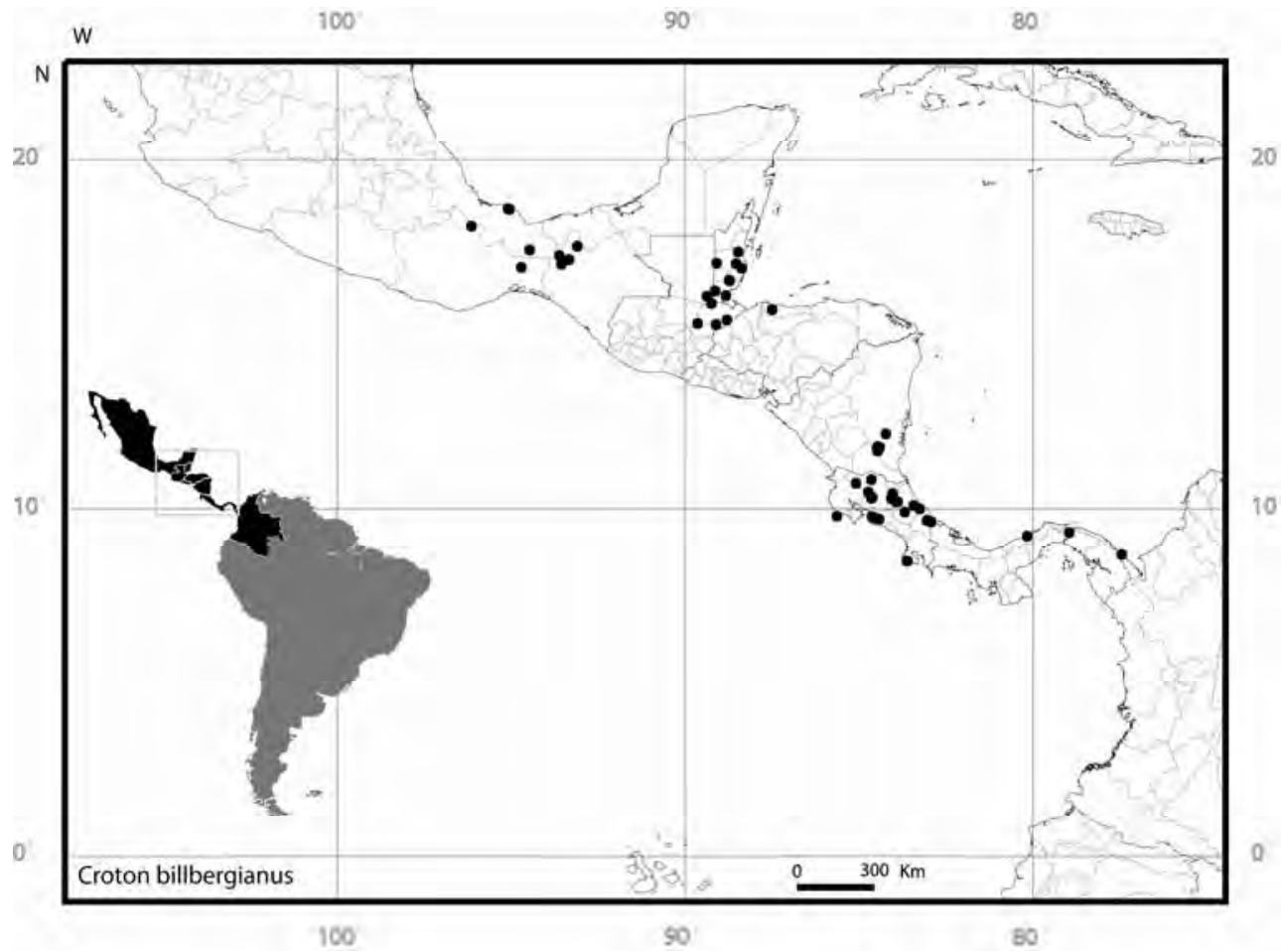

Figura 3: Mapa de distribuição geográfica de Croton billbergianus.

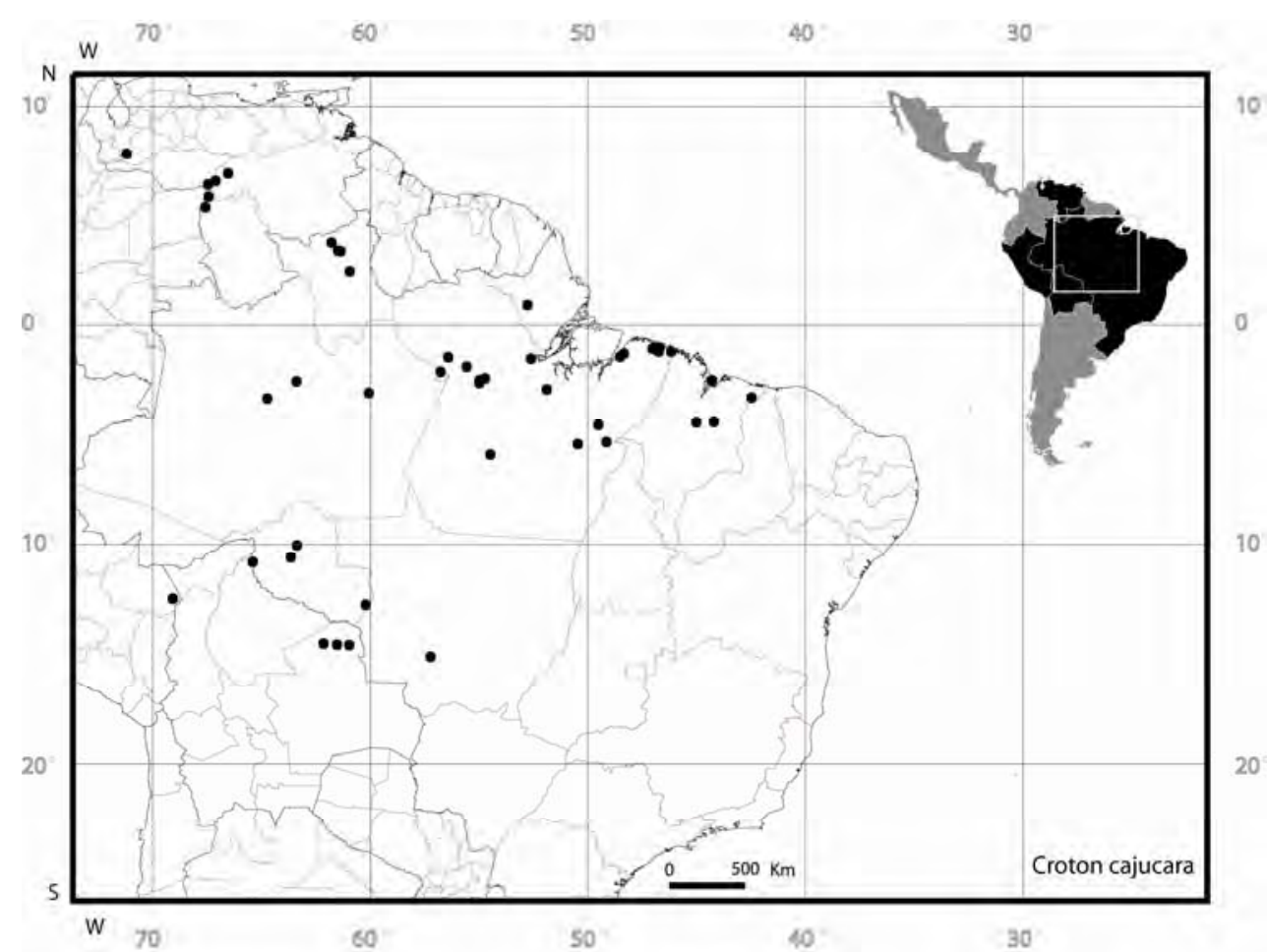

Figura 4: Mapa de distribuição geográfica de Croton cajucara. 


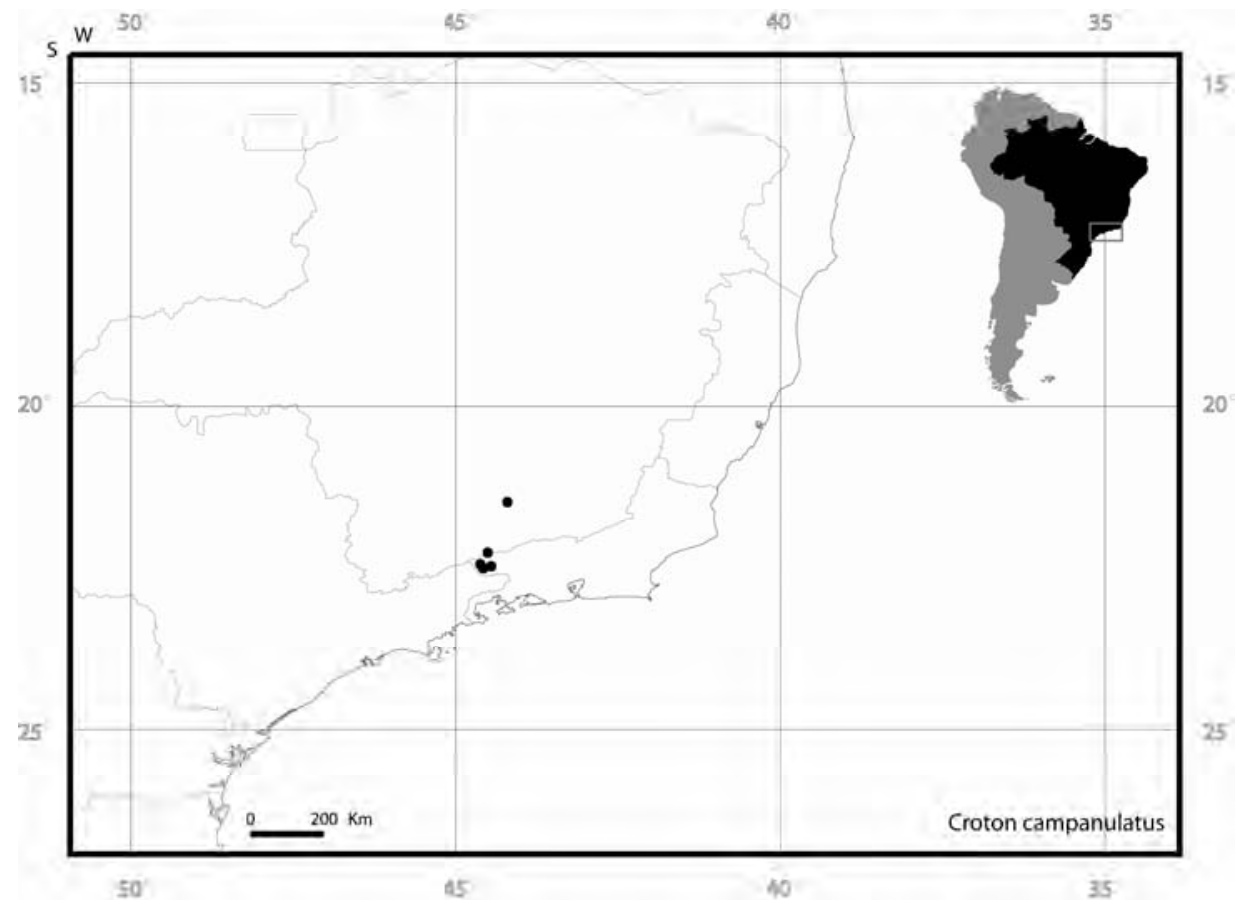

Figura 5: Mapa de distribuição geográfica de Croton campanulatus.

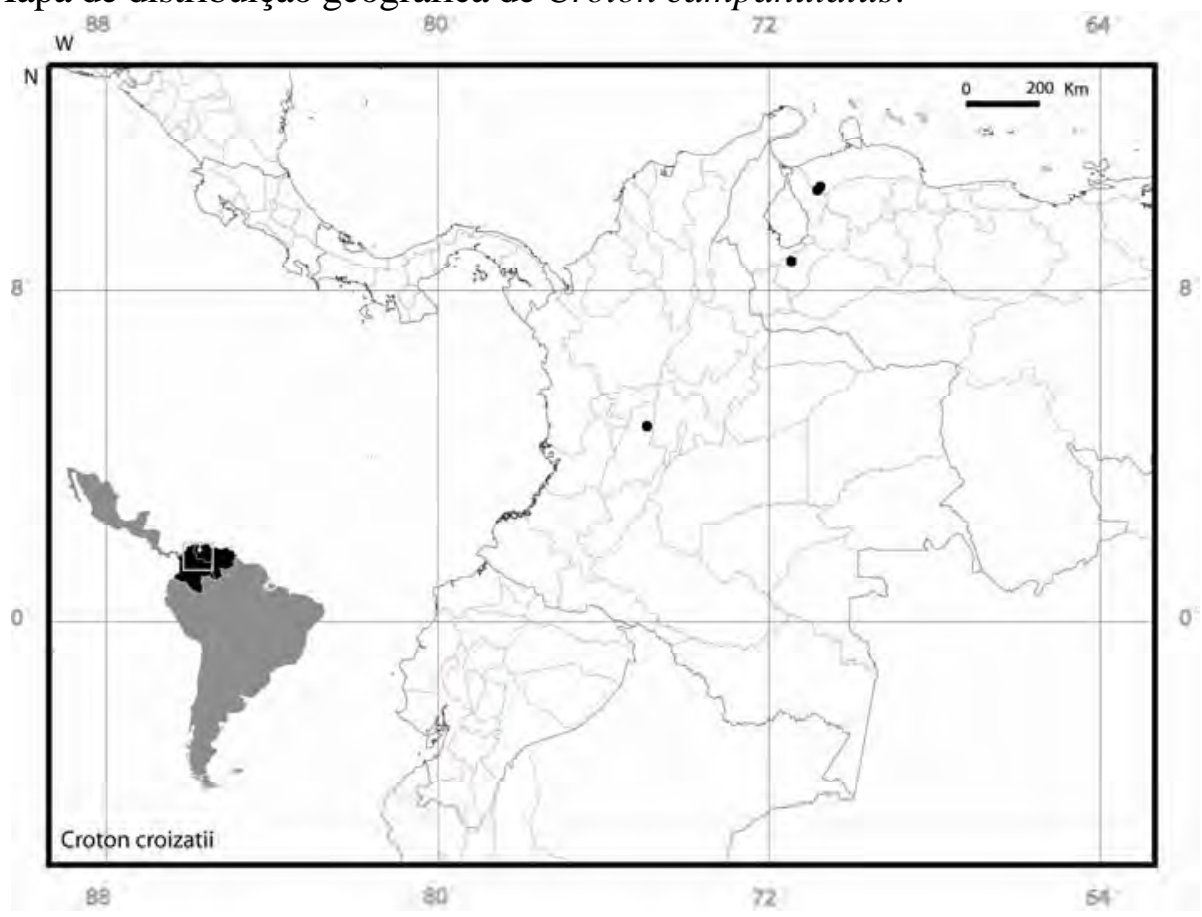

Figura 6: Mapa de distribuição geográfica de Croton croizatii. 


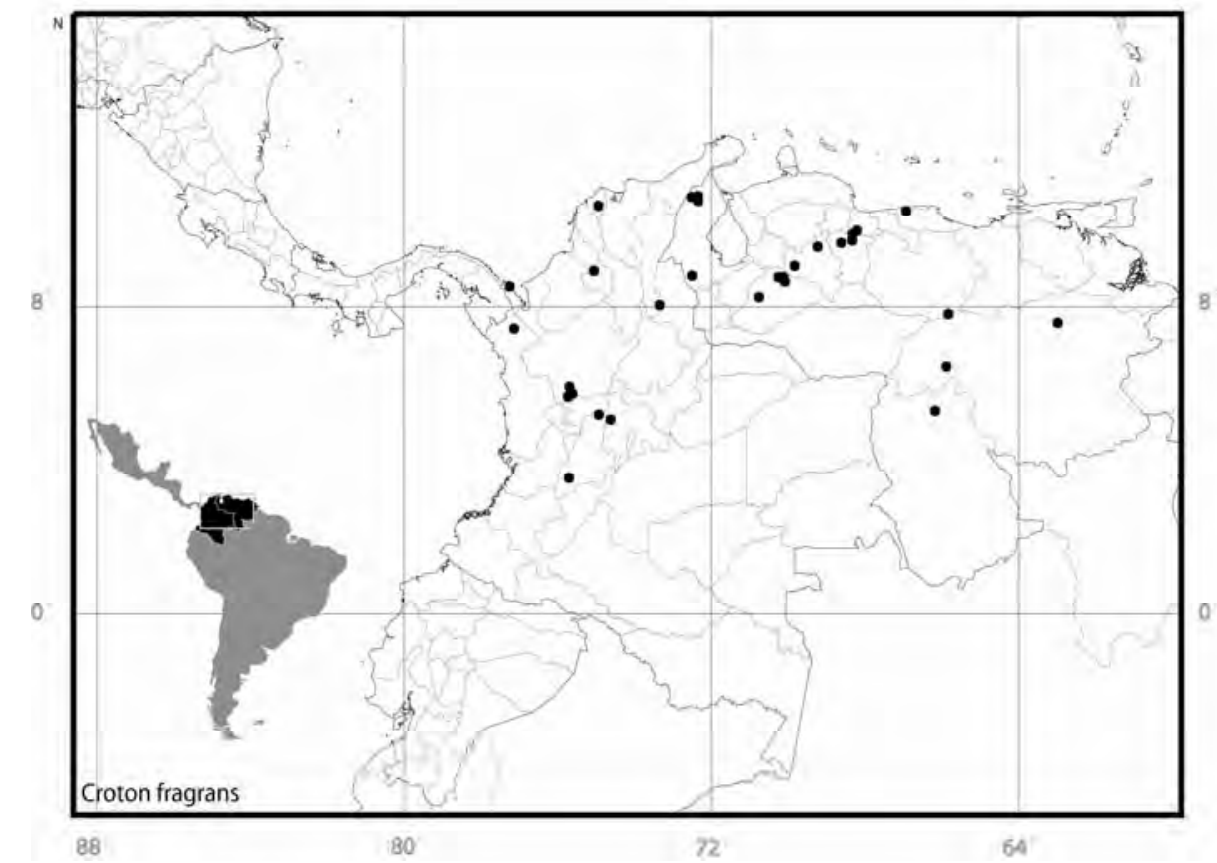

Figura 7: Mapa de distribuição geográfica de Croton fragrans.

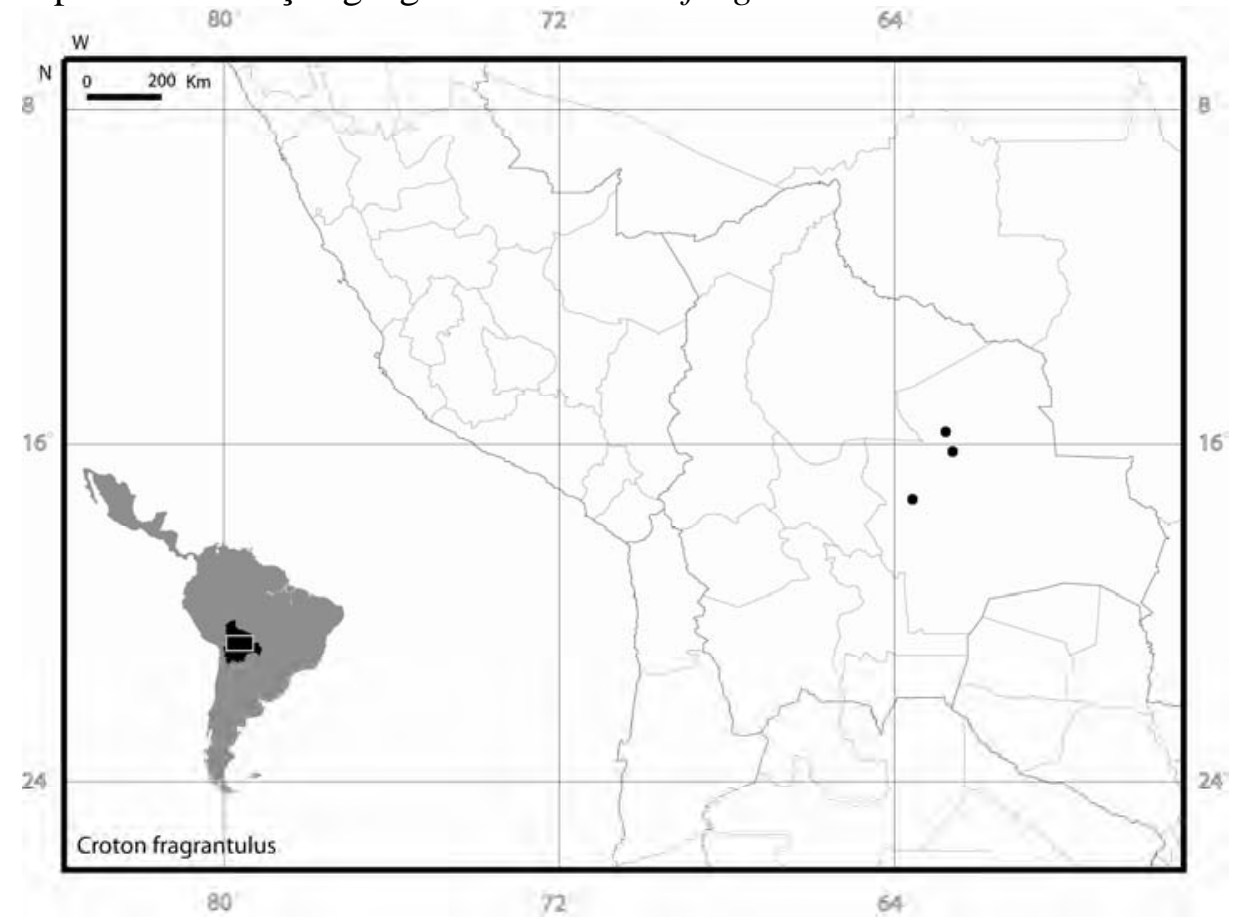

Figura 8: Mapa de distribuição geográfica de Croton fragrantulus. 


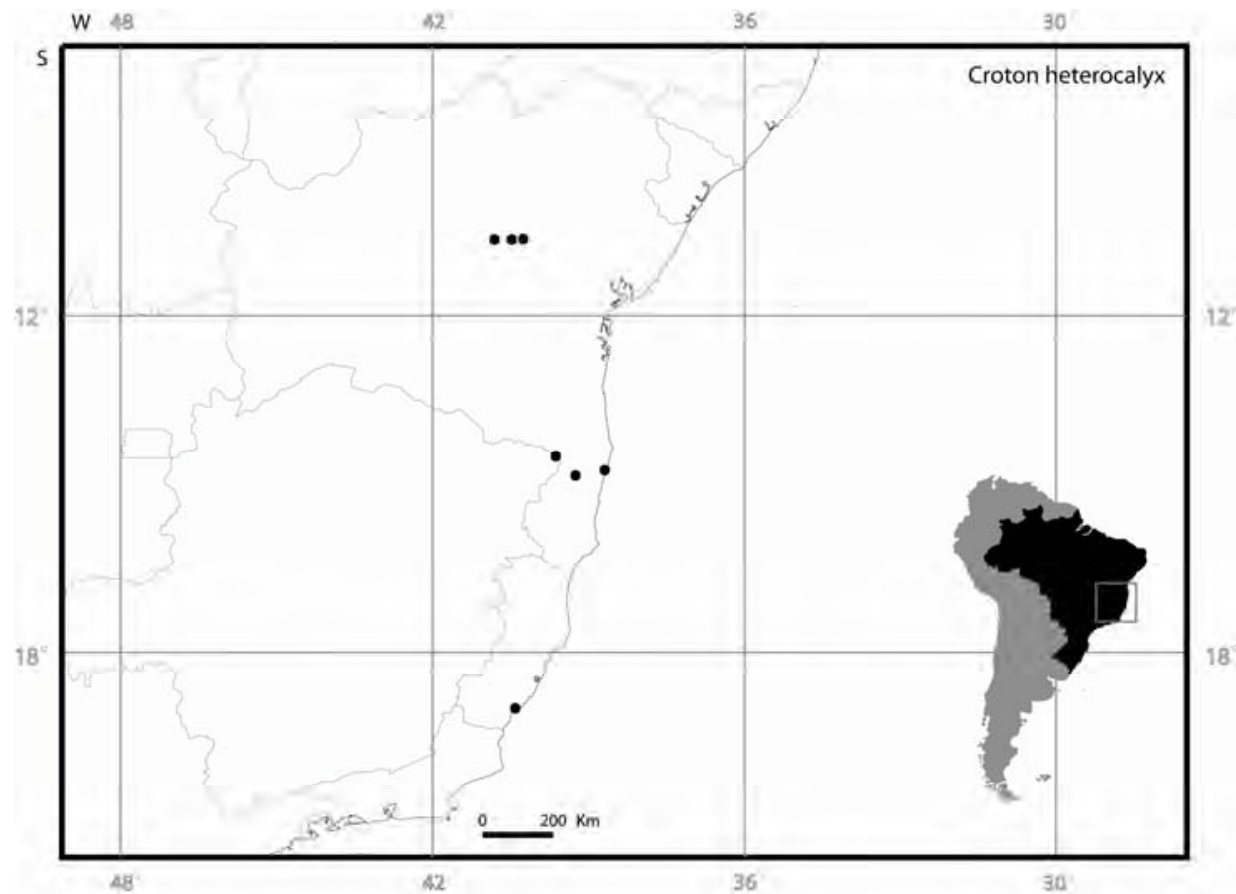

Figura 9: Mapa de distribuição geográfica de Croton heterocalyx.

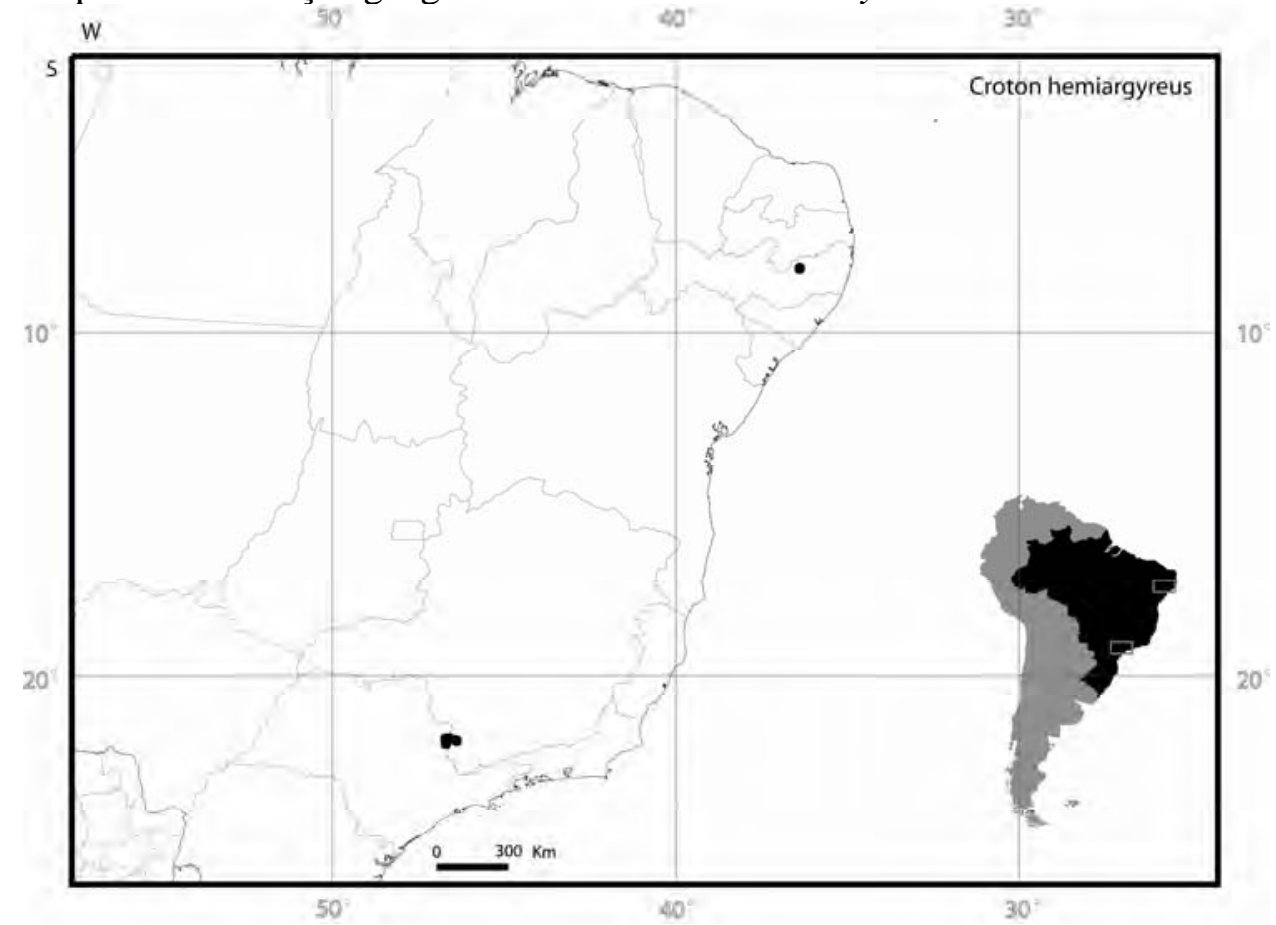

Figura 10: Mapa de distribuição geográfica de Croton hemiargyreus. 


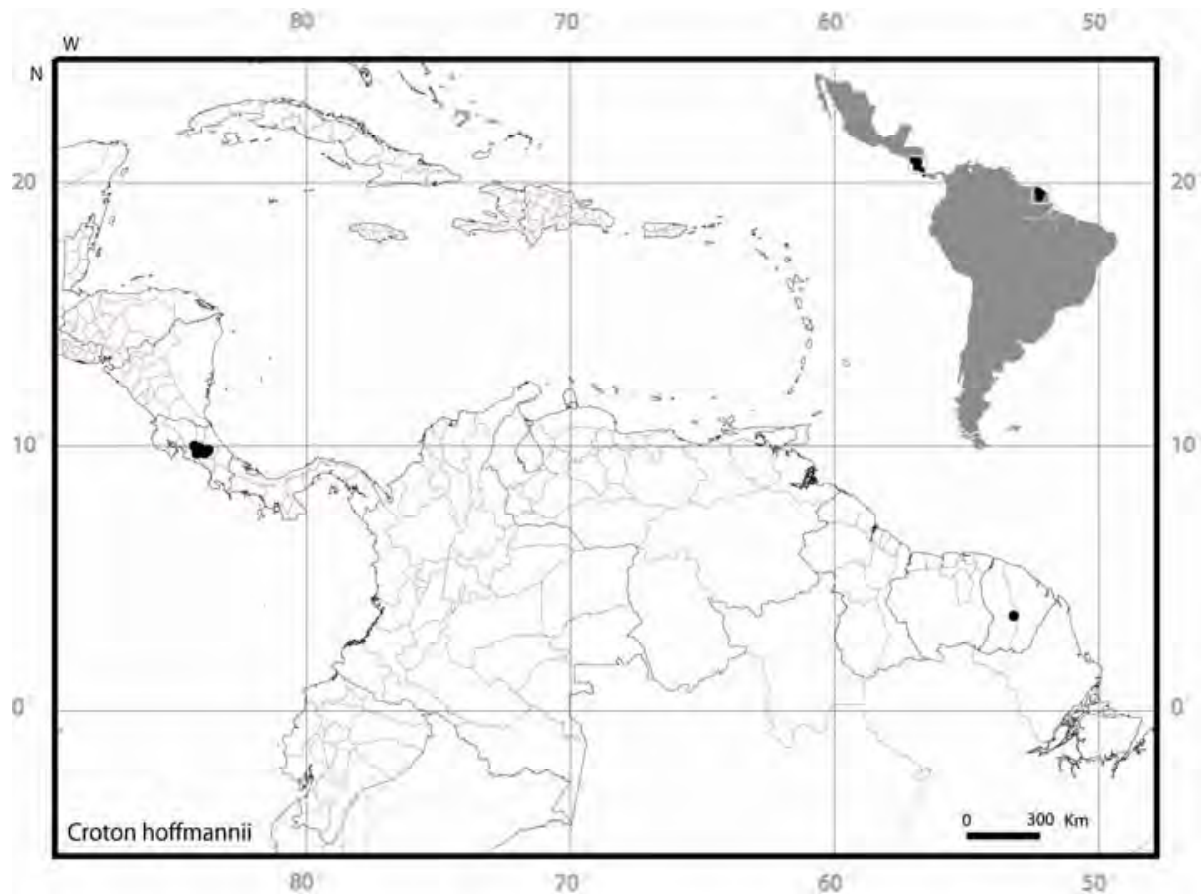

Figura 11: Mapa de distribuição geográfica de Croton hoffmannii.

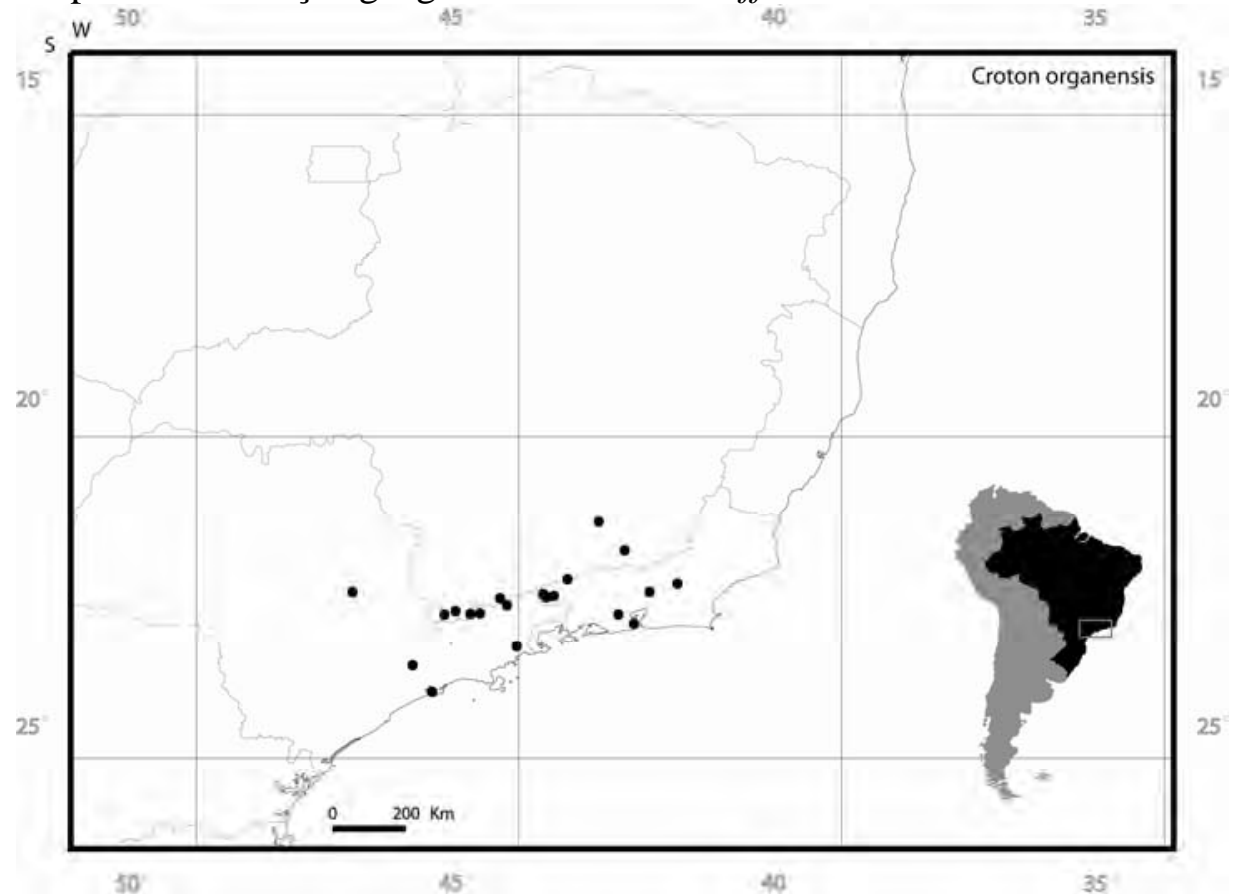

Figura 12: Mapa de distribuição geográfica de Croton organensis. 


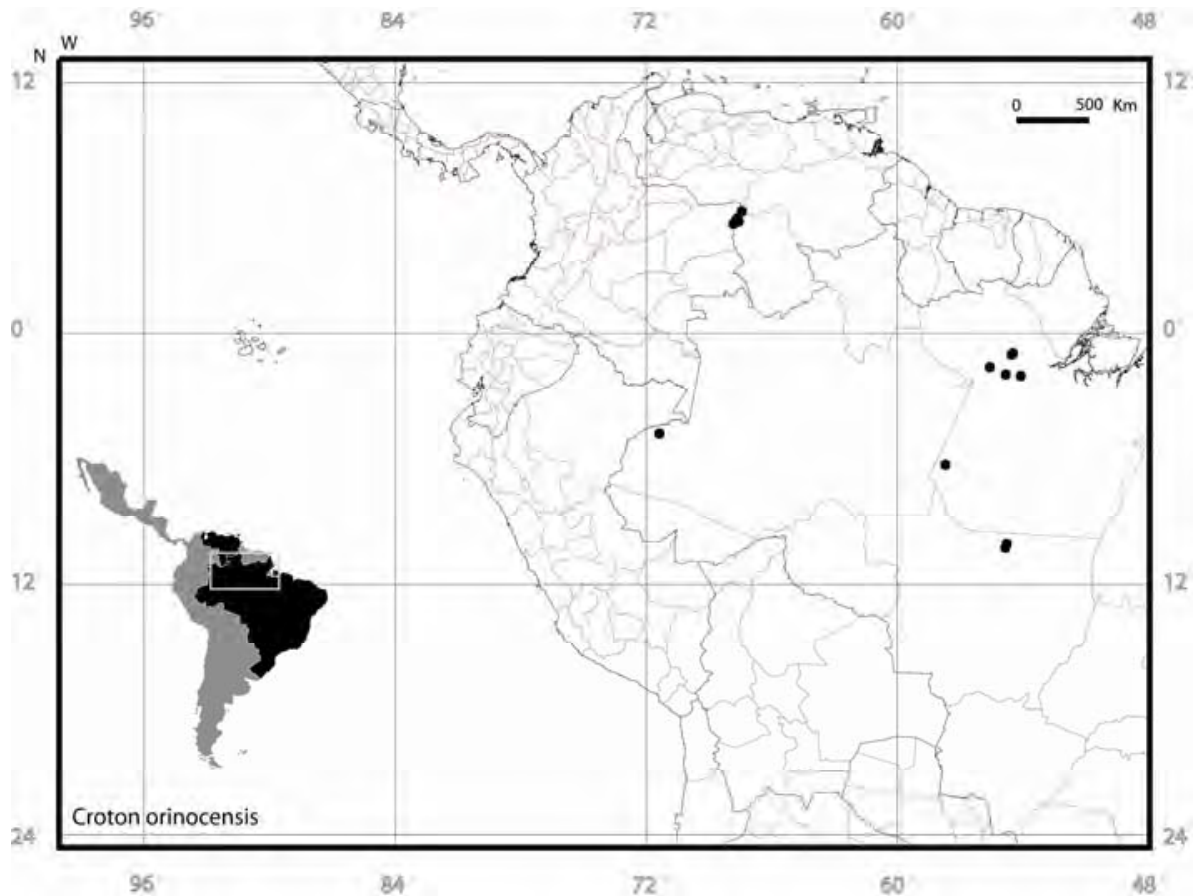

Figura 13: Mapa de distribuição geográfica de Croton orinocensis.

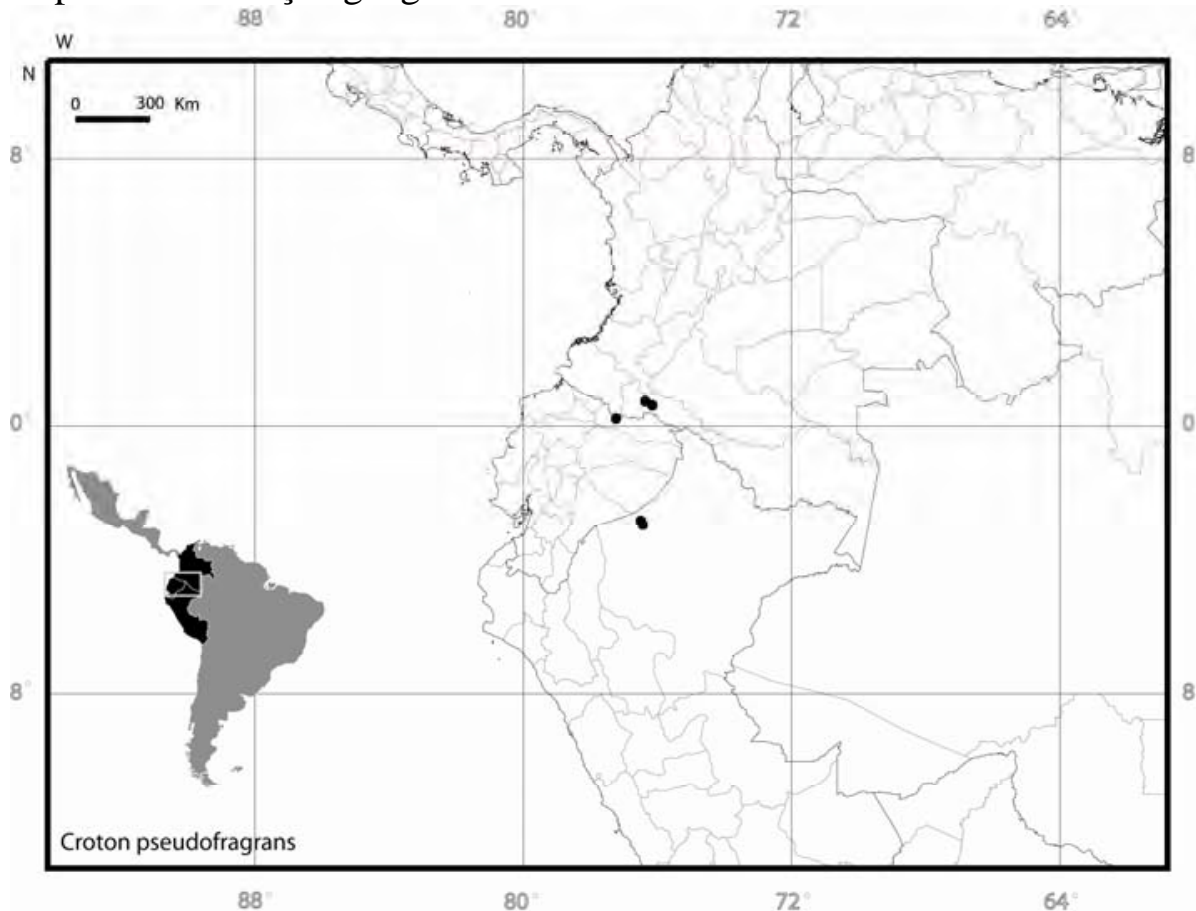

Figura 14: Mapa de distribuição geográfica de Croton pseudofragrans. 


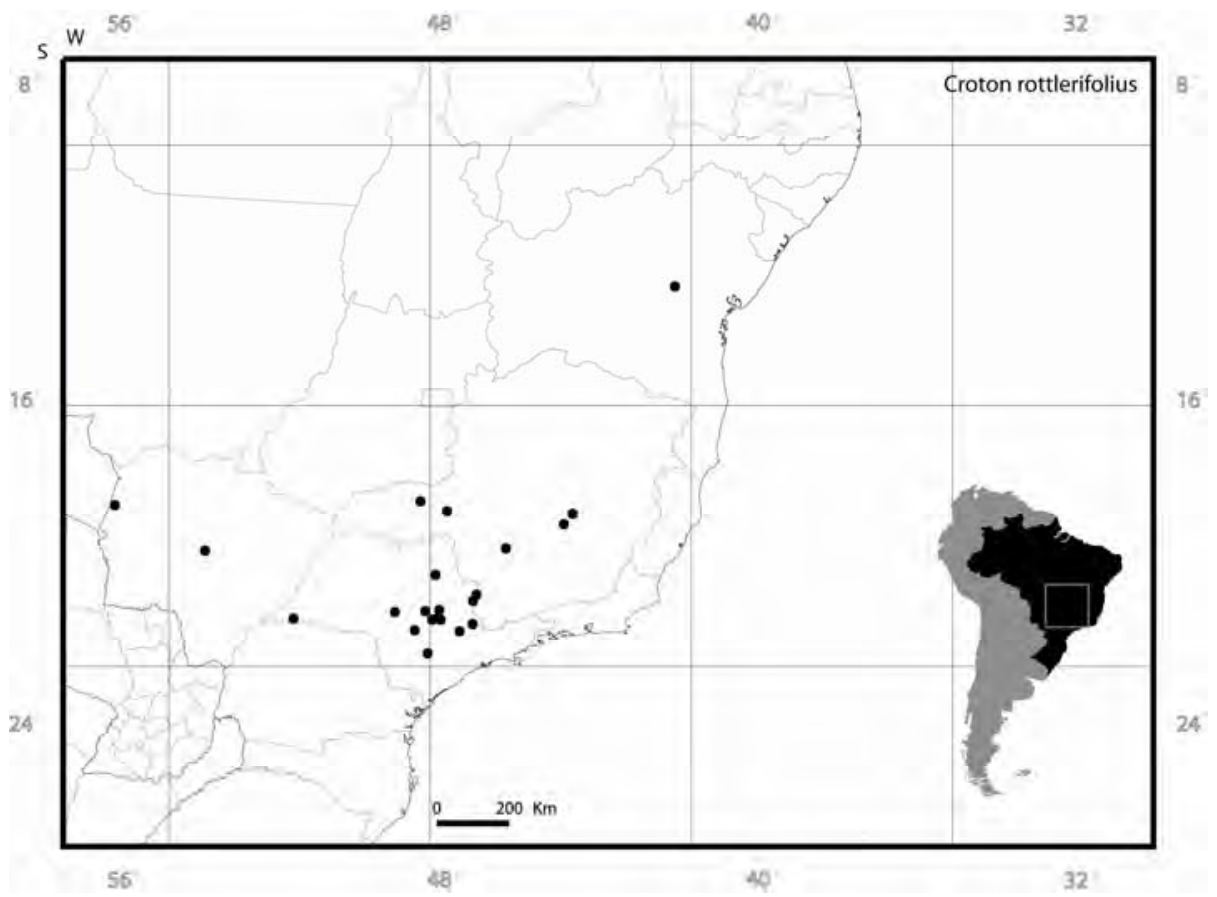

Figura 15: Mapa de distribuição geográfica de Croton rottlerifolius.

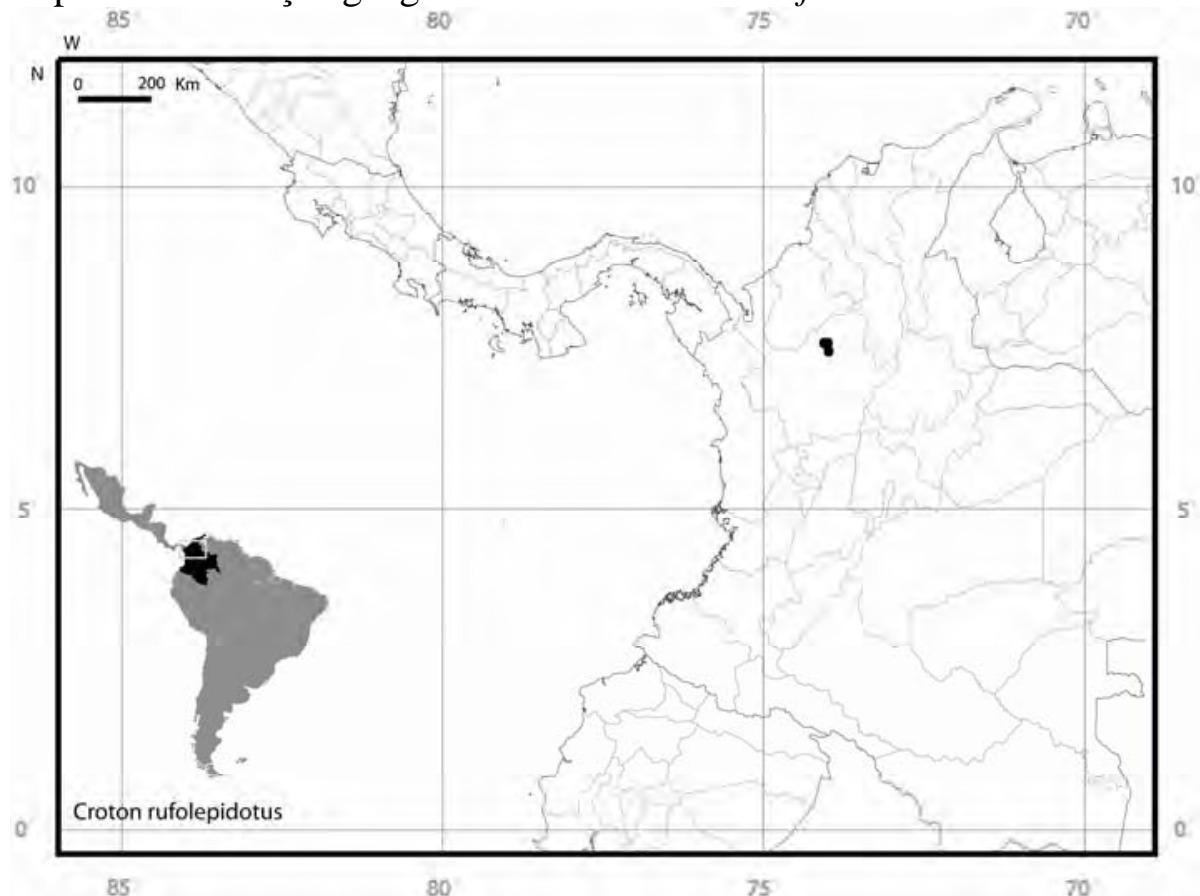

Figura 16: Mapa de distribuição geográfica de Croton rufolepidotus. 


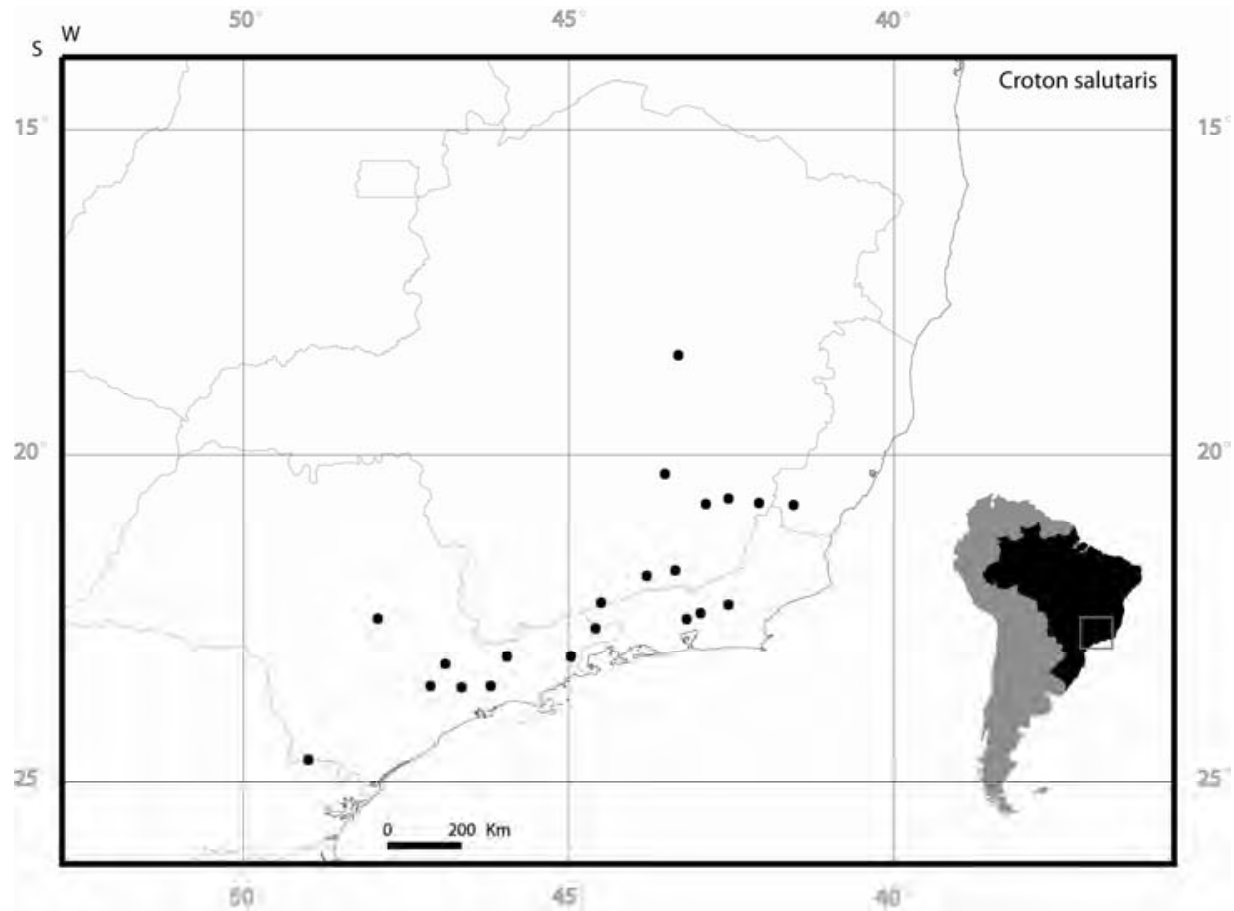

Figura 17: Mapa de distribuição geográfica de Croton salutaris.

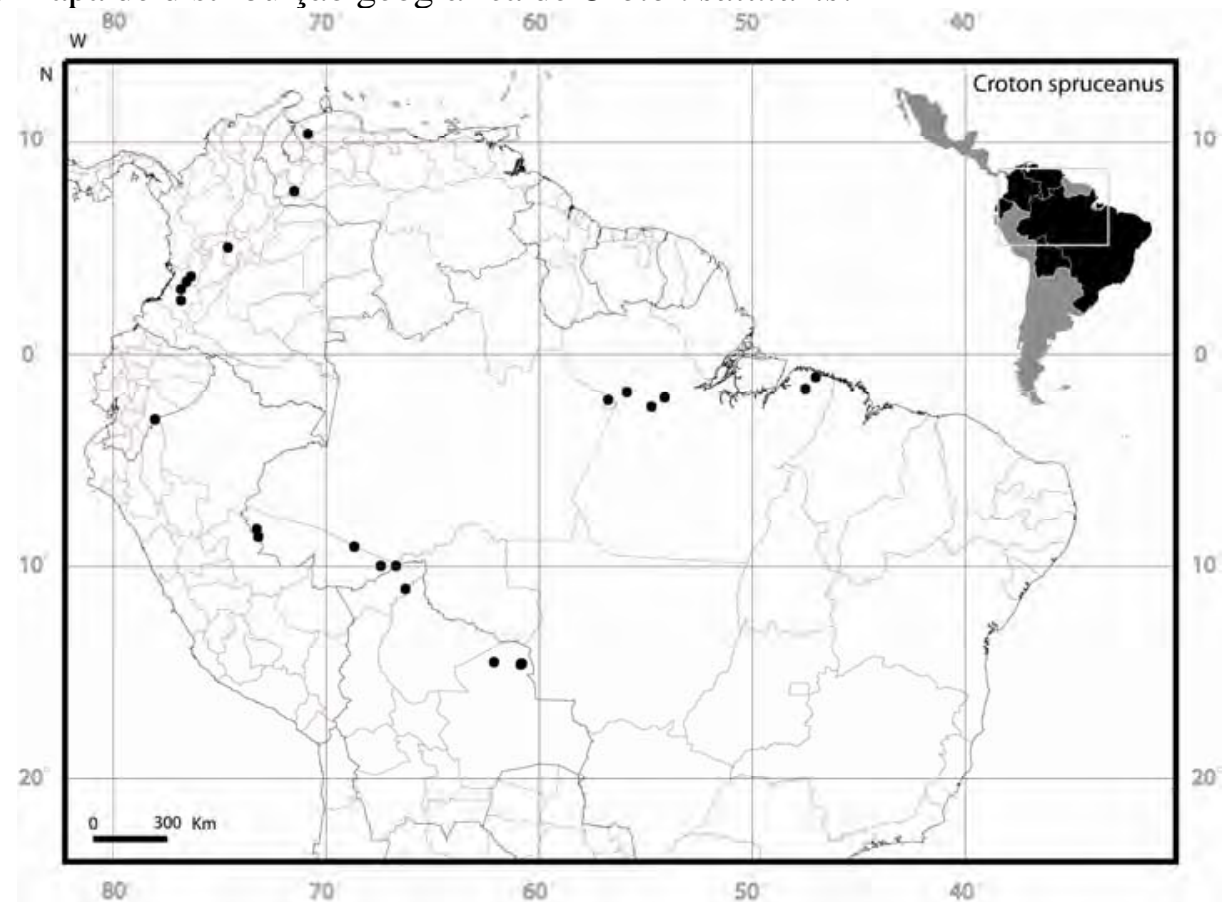

Figura 18: Mapa de distribuição geográfica de Croton spruceanus. 


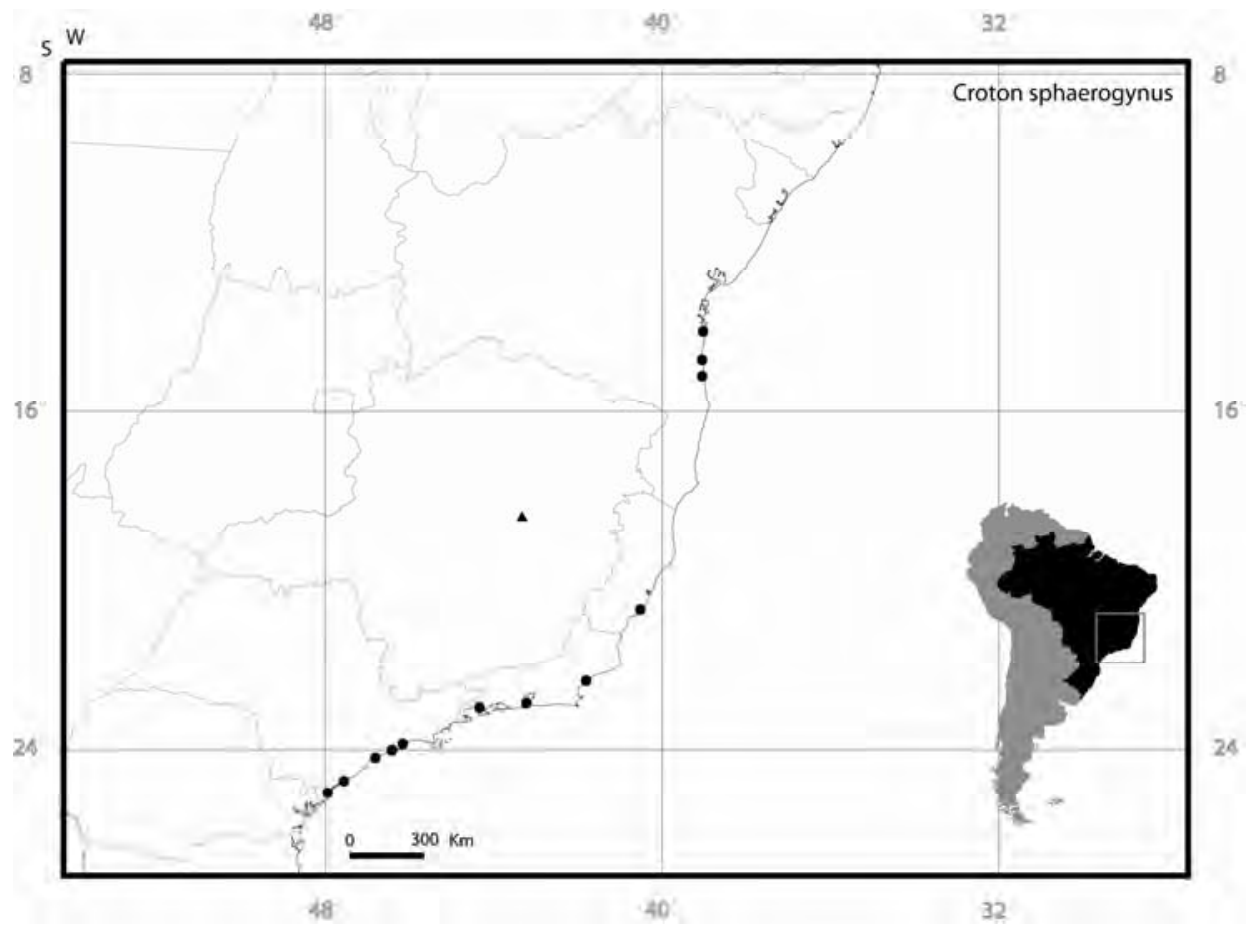

Figura 19: Mapa de distribuição geográfica de Croton sphaerogynus (•) e Croton stellatoferrugineus ( $\mathbf{\Delta}$ ). 
CAPÍTULO 5 


\title{
Modelagem de nicho ecológico de espécies de Croton sect. Cleodora (Euphorbiaceae) ocorrentes no Brasil ${ }^{1}$
}

Resumo. Croton L. é o segundo maior gênero das Euphorbiaceae, com mais de 1200 espécies distribuídas nos trópicos e subtrópicos. No Brasil, o gênero está representado por aproximadamente 350 espécies, incluindo ervas, arbustos e árvores que ocorrem em praticamente todos os tipos de vegetação, com um grande número de espécies concentradas na parte leste do país, principalmente em áreas de vegetação aberta. Pontos de ocorrência de seis espécies de Croton sect. Cleodora associados a dados ambientais foram empregados para produzir modelos preditivos, apresentados através de mapas com a distribuição potencial dessas espécies, utilizando o algorítmo Maxent (Maximum entropy method).

Palavras-chave: Modelagem de distribuição de espécies, HAND, SRTM, flora Neotropical.

\begin{abstract}
Croton L. is the second largest genus of Euphorbiaceae, with more than 1200 species distributed in the tropics and subtropics. In Brazil, the genus is represented by approximately 350 species, including herbs, shrubs and trees found in all types of vegetation, with a large number of species concentrated in the eastern part of the country, particularly in areas of open vegetation. Occurrence points of 6 species belonging to Croton sect. Cleodora associated with environmental data were used to produce predictive models, presented through maps of the potential distribution of these species, using the algorithm Maxent (Maximum entropy method).
\end{abstract}

Key words: Species distribution modelling, HAND, SRTM, Neotropical flora.

\footnotetext{
${ }^{1}$ Manuscrito elaborado com a colaboração de Cristina Bestetti Costa, Luciana Satiko Arasato e Silvana Amaral (DPI - INPE).
} 


\section{Introdução}

A modelagem preditiva de habitat é uma importante ferramenta para a melhor compreensão dos fatores que controlam a distribuição das espécies. Tal abordagem combina dados de ocorrência com variáveis ambientais/ecológicas para criar um modelo dos requisitos das espécies para as variáveis examinadas (Anderson et al., 2003). Segundo Guisan \& Zimmermann (2000), apesar da importância primordial em autoecologia, atualmente esses modelos vêm sendo empregados em estudos do impacto das mudanças ambientais na distribuição de espécies, em testes de hipóteses biogeográficas, conservação e manejo de espécies invasoras (p.e. Peterson \& Papes 2003; Guisan et al. 2006; Urbina-Cardona \& Loyola, 2008).

O gênero Croton L., o segundo maior da família Euphorbiaceae, apresenta distribuição pantropical e possui aproximadamente 1223 espécies (Govaerts et. al., 2000). Um dos principais centros de diversidade do gênero está localizado no Brasil, onde ocorrem cerca de 350 espécies (Berry et al., 2005), incluindo ervas, arbustos e árvores, em todos os tipos de vegetação, nitidamente concentradas na parte leste do país, em áreas de vegetação aberta. As espécies de Croton podem ser facilmente reconhecidas no campo por um conjunto de caracteres que incluem a presença de tricomas estrelados ou escamiformes, inflorescências com flores unissexuais, látex incolor ou colorido, folhas que se tornam alaranjadas antes de cairem e frequentemente com glândulas no ápice do pecíolo (Berry et al., 2005).

Croton sect. Cleodora (Kloztch) Baill. é exclusivamente Neotropical e, em sua delimitação atual (Caruzo, em prep.), possui 18 espécies, dentre as quais 12 ocorrem no Brasil. As espécies da seção apresentam hábito predominantemente árboreo e ocorrem em florestas, pluviais ou estacionais (Caruzo, em prep.). Além disso, assim como muitas outras espécies árboreas de Croton, as Cleodora ocorrem em áreas perturbadas, são heliófilas e possuem crescimento rápido; características também compartilhadas com espécies de outras seções do gênero (p.e. Riina et al., 2009).

O presente trabalho é uma contribuição ao estudo da biogeografia do grupo, tendo como principal objetivo entender os fatores ambientais relacionados aos padrões de distribuição das espécies de Croton sect. Cleodora. 


\section{Material e métodos}

Os modelos preditivos de distribuição das espécies Croton cajucara, C. organensis, C. rottlerifolius, C. salutaris, C. sphaerogynus e C. spruceanus foram produzidos utilizando-se o modelo estatístico probabilístico Maxent (Maximum entropy method), baseado no princípio da máxima entropia (Phillips et al. 2006). Para isso, foram utilizados conjuntos de dados de ocorrência georreferenciados das espécies e selecionadas as variáveis para a produção do melhor modelo preditivo de distribuição. Foram utilizadas apenas as espécies com mais de 10 ocorrências georreferenciadas, uma vez que os modelos gerados com um número inferior não são satisfatórios. Essas ocorrências foram levantados durante a revisão da seção Cleodora (Caruzo, em prep.).

Para a geração dos modelos, as ocorrências extra-brasileiras dessas espécies foram descartadas. Os dados brasileiros de ocorrência foram separados aleatoriamente em 2 grupos, sendo 75\% utilizados como dados de entrada, para treinamento dos modelos e 25\% para o teste dos modelos.

\section{Modelagem de distribuição de espécies}

A metodologia adotada na modelagem de distribuição das espécies foi semelhante àquela utilizada por Arasato et al. (2009). O algorítmo Maxent (Entropia Máxima) foi utilizado para a modelagem do potencial da distribuição das espécies de Croton sect. Cleodora. Foram mantidos os parâmetros padrões do algoritmo (tab. 1), incluindo-se o arquivo com os dados para avaliação do modelo (Test sample file).

Para verificar a importância e influência das variáveis ambientais nos modelos de distribuição das espécies, foi utilizado o teste jackknife para os dados de treinamento, de teste e AUC (Area Under the Curve). Curvas ROC (receiver operating characteristic) foram usadas para verificar se o resultado da modelagem seria superior à resposta aleatória. Estas estatísticas foram calculadas pelas ferramentas de pós-análise disponíveis no software do Maxent (Phillips et al, 2006).

\section{Variáveis ambientais (Tab. 2)}

Para a caracterização de todo o gradiente climático encontrado no Brasil, as variáveis climáticas e bioclimáticas foram obtidas a partir do projeto WordClim - Global Climate Data $^{2}$ (Hijmans et al, 2005), com resolução espacial de aproximadamente 18,5 km (10

\footnotetext{
${ }^{2}$ http://www.worldclim.org/
} 
minutos de arco). Para selecionar variáveis pouco correlacionadas, foram gerados modelos com todas as variáveis ambientais disponíveis, para seleção daquelas com comportamentos diferentes e mais informativos, que foram então empregadas para gerar os modelos preditivos definitivos de distribuição de cada uma das espécies.

A base de dados sobre solos utilizada foi desenvolvida pela Embrapa Solos, na escala de 1:5.000.000, que segue o sistema brasileiro de classificação dos solos da Embrapa ${ }^{3}$ (1999), sendo a base cartográfica a do IBGE (2001)

A variável HAND (Height Above the Nearest Drainage, ou seja, distância vertical à drenagem mais próxima) de cada ponto de ocorrência das espécies, foi detectada remotamente através da topografia da cobertura vegetal, proveniente de dados de SRTM$\mathrm{DEM}^{4}$, metodologia desenvolvida por Rennó et al. (2008). Esse dado tem projeção latlong, datum WGS84 e resolução de aproximadamente $1 \mathrm{~km}$ no equador (30 segundos de arco). Para a geração do dado foi considerado um limiar de 50 pontos de ocorrência para o cálculo da distância da drenagem através do algoritmo HAND.

A densidade de drenagem foi gerada a partir da rede de drenagem fornecida pelo projeto HydroSHEDS ${ }^{5}$, derivada das imagens SRTM, com resolução espacial de 3arcsegundos, ou aproximadamente 500m (Lehner et al, 2006). O algoritmo utilizado para o cálculo da densidade de drenagem foi o Kernel (Silverman, 1986, p.76, equação 4.5) implementado no programa ArcGis 9.2. Para tanto foi definido um raio de influência de $10.000 \mathrm{~km}$, evidenciando a complexidade da drenagem. A resolução final da grade de densidade de drenagem foi de $500 \mathrm{~m}$ (Ximenes, 2008).

\section{Resultados e Discussão}

\section{Croton cajucara Benth. (Fig. 1)}

Croton cajucara é uma espécie amazônica e ocorre principalmente nas bordas das florestas de terra firme, em altitudes inferiores a 200 m (Caruzo, em prep.).

Foram utilizados um total de 35 pontos de ocorrências para essa espécie. As variáveis utilizadas para este modelo foram: bio3, bio4, bio14, bio18, bio19, prec5, prec11, tmin5, tmax6, tmax9, densdren, hand, altitude e solo.

\footnotetext{
${ }^{3}$ http://www.cnps.embrapa.br/ sibcs/

${ }^{4}$ http://www2.jpl.nasa.gov/srtm/

${ }^{5}$ http://hydrosheds.cr.usgs.gov/
} 
As contribuições das variáveis para essa espécie, no modelo gerado pelo Maxent, foram: bio19 24,2\%; solos 20,4\%, bio14 15,3\%, bio18 11,4\%, galt 9\%, hand50 5,8\%, prec5 5,6\%, densdren 4,5\%, bio3 2,3\%, tmax6 0,6\%, prec11 0,5\%, bio4 0,4\%, tmin5 0\%.

Segundo o Maxent, as variáveis que mais contribuíram para o modelo de Croton cajucara, e que devem estar influenciando a distribuição dessa espécie, são: precipitação no trimestre mais frio (23,9\%), tipo de solo (20,4\%) e precipitação dos meses mais secos $(17,7 \%)$.

As florestas de terra firme, onde está presente Croton cajucara, ocupam a maior parte da bacia amazônica, em planaltos pouco elevados (entre 30-200 m) e apresentam solos de substrato arenoso ou argiloso (Rizzini, 1997). Croton cajucara é geralmente encontrado em solos de substrato arenoso.

\section{Croton rottlerifolius Baill. (Fig. 2)}

Segundo Caruzo (em prep.), Croton rottlerifolius é encontrada em áreas de floresta estacional semidecidual das regiões nordeste, sudeste e centro-oeste do Brasil, sendo mais ou menos congruente com a região do “arco pleistocênico” de Prado \& Gibbs (1993).

Para essa espécie foi utilizado um total 24 pontos de ocorrência. As variáveis ambientais utilizadas foram: bio2, bio4, bio11, bio14, bio15, bio18, prec4, tmin8, tmax6, tmax11, densdren, hand, altitude e solo.

A porcentagem de contribuição de cada uma das variáveis para o modelo de Croton rottlerifolius, segundo o Maxent, foram: bio4 27,5\%, hand50 16,7\%, bio18 13,6\%, prec4 12,7\%, solos 12,4\%, tmax6 4,1\%, bio15 4,1\%, bio14 3,7\%, bio11 2,4\%, bio2 1,6\%, densdren $0,6 \%$, galt $0,3 \%$, tmax $110,2 \%$, tmin8 $0 \%$.

As variáveis que mais contribuíram nos modelos e que provavelmente regulam a distribuição de Croton rottlerifolius são: sazonalidade de temperatura (27,5\%), distância vertical à drenagem mais próxima (16,7\%) e precipitação do trimestre mais quente (13,6\%). O tipo de vegetação nas regiões de ocorrência dessa espécie (florestas estacionais semideciduais) apresentam, de acordo com Veloso et al. (1991), dois períodos anuais bem marcados por chuvas e secas, e solos de origem ígnea e/ou eruptiva (mais “ricos” em relação aos solos encontrados nos seus tipos vegetacionais vizinhos - cerrado e floresta amazônica). Essas características estão relacionadas às variáveis que mais contribuíram para o modelo da espécie, e devem ser os fatores determinantes para o estabelecimento de C. rottlerifolius. 
As florestas sazonalmente secas ocorrem de maneira disjunta em toda a região Neotropical (Pennington et al., 2000). Segundo Rizzini (1997), no Brasil, as florestas secas (ou mesófilas) estão disseminadas abundantemente através da área central do país (em regiões de cerrado) sob a forma de manchas. Na figura 2, é possível observar que o modelo de distribuição preditivo para Croton rottlerifolius segue o padrão de distribuição desse tipo de vegetação, sendo mais ou menos conincidente com a unidade fitogeográfica das florestas tropicais sazonalmente secas, determinada por Prado (2000).

\section{Croton organensis Baill. (Fig. 3)}

Croton organensis é uma espécie arbórea das florestas ombrófilas densas do sudeste do Brasil, encontradas nas encostas da Serra da Mantiqueira e da Serra do Mar (Caruzo, em prep.).

Para essa espécie foram utilizados 19 pontos de ocorrência. As variáveis ambientais utilizadas para a geração dos modelos foram: bio3, bio4, bio6, bio18, bio19, prec4, prec10, tmax11, densdren, hand, altitude e solo.

As contribuições das variáveis para essa espécie, no modelo gerado pelo Maxent, foram: tmax11 50,3\%, bio18 22,2\%, solo 17,7\%, bio19 4,4\%, bio6 2,3\%, prec10 1,3\%, bio3 $0,9 \%$, prec4 0,4\%, bio4 0,4\%, densdren $0,2 \%$, galt $0 \%$, hand50 0\%.

As variáveis que mais contribuíram no modelo gerado para Croton organensis foram temperatura máxima do mês de novembro (50,3\%), precipitação do trimestre mais quente (22,2\%) e tipo de solo (17,7\%).

O modelo de distribuição potencial para Croton organensis, é mais ou menos congruente (com exceção de uma pequena área potencial de ocorrência na região central do Mato Grosso) com a distrubuição de Croton organensis referida por Caruzo (em prep.). A partir do modelo é possível verificar que a distribuição dessa espécie está associada às regiões das serras do Mar e da Mantiqueira, no sudeste do Brasil, com exceção da região central de mato Grosso indicada pelo modelo.

\section{Croton salutaris Casar. (Fig. 4)}

Segundo Caruzo (em prep.), Croton salutaris é uma espécie arbórea das florestas ombrófilas densas do sudeste do Brasil. Essa espécie é encontrada, principalmente, nas encostas da Serra da Mantiqueira e da Serra do Mar, em altitudes que variam de 500 a 1500 metros (nas denominadas florestas ombrófilas densas montanas). 
Foi utilizado um total de 24 pontos de ocorrência para a espécie. As variáveis utilizadas foram: bio3, bio4, bio5, bio9, bio15, bio18, bio19, prec11, prec5, tmax 8, tmin 3, densdren, hand, altitude e solo.

As contribuições das variáveis para esta espécie, segundo o Maxent, foram, respectivamente: bio4 (sazonalidade de temperatura) 34,4\%, solo (tipo de solo) 21\%, bio9 (temperatura média do trimestre mais seco) 18,6\%, bio15 9\%, galt 7,3\%, tmax8 4,2\%, bio19 2,8\%, prec11 1,7\%, tmin3 0,4\%, bio3 0,4\%, hand50 0,1\%, demais variáveis 0\%.

É possível observar na figura 3 que o modelo preditivo de distribuição, é concordante com a distrubuição da espécie referida por Caruzo (em prep.), onde a distribuição de Croton salutaris está associada à região das serras do Mar e da Mantiqueira, no sudeste do Brasil (padrão semelhante ao observado para C. organensis), com exceção da região de Porto Alegre, no Rio Grande do Sul, indicada pelo modelo.

\section{Croton sphaerogynus Baill. (Fig. 5)}

Croton sphaerogynus ocorre nas florestas de restinga da Costa Atlântica do Brasil, estendendo-se do litoral sul da Bahia ao litoral sul de São Paulo (Caruzo, em prep.).

Para essa espécie foram utilizados 13 pontos de ocorrência, e as variáveis climáticas utilizadas foram: bio3, bio8, bio18, tmax6, tmax9, densdren, hand50 e solos.

As contribuições das variáveis no modelo gerado pelo Maxent foram: tmax9 32,6\%, hand50 23,7\%, solo 21,3\%, bio18 10,3\%, densdren 9,1\%, bio3 2\%, bio8 0,9\%, tmax6 0\%. As variáveis que mais influenciaram o modelo, para esse conjunto de dados, foram: temperatura máxima do mês de setembro, distância vertical da drenagem mais próxima e tipo de solo.

É possível afirmar, em uma interpretação visual, que o modelo gerado não foi muito restritivo em relação às áreas de ocorrência potencial de Croton sphaerogynus, pois a área de distribuição potencial está mais ampla do que a distribuição conhecida até o momento para essa espécie.

Croton sphaerogynus é encontrado em florestas de restinga, principalmente nas planícies quaternárias arenosas do litoral. A contribuição da variável solo nos modelos preditivos de distribuição dessa espécie (para todos os conjuntos de dados), associada à observação constante da espécie em áreas com substrato arenoso, corrobora a hipótese de que o tipo de solo deve ser um fator importante em sua distribuição. 


\section{Croton spruceanus Benth. (Fig. 6)}

Croton spruceanus é uma espécie amazônica, que ocorre principalmente nas bordas das florestas de terra firme (Caruzo, em prep.).

Foram utilizados 11 pontos de ocorrência para essa espécie. As variáveis ambientais utilizadas foram: bio4, bio5, bio14, prec3, hand50, densdren, galt e solo.

As contribuições das variáveis para o modelo gerado pelo Maxent para essa espécie foram: densdren 38\%, solo 31\%, prec3 20,5\%, galt 6,1\%, bio14 2,5\%, bio5 1,5\%, bio4 0,3\%, hand50 0\%.

As variáveis que mais contribuíram na geração do modelo foram: densidade de drenagem, tipo de solo e precipitação do mês de março. Nos tipos vegetacionais onde Croton spruceanus é encontrado (florestas de terra firme), o solo é formado por substrato arenoso ou argiloso (Rizzini, 1997).

Apesar da distribuição dessa espécie estar possivelmente relacionada a solos arenosos e baixas altitudes, o modelo generalizou a distribuição potencial de Croton spruceanus para localidades extra-amazônicas o que provavelmente signifique que algorítimo ou as variáveis ambientais utilizadas na geração do modelo não foram eficientes para a definição dos atuais limites de distribuição da espécie.

\section{Importância da variável “tipos de solo” nos modelos}

Observando-se os valores de contribuição das variáveis gerados pelo Maxent em cada uma das espécies analisadas, fica evidente a contribuição do tipo de solo na modelagem da distribuição das espécies brasileiras de Croton sect. Cleodora.

Para testar essa hipótese em todas as espécies estudadas, foram gerados modelos no Maxent retirando-se a variável “tipo de solo”. Na tabela 3 é possível observar o desempenho dos modelos gerados pelo Maxent, através dos valores de AUC (Area Under the Curve), com e sem os dados da variável "tipos de solo". Nota-se que, para a maioria das espécies, os valores de AUC sofrem uma leve diminuição com a retirada da variável (com exceção de Croton organensis, onde os valores de AUC aumentam com a retirada dessa variável) e, mesmo com essa diferença pouco significativa, pode-se dizer que essa variável desempenha, um papel muito importante na distribuição das espécies da seção. 


\section{Referências}

Anderson, R.P.; Lew, D. \& Peterson, A.T. 2003. Evaluating predictive models of species’ distributions: criteria from selecting optimal models. Ecological Modelling. 162: 211232.

Arasato, L.S.; Amaral, S. \& Ximenes, A. C. 2009. Densidade de Drenagem e HAND (Height Above the Nearest Drainage) do SRTM para modelagem de distribuição de espécie de palmeiras no Brasil. In: Simpósio Brasileiro de Sensoriamento Remoto, 14. (SBSR), Natal. p. 5089-5097. DVD, On-line. ISBN 978-85-17-00044-7. (INPE15815-PRE/10425). Disponível em: < http://urlib.net/dpi.inpe.br/sbsr@80/2008/11.17.20.42.48 >. Acesso em: 17 nov. 2009.

Berry, P.E.; Hipp, A.L.; Wurdack, K.J.; Van Ee, B. \& Riina, R. 2005. Molecular phylogenetics of the giant genus Croton and tribe Crotoneae (Euphorbiaceae sensu stricto) using ITS and trnL-trnF DNA sequence data. Amer. J. Bot. 92(9): 1520-1534.

Empresa Brasileira de Pesquisa Agropecuária - EMBRAPA. 1999. Centro Nacional de Pesquisa de Solos (Rio de Janeiro, RJ). Sistema Brasileiro de Classificação de Solos. Brasília: Embrapa Produção da Informação; Rio de Janeiro: Embrapa Solos. 412p.

Guisan, A. \& Zimmermann, N.E. 2000. Predictive habitat distribution models in ecology. Ecological Modelling 135: 147-186.

Guisan, A.; Broennimann, O.; Engler, R.; Vust, M.; Yoccoz, N.G.; Lehmann, A. \& Zimmermann. 2006. Using nich-based models to improve the sampling of rare species. Consevation Biology 20(2): 501-511.

Govaerts, R.; Frodin, D.G. \& Radcliffe-Smith, A. 2000. World Checklist and Bibliography of Euphorbiaceae (and Pandaceae), v. 2. Kew, Royal Botanic Gardens. Jablonski, E. Botany of the Guayana highlands-part VI: Euphorbiaceae. Mem. New York Bot. Gard. 12: 150-169.

Hijmans, R.J.; Cameron, S.E.; Parra, J.L., Jones, P.G. \& Jarvis, A. 2005. Very high resolution interpolated climate surfaces for global land areas. International Journal of Climatology 25: 1965-1978.

IBGE. EMBRAPA. 2001. Mapa de Solos do Brasil, 1:5.000.000. Rio de Janeiro, RJ.

Lehner, B.; Verdini, K. \& Jarvis, A. 2006. HydroSHEDS - Technical Documentation. Versão 1. Disponível em: 
http://gisdata.usgs.net/HydroSHEDS/downloads/HydroSHEDS_TechDoc_v10.pdf> . Acesso em: 20 de out de 2008.

Pennington, R.T.; D.E. Prado \& C.A. Pendry. 2000. Neotropical seasonally dry forests and Quaternary vegetation changes. Journal of Biogeography. 27: 261-237.

Peterson, A.T. \& Papes, M. 2003. Predicting the potencial invasive distributions of four alien plant species in North America. Weed Science 51: 863-868.

Phillips, S.J.; Anderson, R.P. \& Schapire, R.E. 2006. Maximum entropy modeling of species geographic distributions. Ecological Modelling. 190: 231-259.

Prado, D.E. 2000. Seasonally dry forestsof tropical South America: from forgotten ecosystems to a new phytogeographic unit. Edinburgh Journal of Botany 57: 437461.

Prado, D.E. \& Gibbs, P.E. 1993. Patterns of species distribution in the dry seasonal forests of South America. Annals of the Missouri Botanical Garden 80: 902-927.

Rennó, C.D.; Nobre, A.D.; Cuartas, L.A; Soares, J.V.; Hodnett, M.G.; Tomasella, J.; Waterloo, M.J. 2008. HAND, a new terrain descriptor using SRTM-DEM: Mapping terra-firme rainforest environments in Amazônia. Remote Sensing of Environment. 112: 3469-348.

Riina, R.; Berry, P.E. \& van Ee, B.W. 2009. Molecular Phylogenetics of the Dragon's Blood Croton sect. Cyclostigma (Euphorbiaceae): A Polyphyletic Assemblage Unraveled. Systematic Botany 34(2): 360-374.

Rizzini, C.T. 1997. Tratado de Fitogeografia do Brasil: aspectos ecológicos, sociológicos e florísticos. Âmbito cultural edições ltda. Rio de Janeiro, RJ. 747p.

Silverman, B.W. 1986. Density Estimation for Statistics and Data Analysis. New York: Chapman and Hall. 176p.

Stockwell, D.R.B. \& Noble, I.R. 1992. Induction of sets of rules from animal distribution data: A robust and informative method of analysis. Mathematics and Computers in Simulation 33: 385-390.

Urbina-Cardona, J.N. \& Loyola, R.D. 2008. Applying nich-based models to predict endangered-hylid potential distributions: are neotropical protected areas effective enough? Tropical Conservation Science 1(4): 417-445.

Veloso, H.P.; Rangel Filho, A.L.R. \& Lima, J.C.A. 1991. Classificação da vegetação brasileira, adaptada a um sistema universal. Rio de Janeiro: IBGE, Departamento de Recursos Naturais e Estudos Ambientais. 123p. 
Ximenes, A. C. 2008. Mapas auto-organizáveis para a identificação de ecorregiões do interflúvio Madeira-Purus: uma abordagem da biogeografia ecológica. (INPE15332-TDI/1372). Dissertação (Mestrado em Sensoriamento Remoto) - Instituto Nacional de Pesquisas Espaciais, São José dos Campos. 2008. Disponível em: < http://urlib.net/sid.inpe.br/mtc-m18@80/2008/08.18.14.02 >. Acesso em: 28 out. 2008. 155 p. 
Tabela 1. Parâmetros específicos do Maxent

\begin{tabular}{lc}
\hline Random test percentage & 0 \\
Regularization multiplier & 1 \\
Maximum interations & 500 \\
Convergence threshold & 0,00001 \\
Max number of background points & 10000 \\
\hline
\end{tabular}

Tabela 2. Variáveis ambientais utilizadas.

\begin{tabular}{|c|c|}
\hline \multirow[t]{11}{*}{ Bioclimáticas } & $\begin{array}{l}\text { bio } 2 \text { - Intervalo médio diurno (media } \\
\text { mensal (max temp - min temp)) }\end{array}$ \\
\hline & bio 3 - Isotermalidade \\
\hline & bio 4 - Sazonalidade de temperatura \\
\hline & $\begin{array}{l}\text { bio } 5 \text { - Temperatura máxima do mês mais } \\
\text { quente }\end{array}$ \\
\hline & $\begin{array}{l}\text { bio } 8 \text { - Temperatura média do trimestre } \\
\text { (estação) mais úmido }\end{array}$ \\
\hline & $\begin{array}{l}\text { bio } 9 \text { - Temperatura média do trimestre } \\
\text { (estação) mais seco }\end{array}$ \\
\hline & $\begin{array}{l}\text { bio } 11 \text { - Temperatura média do trimestre } \\
\text { (estação) mais frio }\end{array}$ \\
\hline & $\begin{array}{l}\text { bio } 14 \text { - Precipitação dos meses mais } \\
\text { secos }\end{array}$ \\
\hline & bio 15 - Sazonalidade da precipitação \\
\hline & $\begin{array}{l}\text { bio } 18 \text { - Precipitação do trimestre } \\
\text { (estação) mais quente }\end{array}$ \\
\hline & $\begin{array}{l}\text { bio } 19 \text { - Precipitação do trimestre } \\
\text { (estação) mais frio }\end{array}$ \\
\hline \multirow[t]{3}{*}{ Climáticas } & tmin - temperatura mínima do mês 1-12 \\
\hline & tmax - temperatura máxima do mês 1-12 \\
\hline & prec 1-12 - precipitação do mês de julho \\
\hline “Relevo" & $\begin{array}{l}\text { densdren - densidade de drenagem } \\
\text { galt - altitude } \\
\text { hand - distância vertical da drenagem } \\
\text { mais próxima }\end{array}$ \\
\hline Solo & $\begin{array}{l}\text { solos - sitema brasileiro de classificação } \\
\text { dos solos da Embrapa }\end{array}$ \\
\hline
\end{tabular}


Tabela 3. Desempenho dos modelos do Maxent com e sem a variável solo

\begin{tabular}{|l|c|c|}
\hline \multicolumn{1}{|c|}{ Espécie } & $\begin{array}{c}\text { AUC* } \\
\text { com solo }\end{array}$ & $\begin{array}{c}\text { AUC* } \\
\text { sem solo }\end{array}$ \\
\hline Croton cajucara & 0,970 & 0,950 \\
\hline Croton organensis & 0,992 & 0,995 \\
\hline Croton rottlerifolius & 0,989 & 0,981 \\
\hline Croton salutaris & 0,995 & 0,994 \\
\hline Croton sphaerogynus & 0,998 & 0,998 \\
\hline Croton spruceanus & 0,988 & 0,967 \\
\hline
\end{tabular}

*para dados de treinamento 


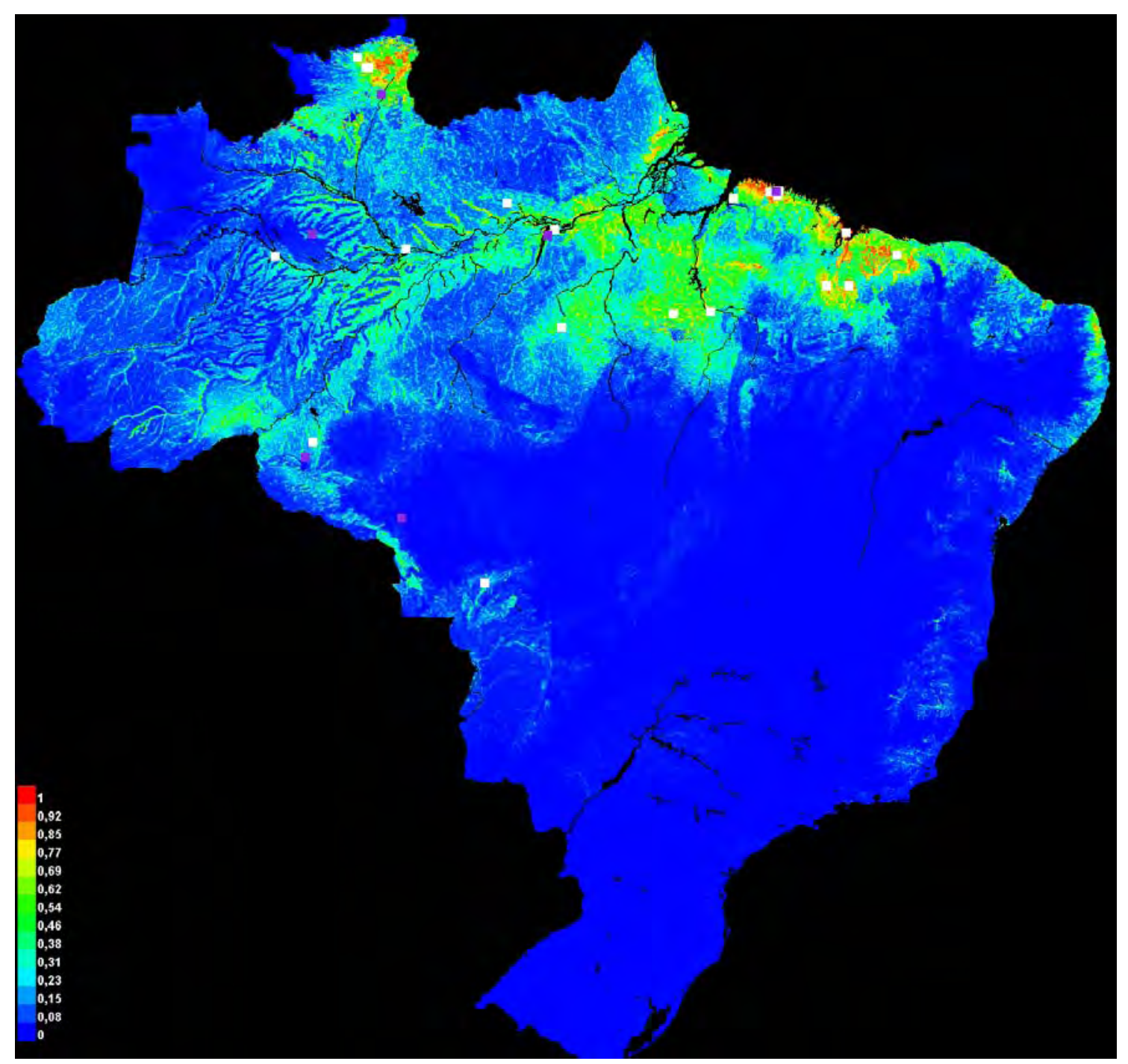

Figura 1. Croton cajucara. Modelo gerado pelo Maxent. Cores mais quentes (vemelho) maior probabilidade de encontrar a espécie. ( $\square$ pontos de ocorrência de teste; $\square$ pontos de ocorrência de treino) 


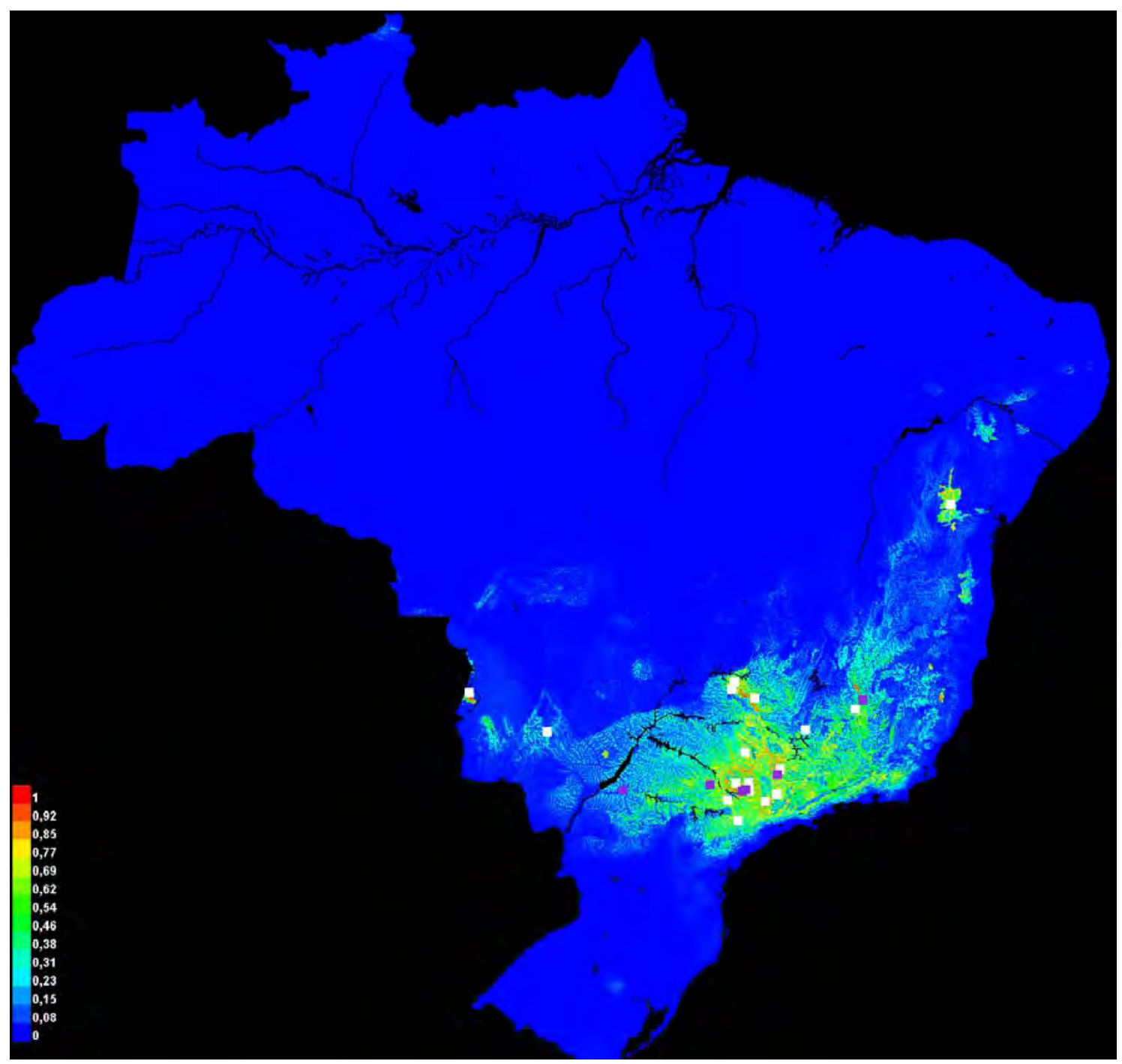

Figura 2. Croton rottlerifolius. Modelo gerado pelo Maxent. Cores mais quentes (vemelho) maior probabilidade de encontrar a espécie. ( $\square$ pontos de ocorrência de teste; $\square$ pontos de ocorrência de treino) 


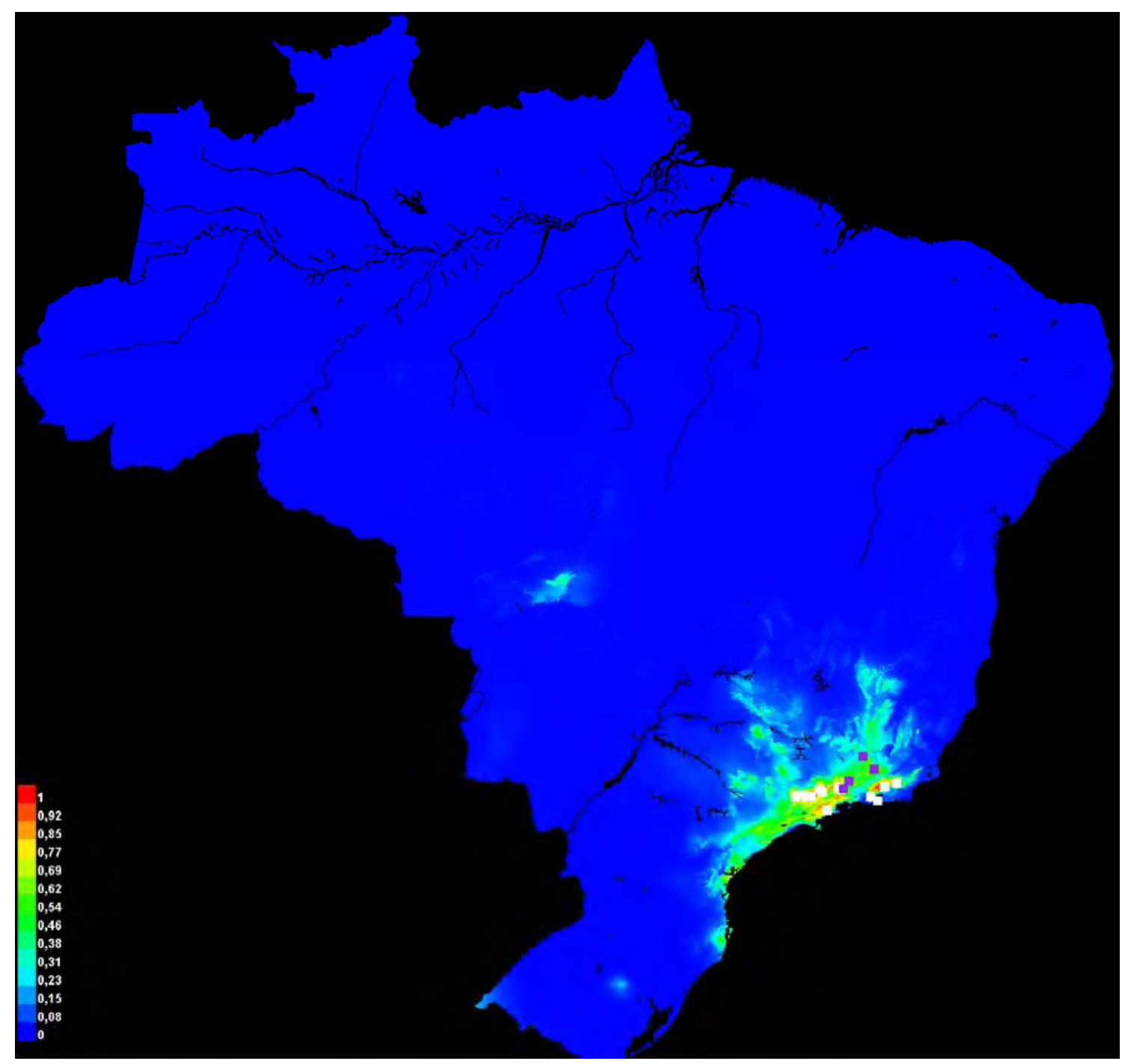

Figura 3. Croton organensis. Modelo gerado pelo Maxent. Cores mais quentes (vermelho) maior probabilidade de encontrar a espécie. ( $\square$ pontos de ocorrência de teste; $\square$ pontos de ocorrência de treino) 


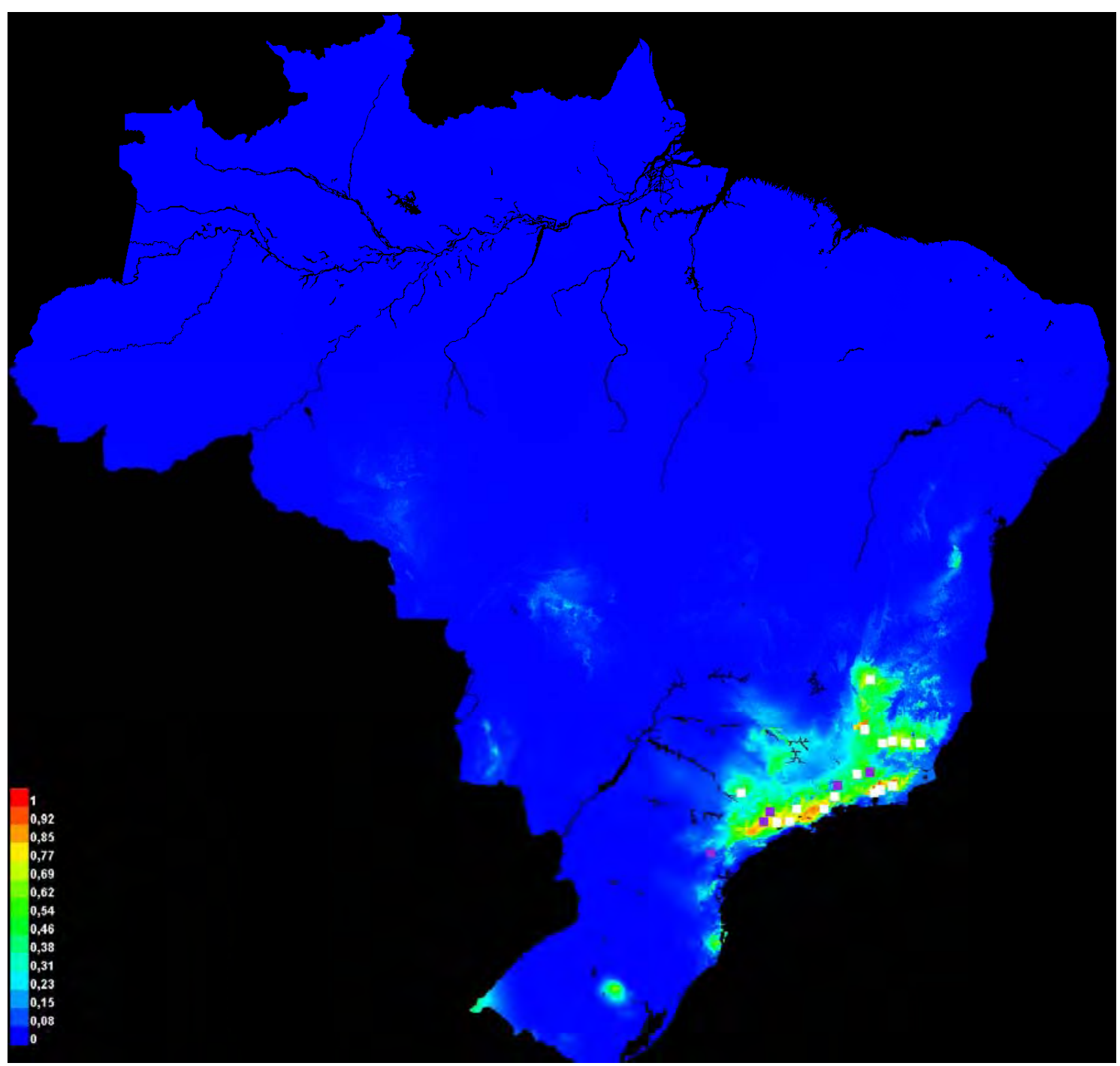

Figura 4. Croton salutaris. Modelo gerado pelo Maxent. Cores mais quentes (vemelho) maior probabilidade de encontrar a espécie. ( $\square$ pontos de ocorrência de teste; $\square$ pontos de ocorrência de treino) 


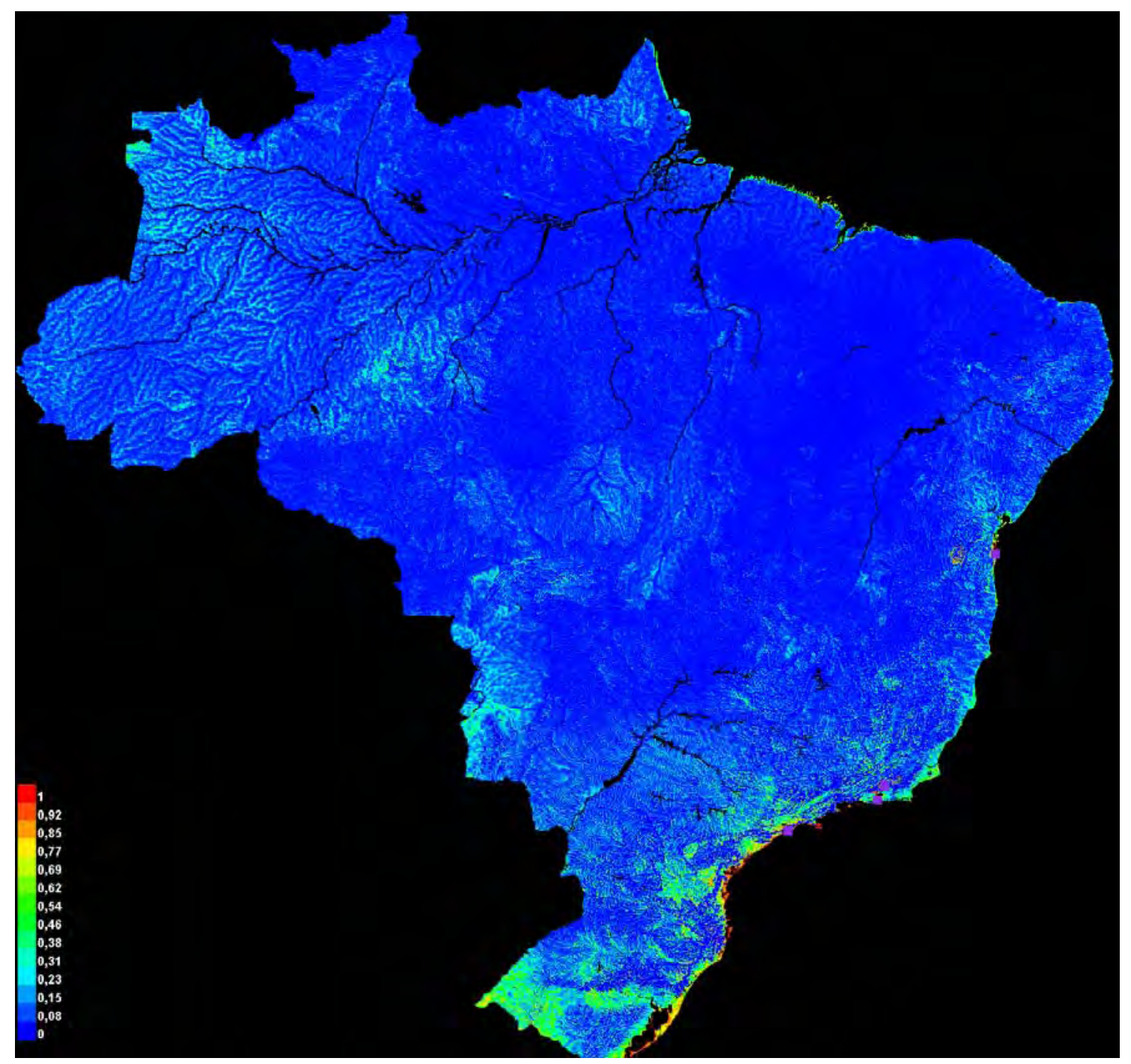

Figura 5. Croton sphaerogynus. Modelo gerado pelo Maxent. Cores mais quentes (vermelho) maior probabilidade de encontrar a espécie. ( $\square$ pontos de ocorrência de teste; $\square$ pontos de ocorrência de treino) 


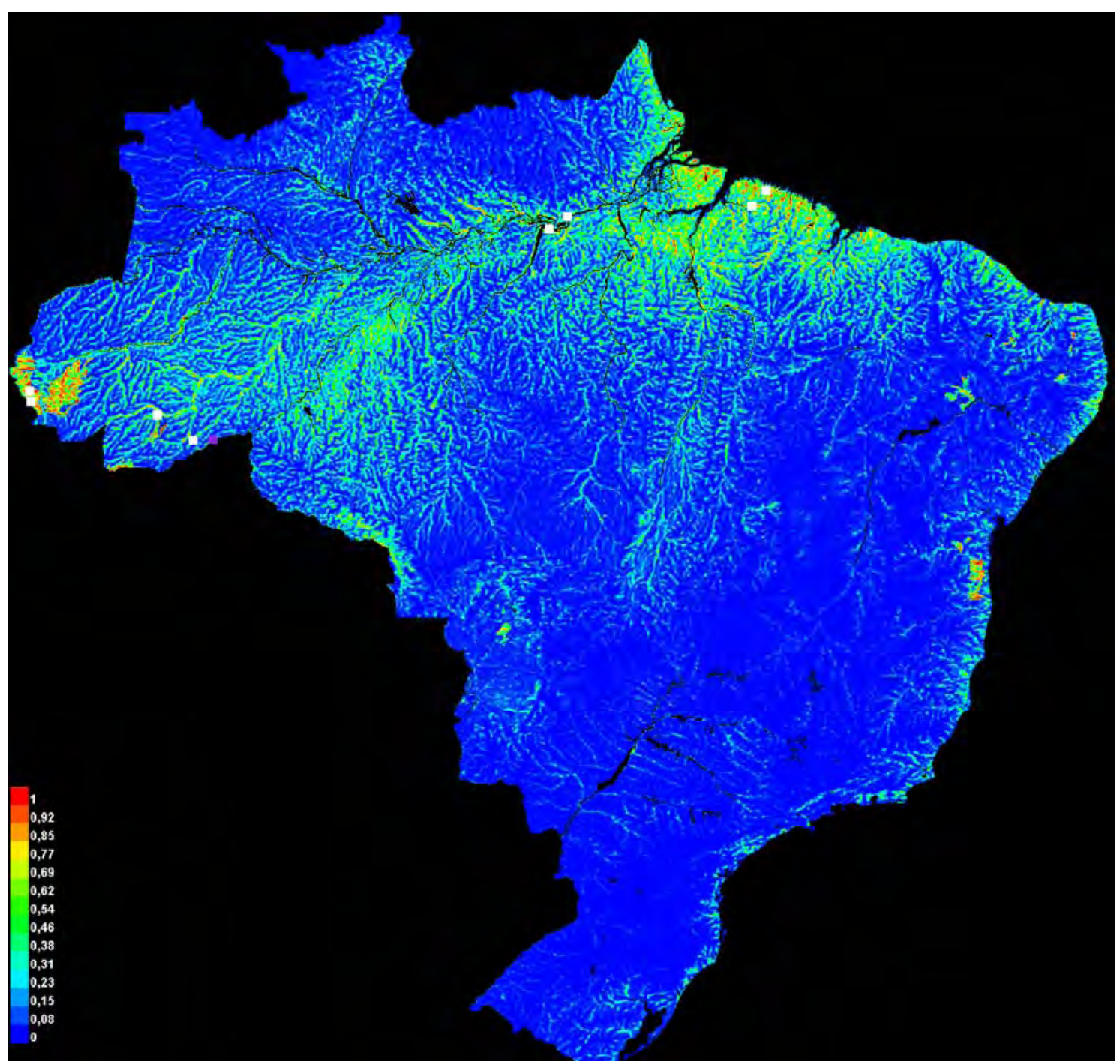

Figura 6. Croton spruceanus. Modelo gerado pelo Maxent. Cores mais quentes (vermelho) maior probabilidade de encontrar a espécie. ( $\square$ pontos de ocorrência de teste; $\square$ pontos de ocorrência de treino) 
ANEXOS 
ANEXo 1 


\title{
Croton campanulatus (Euphorbiaceae s.s.), a new species from the Brazilian Atlantic rain forest
}

\author{
Maria Beatriz Rossi Caruzo ${ }^{1,3}$, Ricarda Rina ${ }^{2}$, Inês Cordeiro ${ }^{3}$, And \\ PAul E. Berry ${ }^{2}$ \\ ${ }^{1}$ Departamento de Botânica, Instituto de Biociências, Universidade de São Paulo, Cx. Postal \\ 11461, 05422-970, São Paulo, São Paulo, Brazil; e-mail: mbrcaruzo@hotmail.com \\ ${ }^{2}$ University of Michigan Herbarium, 3600 Varsity Drive, Ann Arbor, MI 48109-2287, USA \\ ${ }^{3}$ Instituto de Botânica, Secretaria do Meio Ambiente, Cx. Postal 3005, 01061-970, São Paulo, \\ São Paulo, Brazil
}

\begin{abstract}
Croton campanulatus, a new species from southeastern Brazil in the states of Minas Gerais and Rio de Janeiro, is here described and illustrated. Morphological data indicate that this species belongs to Croton section Cleodora based on its arborescent habit, pistillate flowers with imbricate sepals, reduced petals, and multifid styles that are fused at the base.
\end{abstract}

Key Words: Atlantic rain forest, Brazil, Croton, Croton section Cleodora, Euphorbiaceae.

Croton L. is the second largest genus in the family Euphorbiaceae, with an estimated 1223 species (Govaerts et al., 2000). The genus occurs mostly in tropical regions worldwide, but also has some representatives in subtropical and northern temperate areas. In the Neotropics, its centers of diversity are Brazil, the West Indies, and Mexico (Burger \& Huft, 1995). In Brazil, Croton is represented by around 300 species, including herbs, shrubs, and trees occupying all types of vegetation, but with the greatest number of species concentrated in the eastern part of the country.

Croton campanulatus, a new species of Croton sect. Cleodora (Klotzsch) Baill., is known from the Brazilian states of Minas Gerais and Rio de Janeiro, where it grows in montane areas of Serra da Mantiqueira, in Atlantic rain forest.

Croton campanulatus Caruzo \& Cordeiro, sp. nov. Type: Brazil. Rio de Janeiro: Município de Itatiaia, Parque Estadual do Itatiaia, estrada para a piscina do Maromba, ao longo da estrada, $950 \mathrm{~m}, 22^{\circ} 26^{\prime} 10^{\prime \prime} \mathrm{S}$, 443' 49.4"W, mata atlântica, 6 Feb 2006, M. B. R. Caruzo, R. Riina \& N. Camps 93 (holotype: SP; isotypes: K, NY, WIS).

(Fig. 1)

Crotoni hemiaryreo Müll. Arg. affinis sed indumento rufo-argenteo, foliis ad margines integeris, stipulis caducis, bracteis ovato-lanceolatis, staminibus circa 25 , floribus femineis majoribus, stylis inclusis differt.

Tree 4-5 m tall, monoecious, indument rufous-silvery, lepidote trichomes without a central ray, those pale, reddish or sometimes with a reddish center and a pale margin, 0.3$0.5 \mathrm{~mm}$; branchlets cylindric, strongly striate, rufous-silvery, covered by reddish and scattered pale trichomes. Leaves alternate; lamina $3.5-17.5 \times 1.5-9.5 \mathrm{~cm}$, ovate, discolorous, upper surface green with scattered pale trichomes and lower surface silvery with scattered reddish trichomes or trichomes with a reddish center and a pale margin, apex acuminate, base rounded to truncate, margin entire, upper surface lepidote, lower surface densely lepidote, venation pinnate, brochidodromous, secondary veins 4-6, abruptly upturned towards the next ones, tertiary veins percurrent; petiole $1.5-9 \mathrm{~cm}$ long, with a pair of stalked acropetiolar glands; stipules decid- 


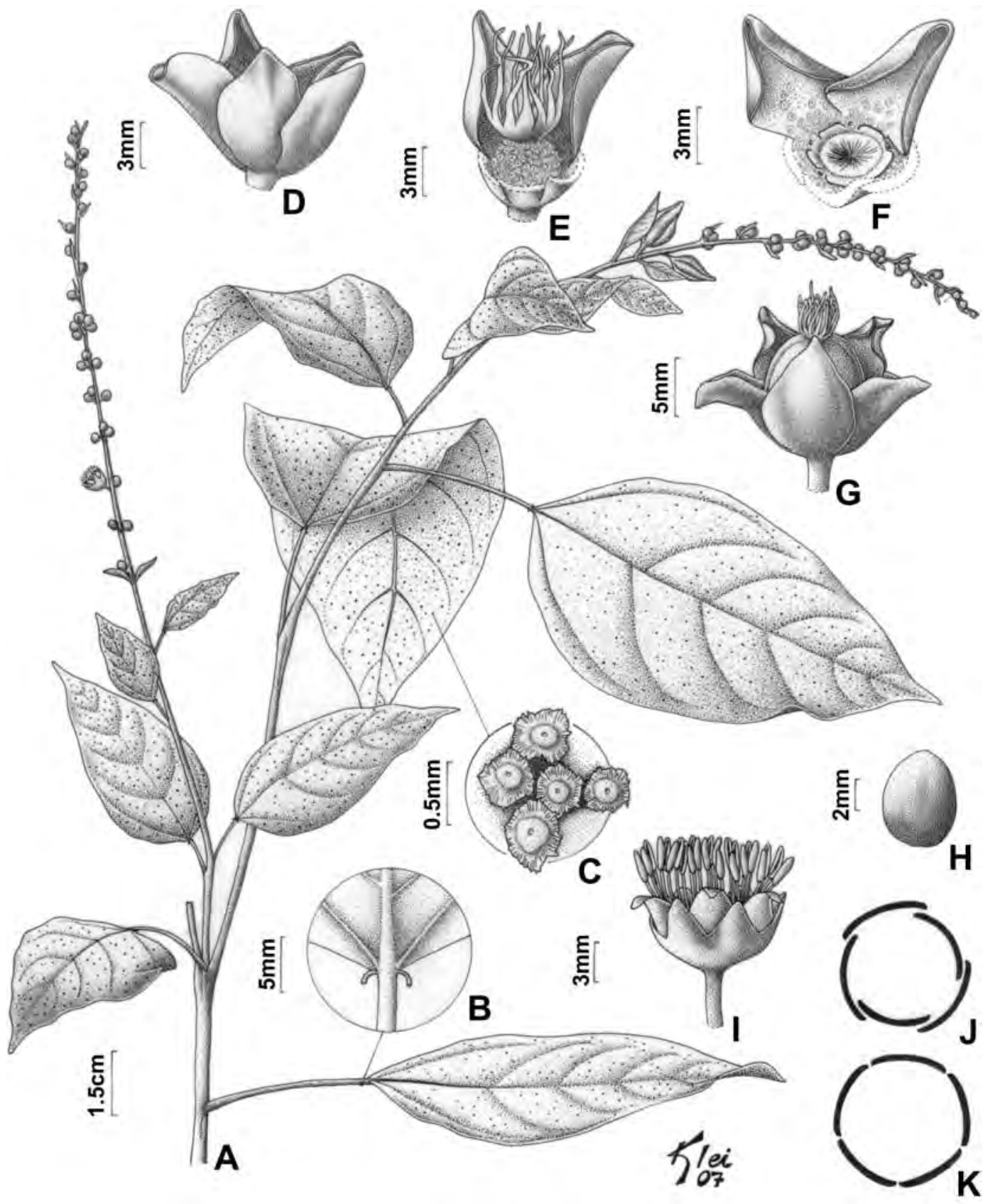

Fig. 1. Croton campanulatus. A. Branch with inflorescences. B. Detail of stalked acropetiolar glands. C. Lepidote trichomes. D. Pistillate flower. E. Gynoecium. F. Detail of pistillate flower disk. G. Fruit. H. Seed. I. Staminate flower. J. Pistillate flower aestivation. K. Staminate flower aestivation. (Drawn from the holotype.)

uous. Inflorescence 4-12 cm long, terminal, without interruption between the pistillate and staminate cymules; inflorescence axis appressed, striate, lepidote; proximal cymules bisexual, with 1 pistillate flower and 2 staminate flowers, distal cymules with 3 staminate flowers; bracts 4-9 mm long, ovate-lanceolate, prophylls 1-2 mm long, lanceolate. Staminate 
flowers 8-10 mm long, campanulate, pedicels 2-3 mm long; calyx 3-4 mm long, lepidote externally, rufous-silvery, covered by reddish and scattered pale trichomes, glabrate internally; calyx lobes united half of their length, 1.5$2 \mathrm{~mm}$ long, entire, equal, valvate, ovate, apex acute; petals $5 \mathrm{~mm}$ long, spathulate, apex obtuse to rounded, lepidote externally; disk 5-segmented; stamens ca. 25, filaments subulate; receptacle villous with simple trichomes. Pistillate flowers $8-10 \mathrm{~mm}$ long, campanulate, not fleshy, sessile to short pedicellate; calyx 7-9 mm long, lepidote externally, rufous-silvery, covered by reddish and scattered pale trichomes, glabrate internally; sepals 5, 7-9 $\mathrm{mm}$ long, equal, quincuncial, broadly ovate, not fleshy; petals reduced to glands; disk entire, deeply 5-lobed; ovary globose, lepidote; styles 3, tetrafid, slightly joined at the base, inserted. Capsules 10$15 \mathrm{~mm}$ long, globose, lepidote, calyx strongly accrescent and inflated, covering the young fruit, pedicel slightly accrescent; seeds 6-8 mm long, globose-elliptic, smooth.

Distribution and habitat.-Brazil, in Minas Gerais and Rio de Janeiro states (Fig. 2). Croton campanulatus is found along streams and roadsides in montane rain forests of the Mata Atlântica region, between 900 and $1500 \mathrm{~m}$ elevation. The species grows in sympatry with other arborescent species of Croton, namely Croton organensis Baill. (another member of sect. Cleodora) and $C$. vulnerarius Baill. (sect. Cyclostigma Griseb.).

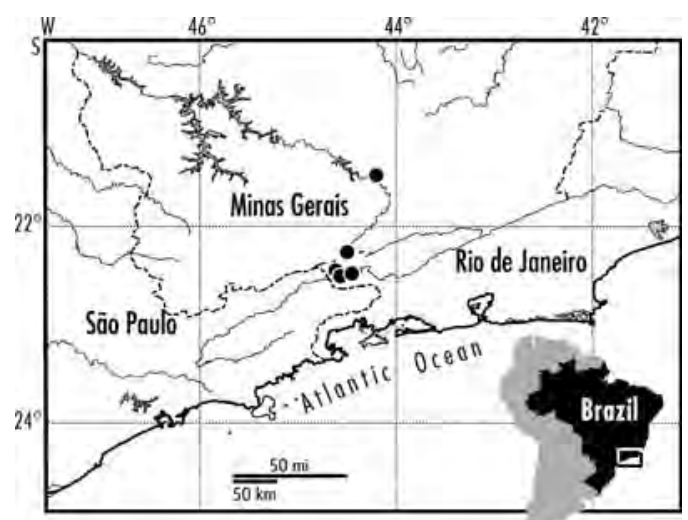

FIG. 2. Geographical distribution of Croton campanulatus.
Etymology.-The specific epithet of this new species refers to its campanulate calyx, present in both staminate and pistillate flowers.

Additional specimens examined. BRAZIL. MinAS GeraIs: Bocaina de Minas, distrito de Mirantão, margem esquerda do rio Preto, fazenda Mauá, ca. de 1500 m, 9 Jan 1988, Pineschi 348 (GUA); Piedade do Rio Grande, córrego das águas limpas, 17 Nov 1990, Souza s.n. (R). RIO DE JANEIRO: Itatiaia, 30 May 1935, A.C. Brade 14650 (RB, MG); Itatiaia, Parque Estadual do Itatiaia, entre a piscina do Maromba e a ponte do Maromba, às margens do rio Campo Belo, $1100 \mathrm{~m}$, Mata Atlântica, 6 Feb 2006, Caruzo et al. 94 (SP, SPF, WIS); Itatiaia, Hotel Donati, 20 Apr 1962, Castellanos 23418 (GUA); Parque Nacional de Itatiaia, 5 Mar 1948, Cunha Mello s.n. (RB); Itatiaia, Parque Nacional de Itatiaia, Três Picos, 1200 m, 27 Mar 1948, Cunha Mello s.n. (RB); Itatiaia, 8 Jan 1947, Duarte \& Pereira s.n. (MG, RB); Serra da Mantiqueira, Itatiaia, National Park, N of Itatiaia, roads to and environments of Maromba falls, 900 m, 5 Sep 1973, Ehrendorfer \& Gottsberger 73905-22.40 (DAV); Rezende, Parque Nacional de Itatiaia, perto do Museu e do abrigo $\mathrm{n}^{\circ}$ 21, 18 Oct 1977, Ferreira \& Briolanjo 157 (RB, SP); Itatiaia, 20 Jan 1873, Glaziou 6679 (P); Itatiaia, Parque Nacional de Itatiaia, Ponte do Maromba, 11 Aug 1997, de Lima 399 (RB); Itatiaia, P. Nacional, 950 m, 4 Mar 1962, Pereira 6974 (MBM, HB); Itatiaia, Parque Nacional de Itatiaia, Trilha do Hotel Simon para os três picos, $1200 \mathrm{~m}$, $22^{\circ} 15^{\prime}-22^{\circ} 28^{\prime} \mathrm{S}$ e $44^{\circ} 34^{\prime}-44^{\circ} 45^{\prime} \mathrm{W}, 18$ May 1999 , Quinet 201 (RB); Itatiaia, Hotel Donati, 21 Apr 1962, Strang 411 (GUA, DAV); Itatiaia, Hotel Donati, Sep 1964, Strang s.n. (GUA, DAV); Itatiaia, Parque Nacional de Itatiaia, Trilha do Hotel Simon para os três picos, 9 Nov 1997, Sylvestre et al. 918 (RB).

Following the sectional synopsis of Croton by Webster (1993), the new species fits the morphological definition of Croton section Cleodora (Klotzsch) Baill. by virtue of its arborescent habit, pistillate flowers with imbricate sepals, reduced petals, and multifid styles. In addition to these characters indicated by Webster (1993), members of section Cleodora have the styles fused at the base, as in Croton campanulatus, or fused almost half of their length in some other species.

Among the other species of section Cleodora, Croton campanulatus is morphologically most similar to $C$. hemiargyreus Müll. Arg., a species with an apparently disjunct distribution, from dry forests in southeastern Brazil (São Paulo, Minas Gerais and Rio de Janeiro) and from the state of Pernambuco in northeastern Brazil. Croton campanulatus differs from $C$. hemiargyreus in several features as indicated in Table I. In addition, several herbarium collections of Croton cam- 
TABLE I

Main Characters distinguishing CRoton Campanulatus From C. hemiargyreus and C. Salutaris.

\begin{tabular}{|c|c|c|c|}
\hline Character & C. campanulatus & C. hemiargyreus & C. salutaris \\
\hline Indument & rufous-silvery & silvery & silvery \\
\hline Trichomes & $\begin{array}{c}\text { lepidote without } \\
\text { a central ray }\end{array}$ & $\begin{array}{c}\text { lepidote without } \\
\text { a central ray }\end{array}$ & $\begin{array}{l}\text { lepidote-porrect } \\
\text { (with a central ray) }\end{array}$ \\
\hline Leaf margin & entire & finely serrate & entire \\
\hline Stamen number & ca. 25 & ca. 15 & ca. 15 \\
\hline Pistillate flower attachment & sessile to short pedicellate & short pedicellate & pedicellate \\
\hline Pistillate flower length & $8-10 \mathrm{~mm}$ & $5-6 \mathrm{~mm}$ & $7-8 \mathrm{~mm}$ \\
\hline Pistillate flower shape & campanulate & campanulate & flask-shaped \\
\hline Pistillate calyx length & $7-9 \mathrm{~mm}$ & $3-4 \mathrm{~mm}$ & $3-4 \mathrm{~mm}$ \\
\hline Pistillate calyx lobes & not fleshy & fleshy & fleshy \\
\hline Pistillate sepals in fruit & strongly accrescent, inflated & strongly accrescent, not inflated & $\begin{array}{c}\text { neither accrescent } \\
\text { nor inflated }\end{array}$ \\
\hline Styles & included & exserted & exserted \\
\hline Habitat & montane rain forest & dry forest & montane rain forest \\
\hline
\end{tabular}

panulatus have been erroneously identified as Croton salutaris Casar. (another member of sect. Cleodora), but the two species can easily be separated by several floral and vegetative characters (Table I).

Molecular data based on the ITS and the chloroplast $\operatorname{trn} L-F$ regions, individually and in combination, give results consistent with morphology and indicate that Croton campanulatus belongs to sect. Cleodora (Caruzo et al., in prep).

\section{Acknowledgments}

Thanks are due to Klei Rodrigo Souza for the illustrations, Kandis Elliot for the map and formatting of the illustration, Mário Gurgel Filho for revising the Latin description, Hajo Esser for reviewing the manuscript, and the CNPq for the fellowship awarded to the first author. Financial support for a field trip to Brazil was provided to the second author by The Lawrence Memorial Award from the Hunt Institute for Botanical Documentation, the William R. Anderson Graduate Student Research Grant Fund from the American Society of Plant Taxonomists (ASPT), and the U.S. National Science Foundation (award \# DEB-0212481 to P. Berry).

\section{Literature Cited}

Burger, W. \& M. Huft. 1995. Flora costaricensis: Euphorbiaceae. Fieldiana Botany 36: 1-169.

Govaerts, R., D. G. Frodin \& A. Radcliffe-Smith. 2000. World checklist and bibliography of Euphorbiaceae (and Pandaceae). 4 vols. Royal Botanic Gardens, Kew, England.

Webster, G. L. 1993. A provisional synopsis of the sections of the genus Croton L. (Euphorbiaceae). Taxon 42: 793-823. 
ANEXo 2 
NOVON Ms 2008111

Croton rufolepidotus (Euphorbiaceae s.s.), a new species from the northern Colombia

Maria Beatriz Rossi Caruzo ${ }^{1,3}$, Ricarda Riina ${ }^{2}$, Inês Cordeiro ${ }^{3}$ and Paul E. Berry ${ }^{2}$

${ }^{1}$ Departamento de Botânica, Instituto de Biociências, Universidade de São Paulo, Cx.

Postal 11461, 05422-970, São Paulo, SP, Brazil; email: mbrcaruzo@hotmail.com

${ }^{2}$ University of Michigan Herbarium and Department of Ecology and Evolutionary

Biology, 3600 Varsity Drive, Ann Arbor, MI 48109-2228, USA

${ }^{3}$ Instituto de Botânica, Secretaria do Meio Ambiente, Cx. Postal 3005, 01061-970, São

Paulo, SP, Brazil 
ABSTRACT. Croton rufolepidotus Caruzo \& Riina (Euphorbiaceae s.s.), a new species from Colombia, is here described and illustrated. The new species is endemic to an area of lowland secondary forests in Antioquia. Morphological characters indicate that this species belongs to Croton section Cleodora (Klotzsch) Baill., due to its arborescent habit, petiolar glands, 15 to 25 stamens, as well as the pistillate flowers with imbricate sepals and multifid styles.

Key Words: Colombia, Croton rufolepidotus, Croton section Cleodora, Euphorbiaceae, IUCN Red List.

Croton L. is a pantropical genus with an estimated 1223 species in the Euphorbiaceae family (Govaerts et al., 2000). Although the genus occurs mostly in tropical regions worldwide, it also has some representatives in subtropical and northern temperate areas. In the Neotropics, its centers of diversity are Brazil, the West Indies, and Mexico (Burger \& Huft, 1995). In Colombia, there are 80 species of Croton (Murillo, 2004), including herbs, shrubs, and trees occurring in all kind of habitats, with the greatest number of species concentrated in the Andean region of the country (Murillo, 1999). As a result of ongoing systematic studies on Croton sect. Cleodora by the senior author, new species have been described (Caruzo et al. 2008, Caruzo et al. in press). In this paper we describe Croton rufolepidotus Caruzo \& Riina, a new species of Croton sect. Cleodora (Klotzsch) Baill., which is known from the department of Antioquia in Colombia, where it grows in lowland secondary forests.

Croton rufolepidotus Caruzo \& Riina, sp. nov. TYPE: Colombia. Antioquia. Tarazá, Corr. El 12, camino El 12-Barroblanco, km 4 NO Medellín, 210 km en troncal 
del Caribe, bht/bmht, 7³0’N, 75¹6’W, 25 July 1987, R. Callejas, J. Betancur \& F.J. Roldán 3611 (holotype, MO; isotypes, DAV, HUA). Fig. 1.

Crotoni salutaris Casar. affinis sed ramulis cylindricis, stipulis auriculatis, bracteis linearis, staminibus 15--25, floribus femineis majoribus, lobis calycis foliaceis, stylis multifidis differt.

Tree 6--10 m tall, monoecious, indument rufous-silvery, lepidote trichomes without a central ray, trichomes pale, reddish or sometimes with a reddish center and a pale margin; branchlets terete, rufous-silvery, covered by reddish and scattered pale trichomes. Leaves alternate; lamina 3--11.5 x 1--4.5 cm, narrowly ovate to ovateelliptic, discolorous, apex narrowly acute to acuminate, base rounded to slightly cordate, margin entire, upper surface glabrous, lower surface densely lepidote, covered by pale trichomes and scattered reddish trichomes or trichomes with a reddish center and a pale margin, venation pinnate, brochidodromous, secondary veins 5 to 11, abruptly upturned towards the next ones, tertiary veins inconspicuous; petiole $0.5--1.5 \mathrm{~cm}$, with a pair of stalked basilaminar glands ca. 1 mm diam., stalks 1--1.5 mm; stipules 0.5--1.5 cm, auriculate, apex caudate, deciduous. Inflorescence 2.5--6.5 cm, terminal; inflorescence axis terete, striate, lepidote; proximal cymules female, with a single pistillate flower, distal cymules male, with 1 or 2 staminate flowers, bracts 3--5 mm, linear, prophylls inconspicuous. Staminate flowers ca. $1 \mathrm{~cm}$, campanulate, pedicels ca. $6 \mathrm{~mm}$; calyx ca. 4 mm, lepidote externally, rufous-silvery, covered by reddish and scattered pale trichomes, glabrate internally; calyx lobes 5, united up to half of their length, ca. $2 \mathrm{~mm}$, entire, equal, valvate, triangular, apex acute; petals ca. $4 \mathrm{~mm}$, spathulate, densely villous externally, apex with an uneven margin; disk 5-segmented; stamens 15 to 25, filaments subulate; receptacle villose with simple trichomes. Pistillate flowers 1--1.4 cm, flask- 
shaped; pedicel 4--6 mm; calyx 6--8 mm, lepidote externally, rufous-silvery, covered by reddish and scattered pale trichomes, glabrate internally; calyx lobes 5, united at the base, 6 -- $8 \mathrm{~mm}$, equal, quincuncial, ovate-lanceolate, foliaceous, not fleshy; petals absent; disk entire, slightly 5-lobed; ovary subglobose, lepidote; styles 3, connate into a short column at the base, then branching into 24 terminal arms about 1/3 to 1/2 stylar length. Capsules ca. 1.5 cm long, subglobose, 3-angled, lepidote, sepals slightly accrescent; seeds not seen.

Habitat and Distribution: Croton rufolepidotus is endemic to Antioquia, Colombia, where it grows in lowland secondary forests, between 180 and 310 m elevation. According to R. Callejas (pers. comm.), much of the area where this species has been collected has since been deforested for coca (Erythroxylum coca L. and E. novogranatense (D. Morris) Hieron.) plantations.

IUCN Red List category: Following the IUCN red list criteria (IUCN, 2001) Croton rufolepidotus can be considered as Critically Endangered (CR B1ab) due to its restrict distribution (known in only one location) and continuing decline of the area and quality of habitat where the species occurs.

Etymology. The specific epithet of this new species is taken from the Latin and refers to the rufous color of its lepidote indument.

Relationships. Following the sectional synopsis of Croton by Webster (1993), and based on current revisionary work and phylogenetic studies on Croton section Cleodora by the first author, the new species clearly belongs to this Neotropical section. The suite of 
characters shared by members of section Cleodora are the arborescent habit, the petiolar glands in an abaxial or lateral position, 15 to 25 stamens, quincuncial or imbricate, usually accrescent, and sometimes fused pistillate sepals, and quadrifid (12 terminal tips) or multifid (more than 12 terminal tips) styles fused at base or more of their length, usually forming a crown.

Among the other species within section Cleodora, this new species is morphologically similar to Croton salutaris Casar., from southeastern Brazil (São Paulo, Minas Gerais, Rio de Janeiro and Espírito Santo), in the Atlantic rain forest, but it differs from C. rufolepidotus in several features as indicated in Table 1. The vegetative features that easily distinguish $C$. salutaris from $C$. rufolepidotus are the stipule shape (linear-lanceolate in C. salutaris vs. auriculate in C. rufolepidotus) and the morphology of branchlets (angular in C. salutaris vs. terete in C. rufolepidotus).

Paratypes. COLOMBIA. Antioquia: Tarazá, Corr. El Doce, 210 km NNE of Medellín, carr. El Doce-Barro Blanco, near entrance to Hac. Las Mercedes, rd. outside of finca, $7^{\circ} 30^{\prime} \mathrm{N}, 7^{\circ} 16^{\prime}$ W, 25 July 1987, W.W. Thomas \& C.J. Castaño C. 5525 (COL, HUA, JAUM, MO, NY); Tarazá, Corr. El 12, Vía El 12-Doce-Barroblanco, Hac. las Mercedes, potrero San Juan, bht/bhmt, $7^{\circ} 30^{\prime}$ N, $75^{\circ} 20^{\prime}$ W, 7 Nov. 1987, R. Callejas, F.J. Roldán, A.L. Arbeláez \& D.L. Echeverry 5425 (F, HUA).

Acknowledgments. Thanks are due to Klei Rodrigo Souza for the illustrations and to CNPq (Brazil) for the fellowship awarded to the first author. We are also grateful to the herbaria COL, DAV, F, HUA, AUM, MEDEL, MO, and NY for providing access to their collections. We thank Gordon McPherson and one anonymous reviewer for their comments and corrections. 
Literature cited

Burger, W. \& M. Huft. 1995. Flora costaricensis: Euphorbiaceae. Fieldiana Botany 36: 1-169.

Caruzo, M.B.R., R. Riina I. Cordeiro \& P.E. Berry. 2008. Croton campanulatus (Euphorbiaceae s.s.), a new species from the Brazilian Atlantic rain forest. Brittonia 60(3): 261--264.

Caruzo, M.B.R., I. Cordeiro, P.E. Berry \& R. Riina. In press. A new species of Croton section Cleodora (Euphorbiaceae s.s.) from Minas Gerais, Brazil. Phytotaxa. XX: XX-$\mathrm{XX}$.

Govaerts, R., D.G. Frodin \& A. Radcliffe-Smith. 2000. World checklist and bibliography of Euphorbiaceae (and Pandaceae). 4 vols. Royal Botanic Gardens, Kew, England.

IUCN 2001. IUCN Red List Categories and Criteria, Version 3.1. Prepared by the IUCN Species Survival Commission. IUCN. Gland, Switzerland, and Cambridge, United Kingdom.

Murillo, J. 1999. Composición y distribución del género Croton (Euphorbiaceae) en Colombia, con cuatro especies nuevas. Caldasia 21(2): 14--166.

Murillo J. 2004. Las Euphorbiaceae de Colombia. Biota Colombiana 5(2): 183--200.

Webster, G.L. 1993. A provisional synopsis of the sections of the genus Croton L. (Euphorbiaceae). Taxon 42: 79--823. 
Figure 1. Croton rufolepidotus. A. Branch with flowers and fruits. B. Pistillate flower. C. Detail of the gynoecium. D. Fruit. E. Male flower. F. Petal of the male flower. G. Pistillate flower aestivation. H. Staminate flower aestivation. Drawn from the MO holotype Callejas et al. 3611. 


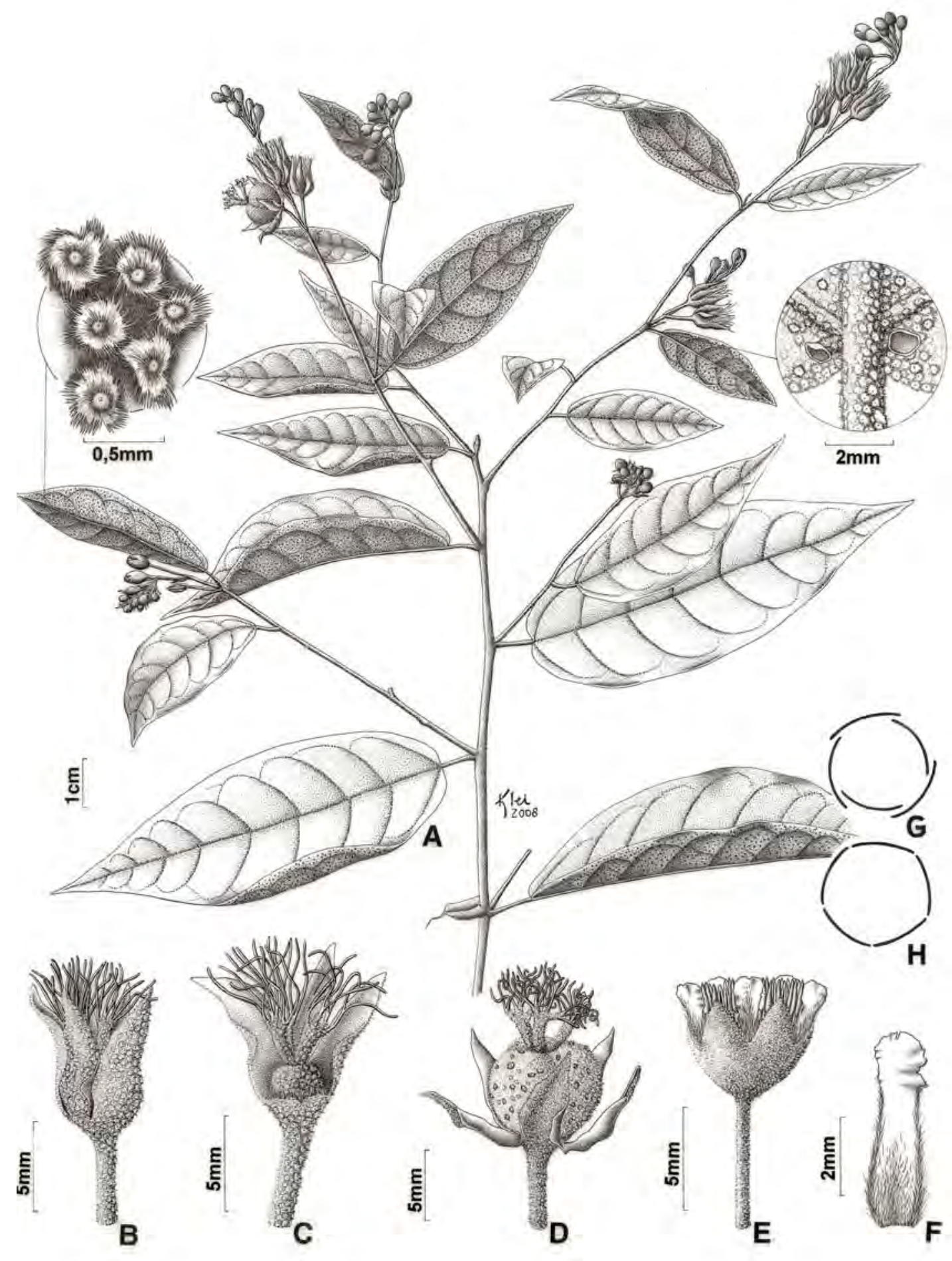

FIGURE 1 
ANEXo 3 
A new species of Croton section Cleodora (Euphorbiaceae s.s.) from Minas Gerais, Brazil

MARIA BEATRIZ ROSSI CARUZO ${ }^{1,2}$, INÊS CORDEIRO ${ }^{2}$, PAUL E. BERRY ${ }^{3} \&$ RICARDA RIINA 3,4

${ }^{1}$ Departamento de Botânica, Instituto de Biociências, Universidade de São Paulo, Cx. Postal 11461, 05422-970, São Paulo, SP, Brazil; email: mbrcaruzo@hotmail.com ${ }^{2}$ Instituto de Botânica, Secretaria do Meio Ambiente, Cx. Postal 3005, 01061-970, São Paulo, SP, Brazil

${ }^{3}$ University of Michigan Herbarium, 3600 Varsity Drive, Ann Arbor, MI 48109-2228, USA

${ }^{4}$ Real Jardín Botánico, CSIC, Plaza Murillo 2, Madrid 28014, Spain 


\begin{abstract}
Croton stellatoferrugineus, a new species from Brazil, is here described and illustrated. This new species is endemic to dry forests at the base of "Pico do Itambé", the highest point of the Espinhaço range, in Minas Gerais State, occurring between 700—900 m elevation. Croton stellatoferrugineus presents morphological features consistent with its inclusion in Croton section Cleodora, due to its shrubby habit, petiolar basilaminar glands, 15 stamens, pistillate flowers with quincuncial aestivation, and multifid styles connate at the base.
\end{abstract}

\title{
Resumo
}

Croton stellatoferrugineus, uma nova espécie do Brasil, é aqui descrita e ilustrada. Esta nova espécie é endêmica das florestas secas na base do "Pico do Itambé”, o ponto mais alto da cadeia do Espinhaço, no Estado de Minas Gerais, ocorrendo entre 700—900 m de altitude. Croton stellatoferrugineus possui características morfológicas que permitem incluí-lo em Croton seção Cleodora, tais sejam seu habito arbustivo, glândulas do pecíolo basilaminares, 15 estames, flores pistiladas de prefloração quincuncial e estiletes multífidos conados na base.

Key Words: Croton stellatoferrugineus, Croton section Cleodora, Espinhaço Range, Minas Gerais, Brazil 


\section{Introduction}

Croton L. is ranked as the $11^{\text {th }}$ biggest flowering plant genus according to Frodin (2004), with an estimated 1223 species (Govaerts et al., 2000). The genus occurs mostly in tropical regions worldwide, but also with some representatives in subtropical and northern temperate areas, and most of its species are important elements of secondary vegetation, which make many species used to reforestation of degraded forests. Its main centers of diversity in the Neotropics are Brazil, West Indies, and Mexico (Burger \& Huft, 1995). Even with a large number of species already known for the genus, many species have been described for the Neotropical region in the last decade (Secco et al. 2001; Gordillo \& Luna 2005; Secco et al. 2005; Smith 2006; Riina et al. 2007; Caruzo et al. 2008; Cordeiro et al. 2008; Lima \& Pirani 2008; Secco 2008; van Ee \& Berry 2009; Secco 2009; Caruzo et al. in press; Carneiro-Torres et al. in press). Brazil has approximately 350 species of Croton, including herbs, shrubs, and trees occupying all kind of habitats, with the greatest number of species concentrated in the eastern part of the country. Croton stellatoferrugineus Caruzo \& Cordeiro, a new species of Croton sect. Cleodora (Klotzsch) Baill., is known only from the "Pico do Itambé”, the highest point of the Espinhaço range, in central Minas Gerais state, southeastern Brazil, where it grows in dry forests.

\section{Taxonomic treatment}

Croton stellatoferrugineus Caruzo \& Cordeiro, sp. nov. (Figs. 1A-E, 2A-H)

Crotoni sphaerogynus Baill. affinis sed indumento ferrugineo, bracteis foliaceis, floribus femineis campanulatis, stylis multifidis ca. 24-partitis differt. Type: — BRAZIL: Minas Gerais: Santo Antônio do Itambé, estrada para as cachoeiras e para a ponte de pedra, próximo à ponte, $18^{\circ} 27^{\prime} 16,2^{\prime \prime}$ 'S e $43^{\circ} 18$ '29,4’’ W, 
750 m, fl., fr., 25 Jun 2008, M.B.R. Caruzo, L.R. Lima, S.E. Martins \& A.L. Santos 120 (holotype SP, isotypes K, MICH, MO, NY, SPF).

Shrub 1-3 m tall, monoecious, indument ferrugineous; branchlets terete, ferrugineous, covered by stellate and multiradiate trichomes. Leaves alternate; lamina 3-11.5 x 1-4.5 cm, narrowly ovate to ovate-elliptic, slightly discolorous, apex narrowly acute, base slightly cordate, margin entire, upper surface pubescent, ferrugineous, covered by stellate trichomes, usually with a long central erect ray, lower surface densely pubescent, ferrugineous, covered by multiradiate trichomes, venation pinnate, brochidodromous, secondary veins abruptly upturned towards the next ones, tertiary veins sinuous; petiole $0.5-2 \mathrm{~cm}$ long, with a pair of sessile basilaminar chestnut-brown glands; stipules ca. $5 \mathrm{~mm}$ long, linear. Inflorescence 5-20 cm long, terminal; inflorescence axis flat, striate, pubescent; proximal cymules female, with a single pistillate flower, distal cymules male, with $1-2$ staminate flowers, bracts $0.4-1$ cm long, foliaceous, prophylls $1-3 \mathrm{~mm}$ long, linear. Staminate flowers $5 \mathrm{~mm}$ long, campanulate, pedicels $2 \mathrm{~mm}$ long; calyx $2 \mathrm{~mm}$ long, pubescent externally, ferrugineous, covered by stellate and multiradiate trichomes, glabrate internally; sepals 5 , united up to half their length, then free for $1 \mathrm{~mm}$, entire, equal, valvate, ovate, apex acute; petals 5, 2 mm long, ovate to ovate-lanceolate, apex acute to rounded, reflexed; disk 5-segmented; stamens 15, filaments subulate, glabrate; receptacle villose with simple trichomes. Pistillate flowers $5 \mathrm{~mm}$ long, campanulate, sessile; calyx $4 \mathrm{~mm}$ long, pubescent externally, ferrugineous, covered by stellate and multiradiate trichomes, glabrate internally; sepals 5, united up to half of their length, then free for the terminal $3 \mathrm{~mm}$, equal, quincuncial, ovate-lanceolate, slightly fleshy, ferrugineous, pale trichomes extending up to the central part of the sepals, margins villose; petals absent; disk 5segmented; ovary globose, pubescent; styles 3, connate into a short column at the base, 
then branching into 24-30 terminal arms about 1/3 the way up the style. Capsules $0.7-1 \mathrm{~cm}$ long, globose, pubescent, calyx slightly accrescent, not inflated; seeds $4-5$ mm long, subglobose, smooth; caruncle small, reniform.

Distribution and habitat: - So far only known from the "Pico do Itambé”, in the Espinhaço range, Minas Gerais state, southeastern Brazil, where it grows in seasonally dry forests, between 700—900 m elevation.

Etymology: - The specific epithet refers to the rusty color of its stellate indument.

The species can be recognized in the field by its densely ferrugineous indumentum and the foliaceous bracts with glands similar to those found at the base of the leaves.

From the results of an ongoing taxonomic revision of section Cleodora by the senior author, Croton stellatoferrugineus clearly belongs to that section. The features shared by members of section Cleodora are the arborescent or shrubby habit, presence of basilaminar or acropetiolar glands, stamens between $15-25$, pistillate sepals imbricate, usually accrescent, and sometimes fused at the base or up to half of their length, and quadrifid or multifid styles fused at the base or higher up. This new species has a shrubby habit, basilaminar glands (fig. 2A), 15 stamens, imbricate sepals united up to half of their length (fig. 1C, 2C), and multifid styles fused at the base (fig. 1D), all features indicating that $C$. stellatoferrugineus belongs to section Cleodora.

Croton stellatoferrugineus is morphologically most similar to Croton sphaerogynus Baill. (1864), a species from “restinga” forests of Brazil (São Paulo, Rio de Janeiro, Espírito Santo and Bahia), but it differs from it in several features as indicated in Table 1. The main features that easily distinguish C. sphaerogynus from $C$. stellatoferrugineus are the indumentum color (whitish with some sparse points slightly 
ferrugineous in C. sphaerogynus vs. strongly ferrugineous in C. stellatoferrugineus; see Figs. 2 and 3), type of trichomes (adpressed stellate in C. sphaerogynus vs. stellate or multiradiate in C. stellatoferrugineus), bracts (foliaceous in C. stellatoferrugineus vs. linear, not foliaceous in C. sphaerogynus; see Figs. 1B and 1G), and seed shape (subglobose in C. stellatoferrugineus vs. globose in C. sphaerogynus; see Figs. 1E and 1J). Besides these morphological differences, $C$. stellatoferrugineus occurs in seasonally dry forest in Minas Gerais, far from C. sphaerogynus, which occurs in moist forests from seashore plains ("restinga” forest) in the states of São Paulo, Rio de Janeiro, Espírito Santo and Bahia. (see Table 1).

Another species morphologically related to Croton stellatoferrugineus is $C$. heterocalyx Baill. (1864), which has a disjunct distribution between dry forests and "restinga" forest in southeastern and northeastern Brazil (Caruzo \& Cordeiro, in prep.). Both these species occur in dry forests and have similar ferrugineous indument. However, C. stellatoferrugineus can be easily distinguished from C. heterocalyx due to the different characters listed in Table 1, among which leave shape (ovate to cordate in C. heterocalyx vs. narrowly ovate to ovate-elliptic in C. stellatoferrugineus), morphology of branchlets (cylindric in C. heterocalyx vs. flat in C. stellatoferrugineus), and male flowers (cupola-shaped in $C$. heterocalyx vs. campanulate in $C$. stellatoferrugineus; see Figs. 2 and 3F) are the most notable.

Additional specimens examined (paratypes): - BRAZIL: Minas Gerais: Serra do Espinhaço, southeastern drainage of Pico do Itambé, about $5 \mathrm{~km}$ directly west and north of Santo Antônio do Itambé, 9 Feb 1972, fl., fr., W.R. Anderson et al. 35673 (MBM, MICH, NY, UB, US, VEN); Santo Antônio do Itambé, ponte de pedra sobre o riacho mãe-d'água, 18³3’8.4’’S e 43²0’15.8’’W, 811 m, fr., 18 Feb 2009, I. Cordeiro et al. 3033 (SP). 


\section{Acknowledgments}

Thanks are due to Klei Rodrigo Souza for the line illustrations and to CNPq (Brazil) for the fellowship awarded to the first and second authors. We are also grateful to the herbaria K, MBM, MICH, MO, NY, SP, SPF, UB, US, and VEN for providing access to their collections.

\section{References}

Baillon, H. (1864) Euphorbiaceés Americaines. Adansonia 4: 257-377.

Burger, W. \& Huft, M. (1995) Flora costaricensis: Euphorbiaceae. Fieldiana Botany 36: $1-169$.

Carneiro-Torres, D.S., Cordeiro, I., Giulietti, A.M., Berry, P.E \& Riina, R.. Taxonomic notes and three new species of Croton (Euphorbiaceae s.s.) from the Brazilian Caatinga. Brittonia (in press).

Caruzo, M.B.R.; Riina, R.; Cordeiro, I. \& Berry, P.E. (2008) Croton campanulatus (Euphorbiaceae s.s.), a new species from the Brazilian Atlantic rain forest. Brittonia 60(3): $261-264$.

Caruzo, M.B.R.; Riina, R.; Cordeiro, I. \& Berry, P.E. Croton rufolepidotus

(Euphorbiaceae s.s.), a new species from Colombia. Novon. (in press).

Cordeiro, I., Berry, Paul, Caruzo, M. B. R., van Ee, B. (2008) Croton laceratoglandulosus (Euphorbiaceae s.s.), a new glandular-stipulate species from Brazil and Bolivia, and its systematic position based on molecular analysis. Botanical Journal of the Linnean Society. 158: 493-498.

Frodin, D.G. (2004) History and concepts of big plant genera. Taxon 53(3): 753—776.

Gordillo, M.M. \& Luna, E. (2005). Especie nueva de Croton (Euphorbiaceae) de Brasil. Novon 15(4): 568—571. 
Govaerts, R., Frodin, D.G. \& Radcliffe-Smith, A. (2000) World checklist and bibliography of Euphorbiaceae (and Pandaceae). 4 vols. Royal Botanic Gardens, Kew, England.

Lima, L.R. \& Pirani, J.R. (2008) Three new species of Croton (Euphorbiaceae) from Brazil. Kew Bulletin 63: 121-129.

Riina, R., Berry, P.E. \& Cornejo, X. (2007) A new species of “sangre de drago” (Croton sect. Cyclostigma, Euphorbiaceae) from coastal Ecuador. Brittonia 59(1): 97-101.

Secco, R. (2008) Croton dissectistipulatus, a new species of Euphorbiaceae from Amazonian Brazil. Brittonia 56(4): 353-356.

Secco, R. (2009) Uma nova espécie de Croton sect. Geiseleria (Euphorbiaceae)da Amazônia Oriental brasileira. Revista Brasileira de Botânica 32(2): 249—252.

Secco, R., Berry, P.E. \& Rosa, N.A. (2001) Croton diasii and Croton trombetensis, two new Euphorbiaceae from Amazonian Brazil. Novon 11(1): 119—123.

Secco, R., Berry, P.E. \& Rosário, C.S. (2005) A new species of Croton sect. Luntia (Euphorbiaceae) from western Amazonian Brazil. Novon 15(4): 583—585.

Smith, B.A. (2006) A new species of Croton from Ecuador. Novon 16(2): 272-275. van Ee, B. W. \& Berry, P.E. (2009) A phylogenetic and taxonomic review of Croton (Euphorbiaceae s.s.) on Jamaica including the description of Croton jamaicensis, a new species of section Eluteria. Systematic Botany 34(1): 129—140.

Webster, G.L. (1993) A provisional synopsis of the sections of the genus Croton L. (Euphorbiaceae). Taxon 42: 79—823. 
FIGURE 1. Comparison of Croton stellatoferrugineus and C. sphaerogynus. A-E. Croton stellatoferrugineus. A. Flowering branch. B. Floral bract, dorsal and ventral views. C. Pistillate flower. D. Gynoecium. E. Seed, dorsal view; A-E. Cordeiro et al. 3033 (SP). F-J. Croton sphaerogynus. F. Flowering branch. G. Floral bract, dorsal view. H. Pistillate flower. I. Gynoecium. J. Seed, dorsal view; F-J. Caruzo \& Lima 121 (SP).

FIGURE 2. Morphological features of Croton stellatoferrugineus. A. One of the two basilaminar glands. B. Habit, showing senescent orange leaves (first plant to the right). C. Pistillate flower. Note ferrugineous indument, basally connate sepals with quincuncial aestivation of the lobes, and styles branched into at least 24 terminal tips. D. Staminate flowers. Note reflexed petals. E. Bracts with basal gland. F. Stipule partly hidden by ferrugineous trichomes. G. Infructescence. H. Detail of fruit, with slightly accrescent calyx. A-B, E-H. Cordeiro et al. 3033 (SP).C-D. Caruzo et al. 120 (SP).

FIGURE 3. Morphological features of Croton sphaerogynus and C. heterocalyx. A-E. Croton sphaerogynus. A. Habit. B. Basilaminar glands. C. Pistillate flower, showing revolute sepal lobes, stylar column, and ca. 12 terminal tips. D. Staminate flower. E. Fruits; A. Caruzo et al. 120 (SP); B-D. Caruzo \& Lima 121 (SP); E. Sant'Ana et al. 1122. F-I. Croton heterocalyx. F. Staminate flowers. G. Stipule. H. Inflorescence. I. Fruit; F-I. Caruzo et al. 140 (HUEFS). 
Table 1. Main characters distinguishing Croton stellatoferrugineus from $C$.

sphaerogynus and C. heterocalyx

\begin{tabular}{|c|c|c|c|}
\hline Character & C. stellatoferrugineus & C. sphaerogynus & C. heterocalyx \\
\hline $\begin{array}{l}\text { Leaf indument } \\
\text { (lower surface) }\end{array}$ & pubescent & $\begin{array}{l}\text { hirsute to } \\
\text { glabrescent }\end{array}$ & pubescent \\
\hline Trichomes & $\begin{array}{l}\text { stellate and } \\
\text { multiradiate }\end{array}$ & adpressed-stellate & $\begin{array}{l}\text { stellate and } \\
\text { multiradiate }\end{array}$ \\
\hline Leaf base & $\begin{array}{l}\text { slightly cordate, lobes } \\
\text { not overlapping }\end{array}$ & $\begin{array}{l}\text { auriculate to } \\
\text { strongly cordate, } \\
\text { lobes overlapping }\end{array}$ & $\begin{array}{l}\text { rounded to } \\
\text { cordate, lobes not } \\
\text { overlapping }\end{array}$ \\
\hline Bracts & foliaceous, with glands & $\begin{array}{l}\text { not foliaceous, } \\
\text { without glands }\end{array}$ & $\begin{array}{l}\text { not foliaceous, } \\
\text { without glands }\end{array}$ \\
\hline $\begin{array}{l}\text { Staminate flower } \\
\text { shape }\end{array}$ & campanulate & campanulate & cupola-shaped \\
\hline $\begin{array}{l}\text { Pistillate flower } \\
\text { shape }\end{array}$ & campanulate & flask-shaped & flask-shaped \\
\hline $\begin{array}{l}\text { Pistillate flower } \\
\text { sepals }\end{array}$ & $\begin{array}{l}\text { united up to half their } \\
\text { length, lobes erect }\end{array}$ & $\begin{array}{l}\text { united at the base, } \\
\text { lobes revolute }\end{array}$ & $\begin{array}{l}\text { united at the base, } \\
\text { lobes erect }\end{array}$ \\
\hline $\begin{array}{l}\text { Pistillate flower } \\
\text { indument color }\end{array}$ & ferrugineous & glaucous & ferrugineous \\
\hline Style division & $>24$ terminal tips & 12 terminal tips & $>24$ terminal tips \\
\hline Seed shape & subglobose & globose & subglobose \\
\hline Habitat & seasonally dry forest & $\begin{array}{l}\text { "restinga” wet } \\
\text { forest }\end{array}$ & $\begin{array}{l}\text { seasonally dry } \\
\text { forest and } \\
\text { “restinga” forest }\end{array}$ \\
\hline
\end{tabular}




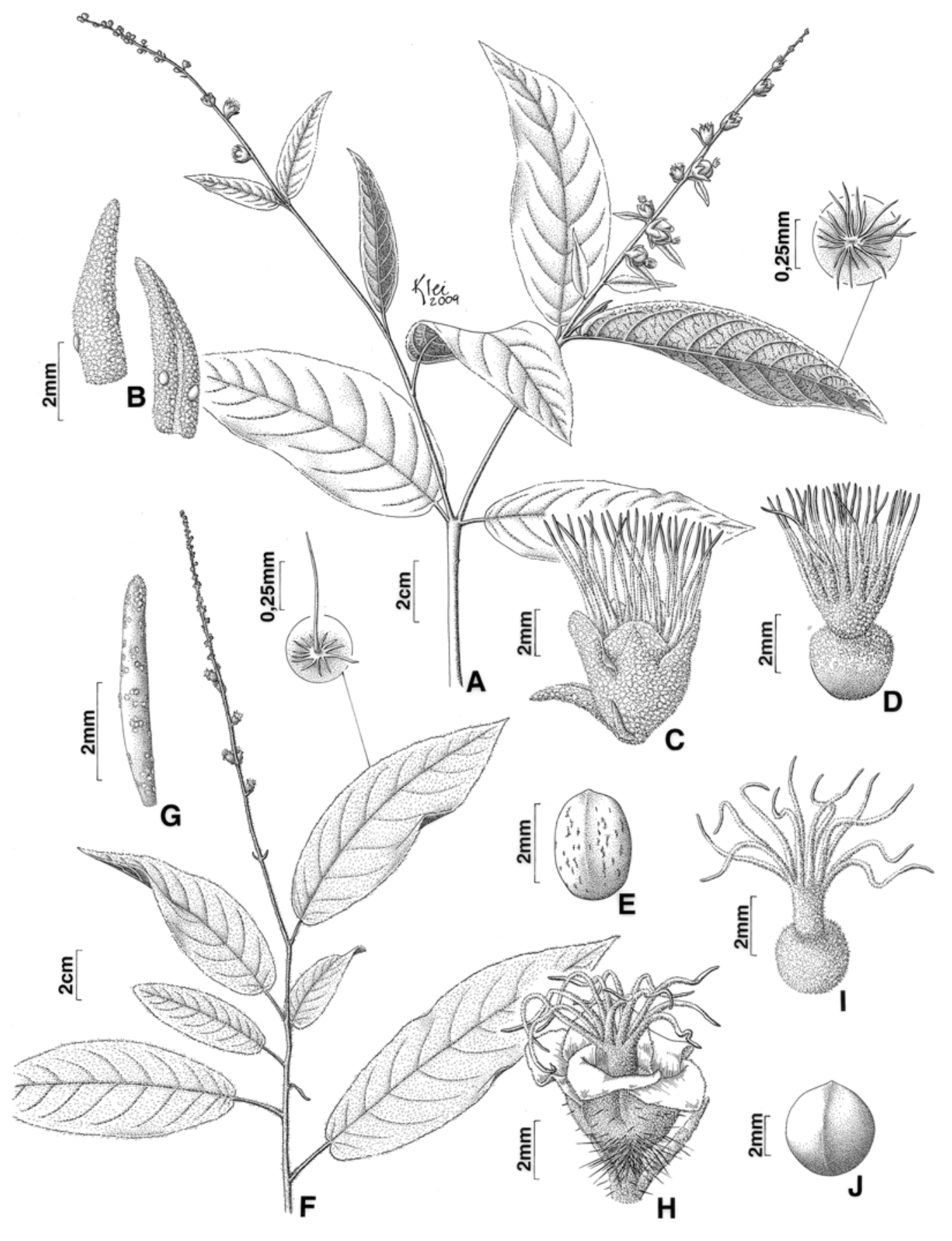

FIGURE 1 

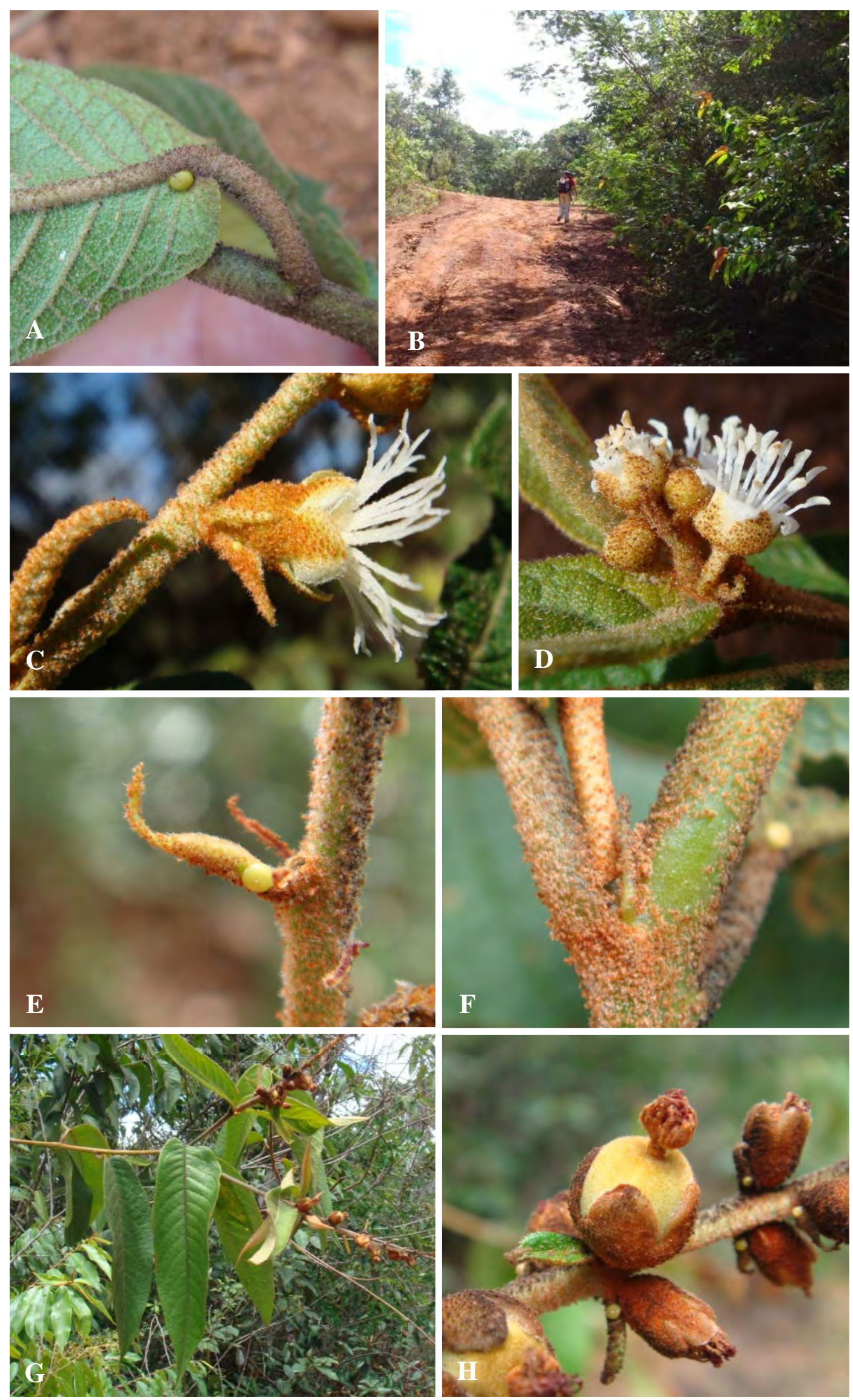

FIGURE 2 

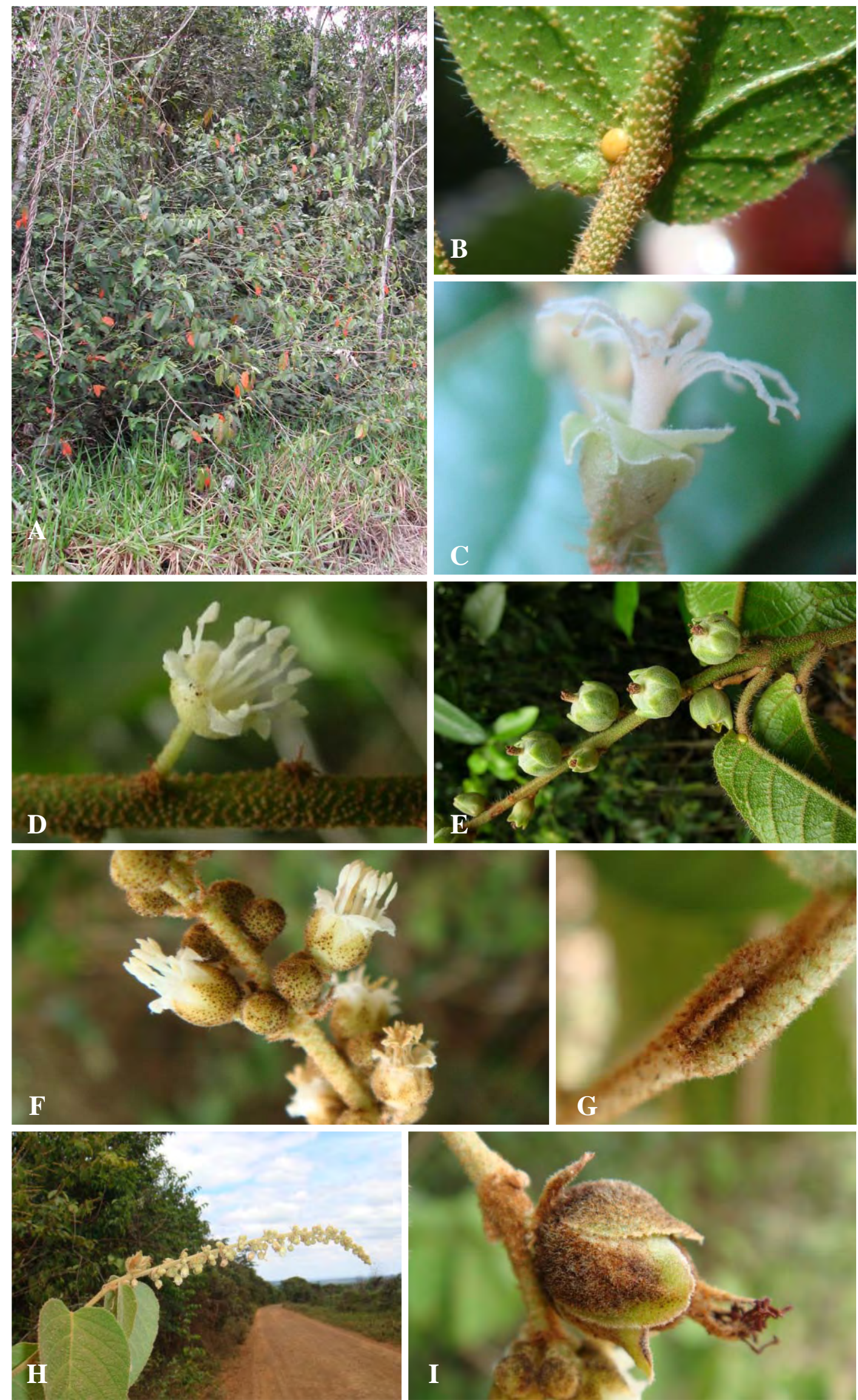

FIGURE 3

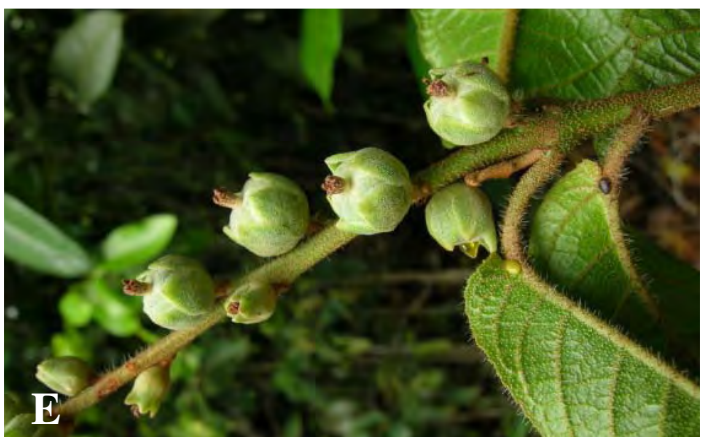




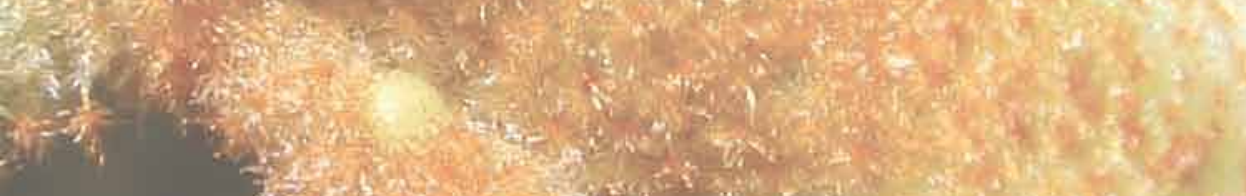
旅列
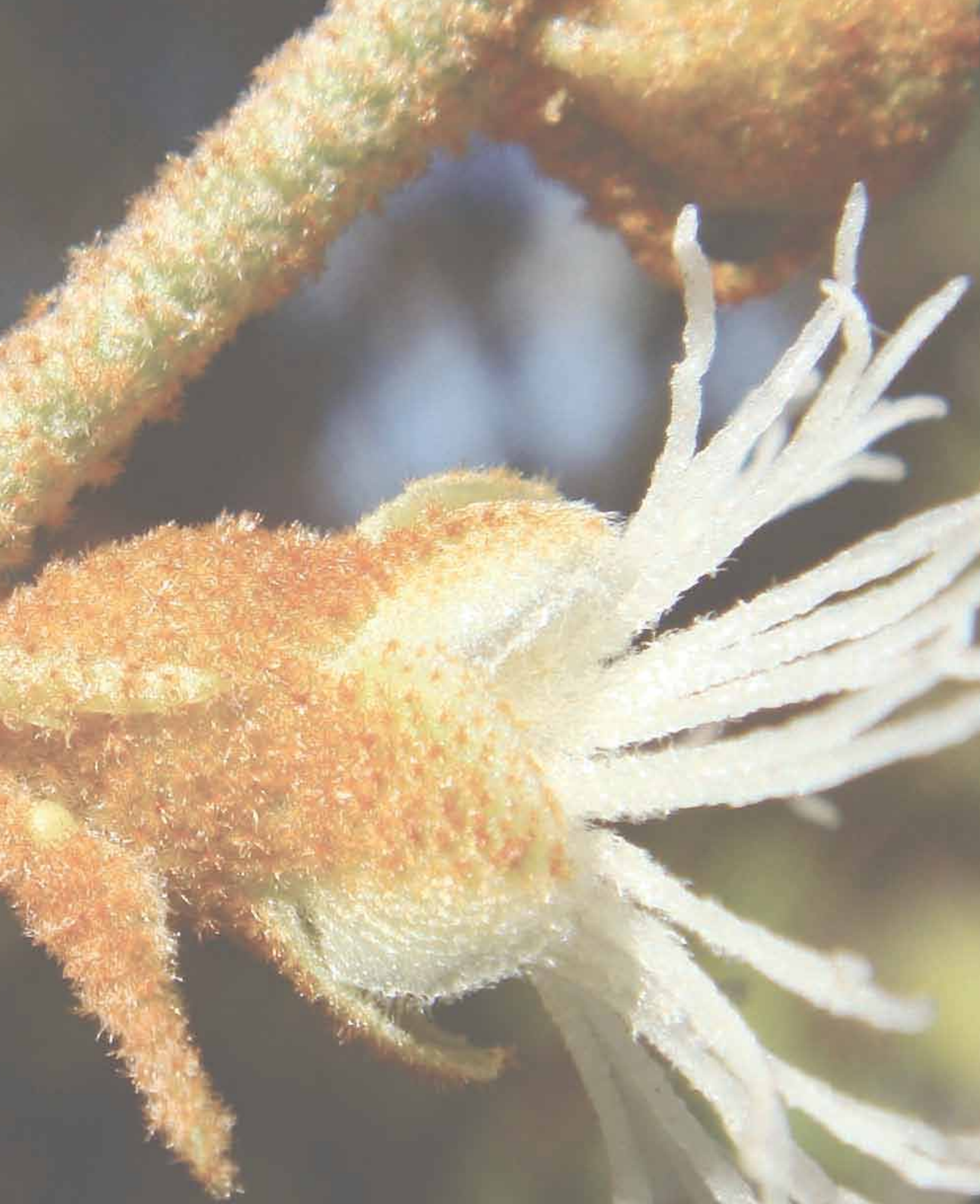